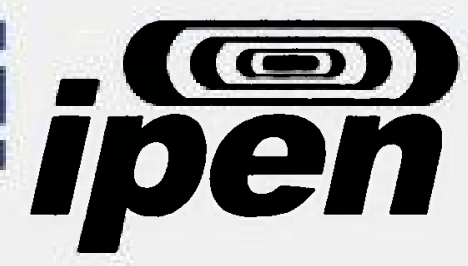

AUTARQUIA ASSOCIADA A UNIVERSIDADE DE SÃO PAULO

\title{
IDENTIFICAÇÃO, QUANTIFICAÇÃO E COMPARAÇÃO DAS SUBTÃNCIAS QUIMMICAS RESPONSÁVEIS PELOS AROMAS DA CACHAÇA DE ALAMBIQUE E DO RUM COMERCIAL TRATADOS PELO PROCESSO DE IRRADIAÇÃO
}

MARIA DJILIAH CAMARGO ALVARENGA DE SOUZA

Tese apresentada como parte dos requisitos para obtenção do Grau de Doutor em Ciências na Área de Tecnologia Nuclear - Aplicações.

Orientadora:

Dra. Nélida Lucia del Mastro

São Paulo

2006 
INSTITUTO DE PESQUISAS ENERGÉTICAS E NUCLEARES

Autarquia associada à Universidade de São Paulo

\author{
IDENTIFICAÇÃO, QUANTIFICAÇÃO E COMPARAÇÃO DAS SUBSTÂNCIAS \\ QUIMMICAS RESPONSÁVEIS PELOS AROMAS DA CACHAÇA DE ALAMBIQUE E \\ DO RUM COMERCIAL TRATADOS PELO PROCESSO DE IRRADIAÇÃO
}

\title{
MARIA DJLIAH CAMARGO ALVARENGA DE SOUZA
}

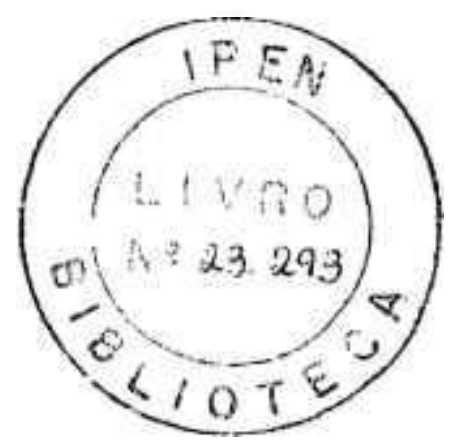

Tese apresentada como parte dos requisitos para obtenção do Grau de Doutor em Ciências na Área de Tecnologia Nuclear - Aplicações.

Orientadora: Dra. Nélida Lucia del Mastro

SÃO PAULO

2006 


\section{AGRADECIMENTOS}

Ao Instituto de Pesquisas Energéticas e Nucleares pela oportunidade de realizar este trabalho, especialmente ao Centro de Tecnologia das Radiações;

À Dra. Nélida Lucia del Mastro pela orientação, estímulo e amizade;

Aos Engenheiros Elizabeth Sebastiana Ribeiro Somessari e Carlos Gaia da Silveira do Centro de Tecnologia das Radiações do IPEN - CNEN/SP pela colaboração na irradiação das amostras;

Ao Dr. Geraldo José Zenid, responsável pelo Grupo de Propriedades Básicas da Madeira do Instituto de Pesquisas Tecnológicas pela doação das amostras de carvalho;

Ao Prof. Dr. Douglas Wagner Franco do Departamento de Química e Física Molecular do Instituto de Química de São Carlos/USP pela infra-estrutura cedida e pelo auxílio na realização das análises de alcoóis, ésteres, aldeídos e ácidos;

Ao Dr. Luiz Andrade Sobrinho do Departamento de Química e Física Molecular do Instituto de Química de São Carlos/USP pelo auxílio dado durante as determinações de alcoóis, ésteres, aldeídos e ácidos;

Ao Prof. Dr. Terry Acree do Departamento de Food Science and Technology da Cornell University - Geneva/NY, EUA por ter me orientado e recebido tão gentilmente em seu laboratório;

Ao Dr. Ed Lavin do Departamento de Food Science and Technology da Cornell University - Geneva/NY, EUA por me instruir durante as análises olfatométricas;

Ao M.Sc. Pablo Antonio Vásquez Salvador pelo carinho, companheirismo e apoio dado durante toda a execução da tese;

Ao Conselho Nacional de Pesquisa e Desenvolvimento ( $\mathrm{CNPq}$ ) pelas bolsas de doutorado e sanduíche concedidas;

E a todos que de alguma forma contribuíram para realização deste trabalho. 


\section{SUMÁRIO}

Página

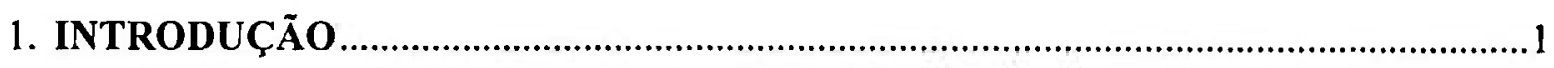

2. OBJETIVOS

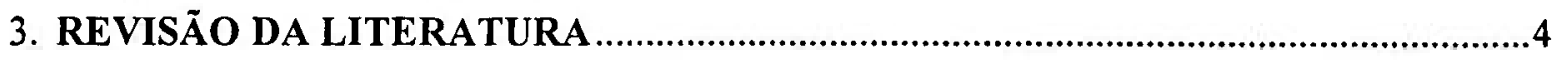

3.1. Irradiação de Alimentos ............................................................................................

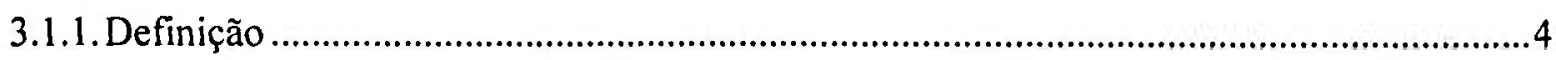

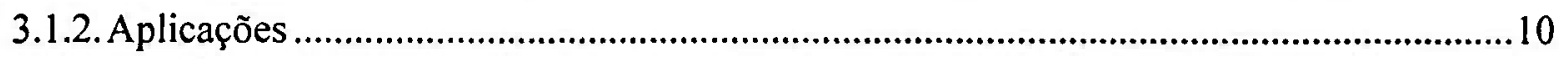

3.2. Irradiação de Bebidas ...........................................................................................11

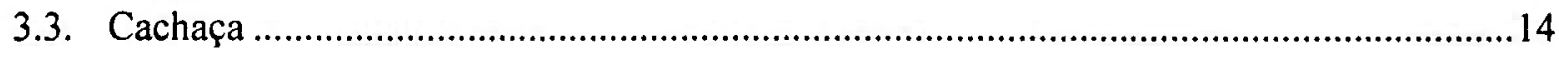

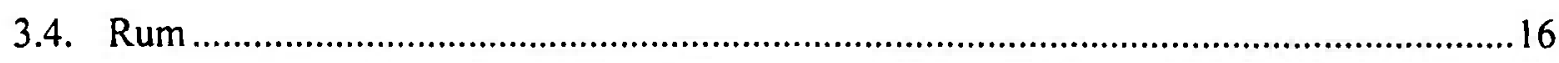

3.5. Etapas de Produção das Bebidas Destiladas provenientes da Cana-de-Açúcar .................18

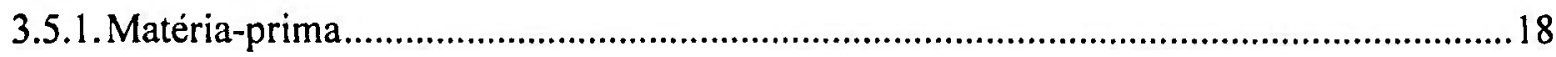

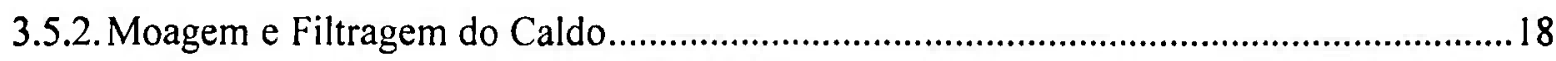

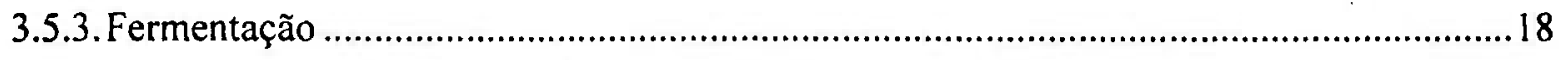

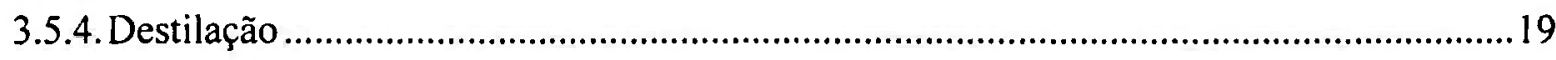

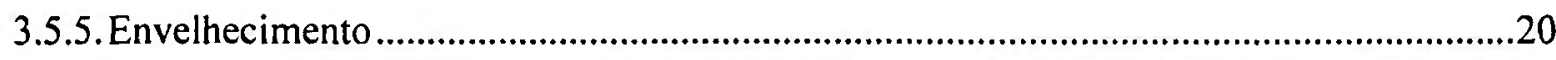

3.6. Principais Componentes do "Flavor" das Bebidas Alcoólicas .........................................22

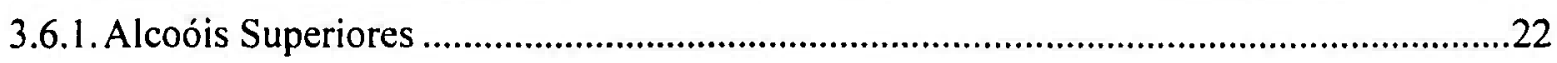

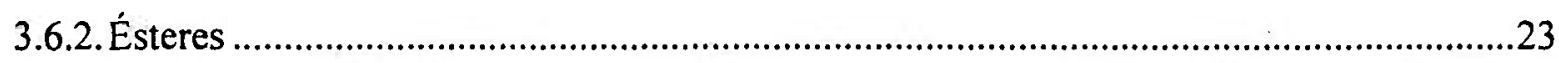

3.6.3. Ácidos …

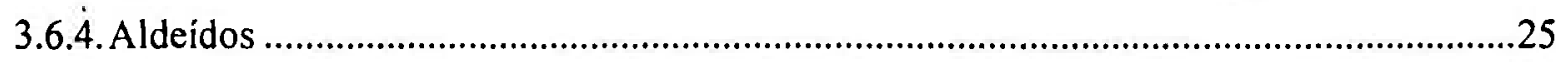

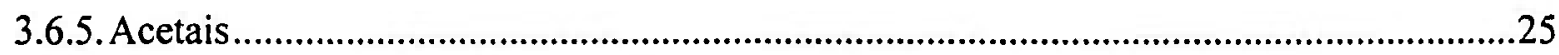

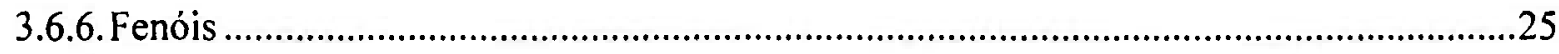

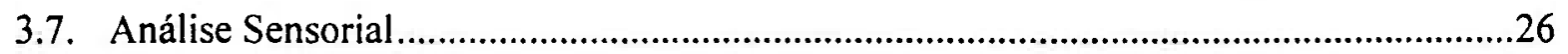




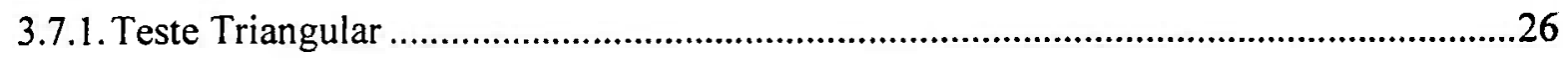

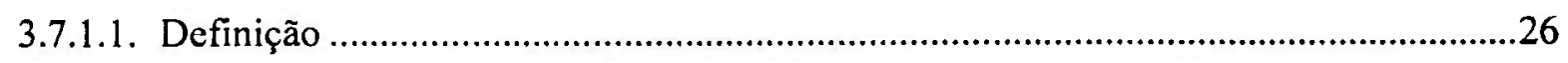

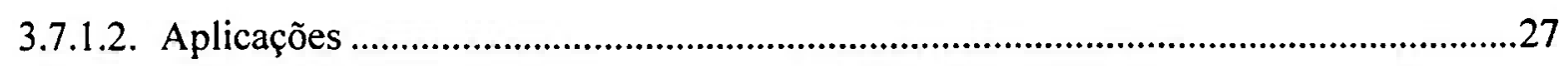

3.7.2. Análise Descritiva Quantitativa .............................................................................2

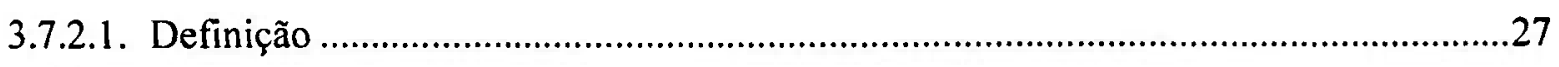

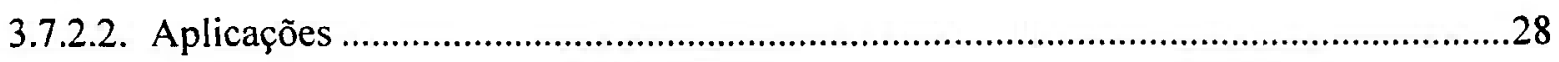

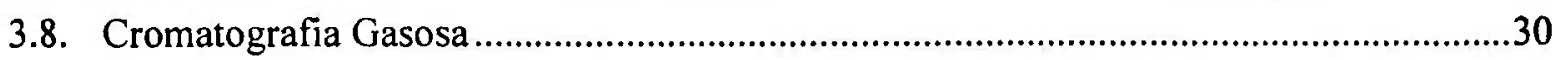

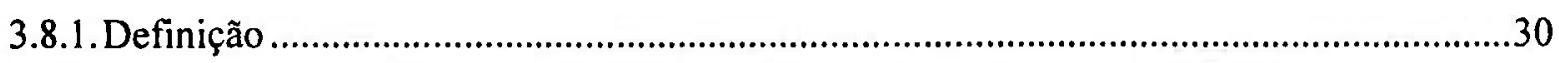

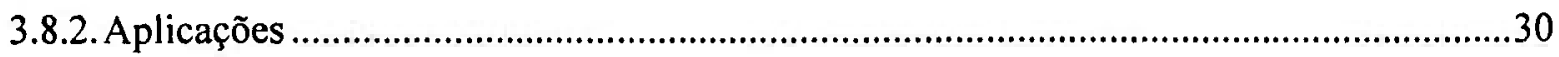

3.9. Cromatografia Liquida de Alta Eficiência .................................................................

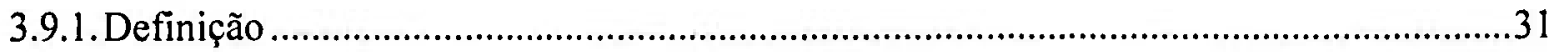

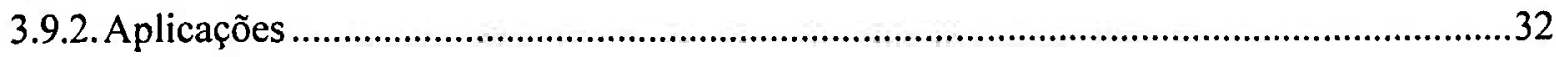

3.10. Cromatografia Gasosa/Olfatometria ........................................................................33

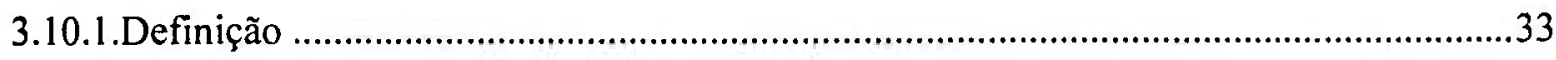

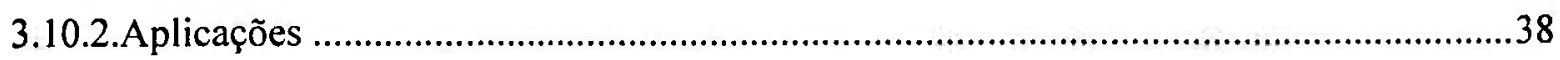

3.11. Cromatografia Gasosa/Espectrometria de Massa.............................................................38

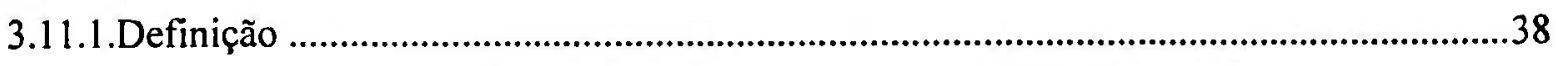

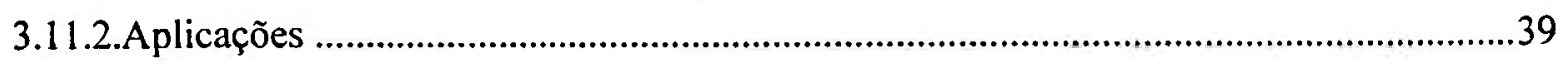

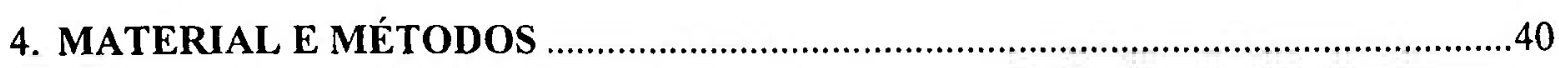

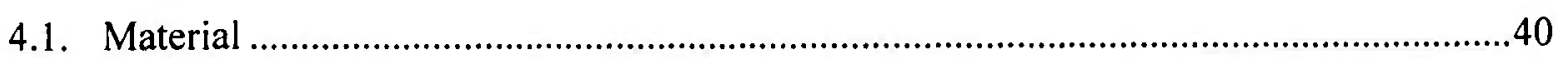

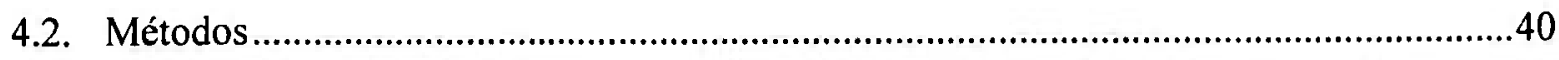

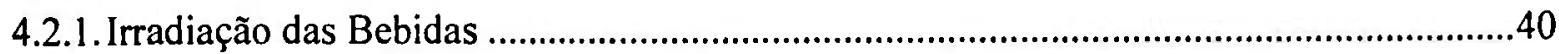

4.2.2. Determinação de Ésteres e Alcoóis Superiores por Cromatografia Gasosa de Alta Resolução . .41

4.2.3. Determinação de Aldeídos por Cromatografia Líquida de Alta Eficiência .......................42

4.2.4. Determinação de Ácidos por Cromatografia Gasosa de Alta Resolução............................44

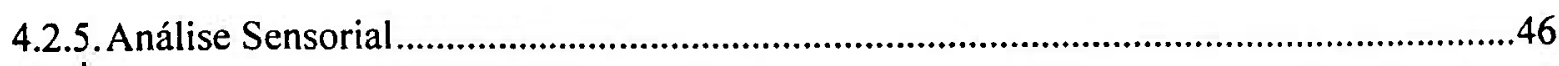

4.2.5.1. Teste Triangular ...........................................................................................46

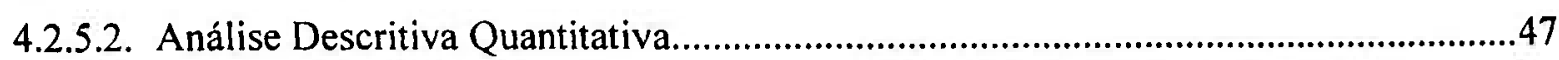

4.2.5.2.1. Pré-Seleção dos Provadores ....................................................................................4

4.2.5.2.2. Desenvolvimento da Terminologia .........................................................................4 
4.2.5.2.3. Treinamento e Seleção Final dos Provadores ............................................................51

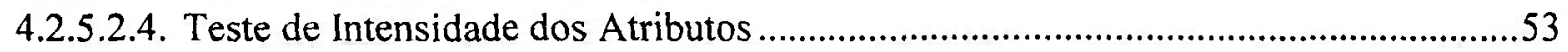

4.2.6. Determinação dos Odores Ativos por Cromatografia Gasosa/Olfatometria .....................56

4.2.7. Análise Estatística - Determinação de Ésteres, Alcoóis Superiores, Aldeídos e

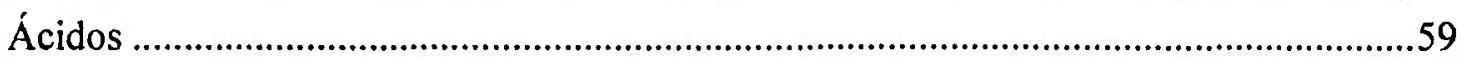

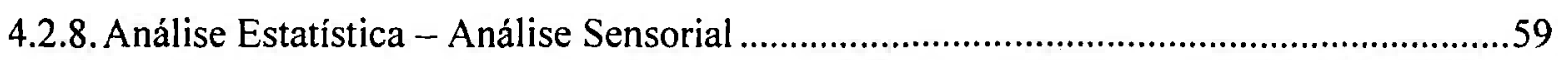

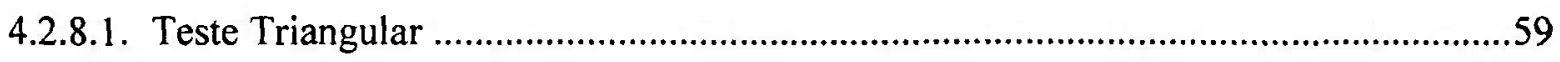

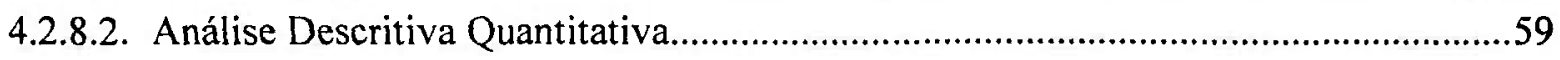

4.2.8.2.1. Pré-seleção dos Provadores........................................................................................59

4.2.8.2.2. Seleção Final dos Provadores ..................................................................................59

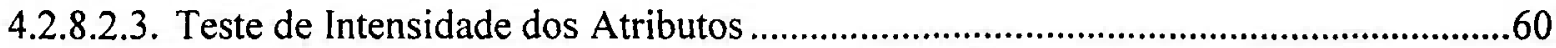

4.2.8.3. Análise Estatística - Determinação dos Odores Ativos por

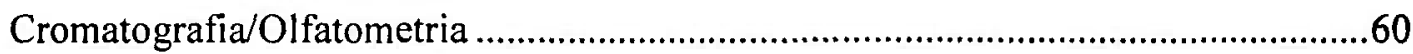

5. RESULTADOS E DISCUSSÃO

5.1. Determinação de Ésteres, Alcoóis Superiores, Aldeídos e Ácidos .................................61

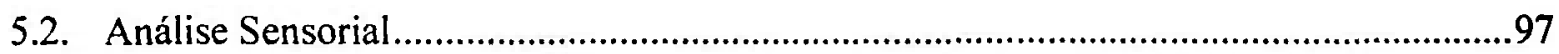

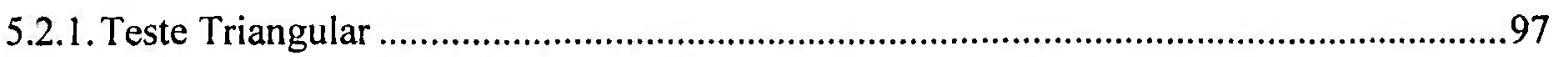

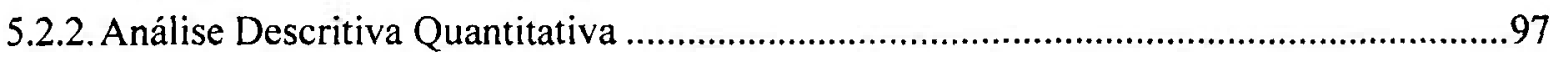

5.3. Determinação dos Odores Ativos por Cromatografia/Olfatometria .............................102

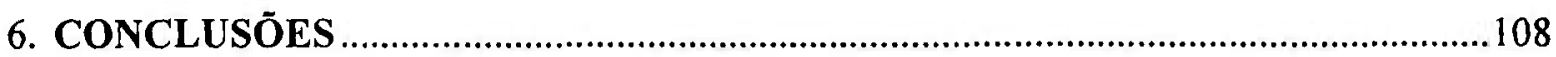

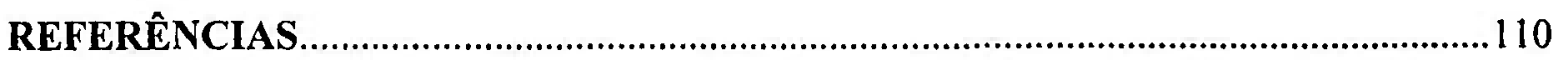




\section{LISTA DE TABELAS}

Página

TABELA 1 - Termos descritores obtidos por CG/O usados como base para análise descritiva e a composição dos padrões de referência correspondentes.

TABELA 2 - Médias* das concentrações de acetato de etila em $\mathrm{mg} / 100 \mathrm{~mL}$ álcool anidro encontradas nas amostras de bebidas analisadas

TABELA 3 - Médias* das concentrações de metanol em $\mathrm{mg} / 100 \mathrm{~mL}$ álcool anidro encontradas nas amostras de bebidas analisadas.

TABELA 4 - Médias* das concentrações de propanol em $\mathrm{mg} / 100 \mathrm{~mL}$ álcool anidro encontradas nas amostras de bebidas analisadas.

TABELA 5 - Médias* das concentrações de isobutanol em $\mathrm{mg} / 100 \mathrm{~mL}$ álcool anidro encontradas nas amostras de bebidas analisadas.

TABELA 6 - Médias* das concentrações de butanol em $\mathrm{mg} / 100 \mathrm{~mL}$ álcool anidro encontradas nas amostras de bebidas analisadas.

TABELA 7 - Médias* das concentrações de álcool isoamílico em $\mathrm{mg} / 100 \mathrm{~mL}$ álcool anidro encontradas nas amostras de bebidas analisadas.

TABELA 8 - Soma das concentrações dos alcoóis isoamílico, isobutílico e n-propílico em $\mathrm{mg} / 100 \mathrm{~mL}$ álcool anidro nas amostras analisadas.

TABELA 9 - Médias* das concentrações de ácido acético em $\mathrm{mg} / 100 \mathrm{~mL}$ álcool anidro encontradas nas amostras de bebidas analisadas.

TABELA 10 - Médias* das concentrações de ácido propiônico em $\mathrm{mg} / 100 \mathrm{~mL}$ álcool anidro encontradas nas amostras de bebidas analisadas.

TABELA 11 - Médias* das concentrações de ácido isobutírico em $\mathrm{mg} / 100 \mathrm{~mL}$ álcool anidro encontradas nas amostras de bebidas analisadas.

TABELA 12 - Médias* das concentrações de ácido butírico em $\mathrm{mg} / 100 \mathrm{~mL}$ álcool anidro encontradas nas amostras de bebidas analisadas. 
TABELA 13 - Médias* das concentrações de ácido valérico em $\mathrm{mg} / 100 \mathrm{~mL}$ álcool anidro encontradas nas amostras de bebidas analisadas.

TABELA 14 - Médias* das concentrações de ácido isovalérico em $\mathrm{mg} / 100 \mathrm{~mL}$ álcool anidro encontradas nas amostras de bebidas analisadas.

TABELA 15 - Médias* das concentrações de ácido isocapróico em $\mathrm{mg} / 100 \mathrm{~mL}$ álcool anidro encontradas nas amostras de bebidas analisadas.

TABELA 16 - Médias* das concentrações de ácido capróico em mg/100mL álcool anidro encontradas nas amostras de bebidas analisadas.

TABELA 17 - Médias* das concentrações de ácido heptanóico em mg/100mL álcool anidro encontradas nas amostras de bebidas analisadas.

TABELA 18 - Médias* das concentrações de ácido caprílico em $\mathrm{mg} / 100 \mathrm{~mL}$ álcool anidro encontradas nas amostras de bebidas analisadas.

TABELA 19 - Médias* das concentrações de ácido cáprico em $\mathrm{mg} / 100 \mathrm{~mL}$ álcool anidro encontradas nas amostras de bebidas analisadas.

TABELA 20 - Médias* das concentrações de ácido mirístico em mg/100mL álcool anidro encontradas nas amostras de bebidas analisadas.

TABELA 21 - Médias* das concentrações de ácido láurico em $\mathrm{mg} / 100 \mathrm{~mL}$ álcool anidro encontradas nas amostras de bebidas analisadas.

TABELA 22 - Médias* das concentrações de ácido palmítico em $\mathrm{mg} / 100 \mathrm{~mL}$ álcool anidro encontradas nas amostras de bebidas analisadas.

TABELA 23 - Soma das concentrações dos ácidos em $\mathrm{mg} / 100 \mathrm{~mL}$ álcool anidro encontrados nas amostras de bebidas analisadas.

TABELA 24 - Médias* das concentrações de formaldeído em $\mathrm{mg} / 100 \mathrm{~mL}$ álcool anidro encontradas nas amostras de bebidas analisadas.

TABELA 25 - Médias* das concentrações de 5 hidroximetilfurfural em $\mathrm{mg} / 100 \mathrm{~mL}$ álcool anidro encontradas nas amostras de bebidas analisadas.

TABELA 26 - Médias* das concentrações de acetaldeído em $\mathrm{mg} / 100 \mathrm{~mL}$ álcool anidro encontradas nas amostras de bebidas analisadas.

TABELA 27 - Médias* das concentrações de acroleína em $\mathrm{mg} / 100 \mathrm{~mL}$ álcool anidro encontradas nas amostras de bebidas analisadas. 
TABELA 28 - Médias* das concentrações de furfural em $\mathrm{mg} / 100 \mathrm{~mL}$ álcool anidro encontradas nas amostras de bebidas analisadas.

TABELA 29 - Médias* das concentrações de propinaldeído em $\mathrm{mg} / 100 \mathrm{~mL}$ álcool anidro encontradas nas amostras de bebidas analisadas.

TABELA 30 - Médias* das concentrações de butiraldeído em $\mathrm{mg} / 100 \mathrm{~mL}$ álcool anidro encontradas nas amostras de bebidas analisadas.

TABELA 31 - Médias* das concentrações de benzaldeído em $\mathrm{mg} / 100 \mathrm{~mL}$ álcool anidro encontradas nas amostras de bebidas analisadas.

TABELA 32 - Médias* das concentrações de isovaleraldeído em $\mathrm{mg} / 100 \mathrm{~mL}$ álcool anidro encontrados nas amostras de bebidas analisadas.

TABELA 33 - Médias* das concentrações de valeraldeído em $\mathrm{mg} / 100 \mathrm{~mL}$ álcool anidro encontrados nas amostras de bebidas analisadas.

TABELA 34 - Soma das concentrações dos aldeídos em $\mathrm{mg} / 100 \mathrm{~mL}$ álcool anidro encontrados nas amostras de bebidas analisadas.

TABELA 35 - Soma das concentrações de furfural e 5 hidroximetilfurfural em $\mathrm{mg} / 100 \mathrm{~mL}$ álcool anidro nas amostras analisadas.

TABELA 36 - Valores do fator de correlação (R2) entre os ésteres e alcoóis superiores analisados e as doses de radiação aplicadas nas amostras.

TABELA 37 - Valores do fator de correlação (R2) entre os ácidos analisados e as doses de radiação aplicadas nas amostras.

TABELA 38 - Valores do fator de correlação (R2) entre os ácidos analisados e as doses de radiação aplicadas nas amostras.

TABELA 39 - Valores do fator de correlação (R2) entre os aldeídos analisados e as doses de radiação aplicadas nas amostras.

TABELA 40 - Valores do fator de correlação (R2) entre os aldeídos analisados e as doses de radiação aplicadas nas amostras.

TABELA 41 - Lista final dos atributos selecionados com suas respectivas definições.

TABELA 42 - Odores encontrados na cachaça não envelhecida não irradiada.

TABELA 43 - Odores encontrados na cachaça não envelhecida irradiada.

TABELA 44 - Odores encontrados no rum não irradiado.

TABELA 45 - Odores encontrados no rum irradiado. 


\section{LISTA DE FIGURAS}

Página

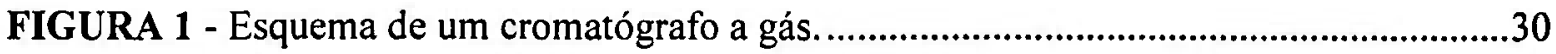

FIGURA 2 - Esquema de um cromatógrafo líquido de alta eficiência...................................32

FIGURA 3 - Resumo do procedimento da cromatografia gasosa/olfatometria usando a metodologia da análise por diluição "CharmAnalysis". ....................................36

FIGURA 4 - Esquema de um cromatógrafo gasoso/espectrômetro de massa..........................39

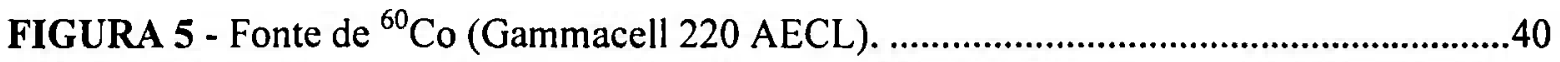

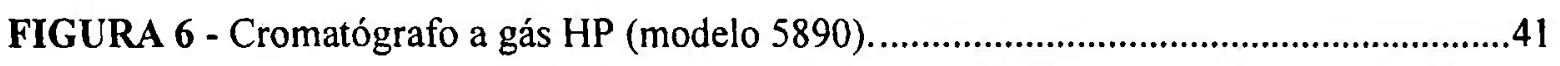

FIGURA 7 - Modelo de ficha utilizado para o teste triangular. ............................................46

FIGURA 8 - Modelo de ficha utilizado para a descrição dos atributos.....................................48

FIGURA 9 - Ficha utilizada para o levantamento dos atributos sensoriais..............................50

FIGURA 10 - Sessões realizadas para o desenvolvimento da terminologia. ............................51

FIGURA 11 - Amostras referências apresentadas durante o treinamento...............................51

FIGURA 12 - Ficha utilizada para a memorização dos termos sensoriais encontrados nas

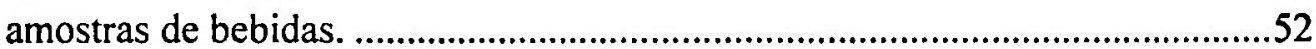

FIGURA 13 - Apresentação das amostras para o Teste de Intensidade dos Atributos. ...........53

FIGURA 14 - Provadores realizando o Teste de Intensidade dos Atributos............................53

FIGURA 15 - Modelo de ficha utilizado para o Teste de Intensidade dos Atributos. .............55

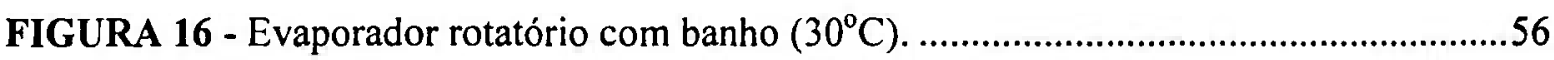

FIGURA 17 - Esquema da micro-extração em fase sólida (SPME). ........................................57

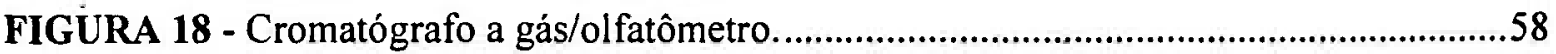

FIGURA 19 - Variação da concentração de acetato de etila em função da dose aplicada em bebidas destiladas. 
FIGURA 20 - Variação da concentração de metanol em função da dose aplicada em bebidas destiladas.

FIGURA 21 - Variação da concentração de propanol em função da dose aplicada em bebidas destiladas.

FIGURA 22 - Variação da concentração de isobutanol em função da dose aplicada em bebidas destiladas.

FIGURA 23 -Variação da concentração de butanol em função da dose aplicada em bebidas destiladas.

FIGURA 24 - Variação da concentração de álcool isoamílico em função da dose aplicada em bebidas destiladas.

FIGURA 25 - Variação da concentração de ácido acético em função da dose aplicada em bebidas destiladas.

FIGURA 26 - Variação da concentração de ácido propiônico em função da dose aplicada em bebidas destiladas.

FIGURA 27 - Variação da concentração de ácido isobutírico em função da dose aplicada em bebidas destiladas.

FIGURA 28 - Variação da concentração de ácido butírico em função da dose aplicada em bebidas destiladas.

FIGURA 29 - Variação da concentração de ácido valérico em função da dose aplicada em bebidas destiladas.

FIGURA 30 - Variação da concentração de ácido isovalérico em função da dose aplicada em bebidas destiladas.

FIGURA 31 - Variação da concentração de ácido isocapróico em função da dose aplicada em bebidas destiladas.

FIGURA 32 - Variação da concentração de ácido capróico em função da dose aplicada em bebidas destiladas.

FIGURA 33 - Variação da concentração de ácido heptanóico em função da dose aplicada em bebidas destiladas.

FIGURA 34 - Variação da concentração de ácido caprílico em função da dose aplicada em bebidas destiladas. 
FIGURA 35 - Variação da concentração de ácido cáprico em função da dose aplicada em bebidas destiladas.

FIGURA 36 - Variação da concentração de ácido mirístico em função da dose aplicada em bebidas destiladas.

FIGURA 37 - Variação da concentração de ácido láurico em função da dose aplicada em bebidas destiladas.

FIGURA 38 - Variação da concentração de ácido palmítico em função da dose aplicada em bebidas destiladas.

FIGURA 39 - Variação da concentração de formaldeído em função da dose aplicada em bebidas destiladas.

FIGURA 40 - Variação da concentração de 5 hidroximetilfurfural em função da dose aplicada em bebidas destiladas.

FIGURA 41 - Variação da concentração de acetaldeído em função da dose aplicada em bebidas destiladas.

FIGURA 42 - Variação da concentração acroleína em função da dose aplicada em bebidas destiladas.

FIGURA 43 - Variação da concentração furfural em função da dose aplicada em bebidas destiladas.

FIGURA 44 - Variação da concentração propionaldeído em função da dose aplicada em bebidas destiladas.

FIGURA 45 - Variação da concentração butiraldeído em função da dose aplicada em bebidas destiladas.

FIGURA 46 - Variação da concentração benzaldeído em função da dose aplicada em bebidas destiladas.

FIGURA 47 - Variação da concentração isovaleraldeído em função da dose aplicada em bebidas destiladas.

FIGURA 48 - Variação da concentração valeraldeído em função da dose aplicada em bebidas destiladas.

FIGURA 49 - Gráfico aranha de cachaça não envelhecida e rum não irradiados. 100

FIGURA 50 - Gráfico aranha de cachaça não envelhecida não irradiada e irradiada. 101

FIGURA 51 - Gráfico aranha de rum não irradiado e irradiado. 
FIGURA 52 - Os odores mais potentes na cachaça não envelhecida e rum não irradiados...106 FIGURA 53 - Os odores mais potentes nas cachaças não envelhecidas não irradiadas e

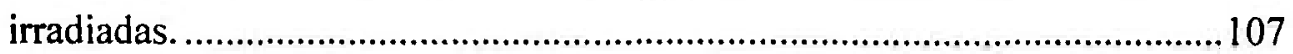

FIGURA 54 - Os odores mais potentes nos runs não irradiados e irradiados. .......................107 


\title{
IDENTIFICAÇÃO, QUANTIFICAÇÃO E COMPARAÇÃO DAS SUBSTÂNCIAS QUÍMICAS RESPONSÁVEIS PELOS AROMAS DA CACHAÇA DE ALAMBIQUE E DO RUM COMERCIAL TRATADOS PELO PROCESSO DE IRRADIAÇÃO
}

\author{
Maria Djiliah Camargo Alvarenga de Souza
}

\begin{abstract}
RESUMO
Quando aplicada em bebidas alcoólicas, a radiação ionizante pode ser usada para descontaminação de malte ou esterilização de mostos e tem sido proposta sua aplicação na aceleração do envelhecimento. Devido à internacionalização da cachaça, alguma confusão tem surgido sobre a sua identidade e a do rum. Este trabalho teve como propósito identificar, quantificar e comparar as substâncias químicas responsáveis pelo aroma de amostras de cachaça de alambique e de rum comercial, por meio de análises instrumentais e sensoriais. Pode-se afirmar haver forte correlação entre a concentração dos compostos voláteis analisados com a dose de radiação aplicada (0,150 e 300Gy), em todas as amostras. De acordo com os testes triangulares, apenas para aroma, todos os provadores puderam distinguir nas amostras não irradiadas e irradiadas com 300Gy, a cachaça envelhecida do rum e a cachaça não envelhecida do rum, porém, não foram observadas diferenças entre a cachaça não envelhecida e a envelhecida. Os resultados da Análise Descritiva Quantitativa mostraram que as amostras não irradiadas de cachaça não envelhecida e as do rum diferiram entre si em relação aos atributos de aroma definidos como álcool, vinagre, baunilha, citros, melão, condimento, vegetal e grama, mas não em relação aos atributos caramelo e maçã. As amostras de cachaças não envelhecidas não irradiadas e irradiadas (300Gy) e as de rum não irradiadas e irradiadas (300Gy) diferiram entre si em relação aos atributos de aroma definidos como maçã, caramelo, vinagre, baunilha, citros, melão, condimento, vegetal e grama, mas não em relação ao aroma de álcool. De acordo com os resultados da cromatografia gasosa/olfatometria foi encontrada diferença significativa entre cachaça e rum não irradiados; cachaça não irradiada e cachaça irradiada (300Gy); e rum não irradiado e irradiado (300Gy), quando foram comparados seus aromas.
\end{abstract}




\title{
IDENTIFICATION, QUANTIFICATION AND COMPARISON BETWEEN THE CHEMICAL SUBSTANCES RESPONSABLE OF THE IRRADIATED POT STILL CACHAÇA AND COMERCIAL RUM AROMAS
}

\author{
Maria Djiliah Camargo Alvarenga de Souza
}

\begin{abstract}
The irradiation process has being presented as an alternative technique in food preservation. When apply on beverages, radiation is mainly used for malt decontamination or sterilization of musts and had been proposed also to accelerate aging. Some confusion over rum and cachaça identities has arisen due to the internationalization of cachaça. This research aims to identify, quantify and compare the effect of gamma radiation on the aroma of the Brazilian spirit with rum, irradiated and non irradiated, by instrumental and sensory analysis. Results showed that the content of volatile compounds presented strong correlation with the radiation dose $(0,150$ and $300 \mathrm{~Gy})$ for all the samples. According to Triangle Test for aroma, all the judges could distinguish among non irradiated and irradiated samples (300Gy), aged cachaça from rum and non aged cachaça from rum, but they couldn't distinguish aged cachaça from non aged cachaça. Analysis of variance (ANOVA) of the results from the quantitative descriptive analysis showed that non irradiated non aged cachaça and rum were different in their alcohol, vinegar, vanilla, citrus, melon, spice, vegetal and grass except caramel and apple aroma attributes. Non irradiated cachaça and irradiated cachaça (300Gy); and non irradiated rum and irradiated rum (300Gy) were different in their apple, caramel, vinegar, vanilla, citrus, melon, spice, vegetal and grass except alcohol aroma attributes. According to the gas chromatography/olfatometry results, significant difference was found among non irradiated cachaça and rum; non irradiated cachaça and irradiated cachaça (300Gy); and non irradiated rum and irradiated rum (300Gy) when their aromas were compared.
\end{abstract}




\section{INTRODUÇÃO}

A irradiação tem sido reconhecida como um método alternativo de conservação de alimentos. O uso da radiação também é recomendado para o aperfeiçoamento de propriedades tecnológicas de produtos destinados ao consumo humano. Há descrições na literatura que sugerem a aplicação da radiação gama em bebidas alcoólicas com o propósito de incrementar certos índices de qualidade, melhorar as características sensoriais ou esterilizar os mostos (DIEHL, 1990, SINGLETON, 1963 e URBAIN, 1986).

Sabe-se que um dos processos básicos para a melhoria da qualidade da cachaça é o envelhecimento, na qual a aguardente permanece de seis meses a dois anos convenientemente armazenada. Esse processo causa modificações na bebida, reduzindo a concentração alcoólica e melhorando significativamente suas propriedades sensoriais. $\mathrm{O}$ alto custo da madeira própria para esse fim, o grande número de recipientes necessários, a imobilização prolongada do capital de giro sob a forma de estoque de bebida e de vasilhames e o espaço construído levam à busca de meios que possibilitem o envelhecimento mais rápido e com menor investimento de capital (MAGA, 1989). Desta forma, desperta grande interesse a possibilidade de utilização da radiação gama na melhoria da qualidade de cachaças em curto prazo (SOUZA, 2000).

Devido à internacionalização da cachaça, alguma confusão sobre a sua identidade e a do rum tem surgido. Segundo técnicos norte-americanos do "Bureau of Alcohol, Tobacco \& Firearms", a cachaça classifica-se como um tipo de rum, por não haver informações técnico-científicas sobre as diferenças relacionadas com a fabricação e principalmente, sobre a caracterização sensorial dessas bebidas (MORAES, 2004). Cachaça é a denominação típica e exclusiva da aguardente de cana produzida no Brasil, com graduação alcoólica de 38 a 48 \% em volume, a $20^{\circ} \mathrm{C}$, obtida pela destilação do mosto fermentado do caldo de cana-de-açúcar com características sensoriais peculiares (BRASIL, 2005), enquanto o rum, tradicionalmente produzido em países caribenhos, é a bebida com a graduação alcoólica de 38 a $54 \%$ em volume, a $20^{\circ} \mathrm{C}$, obtida do destilado alcoólico simples de melaço, envelhecido, ou da mistura dos destilados de caldo de cana-de-açúcar e de melaço, envelhecidos total ou parcialmente, em 
recipientes de carvalho ou madeira, conservando, porém suas características peculiares (BRASIL, 2003).

O teste sensorial triangular permite verificar se existe diferença significativa entre duas amostras que sofreram tratamentos diferentes, como por exemplo, cachaça e rum não irradiados e irradiados (DUTCOSKY, 1996).

A análise descritiva quantitativa baseada no desenvolvimento de um vocabulário que descreve todas as sensações percebidas em um alimento por um conjunto de provadores, também permite avaliar a intensidade dos atributos sensoriais encontrados nestas bebidas (LAWLESS \& HELMANN, 1998).

A separação e quantificação dos compostos voláteis presentes nestas bebịdas realizadas por cromatografias gasosas ou líquidas, podem ser usadas como técnicas de identificação acopladas a outros aparelhos, como um espectrômetro de massa (FIFIELD \& KEALEY, 2000).

A cromatografia gasosa/olfatometria (CG/O), que é um conjunto de técnicas que usa o nariz humano como detector dos cromatógrafos a gás, permite quantificar a atividade sensorial das substâncias químicas presentes nestas bebidas (ACREE, 1997). 


\section{OBJETIVOS}

O presente trabalho teve como propósito identificar, quantificar e comparar as substâncias quimicas responsáveis pelo aroma de amostras de cachaça de alambique e de rum comercial tratadas pelo processo de irradiação por meio de análises instrumentais e sensoriais. 


\section{REVISÃO DA LITERATURA}

\subsection{Irradiação de Alimentos}

\subsubsection{Definição}

A irradiação de alimentos é um processo físico de tratamento que consiste em submeter os alimentos, já embalados ou a granel, a doses controladas de radiação ionizante, com finalidades sanitárias, fitossanitárias e ou tecnológicas. A radiação ionizante é considerada qualquer radiação que ioniza átomos de materiais a ela submetidos (BRASIL, 2001). Esta cede sua energia ao meio ao qual se difunde, mediante múltiplos processos de interação. A energia cedida é gasta na excitação e na ionização de moléculas gerando reações químicas que podem provocar modificações permanentes na estrutura físico-química do material irradiado (SANTIN, 1993).

A água está presente na maioria dos alimentos. Em vários vegetais encontra-se numa proporção de $90 \%$, em frutas $80 \%$, em carne $60 \%$ e em pães $40 \%$. Dessa forma, a radiólise da água tem particular interesse na irradiação de alimentos.

O efeito da radiação em um meio pode ser descrito da seguinte maneira:

Fóton incidente

Elétron acelerado $\left(\mathrm{e}^{*}\right)$

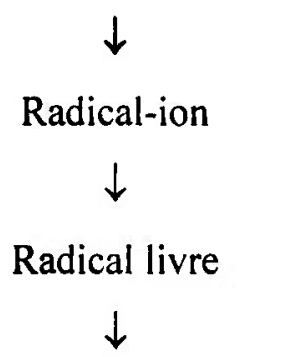

Mudanças químicas decorrentes da quebra de ligações

Efeitos biológicos 
Os produtos da radiólise da água no total são:

$\mathrm{OH} \bullet \quad$ radical hidroxila;

e aq elétron aquoso;

H• átomo de hidrogênio;

$\mathrm{H}_{2} \quad$ hidrogênio molecular;

$\mathrm{H}_{2} \mathrm{O}_{2}$ peróxido de hidrogênio;

$\mathrm{H}_{3} \mathrm{O}^{+} \quad$ próton hidratado

Estes produtos são formados quando a radiação ionizante interage com as moléculas de água, tornando-a ionizada, como ilustrado na equação 1:

$$
\mathrm{H}_{2} \mathrm{O} \rightarrow \mathrm{H}_{2} \mathrm{O}^{+}+\mathrm{e}^{-}
$$

Os raios X e $\gamma$ são radiações "indiretas"; o primeiro passo na sua absorção é a produção de elétrons rápidos de recuo (e $\left.\mathrm{e}^{-}\right) . \mathrm{O} \mathrm{H}_{2} \mathrm{O}^{+}$é um radical-íon. Um íon é um átomo ou molécula que é eletricamente carregada por ter perdido um elétron. Um radical livre contém um elétron desemparelhado na sua órbita externa, tornando-se altamente reativo. $\mathrm{O}_{2} \mathrm{H}_{2} \mathrm{O}^{+}$é carregado e tem um elétron desemparelhado, conseqüentemente ele é tanto um íon quanto um radical livre. Radicais-ions tem uma meia-vida extremamente curta, da ordem de $10^{-10}$ segundos. Eles decaem para formar radicais livres que não tem carga, mas que ainda possuem um elétron desemparelhado. No caso da água, o radical-ion reage com outra molécula de água para formar o radical hidroxila altamente reativo $(\mathrm{OH} \bullet)$ :

$$
\mathrm{H}_{2} \mathrm{O}^{+}+\mathrm{H}_{2} \mathrm{O} \rightarrow \mathrm{H}_{3} \mathrm{O}^{+}+\mathrm{OH} \bullet
$$

O radical hidroxila possui 9 elétrons sendo apenas 1 desemparelhado. Ele é um radical livre altamente reativo, podendo difundir-se em uma curta distância até atingir um alvo crítiço ou uma molécula de soluto.

Enquanto $\mathrm{OH} \bullet, \mathrm{e}^{-}$aq. e $\mathrm{H} \bullet$ são espécies intermediárias reativas, o hidrogênio molecular e o peróxido de hidrogênio são produtos finais estáveis da radiólise da água. De acordo com as equações 3 e 4 , o hidrogênio e o peróxido de hidrogênio são amplamente 
consumidos. Assim, estes são encontrados em pequena quantidade no meio, mesmo a altas doses de radiação.

$$
\begin{aligned}
& \mathrm{H}_{2} \mathrm{O}_{2}+\mathrm{e}^{-} \mathrm{aq} \rightarrow \mathrm{OH} \bullet+\mathrm{OH}^{-} \\
& \mathrm{H}_{2}+\mathrm{OH} \bullet \rightarrow \mathrm{H}_{2} \mathrm{O}+\mathrm{H} \bullet
\end{aligned}
$$

A formação de peróxido de hidrogênio, reconhecidamente um agente oxidante, pode não ter grande importância em alimentos irradiados. De fato tem menos importância que as espécies reativas intermediárias. $O$ radical hidroxila é um poderoso agente oxidante, enquanto o elétron aquoso é forte agente redutor. $O$ átomo de hidrogênio é um agente redutor um pouco menos efetivo. Já que todos os alimentos possuem substâncias que podem ser oxidadas ou reduzidas, estas reações são esperadas quando alimentos contendo água são irradiados (HALL, 1994).

Um fator importante na radiólise é a presença ou não de oxigênio durante a irradiação. $\mathrm{O}$ oxigênio pode facilitar a formação e aumentar a quantidade de espécies reativas no meio (DIEHL, 1990).

O processo de irradiação é rápido e seguro, pois o alimento não entra em contato direto com a fonte radioativa, passando por um campo de radiação a uma determinada velocidade que controla a quantidade de energia ou a dose absorvida (LOAHARANU, 1992).

A dose absorvida é a quantidade de energia absorvida pelo alimento por unidade de massa (BRASIL, 2001). A unidade utilizada é o gray (Gy). Em termos de energia, 1Gy equivale a 1 (um) joule de energia absorvida por quilo do alimento (WORLD HEALTH ORGANIZATION, 1977).

As fontes de radiação utilizadas no tratamento de alimentos se limitam àquelas autorizadas pela Comissão Nacional de Energia Nuclear, a saber: isótopos emissores de radiação gama $\left({ }^{60} \mathrm{Co}\right.$ ou $\left.{ }^{137} \mathrm{Cs}\right)$; raios-X gerados por máquinas que trabalham com energia de até $5 \mathrm{MeV}$ e elétrons gerados por máquinas que trabalham com energia de até $10 \mathrm{MeV}$. Estes valores de energia encontram-se muito abaixo do limiar das reações nucleares que poderiam induzir radioatividade no alimento irradiado (BRASIL, 2001).

Radiações gama e $\mathrm{X}$ de grande penetrabilidade são usadas na irradiação de produtos de grande espessura. Os elétrons provenientes de aceleradores que possuem pequena 
penetração são usados para a irradiação superficial de alimentos ou para produtos a granel, em camadas de espessura fina. Os irradiadores com fonte de ${ }^{60} \mathrm{Co}$, de meia-vida de 5,263 anos, são muito utilizados, atualmente, bem como, os aceleradores de elétrons para o processamento de alimentos (INTERNATIONAL CONSULTIVE GROUP ON FOOD IRRADIATION, 1992).

Para cada tipo de alimento e tratamento são definidas as doses máxima e minima absorvidas; onde a dose mínima absorvida deve ser suficiente para alcançar a finalidade pretendida e a dose máxima absorvida deve ser inferior àquela que comprometeria as propriedades funcionais e ou os atributos sensoriais do alimento. Em situações especiais, como no caso de surtos, visando assegurar a inocuidade do alimento sob o ponto de vista de saúde pública, a autoridade competente do Ministério da Saúde pode definir a dose mínima utilizada para a irradiação de um determinado alimento. Nas situações de controle fitossanitário e zoossanitário podem ser estabelecidos pela autoridade federal competente, doses mínimas de radiação ionizante considerando o tipo de produto, a finalidade e objetivo pretendido (BRASIL, 2001).

Além de se determinar o tipo de irradiação e o intervalo de doses, é importante focalizar:

- o momento mais adequado para a irradiação de determinado produto,

- se o alimento deve estar embalado e com qual tipo de material,

- a temperatura antes, durante e após a irradiação.

Essas variáveis dependem das necessidades e das condições especificas para cada alimento (WORLD HEALTH ORGANIZATION, 1981).

A irradiação repetida do alimento deve ser evitada, pois pode ocorrer um comprometimento sensorial e ou nutricional (WORLD HEALTH ORGANIZATION, 1977). Segundo a legislação brasileira, somente os alimentos de baixo conteúdo hídrico irradiados com o objetivo de combater a re-infestação de insetos podem ser re-irradiados. Não se consideram alimentos submetidos à re-irradiação, quando:

- se irradia com outra finalidade tecnológica alimentos preparados a partir de materiais que foram irradiados,

- se irradia alimentos com conteúdo de ingredientes já irradiados anteriormente em quantidade inferior a $5 \%$ do conteúdo total e massa e, 
- a dose total de radiação ionizante requerida para conseguir o efeito desejado se aplica nos alimentos de modo fracionado como parte de um processo destinado a obter um fim tecnológico específico (BRASIL, 2001).

No Brasil, as normas gerais que regulamentam a irradiação de alimentos foram aprovadas através do Decreto Lei $n^{\circ} 72.718$ de 29 de agosto de 1973 (BRASIL, 1973), pela Portaria nº 09-DINAL do Ministério da Saúde de 08 de março de 1985 (BRASIL, 1985), pela Portaria $n^{\circ} 30-D I N A L$ do Ministério da Saúde de 25 de setembro de 1989 (BRASIL, 1989) e, posteriormente pela Resolução-RDC $n^{0} 21$ de 26 de janeiro de 2001 (BRASIL, 2001) que revogou as portarias de 1985 e 1989.

A legislação brasileira (BRASIL, 2001) estabelece: "Alimento irradiado é todo alimento que tenha sido intencionalmente submetido ao processo de irradiação com radiação ionizante". Em outros países, a dose média global absorvida por um alimento submetido a um processo de irradiação tem como valor máximo $10 \mathrm{kGy}$, com a finalidade de assegurar a inocuidade do alimento, sob os pontos de vista toxicológico, nutricional e microbiológico. Entretanto, nos últimos anos, vem sendo sugerida a aplicação desta tecnologia em doses bem mais elevadas. Vários pesquisadores vêem destacando os dados da literatura sobre alimentos irradiados com doses entre 10 e $70 \mathrm{kGy}$, para obtenção de produtos alimentícios livres de germes, onde inicialmente a contaminação por patógenos é comum e praticamente inevitável (WORLD HEALTH ORGANIZATION, 1999). Assim, a legislação brasileira hoje em vigor não estabelece limite de dose que possa ser aplicada (BRASIL, 2001).

Os alimentos que forem tratados pela irradiação devem satisfażer todos os requisitos sanitários e de saúde, devem garantir a manutenção da qualidade em todas as etapas de sua produção, manejo, estocagem, processamento, acondicionamento, transporte e distribuição. Por conseguinte, o processo de irradiação, de maneira alguma, deve ser utilizado para "maquiar" alimentos deteriorados, de má qualidade ou que não estiverem em conformidade com as boas práticas de fabricação (WORLD HEALTH ORGANIZATION, 1981). Assim, a irradiação, como qualquer outro processo de tratamento de alimentos, não deve ser utilizada em substituição as boas práticas de fabricação e ou agrícolas. As boas práticas de irradiação devem também ser estabelecidas e implementadas de acordo com o que determina a legislação (BRASIL, 2001). 
A fiscalização e o licenciamento das instalações e o controle de processos estão a cargo dos órgãos federal, estadual, municipal, mediante expedição de alvará sanitário, após autorização da Comissão Nacional de Energia Nuclear (CNEN) e cadastramento junto ao órgão competente do Ministério da Saúde. Tais instalações devem ser projetadas de modo a satisfazerem às exigências da Comissão Nacional de Energia Nuclear em relação à Proteção Radiológica e do Ministério da Saúde, no que concerne à segurança radiológica, eficácia e boas práticas de manuseio e dispor de pessoal qualificado que possua capacitação e formação profissional (BRASIL, 2001).

A embalagem deve ter condições higiênicas aceitáveis, ser apropriada para o procedimento de irradiação, estar de acordo com a legislação vigente e aprovada pela autoridade sanitária competente. Nos casos em que não estejam previstas em legislação nacional, as embalagens em contato direto como o alimento deve ser aquelas relacionadas pela Organização Mundial de Saúde. A rotulagem dos produtos alimentícios deverá trazer além dos dizeres exigidos para os alimentos em geral e específico do alimento, a expressão: "Alimento tratado por processo de irradiação," com letras de tamanho não inferior a um terço (1/3) da letra de maior tamanho nos dizeres da rotulagem. Quando um produto irradiado é utilizado como ingrediente em outro alimento, deve-se declarar essa circunstância na lista de ingredientes, entre parênteses, após o nome do mesmo. Para a comercialização, na nota fiscal da indústria que irradiar o alimento e na embalagem quando o produto já estiver embalado deve constar que foi utilizado o processo de irradiação de alimentos, de acordo com as normas de rotulagem e; nos locais de venda ao consumidor deve constar, em placas, cartazes ou assemelhados, a seguinte informação: "Alimento tratado por processo de irradiação" (BRASIL, 2001).

Os custos da irradiação são influenciados por um grande número de fatores. Há uma imensa variedade de produtos alimentícios, doses aplicadas, efeitos desejados, tipos e densidades de embalagens, condições de manuseio, requerimentos de logística e condições do local para serem considerados na seleção do equipamento de irradiação e no estabelecimento dos custos de processos unitários (URBAIN, 1993). 


\subsubsection{Aplicações}

A irradiação é um processo flexível, e dependendo da dose utilizada se obtém um resultado específico (DIEHL, 1993).

Aplicações de doses baixas (menos que $1 \mathrm{kGy}$ ) têm como objetivo:

- inibir o brotamento de batatas, cebolas e permitir um armazenamento longo sem uso de inibidores de germinação químicos.

- causar a morte de insetos e outras pragas, prevenindo as perdas causadas durante o armazenamento e como tratamento quarentenário.

- destruir parasitas em alimentos (Entamoeba histolytica, Toxoplasma gondii).

Aplicações de doses médias (1 a $10 \mathrm{kGy}$ ) reduzem populações de bactérias e leveduras presentes na superficie e interior dos alimentos, mantendo suas propriedades e protegendo contra a intoxicação alimentar provocado por Salmonella sp, Shigella sp, Campylobacter sp, Vibrio sp, Yersiniae sp e outros patógenos não formadores de esporos. Nesta faixa de dose é obtido o incremento de propriedades tecnológicas.

Aplicações de doses elevadas, acima de $10 \mathrm{kGy}$ destroem populações de patógenos formadores de esporos e conduzem à obtenção de alimentos ou ingredientes esterilizados. Esta faixa de dose pode ser aplicada também na melhoria de propriedades tecnológicas.

A tecnologia de irradiação de alimentos é usada em diversos tipos de produtos, dentre eles, especiarias, grãos, carne de frango, frutas e legumes. Aproximadamente, quinhentas mil toneladas de produtos e ingredientes alimentícios são irradiadas anualmente no mundo, volume insignificante em relação à produção mundial. Atualmente, no entanto, é crescente a tendência da utilização desta técnica, sendo esta praticada em vários paises, como: África do Sul, Alemanha, Argentina, Bangladesh, Bélgica, Brasil, Canadá, Chile, China, Coréia, Costa Rica, Croácia, Cuba, Dinamarca, Espanha, Estados Unidos, Fèderação Russa, Filipinas, Finlândia, França, Holanda, Hungria, Índia, Indonésia, Irã, Israel, Itália, Iugoslávia, Japão, México, Noruega, Paquistão, Polônia, Reino Unido, República Tcheca, Síria, Tailândia, Ucrânia, Uruguai e Vietnã (DEL MASTRO, 1999).

$\mathrm{Na}$ Bélgica se irradiam mariscos congelados e ingredientes de alimentos desidratados para destruir bactérias patogênicas, causadoras de surtos. Na França irradiam-se produtos avícolas congelados e desossados e especiarias. Na Argentina, Dinamarca, Estados 
Unidos, Finlândia, Hungria, Israel, Noruega e República Tcheca, as especiarias são também irradiadas (LOAHARANU, 1992).

Atualmente existem seis irradiadores comerciais de grande porte em operação no Brasil.

Pesquisas de mercado e de comercialização realizadas em 20 países mostraram que $58 \%$ dos consumidores estão mais preocupados com a qualidade do produto alimentício do que com o tratamento usado para preservação deste, onde $42 \%$ destes consumidores preferem os produtos irradiados, devido as suas propriedades (LOAHARANU, 1994).

\subsection{Irradiação de Bebidas}

Poucos estudos comparativos, visando à esterilização e redução do tempo e do custo do envelhecimento de diferentes bebidas, têm sido realizados, envolvendo diversos sistemas experimentais.

MAGA (1989) descreveu que existem vantagens na utilização do envelhecimento rápido de bebidas destiladas, incluindo maior economia, menos barris e maior rendimento, devido à redução da evaporação do produto durante a estocagem.

Segundo URBAIN (1986), várias razões podem ser apontadas para o uso da radiação em vinhos:

- esterilização do mosto;

- mudanças das características sensoriais do vinho; $\mathrm{e}$

- aceleração do envelhecimento.

RIBEREAU-GAYON (1933) em seus estudos de envelhecimento de vinhos, por processos físicos, verificou que o vinho submetido aos raios de ultra-som, não apresentou nenhum melhoramento, nem modificação sensível à análise ou à degustação. Os raios infravermelhos desprovidos de atividade química comportam-se como uma simples fonte de calor podendo esterilizar o vinho, mas, não o envelhecem nem o "amaciam".

SINGLETON (1963) investigou os efeitos da radiação gama de ${ }^{60}$ Co sobre a qualidade sensorial e composição de vinho do porto, vinho tinto seco e branco seco. Observou que houve descoloração das amostras, diminuição do potencial redox e aumento da concentração de aldeídos. Encontrou alguns atributos desejáveis e não notou atributos prejudiciais no que diz respeito ao aroma e sabor das bebidas para a dose de irradiação de 
lkGy. No entanto, para doses maiores que 1 kGy houve mudança drástica no aroma e no sabor destas bebidas.

BREGVADZE \& SHIKHASHVILI (1971) apud SILVA JÚNIOR (1999) pesquisaram a influência da radiação gama no envelhecimento de "brandies", utilizando amostras recém-destiladas, submetidas aos seguintes tratamentos: 1) mantida em contato com raspas de carvalho, por 25 dias; 2) colocada em contato com raspas de carvalho submetida à radiação gama (200 e 1000Gy) durante 12 dias e; 3) armazenada em barris por 3 anos. Estes pesquisadores concluíram que o processo de envelhecimento é bem mais rápido quando se utiliza radiação gama, ocupando posição intermediária entre os casos 1 e 3.

DZHAPOLADYAN et al. (1971) apud SILVA JÚNIOR (1999) verificaram um método de produção de agentes que aceleram o envelhecimento de "brandies", obtidos por radiação gama ( 500 a $7500 \mathrm{~Gy}$ ) em carvalho.

A irradiação do carvalho com raios ultravioletas com lâmpadas de mercúrio, por 10 a 50 horas, promoveu a formação de compostos relacionados com o "flavor" de "brandies". Verificou-se também que o tratamento afetou a solubilidade de taninos, lignina, sacarídeos e aminoácidos (DZHAPOLADYAN et al., 1971 apud SILVA JÚNIOR, 1999).

DZHANPOLADYAN \& PETROSYAN (1972) apud SILVA JÚNIOR (1999) também investigaram o efeito da radiação ultravioleta nas bordas e na parte interna do barril de carvalho no envelhecimento de "brandy", tendo observado em ambos os casos, a presença de compostos voláteis, como, polifenóis, peróxidos orgânicos, furfural, alcoóis superiores, aldeídos e acetais, importantes para o "flavor" de bebidas destiladas. Estes pesquisadores sugeriram que o envelhecimento no mínimo de 2-5 anos pode ser substituído por 50 horas de radiação ultravioleta, sob condições próprias de umidade e em presença de ar.

TAKUO (1977) verificou que as doses máximas de radiação gama que não ocasionam modificações desfavoráveis estão em torno de $6 \mathrm{kGy}$ e $2 \mathrm{kGy}$, respectivamente para vinhos tintos e brancos, e são sensivelmente mais fracas que a dose letal para leveduras. Os vinhos irradiados com as doses acima descritas adquiriram caracteristicas semelhantes às de vinhos envelhecidos, porém aqueles irradiados com doses maiores que as mencionadas, adquiriram um gosto madeirizado. 
KOZUB et al (1985) apud SILVA JÚNIOR (1999) também observaram uma redução no tempo de envelhecimento para amostras de vinho tipo "sherry", submetidas à radiação com raios ultravioleta e infravermelho.

Em seus experimentos, URBAIN (1986) chegou à conclusão de que a dose necessária para inativar leveduras e bactérias nos vinhos, após a fermentação é de 6,0-7,0kGy e que diferentes vinhos apresentam resultados distintos. Vinhos secos mantêm sua característica sensorial aceitável, enquanto, vinhos semi-doces desenvolvem sabor amargo. $\mathrm{O}$ autor relatou que mudanças químicas foram observadas em vários vinhos da Califórnia, como um resultado de irradiação no intervalo de dose 1,0-10,0kGy. Ocorreu também significante aumento no "flavor" (conjunto de características relacionadas ao sabor e aroma de um produto) típico do envelhecimento. Para doses menores que $0,1 \mathrm{kGy}$, nenhuma diferença significativa ocorreu.

Para os vinhos coreanos produzidos pela fermentação de arroz e farinha de trigo e consumidos usualmente sem esterilização, uma dose de $2,4 \mathrm{kGy}$ de radiação gama associada a um aquecimento a $70^{\circ} \mathrm{C}$ por 10 minutos, produziu estabilidade à $33^{\circ} \mathrm{C}$ por 10 dias, não alterando as características sensoriais (URBAIN, 1986).

Na Hungria, vinhos secos inoculados com $10^{4}$ leveduras por $\mathrm{mL}$, foram tratados com 6,0kGy de radiação gama onde, esta dose foi insuficiente para obtenção da estabilidade microbiana, porém, uma dose de $2,0 \mathrm{kGy}$, já foi suficiente para conduzir alterações no aroma e sabor (URBAIN, 1986).

No processo de envelhecimento para as bebidas destiladas, o aperfeiçoamento do aroma está associado com a extração de material do tonel de carvalho. A irradiação de lascas de madeira de carvalho com raios gama facilita a extração do "flavor", melhorando o aroma da bebida destilada. A irradiação da bebida destilada com $0,1 \mathrm{kGy}$ produziu um aroma equivalente aquele obtido com três anos de envelhecimento normal. Doses maiores causaram prejuízo ao aroma (URBAIN, 1986).

PETROSYAN et al. (1986) apud SILVA JÚNIOR (1999) estudaram um tratamento com raios ultravioleta, em barris de carvalho e obtiveram resultados que indicam modificação do barril. Após tratamento com água quente e fria e secagem, a madeira foi submetida à radiação ultravioleta por 80-100 horas e, posteriormente, colocada em contato com o destilado. Os resultados mostraram que a madeira irradiada apresentou-se mais ativa no 
envelhecimento de destilados, fato comprovado pelo aumento da concentração de radicais livres, maior intensidade nas reações oxidativas, oxidação mais rápida da lignina, intensiva desidratação de pentoses e formação de peróxidos, polifenóis e outros compostos.

Um processo para obtenção de bebidas alcoólicas com características de envelhecidas em curto período de tempo também foi testado. Este processo empregava vibração ultra-sônica, com frequência de 8 a $14 \mathrm{kHz}$ e amplitude de 0,5 a $10 \mathrm{~mm}$, à temperatura de 20 a $75^{\circ} \mathrm{C}$. As bebidas analisadas foram saquê, cerveja, vinho e uísque (SANWA SHURUI COMPANY \& EIM ELETRIC COMPANY, 1989 apud SILVA JUNIOR, 1999).

$\mathrm{Na}$ China, a irradiação de bebidas com raios gama foi utilizada em vinho de batata doce para melhorar o seu sabor. Nos Países Baixos, foram usadas doses de até $7 \mathrm{kGy}$ para a descontaminação do malte, em cervejas (DIEHL, 1990).

Segundo GUOZHU \& XIAOLING (1992), irradiando-se vinho de tâmara com doses de 1,5 a 6,0kGy de raios gama, tem-se a total eliminação de germes e bolores.

No Brasil, alguns estudos mostraram que a aguardente de cana-de-açúcar, contida em tonel irradiado com radiação gama tem a sua cor melhorada e pH diminuído (SILVA JUNIOR, 1999). As aguardentes de cana-de-açúcar, quando tratadas com radiação gama com doses de 2 e $5 \mathrm{kGy}$ tiveram seus conteúdos de ésteres, alcoóis superiores aumentados (SOUZA, 2000).

WALDER et al. (2002), observaram que amostras de aguardente recentemente bidestilada irradiada com $150 \mathrm{~Gy}\left({ }^{60} \mathrm{Co}\right)$ apresentaram características sensoriais melhores do que as da aguardente bidestilada envelhecida em tonel de carvalho, por um ano.

\subsection{Cachaça}

As primeiras aguardentes brasileiras foram obtidas a partir do melaço de açúcar, resíduo dos engenhos instalados pelos colonizadores portugueses. $\mathrm{O}$ primeiro engenho foi construído em Santos, SP, por Martim Afonso de Souza, em 1534. Não se sabe ao certo quando os portugueses conhecedores da técnica de produção da bagaceira improvisaram os primeiros alambiques (LIMA, 1999).

A palavra cachaça pode ter tido origem no termo ibérico "cachazza", usado para designar um vinho barato consumido naquela época em Portugal e Espanha. Pode também ter relação com o nome dado ao reprodutor do porco, também chamado "cachaço", pois como se 
sabe, as carnes duras do caititu, um porco selvagem encontrado nas matas do nordeste brasileiro, eram amolecidas com aguardente (MORAES, 2004).

Segundo a Instrução Normativa $N^{0} 13$ de 29 de junho de 2005, Seção 1 (BRASIL, 2005), a Aguardente de Cana é a bebida com graduação alcoólica de 38 a $54 \%$ em volume, a $20^{\circ} \mathrm{C}$, obtida de destilado alcoólico simples de cana-de-açúcar ou pela destilação do mosto fermentado do caldo de cana-de-açúcar, podendo ser adicionada de açúcares até seis gramas por litro, expressos em sacarose. A bebida que contiver açúcares em quantidade superior a $6 \mathrm{e}$ inferior a $30 \mathrm{~g} / \mathrm{L}$ é denominada Aguardente de Cana Adoçada. O produto denominado Aguardente de Cana Envelhecida deve conter no mínimo 50\% de aguardente de cana ou do destilado alcoólico simples envelhecido em recipiente de madeira apropriado, com capacidade máxima de 700 litros, por um período não inferior a um ano. Aguardente de Cana Premium deve conter $100 \%$ de aguardente de cana ou destilado alcoólico simples de cana-de-açúcar envelhecido em recipiente de madeira apropriado, com capacidade máxima de 700 litros, por um período não inferior a um ano.

A Cachaça é a denominação típica e exclusiva da aguardente de cana produzida no Brasil, com graduação alcoólica de 38 a $48 \%$ em volume, a $20{ }^{\circ} \mathrm{C}$, obtida pela destilação do mosto fermentado do caldo de cana-de-açúcar com características sensoriais peculiares, podendo ser adicionada de açúcares até $6 \mathrm{~g} / \mathrm{L}$, expressos em sacarose. A cachaça que contiver açúcares em quantidade superior a 6 e inferior a $30 \mathrm{~g} / \mathrm{L}$ é denominada Cachaça Adoçada. O produto denominado Cachaça Envelhecida deve conter no mínimo 50\% de cachaça ou aguardente de cana envelhecida, em recipiente de madeira apropriado, com capacidade máxima de 700 litros, por um período não inferior a um ano. Cachaça Premium deve conter $100 \%$ de cachaça ou aguardente de cana envelhecida em recipiente de madeira apropriado, com capacidade máxima de 700 litros, por um periodo não inferior a um ano. Cachaça Extra Premium deve conter $100 \%$ de cachaça ou aguardente de cana envelhecida em recipiente de madeira apropriado, com capacidade máxima de 700 litros, por um período não inferior a três anos.

O Destilado Alcoólico Simples de Cana-de-açúcar, destinado à produção de aguardente de cana, é o produto obtido pelo processo de destilação simples ou por destiloretificação parcial seletiva do mosto fermentado do caldo de cana-de-açúcar, com graduação alcoólica superior a 54 e inferior a $70 \%$ em volume, a $20^{\circ} \mathrm{C}$. O produto denominado Destilado 


\begin{abstract}
Alcoólico Simples de Cana-de-açúcar Envelhecido deve ser armazenado em recipiente de madeira apropriado, com capacidade máxima de 700 litros, por um periodo não inferior a um ano.

A cachaça constitui um item importante da indústria de bebidas no Brasil por ser a cana-de-açúcar, um dos principais produtos agrícolas do país, a matéria-prima desta bebida. $\mathrm{O}$ consumo de aguardente no Brasil é um hábito amplamente difundido, sendo aproximadamente 20 vezes maior que o de qualquer outra bebida destilada. Estima-se uma produção anual média da ordem de 1,3 bilhões de litros, arrecadando 76,5 milhões de reais, porém a presença de pequenas destilarias espalhadas por todo Brasil, muitas delas clandestinas, tornam difícil determinar o volume de cachaça produzida. Sua exportação é de aproximadamente $1 \%$ da produção total, mas, vem aumentando nos últimos anos, acarretando uma crescente preocupação com o padrão de qualidade desse produto (SOUZA, 2000).
\end{abstract}

\title{
3.4. Rum
}

A primeira descrição de uma bebida alcoólica feita de cana-de-açúcar foi feita por um padre francês, Du Terre, que visitou as Índias em 1650. Em 1722, Padre Labat descreveu este destilado dizendo que sua fermentação era espontânea e que sua destilação era realizada em alambiques, onde várias destilações eram feitas antes do produto ser comercializado. Nesta época, tal bebida era produzida em Barbados, Jamaica, Ilhas Virgens e São Domingos, sendo principalmente exportada para o Reino Unido (CLUTTON, 1974).

A origem da palavra rum é incerta, onde algumas fontes possiveis poderiam ser estas: (1) derivação da palavra latina "saccharum" (açúcar), (2) da palavra "rumbullion" que significa grande tumulto, bem como, a palavra "rumbostion," ambas de origem devoniana, usadas por vendedores de Países Orientais para o Caribe e, (3) do espanhol "ron", destilado produzido pelos espanhóis nas Índias, anteriormente a chegada dos ingleses no Caribe (NICOL, 2003).

Mesmo o rum tendo sido produzido desde meados de 1600 , sua primeira definição legai, aceita pela "Royal Commission on Whiskey", somente apareceu em 1909 com "Sir" Algernon Aspinall, sendo "Rum um destilado obtido diretamente de produtos da cana em países produtores de açúcar". Segundo as regulamentações da "U.S. Internal Revenue service" (27CFR 5:21), "Rum é qualquer destilado alcoólico obtido do suco fermentado do melado de 
cana-de-açúcar, do melaço de cana ou outro produto da cana-de-açúcar, destilado com mais de $40 \%$ de álcool, de tal maneira que esta bebida possua sabor, aroma e características geralmente atribuídas ao rum, incluindo misturas deste destilado" (GÓMEZ, 2002).

No Brasil, o Rum, Rhum ou Ron é regulamentado pelo Decreto Federal $n^{0} 4.851$ de 02 de Outubro de 2003, Art. 93. (BRASIL, 2003). De acordo com este decreto o rum é a bebida com a graduação alcoólica de 38 a $54 \% \mathrm{v} / \mathrm{v}$, a $20^{\circ} \mathrm{C}$, obtida do destilado alcoólico simples de melaço, envelhecido, ou da mistura dos destilados de caldo de cana-de-açúcar e de melaço, envelhecidos total ou parcialmente, em recipientes de carvalho ou madeira, conservando suas características peculiares.

O rum deve conter no mínimo $30 \%$ de destilados alcoólicos envelhecidos empregados na sua elaboração, por um período não inferior a um ano, expressos em álcool anidro.

O produto pode ser adicionado de açúcares até uma quantidade máxima de $6 \mathrm{~g} / \mathrm{L}$.

Permite-se o uso de caramelo para correção da e cor e de carvão ativado para descoloração.

O coeficiente de congêneres não pode ser inferior a $40 \mathrm{mg}$ e nem superior a $500 \mathrm{mg} / 100 \mathrm{~mL}$ em âlcool anidro.

O rum pode denominar-se:

1. Rum leve (light rum), quando o coeficiente de congêneres da bebida for inferior a $200 \mathrm{mg} / 100 \mathrm{~mL}$ em álcool anidro,

2. Rum pesado (heavy rum), quando o coeficiente de congêneres da bebida for de 200 a $500 \mathrm{mg} / 100 \mathrm{~mL}$ em álcool anidro, obtido exclusivamente do melaço,

3. Rum envelhecido ou rum velho, que é a bebida que tenha sido envelhecida, em sua totalidade, por um período mínimo de 2 anos (BRASIL, 2003).

Tradicionalmente, os países produtores de rum são: Jamaica, Martinica, Porto Rico, Cuba, Barbados, Haiti, Ilhas Virgens, República Dominicana, Trindade e Guiana. Há outros locais que produzem rum, entre eles, Brasil, Peru, México, parte da Ásia e África (GÓMEZ, 2002).

Em 1990, as Ilhas Virgens produziram 12 milhões de litros de rum, Porto Rico produziu 84 milhões de litros e o México 50 milhões de litros (LUXNER, 1991). 


\subsection{Etapas de Produção das Bebidas Destiladas provenientes da Cana-de-Açúcar}

\subsubsection{Matéria-prima}

A cana-de-açúcar (Saccharum officinarum), cultivada em quase todos os Estados do Brasil é a matéria-prima para a fabricação de cachaça e rum. A qualidade da bebida proveniente da cana depende de seu trato durante a colheita (NICOL, 2003; AMPAQ, 2005).

\subsubsection{Moagem e Filtragem do Caldo}

Imediatamente depois de cortada, a cana madura, fresca e limpa deve ser moída num prazo máximo de 24 a 36 horas. As moendas separam o caldo do bagaço, que será usado para aquecer as fornalhas do alambique. O caldo da cana é decantado, diluído e filtrado para, em seguida, ser preparado com a adição de nutrientes e levado às dornas de fermentação. Algumas moendas são movidas por motor elétrico, outras por roda de água, e têm a função de espremerem a cana para extração do suco (AMPAQ, 2005).

No que diz respeito ao rum, o melaço, subproduto da fabricação do açúcar cristal, ou do açúcar demerara é clarificado, sendo aquecido a $92^{\circ} \mathrm{C}$ e tendo seu $\mathrm{pH}$ reduzido com adição de ácido sulfúrico até 5,5. Posteriormente este é diluído até 15-17\% de açúcares e resfriado, sendo adicionados nutrientes, como, fosfato de amônia, sulfato de amônia ou uréia devido ao baixo conteúdo de compostos nitrogenados orgânicos (GÓMEZ, 2002). Na obtenção de açúcar, o caldo é evaporado até atingir concentração superior a $75 \%$ de sólidos totais, causando a cristalização do açúcar por efeito da supersaturação da solução. Dependendo do estágio de extração pode-se ter mel de primeira, melaço de primeira, mel de segunda, melaço de segunda, e mel final, também chamado, mel residual ou esgotado. A composição dos melaços, em média, é: $20 \%$ umidade, $62 \%$ açúcares, $8 \%$ cinzas, $3 \%$ material nitrogenado e 7\% gomas e ácidos (MORAES, 2004).

\subsubsection{Fermentação}

Em relação à cachaça de alambique, a fermentação ideal ocorre com o caldo de cana numa concentração de açúcares em torno de $15^{\circ}$ Brix (teor de sólidos solúveis totais). A temperatura do mosto (caldo de cana a ser fermentado) deve estar entre 26 a $28^{\circ} \mathrm{C}$ e seu $\mathrm{pH}$ deve variar entre 4,5-5,0. A fermentação normal varia de 20 a 24 horas. $O$ uso de nutriente natural, como por exemplo, o fubá de milho, é um dos procedimentos que historicamente vem 
sendo adotado pelos produtores de cachaça de alambique (AMPAQ, 2005). A adição de farelo de arroz, rico em vitaminas e sais minerais pode ser feita com o intuito de aumentar o rendimento da fermentação (LIMA, 1999).

No que diz respeito ao rum, a fermentação ideal ocorre em uma mistura de água e melaço com uma concentração de açúcares em torno de $16-20^{\circ}$ Brix. A temperatura ambiente deve estar entre $30-33^{\circ} \mathrm{C}$ e o pH entre 5,5 e 5,8. A fermentação normal varia de 48 a 72 horas. Antigamente, utilizava-se nutriente natural na fermentação de rum, atualmente, são usadas leveduras de culturas puras no processo de fermentação, como, Saccharomyces cerevisae, para produção de rum leve ou Schizosacharomyces pombe para a produção de rum pesado. Bactérias, como, Clostridium saccharobutyricum ou Clostridium kluyvery podem ser adicionadas para influenciar nas características da fermentação e contribuir com as propriedades sensoriais do produto final (GÓMEZ, 2002).

\subsubsection{Destilação}

O emprego de cobre na fabricação dos alambiques é um aspecto que favorece a qualidade da cachaça, uma vez que este elemento catalisa a oxidação de compostos sulfurados de aroma desagradável. Os alambiques podem ser classificados como simples e retificadores. Nos alambiques simples, a destilação é obtida aquecendo uma mistura hidroalcoólica, transformando a parte mais volátil em vapor, separando-a por condensação e resfriamento, sem retornar o condensado à mistura original, por no mínimo que seja seu volume. Os alambiques simples podem ter um corpo, dois corpos ou três corpos. Os alambiques retificadores são descontínuos, mas em uma única operação permitem obter destilados de elevada concentração alcoólica, com $90^{\circ} \mathrm{GL}$ ou mais (LIMA, 1999). Os produtos da destilação de um alambique simples são divididos em três frações denominadas cabeça, coração e cauda. $\mathrm{O}$ destilado de coração, fração de melhor qualidade, deverá apresentar o teor alcoólico em torno de $45^{\circ}$ a $50^{\circ} \mathrm{GL}$. O destilado de cabeça, obtido na fase inicial da destilação, é mais rico em substâncias voláteis que o etanol e pode atingir graduação alcoólica entre $65^{\circ} \mathrm{e} 70^{\circ} \mathrm{GL}$. Por sua vez, o destilado de cauda, ou água fraca, obtido no final da destilação, apresenta teor alcoólico abaixo de $38^{\circ} \mathrm{GL}$ e é rico em produtos indesejáveis, tais como furfural e outros. Os destilados de cabeça e de cauda comprometem o sabor da cachaça e podem prejudicar a saúde do consumidor quando incorporados à bebida (AMPAQ, 2005). 
A escolha do equipamento utilizado na destilação do rum tem grande influência na característica final desta bebida (NICOL, 2003). Runs leves, semelhantes à vodca, são altamente retificados (purificados e misturados), produzidos em colunas, sendo posteriormente filtrados em carvão ativado. A destilação contínua, geralmente, consiste de 3 colunas onde a primeira coluna, remove todo o álcool do caldo fermentado; a segunda coluna que remove todas as impurezas de baixo ponto de ebulição envia uma mistura purificada de água/álcool/congêneres para a terceira coluna, que concentra o álcool, removendo os compostos pesados. Para a produção de "destilados neutros" é usada uma série de 6 colunas, onde a primeira coluna é denominada coluna de purificação, onde $\mathrm{CO}_{2}$, aldeídos e outros gases são removidos. A segunda coluna remove todo o etanol; a terceira coluna concentra os aldeídos e retorna o etanol para o processo. A quarta coluna ou de retificação concentra e purifica os vapores de álcool e remove as impurezas. A quinta coluna remove principalmente os aldeídos e a sexta coluna mistura o produto proveniente da coluna anterior com água pura. Já alambiques produzem runs pesados, semelhantes aos uísques. Neste caso, o alambique consiste de um único corpo, um condensador e um ou mais tanques de recebimento. Outra variação de destilação em alambique contém vários corpos em série. O líquido fermentado é bombeado para o primeiro corpo e destilado. O destilado condensado ou "low wine" é coletado no segundo corpo. Este, então, é destilado obtendo o "high wine", que é tratado em uma pequena coluna de retificação (GÓMEZ, 2002).

\subsubsection{Envelhecimento}

Tem-se observado melhora sensível do aroma e sabor da bebida destilada submetida ao armazenamento prolongado, tornando esta "redonda", "lisa" e "suave". A maturação é conseguida através do seu envelhecimento em recipientes adequados e em condições próprias de armazenamento, principalmente com relação à temperatura e à umidade (SINGLETON, 1974).

O desenvolvimento do aroma e sabor durante a maturação é resultante de uma sériè de transformações lentas e relativamente independentes que somadas dão origem às propriedades características de cada bebida após alguns anos de envelhecimento (NISHIMURA \& MATSUYAMA, 1985). 
O periodo de envelhecimento é variável, sendo o produto classificado de acordo com o tempo de armazenamento, sendo este, segundo a legislação brasileira (2005), sujeito às flutuações ocasionadas pela demanda do produto e poder econômico do proprietário da destilaria.

O mecanismo da maturação não está completamente esclarecido e não há ainda indice químico ou físico confiável que indique o progresso da maturação. No entanto, algumas das características da maturação já conhecidas são (NISHIMURA \& MATSUYAMA, 1985):

- O período de maturação varia de um ano a mais de 10 anos;

- As características sensoriais (sabor e aroma) do produto maduro são bem diferentes do produto recém-destilado;

- Ocorre perda de etanol e água através da porosidade da madeira;

- Ocorre esterificação que requer a presença de ácidos, etanol e outros alcoóis superiores;

- Ocorrem polimerização e condensação que requer aldeídos;

- Ocorre formação de novos alcoóis e ácidos, requerendo a presença de ésteres; e

- A qualidade varia entre tonéis individuais porque a velocidade da maturação é afetada pelo teor alcoólico e tipo de bebida, tamanho, natureza (espécie botânica), idade, número de vezes que foi utilizado e tratamento prévio dado aos tonéis, bem como a temperatura e umidade do ambiente.

As espécies botânicas da madeira usadas para fabricação de barris ou tonéis para o envelhecimento do rum são: carvalho branco (Quercus alba) proveniente dos Estados Unidos e da Europa e carvalho espanhol (Quercus sessilis ou Quercus rubor) originário somente na Europa. Além do $Q$. alba que é a melhor e corresponde à cerca de $45 \%$ dos recipientes, outras espécies similares são encontradas nos Estados Unidos, como: $Q$. prinus, $Q$. bicolor, $Q$. muehlenbergii, $Q$. stellata, $Q$. macrocarpa, $Q$. lyrata, $Q$. durandii, todas pertencentes ao grupo do carvalho branco (SINGLETON, 1974).

Várias madeiras brasileiras podem ser usadas para o envelhecimento da cachaça, como: amburana - Amburana cearensis (Fr. All.) A. C. Smith; bálsamo - Myroxylon peruiferum L. F.; jequitibá - Cariniana estrellensis (Raddi) Kuntze; jatobá - Hymeneae spp e ipê - Tabebuia spp, entre outras. DIAS et al. (1998), constatou que cada madeira introduz predominantemente compostos fenólicos específicos na bebida: ácido vanílico e sinapaldeído, 
a amburana; vanilina e ácido elágico, o bálsamo; ácido gálico, o jequitibá; coniferaldeido, o jatobá e ácidos siríngico e vanílico e coniferaldeído, o ipê.

\subsection{Principais Componentes do "Flavor" das Bebidas Alcoólicas}

O "flavor" das bebidas alcoólicas é composto de várias substâncias orgânicas voláteis e não voláteis. Estes compostos conferem o típico aroma e sabor a estas bebidas. Muitas destas substâncias têm sido identificadas e classificadas em vários grupos de acordo com sua natureza química. A maioria dos compostos responsáveis pelo aroma das bebidas destiladas é volátil. O "flavor" e a composição química podem ser relacionados com o processo de manufatura usado (NYKANEN \& NYKANEN, 1991).

\subsubsection{Alcoóis Superiores}

Nas bebidas destiladas, os alcoóis superiores são o maior grupo entre os componentes de aroma, sob o aspecto quantitativo, sendo que em média, o rum contém $0,6 \mathrm{~g} / \mathrm{L}$, o uísque escocês $1 \mathrm{~g} / \mathrm{L}$ e o conhaque $1,5 \mathrm{~g} / \mathrm{L}$. Esses alcoóis, denominados também de óleo fúsel tem um efeito significativo sobre as características sensoriais das bebidas. $\mathrm{O} n-$ propanol, o isobutanol e o amílico são importantes componentes do uísque e vinhos, porém, altas concentrações desses, podem conferir odor desagradável à bebida, sendo sugerido o limite de óleo fúsel entre 60 e $120 \mathrm{~g} / \mathrm{L}$ a $50 \% \mathrm{v} / \mathrm{v}$ de álcool (NYKANEN \& SUOMALAINEN, 1983).

O álcool isoamílico é o principal álcool sintetizado durante a fermentação e dependendo da natureza da bebida pode perfazer $40-70 \%$ do total de óleo fúsel (GUTIERREZ, 1993).

Os alcoóis superiores são subprodutos de síntese de aminoácidos e proteínas nas leveduras, opostamente aos ésteres, a síntese de alcoóis superiores é estimulada por oxigênio, e sua síntese está relacionada linearmente ao crescimento da levedura. Os alcoóis superiores são também formados como produtos secundários do metabolismo de carboidratos (ASKEW \& LISLE, 1971).

Os fatores que influenciam os níveis de alcoóis superiores durante a fermentação são: a matéria prima, a linhagem da levedura, o pH do meio de fermentação, a concentração inicial do inóculo, a temperatura de fermentação, a aeração, a matéria suspensa, a quantidade e 
a natureza dos nutrientes presentes no mosto e a presença de microorganismos contaminantes (MAIA, 1994).

De acordo com L'ANSON (1971), maiores quantidades de alcoóis superiores são encontradas em runs destilados em alambiques do que naqueles destilados em coluna.

Os alcoóis superiores, além de conferir corpo à bebida, podem passar por um processo de esterificação durante o envelhecimento sendo seus ésteres aromaticamente mais agradáveis ao paladar (NYKANEN \& NYKANEN, 1991).

Segundo LIMA (1964), a aguardente de cana-de-açúcar fabricada em alambique, quase sempre sem processos de retificação (sem separação do óleo fúsel), apresenta uma riqueza em óleo fúsel muito elevada, parecendo ser um fator de qualidade das aguardentes.

De acordo com LEHTONEN (1983), álcool isoamílico é o óleo fúsel mais abundante no rum, seguido de isobutanol.

Alguns dos alcoóis superiores encontrados no rum são: álcool isoamilico, isobutanol, 2-butanol, 1-propanol, 2-metil-1-butanol, propanol e isopentanol (NYKANEN \& SUOMALAINEN, 1983).

AMERINE et al. (1972) sugerem que alcoóis superiores podem não ser apenas importantes devido ao seu odor característico, mas também devido a sua ação solvente sobre outras substâncias aromáticas, interferindo no grau de volatilidade.

\subsection{2. Ésteres}

Os ésteres são quantitativamente o maior grupo de componentes do aroma das bebidas destiladas, seus limiares sensoriais são muito baixos e conferem "flavors" característicos, até mesmo quando presentes em baixa concentração, sendo as suas composições qualitativas altamente similares em todas as bebidas alcoólicas (KILLIAN \& OUGH, 1979).

Os ésteres são os compostos chaves no rum, pois, estes contribuem para o seu aroma. Eles são responsáveis pelo aroma de fruta presente nesta bebida. O conteúdo de ésteres no rum varia de 4 a $64 \%$ peso/volume, sendo o predominante, o acetato de etila. Há vários fatores que influenciam a concentração de ésteres no rum, como: nivel de oxigênio, temperatura, $\mathrm{pH}$ de fermentação e linhagem da levedura. Alguns dos ésteres encontrados no 
rum são: acetato de metila, acetato de etila, acetato de butila, isobutirato de etila, butirato de etila, butirato de propila, butirato 2-metil etila e laurato de etila (NYKANEN et al., 1977).

Os ésteres, de modo geral são desejáveis, pois favorecem o aroma da aguardente, sendo oriundos da fermentação, destilação e envelhecimento (HASHIZUME, 1976; WILDENRADT \& SINGLETON, 1974).

$\mathrm{O}$ aroma dos ésteres é mais acentuado quando o álcool que os compõem possui baixo peso molecular (por exemplo, o álcool etílico). Além disso, cada éster tem aroma peculiar. Os acetatos de etila e de butila apresentam aroma frutado, o acetato de isoamila e butirato de amila tem aroma de banana, enquanto os acetatos de alcoóis maiores têm aroma cítrico, porém, menos pungente que os ésteres de alcoóis menores (MAIA, 1994). LLISTÓ et al. (1979) verificaram a presença de acetato de butila, acetato de etila, butirato de etila e acetato de isoamila em 11 marcas de aguardente de cana. MURTA et al. (1982) encontraram etanoatos de metila, etila e de isopentila em aguardentes comerciais.

\subsection{3. Ácidos}

Os ácidos voláteis são os mais comuns em bebidas destiladas, sendo o ácido acético o mais abundante (ROSE, 1977). Os ácidos alifáticos de cadeia não ramificada e seus ésteres de etila constituem o segundo grupo mais abundante de componentes não-alcoóis encontrados em bebidas destiladas (GUYMON, 1974). Os ácidos são importantes precursores dos ésteres (BERRY \& WATSON, 1987).

Os ácidos voláteis contribuem para o "flavor" das bebidas destiladas, pois, são capazes de aumentar levemente a acidez. A concentração de ácido acético varia amplamente em diferentes bebidas destiladas, porém, na maioria dos casos corresponde de 60 a $95 \%$ da acidez total (NYKANEN \& NYKANEN, 1991).

Os ácidos graxos são produzidos durante a fermentação e são facilmente transferidos ao destilado durante a destilação, e a quantidade de ácidos aumenta com o envelhecimento (LEHTONEN, 1983).

O conteúdo total de ácidos no rum pesado é de aproximadamente $100-600 \mathrm{mg} / \mathrm{L}$, onde o acido acético é o predominante. Runs pesados contêm mais ácidos voláteis do que runs leves. Alguns dos ácidos encontrados no rum são: ácido propiônico, ácido isobutírico, ácido isovalérico, ácido valérico, ácido butírico, ácido hexanóico, ácido heptanóico, ácido láurico, 
ácido mirístico, ácido palmítico, ácido oléico, ácido linoléico, ácido benzóico, ácido gálico e ácido vanílico (NYKONEN \& SUOMALAINEN, 1983).

\subsubsection{Aldeídos}

Os aldeídos são uns dos principais componentes responsáveis pelo "flavor" das bebidas, pois um grande número desses apresenta baixo valor de limiar sensorial (ROSE, 1977).

A maioria dos aldeídos em bebidas alcoólicas é formada durante a fermentação, sendo produtos intermediários da rota biossintética de alcoóis superiores formados por descarboxilação de $\alpha$-cetoácidos pelo piruvato descarboxilase (SUOMALAINEN , 1979).

O acetaldeído é o composto predominante em bebidas destiladas, representando 90\% da concentração total dos compostos carbonílicos em uísque e rum (NYKANEN \& NYKANEN, 1991). O acetaldeído é importante para a composição do aroma das bebidas, devido ao seu baixo limiar sensorial, sendo formado durante a destilação por oxidação do álcool etílico. Aldeídos podem totalizar de 5 a $9 \%$ peso/volume em runs da Jamaica, Porto Rico e Martinica (NYKANEN \& NYKANEN, 1983).

\subsubsection{Acetais}

A maioria dos acetais é formada durante a destilação pela reação de uma molécula de aldeído e uma molécula de álcool, formando um hemiacetal. O hemiacetal formado é instável e uma vez combinado com outra molécula de álcool forma um acetal estável. A reação de formação de acetais é reversível. O mais abundante acetal encontrado no rum é o dietil acetal (LEHTONEN \& SOUMALAINEN, 1977).

\subsubsection{Fenóis}

Os fenóis são compostos presentes nas bebidas em pequenas quantidades, mas a sua contribuição é bastante significativa para o aroma das bebidas alcoólicas. Os fenóis são extraídos principalmente durante o envelhecimento via extração alcoólica dos barris, mas estes também podem ser formados durante outros estágios do processo. Alguns fenóis encontrados no rum são: guaiacol, p-etil guaiacol, p-metil guaiacol, eugenol, vanilina, o-cresol, m-cresol e p-cresol (LEHTONEN, 1983). De acordo com DUBOIS \& RIGAUD (1975), são vários os 
fenóis que compõem o rum, como: guaiacol, 4-metil guaiacol, 4-vinil guaiacol, 4-etil guaiacol, 4-propil guaiacol, eugenol, isoeugenol, 4-vinil-2-metoxifenol e vanilina.

\subsection{Análise Sensorial}

De acordo com a definição da Associação Brasileira de Normas Técnicas (ABNT), análise sensorial é uma ciência multidisciplinar, utilizada para analisar, medir, evocar e interpretar reações das características dos alimentos ou materiais, percebidos através dos órgãos dos sentidos (MARCELLINI, 2000), onde vários métodos são empregados, dependendo da sua finalidade (STONE \& SIDEL, 1985).

Para medir a aceitação de um produto usa-se o método afetivo. Com ele, pode-se avaliar a preferência ou aceitação de um produto, junto ao mercado consumidor, aplicando-se diferentes metodologias, como os testes de pareado-preferência, ordenação-preferência e testes com uso de escala hedônica (estruturada e não estruturada) (DUTCOSKY, 1996).

Os métodos discriminativos ou de diferenças possuem o objetivo de determinar se há diferença significativa entre amostras (geralmente $p \leq 0,05$ ). Neste caso são utilizados principalmente, testes pareados, triangulares, duo-trio e ordenação ou "ranking test" (LAWLESS \& HELMANN, 1998).

Os métodos descritivos ou analíticos descrevem qualitativa e quantitativamente os componentes sensoriais de um produto por uma equipe de provadores treinados. Os testes aplicados são os mais diversos, sendo alguns deles: perfil de sabor ("Flavor Profile Method") (CAIRNCROSS \& SJOSTROM, 1950); perfil de textura ("Texture Profile Method") (BRANDT et al., 1963); análise descritiva quantitativa ("Quantitative Descritive Analysis ${ }^{T M}$ ) (STONE et al., 1974) e "Spectrum" ${ }^{T M " ~(M E I L G A A R D ~ e t ~ a l ., ~ 1991) . ~}$

\subsubsection{Teste Triangular}

\subsubsection{Definição}

$O$ teste triangular tem como finalidade verificar se existe diferença significativa entre duas amostras que sofreram tratamento diferente. As três amostras são apresentadas simultaneamente aos provadores; onde duas amostras são iguais e uma diferente, sendo 
perguntado qual é a diferente. Cada amostra é codificada, usando três dígitos (LAWLESS \& HELMANN, 1998).

Recomenda-se de 20 a 40 indivíduos, embora apenas 12 possam ser utilizados em casos mais simples. Os provadores devem ter sido previamente selecionados, mas não precisam de treinamento específico; apenas uma sessão de orientação é suficiente (DUTCOSKY, 1996).

\subsubsection{Aplicações}

Este teste serve para detectar pequenas diferenças e por este motivo é utilizado antes de outros testes, porque não avalia o grau, nem caracteriza os atributos responsáveis pela diferença (LAWLESS \& HELMANN, 1998).

Segundo AMERINE (1965) pode-se fazer a seleção de provadores com base em seu poder discriminativo por meio de testes triangulares.

\subsubsection{Análise Descritiva Quantitativa}

\subsubsection{Definição}

Várias técnicas que enfocam a descrição e a quantificação do aroma de produtos alimentícios têm sido desenvolvidas. A análise descritiva quantitativa envolve a caracterização do produto por atributos e pela intensidade destes (MUÑOZ \& CIVILLE, 1998). Esta técnica categoriza diferentes sensações e providencia uma linguagem usual para a comunicação das percepções (MOSKOWITZ, 1983). Este método avalia todos os atributos sensoriais presentes no produto alimentício, quais sejam: aparência, aroma, sabor e textura (DUTCOSKY, 1996).

A análise descritiva quantitativa (ADQ)® desenvolvida por STONE et al. (1974) permite fazer a análise estatística da avaliação sensorial obtida. A quantificação das respostas sensoriais requer o uso de provadores treinados usando o mesmo vocabulário, bem como definições adequadas e referências padrões qualitativas e quantitativas. Para isto, faz-se necessário o uso também de uma mesma escala para unificar o critério de avaliação.

A aplicação desta técnica envolve as seguintes etapas, relacionadas a seguir (DUTCOSKY, 1996): 
- Etapa 1 - Seleção dos provadores: a equipe deve ser composta de 10 a 12 indivíduos, previamente selecionada e treinada para possuírem habilidade em verbalizar as sensações e trabalhar em grupo, e de demonstrar reprodutibilidade.

-Etapa 2 - Desenvolvimento de terminologia: os provadores avaliam sensorialmente o produto e verbalizam as sensações percebidas, discutindo-as em grupo com a ajuda do líder da equipe. Dois métodos podem ser usados para desenvolver uma lista de termos descritivos:

- Método tradicional: oferece-se o produto para cada provador, solicitando-se que ele faça uma lista completa dos atributos sensoriais que caracterizam o produto. Em seguida, abre-se a discussão, sob a supervisão de um líder; os termos descritivos mais utilizados irão compor a ficha de análise do produto que está sendo avaliado.

- Método de rede (grid): as amostras são apresentadas aos pares ao provador a fim de serem listadas as diferenças e as similaridades entre elas. Em seguida, abre-se a discussão, sob a supervisão de um lider; os termos descritivos mais utilizados para descrever as semelhanças e as diferenças irão compor a ficha de análise do produto que está sendo avaliado.

- Etapa 3 - Treinamento: realiza-se com os próprios produtos a serem avaliados e com materiais de referência. Após o treinamento, usualmente se procede a nova seleção dos provadores com a finalidade de determinar os que conseguem discriminar, apresentam boa reprodutibilidade e produzem resultados consistentes com os demais membros da equipe.

- Etapa 4 - Teste sensorial: após o treinamento, os testes sensoriais podem ser conduzidos em condições que garantam a individualidade dos provadores, bem como os demais requisitos necessários à avaliação.

\subsubsection{Aplicações}

Dentre as principais aplicações da análise descritiva quantitativa destacam-se (STONE \& SIDEL, 1985):

- Monitoração de produtos concorrentes: é importante se saber as diferenças entre produtos concorrentes no mercado, pois tal informação pode ser usada para antecipar mudanças e identificar pontos fracos no produto. A análise descritiva fornece uma base e uma direção para as mudanças no produto. 
- Teste de armazenamento: tem como intuito verificar mudanças no produto com o passar do tempo. A análise descritiva do produto no tempo zero fornece um padrão com o qual as possíveis mudanças podem ser comparadas, eliminando assim a necessidade de um produto controle.

- Desenvolvimento do produto: a análise descritiva pode ser utilizada no desenvolvimento de novos produtos para determinar se as formulações testadas atingem a meta designada, fornecendo informação sensorial precisa sobre o produto acabado.

- Controle de qualidade: pode ser usada para investigar efeitos de ingredientes ou variáveis do processo na qualidade sensorial do produto final. A análise descritiva pode ser usada para estabelecer os limites máximos e mínimos para os atributos sensoriais do produto.

- Comparação de medidas sensoriais com medidas experimentais: a análise descritiva é útil na identificação de atributos que possam ser correlacionadas com as medidas instrumentais.

A análise descritiva quantitativa tem sido usada no estudo de diversos produtos alimentícios, como: queijos (CARPINO et al., 2002; HOUSE \& ACREE, 2002), avelãs (ALASALVAR et al, 2003), entre outros.

Algumas técnicas de análise descritiva têm sido desenvolvidas ou modificadas para especiais necessidades na avaliação de bebidas alcoólicas, como por exemplo, metodologias criadas para avaliação de vinhos, como a análise descritiva da Universidade de Davis-Califórnia (UCD DA) (NOBLE, 1998), para avaliação de cervejas (MECREDY et al., 1974); para uísque (PIGGOTT et al., 1980) e para gin (PIGGOTT \& HOLM, 1983).

GÓMEZ (2002), por meio da análise descritiva, estudou o aroma de várias marcas de rum. MARCELLINI (2000) realizou a análise descritiva de amostras de cachaça comerciais e destiladas em alambiques de cobre e aço-inoxidável. FURTADO (1995) estudou os atributos sensoriais de aguardentes recém-destiladas por meio da análise descritiva quantitativa. CARDELLO \& FARIA (1998) também utilizaram esta técnica em cachaças não envelhecidas e envelhecidas. 


\subsection{Cromatografia Gasosa}

\subsubsection{Definição}

A cromatografia gasosa foi introduzida por James e Martin em 1952. O princípio básico de operação da cromatografia gasosa envolve a volatilização da amostra num local de entrada aquecido (injetor), a separação dos componentes da mistura numa coluna especialmente preparada e a deteç̧ão de cada componente por um detector. Nesta técnica cromatográfica, a fase móvel é um gás quimicamente inerte, chamado gás de arraste, e a fase estacionária pode ser apenas um sólido, ou sólido impregnado com um líquido pouco volátil. As colunas empregadas podem ser empacotadas ou capilares. Há diversos tipos de detectores utilizados, onde a escolha deste dependerá dos compostos a serem estudados. No caso de bebidas destiladas usa-se o detector de ionização de chamas, próprio para a separação e quantificação de alcoóis (CIOLA, 1985).

Basicamente um cromatógrafo a gás (CG) é constituído por: cilindro de gás de arraste, controlador de vazão e regulador de pressão do gás de arraste, injetor, coluna, detector e registrador.

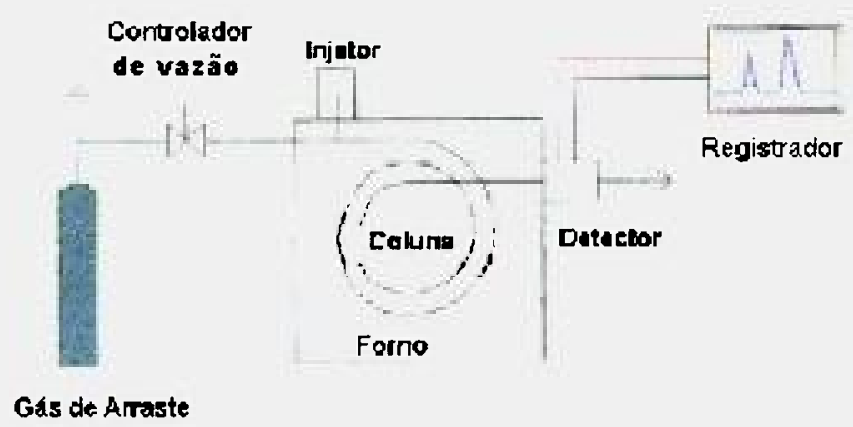

FIGURA 1 - Esquema de um cromatógrafo a gás.

\subsubsection{Aplicậões}

A cromatografia gasosa é, atualmente, uma das técnicas de maior uso. É utilizada para a separação e quantificação de produtos diversos. Os recentes avanços na área de utilização de colunas capilares fazem da cromatografia gasosa uma técnica altamente atrativa. 
$\mathrm{Na}$ indústria alimentícia pode-se usar a cromatografia gasosa para a análise de alguns constituintes de alimentos, como lipídeos e carboidratos, entre outros. Esta técnica pode ser empregada em vários tipos de alimentos na determinação de algum tipo de adulteração, contaminação e decomposição, como: óleos vegetais, banha, leite e produtos lácteos, bebidas alcoólicas destiladas e fermentadas, entre outros. Em alguns casos com técnicas adequadas de concentração da amostra, podem ser detectados constituintes alimentícios a níveis de traços, como por exemplo, esteróides e vitaminas (BONATO, 1995).

\subsection{Cromatografia Líquida de Alta Eficiência}

\subsubsection{Definição}

A cromatografia líquida de alta eficiência ou "High Performance Liquid Chromatography" (HPLC) é uma técnica de cromatografia em que a fase móvel é líquida. A fase móvel encontra-se sob pressão e passa através de uma coluna de vidro ou de metal que contém a fase estacionária. Trata-se de um processo bastante eficiente e rápido. Em princípio, opera-se a coluna de modo semelhante ao cromatógrafo a gás: varrem-se para baixo os componentes da amostra da coluna, com velocidades diferentes, e eluem-se um a um. A eluição da coluna pode ser feita com um único solvente ou com uma mistura de solventes.

Se durante o processo de eluição a composição do eluente se mantem constante, temos um processo de eluição contínua. Se a composição do eluente vai mudando ao longo do tempo de eluição, temos um processo de gradiente. Para proceder a este processo de gradiente recorre-se a um sistema de programação de gradiente que permite uma variação contínua da composição do eluente. Existem numerosas fases estacionárias utilizadas no HPLC: adsorção, partição, troca iônica, exclusão molecular, incluindo permeação em gel e filtração em gel. Dentro da cromatografia de partição ainda temos que considerar dois casos: HPLC de fase normal e HPLC de fase reversa. Na cromatografia de fase reversa a fase estacionária é apolar. Este é pouco usual em cromatografia "normal", mas representa mais de $90 \%$ das aplicações em HPLC. Também é uma cromatografia de partição líquido-líquido na qual a fase estacionária é mais apolar do que a fase móvel. Nestas condições, os compostos polares preferem permanecer na fase móvel, sendo eluídos antes dos materiais não polares que tem maior afinidade para a fase estacionária. A estrutura da fase estacionária não polar é uma fase aderida a uma matriz de partículas de sílica. Um bom exemplo de colunas de fase reversa são 
as habituais colunas $\mathrm{C}_{18}$. A uma matriz de suporte está aderido um n-alcano com 18 átomos de carbono. Este tipo de cromatografia é extremamente sensível à composição da fase móvel. $O$ efeito da variação de fase estacionária (número de átomos de carbono) na separação de uma dada mistura é também assinalável. As fases móveis mais utilizadas são: água, metanol, etanol, isopropanol, acetonitrila e tetrahidrofurano. As pressões associadas à cromatografia de fase reversa são as mais altas da técnica de HPLC podendo atingir os 400 bares. Após a separação na coluna, os vários componentes da amostra vão passar por um detector, com um tempo de retenção que lhes é característico, já que depende do seu modo de interação com a fase estacionária. Existem vários tipos de detectores: absorção UV, "diode array", fluorescência, índice de refração, condutividade e amperometría. Quanto ao manuseamento do HPLC, existem vários cuidados a serem tomados: pressão máxima de trabalho (depende das colunas), pureza dos reagentes, bolhas de ar e corrosão. A FIGURA 2 ilustra um esquema de um cromatógrafo líquido de alta eficiência (FIFIELD \& KEALEY, 2000).

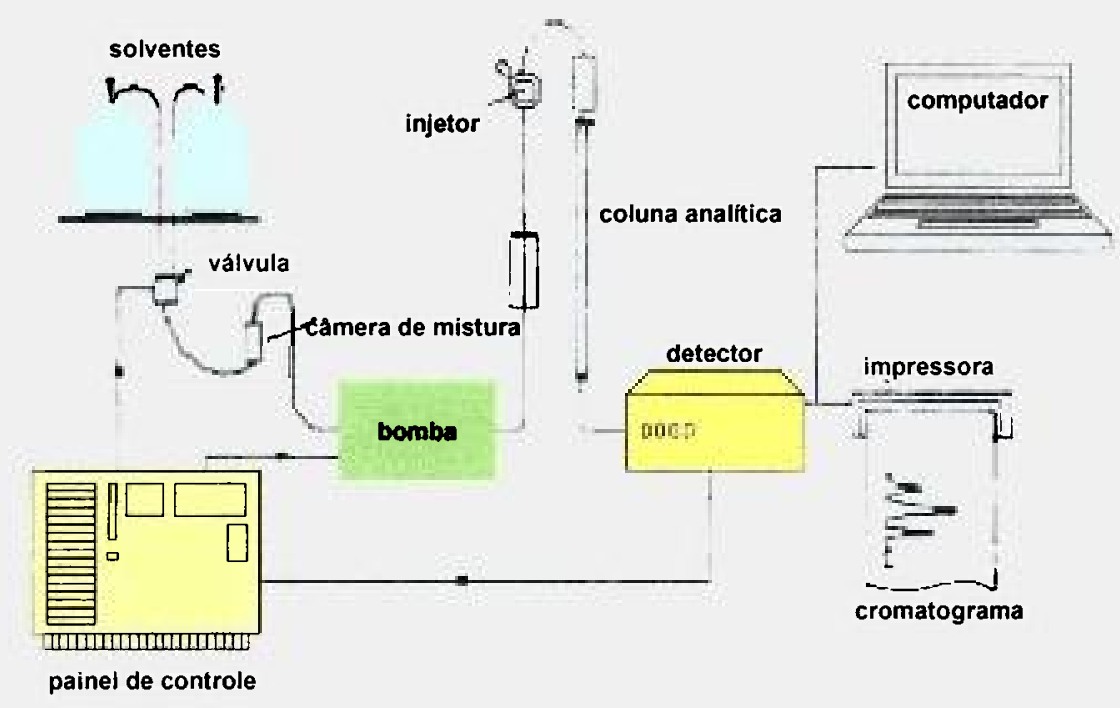

FIGURA 2 - Esquema de um cromatógrafo líquido de alta eficiência.

\subsubsection{Aplicações}

A cromatografia líquida de alta eficiência é amplamente usada para separar substâncias não voláteis incluindo amostras iônicas e poliméricas. Esta técnica é utilizada como uma complementação da cromatografia gasosa. De acordo com a coluna escolhida, a 
cromatografia líquida de alta eficiência pode ser aplicada em óleos, gorduras, aminoácidos, carboidratos, vitaminas, peptídeos, drogas, pesticidas, herbicidas, metabólitos nos fluídos corporais, aditivos, entre outros (FIFIELD \& KEALEY, 2000).

\subsection{Cromatografia Gasosa/Olfatometria}

\subsubsection{Definição}

O desenvolvimento da cromatografia gasosa /olfatometria (CG/O) combina cromatografia, para separar os compostos químicos e a olfatometria, para medir a reposta humana aos odores em vapores de ar. Logo após a descoberta da cromatografia por James e Martin em 1952, técnicas para a inalação de efluentes do cromatógrafo foram publicadas por FULLER et al. (1964) apud FENG \& ACREE (1999) e GUADAGNI et al. (1966) apud FENG \& ACREE (1999). Em 1970, a combinação de efluentes quentes do cromatógrafo com ar umedecido foi recomendada para minimizar o desconforto associado à inalação e o verdadeiro CG/O foi inventado por DRAVNIEK et al. (1975) apud FENG \& ACREE (1999). Quando o cromatógrafo gasoso/olfatômetro é usado em conjunto com a cromatografia gasosa/ espectrometria de massa (CG/EM), a identificação de odores desconhecidos em produtos naturais compostos basicamente por substâncias pouco odoríferas se torna muito fácil. Além de que o estudo de produtos naturais sem o uso da $\mathrm{CG} / \mathrm{O}$ para enfocar odores ínfimos tem gerado muita confusão no que se refere ao conhecimento da química do "flavor" (FENG \& ACREE, 1999).

O sistema olfativo humano é muito mais sensivel do que os instrumentos laboratoriais, onde somente 8 moléculas de algum odor podem disparar um neurônio olfativo e somente 40 moléculas podem causar uma sensação identificável. Teoricamente um nariz humano possui um limite de detecção do odor na ordem de $10^{-19}$ moles, e a sua sensibilidade é muito superior a qualquer instrumento analítico. Por exemplo, um odor volátil pode ser detectado por CG/O na concentração na ordem de $10^{-7} \mathrm{~g} / \mathrm{L}$ e a sua identificação por CG/EM requer concentração maior que $10^{-5} \mathrm{~g} / \mathrm{L}$ para obter um resultado adequado. Desde que a concentração das substâncias voláteis no alimento estiver entre $10^{-11} \mathrm{~g} / \mathrm{L}$ a $10^{-4} \mathrm{~g} / \mathrm{L}$, somente os voláteis mais abundantes poderão ser detectados e identificados sem haver a concentração e extração destes. A química do "flavor" envolve o estudo de detecção química do odor para pesquisar a atividade deste, ou seja, modula o significado do pico produzido pelo 
cromatógrafo pela resposta de cheiro que este produz. Em relação ao aroma, o limiar de detecção é a mínima concentração onde o ser humano consegue obter resposta a um odor. Acima deste limiar, a intensidade de percepção aumenta com a dose de estímulo até alcançar um patamar máximo, onde nenhum aumento na intensidade pode gerar aumento no estímulo. Infelizmente, o limiar de detecção de odor nos seres humanos varia muito, na ordem de $10^{8}$ vezes de indivíduo para indivíduo, embora o limiar medido por $\mathrm{CG} / \mathrm{O}$ pode ser muito reprodutível por um único indivíduo. No entanto, dados quantitativos produzidos por $\mathrm{CG} / \mathrm{O}$ requerem padronização para que possam ser comparados entre pessoas (FENG \& ACREE, 1999).

A importância de um odor para o "flavor" ou aroma de um sistema não pode ser determinada pelo tamanho do pico de um cromatograma produzido por um cromatógrafo gasoso usando um detector químico. Dados derivados de cromatogramas produzidos por um CG/O conduzem a um melhor entendimento da química do "flavor" em muitos produtos naturais, como bebidas não alcoólicas e alcoólicas, vegetais, frutas, entre outros (FENG \& ACREE, 1999).

A cromatografia gasosa/olfatometria apresenta uma mistura química separada ao ser humano que sinaliza quando ele detecta um odor, que pode ser descrito e quantificado. As amostras de alimento são preparadas para análise por CG/O por meio da remoção dos voláteis da matriz do alimento e absorção destes nos primeiros centímetros de uma coluna capilar. A temperatura programada do cromatógrafo distribui os tempos de retenção dos eluentes pela escala de índice de retenção linear (usualmente parafinas com 5 a 20 carbonos). Indexando os tempos de retenção, permite-se que os dados sejam comparados de uma coluna para outra (de mesma polaridade). Comparando os dados obtidos com os dados de tempo de retenção de odores conhecidos, obtém-se a identificação dos odores em questão com considerável acuidade. As amostras são geralmente extraídas e concentradas por diversas formas como, por exemplo, solventes ou por meio de micro extrator de fase sólida (SPME) (FENG \& ACREE, 1999).

Há dois tipos de comportamentos que são medidos por CG/O: dados descritivos e dados de potência. Dados descritivos incluem palavras associadas às experiências das pessoas ao cheiro: floral, fecal, animal; bem como, a intensidade percebida desses cheiros; fraco, forte. "OSME" ("Odor Specific Magnitude Estimation") (SANCHES et al, 1992 apud FENG \& 
ACREE, 1999) é um exemplo de técnica que usa uma escala de intensidade de 0 a 15 para registrar a intensidade dos odores percebidos pelo $\mathrm{CG} / \mathrm{O}$. O método descritivo mais comum é o da intensidade percebida, onde magnitudes estimadas são associadas às percepções de intensidade de um único pico do $\mathrm{CG}$ ou dose de efluentes. Para descrever aroma, um vocabulário de palavras é criado durante a coleta das pré-corridas, usando a máxima concentração extraída da amostra a ser analisada. $\mathrm{CG} / \mathrm{O}$ é padronizada usando um indivíduo que não apresente anosmias especificas para um conjunto de odores padrões. Testa-se a capacidade do indivíduo de detectar odores em várias concentrações. FRIEDRICH \& ACREE (1998) apud FENG \& ACREE (1999) propuseram um conjunto de mais de 50 padrões escolhidos para representar todas as classes descritas na ASTM DS-66 para odores de alimentos. Isto ajuda a obter uma melhor medida da acuidade sensorial específica de uma pessoa usada para coletar dados no CG/O.

Dados de potência são medidas da quantidade do estimulante químico que produz uma certa resposta descritiva a um tempo de eluição ou índice de retenção em particular proveniente do cromatógrafo a gás. Tal medida é obtida por uma série de diluições de uma única amostra (ou concentrações) determinada repetidamente até que o limite de detecção para todos os compostos com odor tenha sido determinado. A potência correlaciona a concentração do odor pelo seu limite de detecção. Há duas técnicas de diluição que são usadas para determinar a potência relativa: "Aroma Extract Dilution Analysis" ("AEDA") desenvolvida por ULLRICH et al. (1987) apud FENG \& ACREE (1999) e "CharmAnalysis ${ }^{T M "}$ criada por ACREE et al. (1984). O resumo do procedimento da cromatografia gasosa/olfatometria usando a metodologia da análise por diluição "CharmAnalysis" é dado na FIGURA 3. 

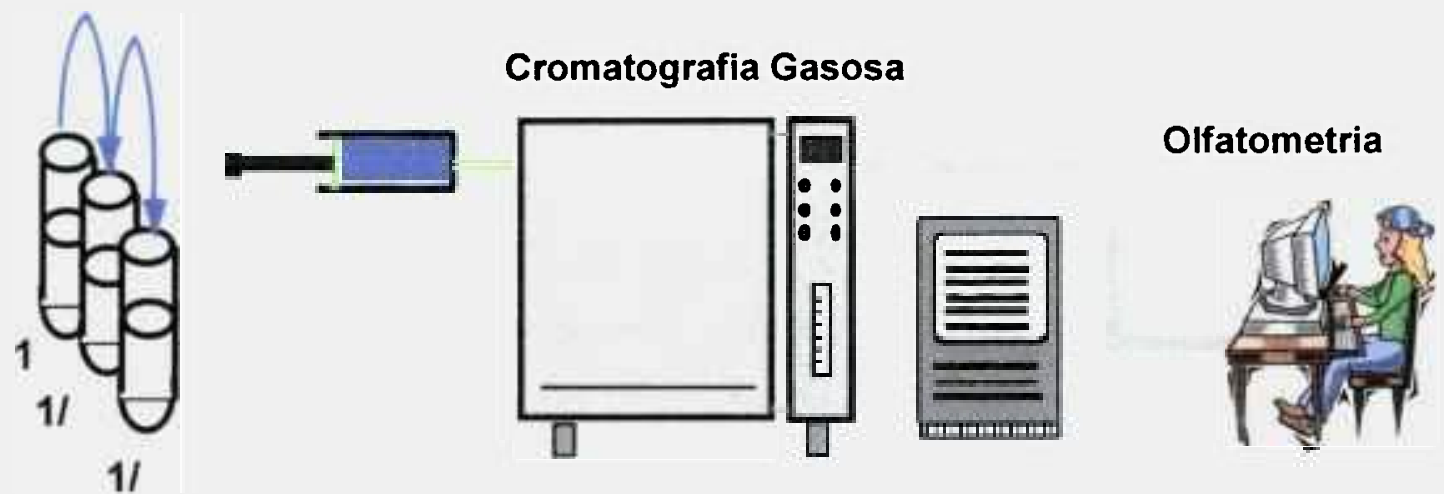

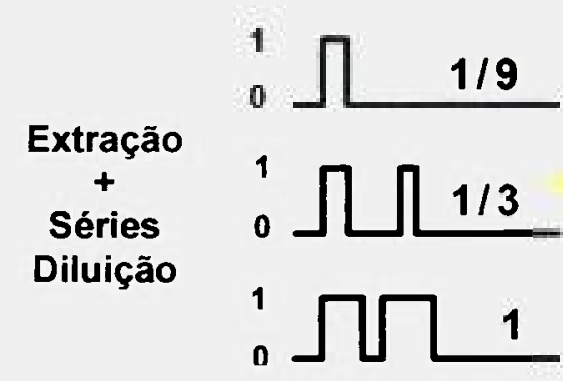

Tempo

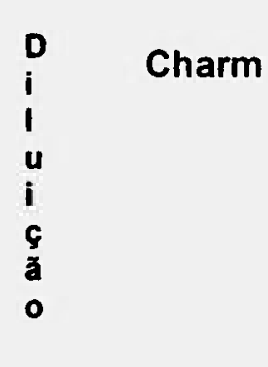

Índice de Retenção

FIGURA 3 - Resumo do procedimento da cromatografia gasosa/olfatometria usando a metodologia da análise por diluição "CharmAnalysis".

Ambas as técnicas utilizam respostas de uma única pessoa para minimizar a variância devido às diferenças de acuidade entre indivíduos. Replicatas devem ser feitas para produzir dados quantitativos baseados nos limites de detecção do odor (ACREE et al, 1994). A maior diferença entre estes dois métodos está na maneira em que os dados do $\mathrm{CG} / \mathrm{O}$ são coletados. Em ambos, o extrato é diluído por um fator de diluição constante, 2 ou 3 até que a pessoa não consiga detectar nenhum odor durante a corrida no cromatógrafo. Os valores de "AEDA", isto é, os números de diluições necessárias para eliminar um odor em um tempo de retenção particular, são usados como estimativas da potência para aquele odor. Em "CharmAnalysis" um pico é construído a partir das respostas "sim-não" registradas no computador enquanto a pessoa esta inalando a amostra no CG/O. Os valores "Charm" são as áreas dos picos gerados pela combinação dos dados "sim-não" como uma função do índice de retenção. A altura destes picos é o valor da diluição para o composto. "AEDA" registra o valor de diluição máximo detectado. Em "CharmAnalysis", um programa computacional especial, 
mostra o valor de diluição pelo tempo. "CharmAnalysis ${ }^{T M "}$ usa um programa que permite aos experimentadores coletar dados descritivos ao mesmo tempo em que os dados de potência são coletados. Este também pode ser configurado para coletar os dados tempo-itensidade bem como os dados descritivos simultaneamente. Obviamente, este modo requer um alto treinamento dos individuos. Para que os resultados sejam reproduziveis e comparáveis com dados de outros laboratórios, os tempos de retenção são indexados. Nos índices Kovats, uma solução de n-parafina é injetada no cromatógrafo e seus tempos de eluição dos hidrocarbonetos são registrados num detector de ionização de chama sob as mesmas condições das corridas no $\mathrm{CG} / \mathrm{O}$. O tempo de retenção das n-parafinas é usado para converter valores de tempo dos dados do CG/O para índices de retenção (FENG \& ACREE, 1999).

Os dados do CG/O, expressos em valores "Charm," não têm significado absoluto. Eles são medidas relativas da potência do odor que elue do CG. As concentrações relativas das amostras injetadas no CG/O dependem do método usado para a preparação destas amostras. Quando alguém cheira a mistura de voláteis do "headspace" sobre o alimento (cheiro ortonasal), este está experimentando os voláteis de potências relativas diferentes do que quando este cheirou extratos eluindo do $\mathrm{CG} / \mathrm{O}$. Esta diferença entre os dados dos extratos do CG/O e a composição do "headspace" ortonasal é muito maior em alimentos que contém gordura. Uma das melhores medidas de padrão de voláteis determinadas ortonalsamente são as unidades de odor ou valores da atividade do odor (OAV), cuja concentração de cada volátil determinado na matriz do alimento é dividida pelo seu limite de detecção do odor (FENG \& ACREE, 1999).

Embora numericamente diferentes, valores "Charm", valores de diluição "AEDA" e OAVs podem ser comparados normalizando os dados para produzir um espectro de odor. $\mathrm{O}$ espectro do odor (OSV) é a normalização do valor "charm" modificado com o expoente da Lei de Stevens (STEVENS, 1958) $\Psi=\mathrm{k} \Phi^{\mathrm{n}}$, onde $\Psi$ é a intensidade percebida do estímulo, $\mathrm{k}$ é uma constante, $\Phi$ é o nível do estímulo e n é uma expoente entre 0,3 e 0,8 para odor. Neste caso, usa-se $n=0,5$. Um cromatograma do espectro de odor é o gráfico dos valores deste espectro pelos índices de retenção, apresentando um padrão de potência relativa independente das concentrações. Estes espectros são normalizados para o odor mais potente, dando valores entre 0 a 100 (ACREE, 1997). 
A identificação destes odores pode ser feita por espectrometria de massa da amostra com padrões, onde "se dois compostos químicos possuem o mesmo tempo de retenção e o mesmo odor, serão então o mesmo composto químico. E se um dos compostos é um padrão, o outro poderá ser identificado com considerável certeza" (FENG \& ACREE, 1999).

\subsubsection{Aplicações}

A maior aplicação da técnica de CG/O na indústria está no fornecimento de um elo entre a analise química de ingredientes ou produtos e os dados sensoriais que são responsáveis pela qualidade do produto. A química analítica pode enfocar a medida dos compostos que tem grande contribuição na qualidade do produto. Por meio da preparação de um espectro de odor de um padrão "perfeito" de um ingrediente ou produto, a indústria pode testar amostras suspeitas por uma fonte de contaminação, odor prejudicial, ou qualquer desvio do padrão "perfeito" para a regulação da qualidade. O uso da CG/O para desenvolver novos produtos ou para acessar a química do "flavor" de produtos competitivos é muito comum nas indústrias que dispõem da tecnologia (FENG \& ACREE, 1999).

Vários são os exemplos encontrados na literatura internacional sobre o uso desta técnica, como, a caracterização do fruto da lichia (PETER et al, 1998), caracterização de vinhos (CHISHOLM, 1994; LEE \& NOBLE, 2003 e CULLERE et al. 2004), caracterização dos voláteis da maçã (CUNNINGHAM et al, 1986), caracterização de mangas (KITTEL, 2003) e caracterização de queijos (CARPINO et al, 2002), entre outros.

\subsection{Cromatografia Gasosa/Espectrometria de Massa}

\subsubsection{Definição}

A identificação dos picos obtidos a partir de seus tempos de retenção em um cromatógrafo gasoso pode ser ambígua ou inconclusiva. $\mathrm{O}$ uso de outras técnicas acopladas diretamente ao cromatógrafo gasoso pode corrigir estes erros. Em um cromatógrafo gasoso acoplado a um espectrômetro de massa (CG/EM), a identificação dos compostos separados pode ser feita por meio da alimentação de gases efluentes da coluna do cromatógrafo gasoso para o espectrômetro de massa. A interface destes dois equipamentos necessita que 0 
espectrômetro de massa opere em pressões baixas $10^{-7}$ a $10^{-9} \mathrm{~N} / \mathrm{m}$, enquanto que o gás da coluna emerge a pressão atmosférica (FIFIELD \& KEALEY, 2000).

Esta técnica baseia-se no bombardeamento de uma substância com um feixe de elétrons, e o resultado desse bombardeamento é registrado quantitativamente, na forma de espectro de fragmentos iônicos positivos, denominado espectro de massa. Esta separação é feita em função de suas massas, obtendo-se uma razão massa por carga $(\mathrm{m} / \mathrm{c})$ ou $(\mathrm{m} / \mathrm{e})$ (KITSON et al, 1996).

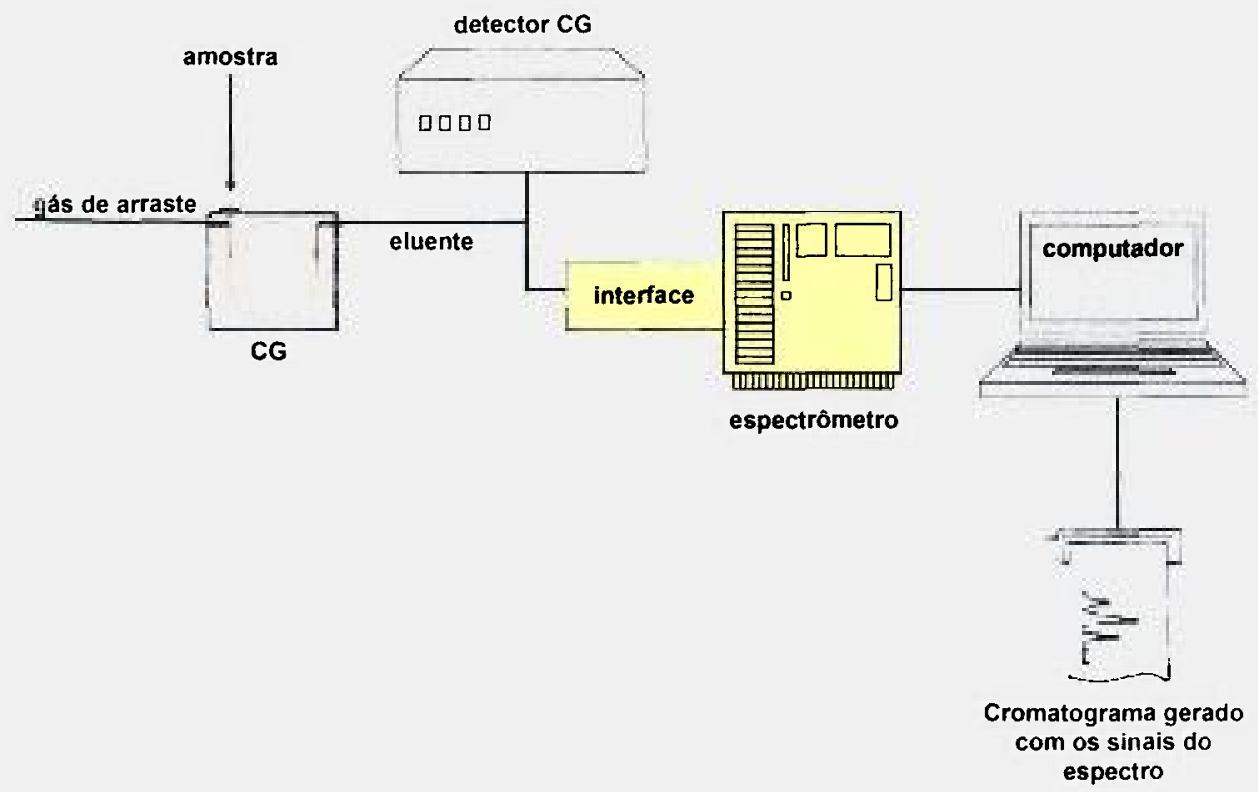

FIGURA 4 - Esquema de um cromatógrafo gasoso/espectrômetro de massa.

\subsubsection{Aplicacões}

A cromatografia gasosa pode ser usada como técnica de identificação, em casos especiais, quando acoplada a outros aparelhos, como um espectrômetro de massa, devido sua alta sensibilidade. Vários são os exemplos encontrados na literatura internacional sobre o uso deste método na identificação da composição de produtos naturais, como, bebidas alcoólicas (ANDRADRE SOBRINHO et al, 2002; LEE \& NOBLE, 2003), mangas (LOPES et al., 1999), entre outros. 


\section{MATERIAL E MÉTODOS}

\subsection{Material}

Amostras de cachaça com e sem envelhecimento prévio em tonéis de carvalho (Quercus alba $\mathrm{sp}$ ), obtidas em alambiques de produtores locais, bem como, amostras de rum obtidas no comércio foram utilizadas nos experimentos.

\subsection{Métodos}

\subsubsection{Irradiação das Bebidas}

As amostras de cachaça e de rum $(60 \mathrm{~mL})$ foram transferidas de suas embalagens originais e irradiadas em frascos de vidro de $100 \mathrm{~mL}$ (pyrex) tampados, com e sem adição de $\cong 8 \mathrm{~cm}^{2}$ de raspas de carvalho (Quercus alba $\mathrm{sp}$ ) cedidas gentilmente pelo Instituto de Pesquisas Tecnológicas (IPT) por 24 horas até o momento da irradiação (SALGADO et al, 1996), em uma fonte de ${ }^{60} \mathrm{Co}$ Gammacell 220 (AECL), taxa de dose entre 4,29 e 4,79kGy/h, com 0,150 e 300Gy no Centro de Tecnologia das Radiações-IPEN/USP (FIGURA 5). Após a irradiação, as amostras foram armazenadas sob refrigeração $\left(4-7^{\circ} \mathrm{C}\right)$.

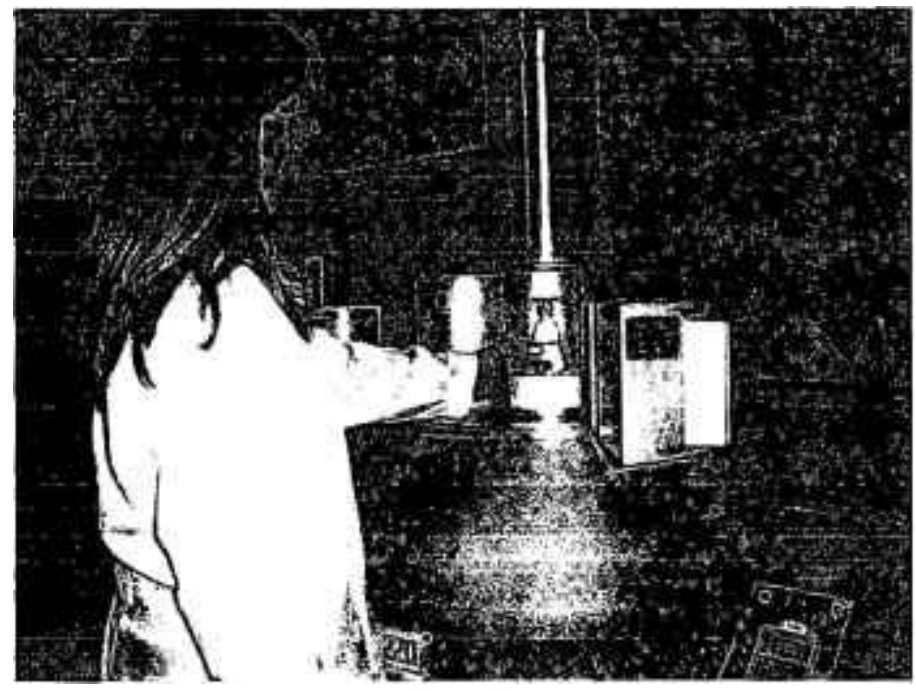

FIGURA 5 - Fonte de ${ }^{60} \mathrm{Co}$ (Gammacell 220 AECL). 


\subsubsection{Determinação de Ésteres e Alcoóis Superiores por Cromatografia Gasosa de Alta}

\section{Resolução}

As análises dos alcoóis e acetato de etila foram realizadas no Departamento de Química e Física Molecular do Instituto de Química de São Carlos/USP em um cromatógrafo a gás HP (modelo 5890) equipado com um injetor split/splitless e detector de ionização de chama (FID). Foi usada uma coluna moderadamente polar, fase estacionária polietilenoglicol modificado com ácido nitrotereftálico HP-FFAP ( $50 \mathrm{~m} \times 0,20 \mathrm{~mm}$; espessura de filme $0,33 \mu \mathrm{m})$. O sistema de injeção usado foi "split" de razão de $1: 15$. O fluxo de $\mathrm{H}_{2}$ na coluna foi $1,3 \mathrm{~mL} / \mathrm{min}$. As vazões dos gases no detector foram $30,0 \mathrm{~mL} / \mathrm{min}$ de $\mathrm{H}_{2}$ e $300 \mathrm{~mL} / \mathrm{min}$ de ar. $\mathrm{O}$ programa de temperatura utilizado foi: $50^{\circ} \mathrm{C}$ (por $2 \mathrm{~min}$ ), taxa de aquecimento de $10^{\circ} \mathrm{C} / \mathrm{min}$ até $190^{\circ} \mathrm{C}$ (por $5 \mathrm{~min}$ ), taxa de aquecimento de $20^{\circ} \mathrm{C} / \mathrm{min}$ até $230^{\circ} \mathrm{C}$ (por $2 \mathrm{~min}$ ). A temperatura do injetor e do detector usada foi de $250^{\circ} \mathrm{C}$ (FIGURA 6).

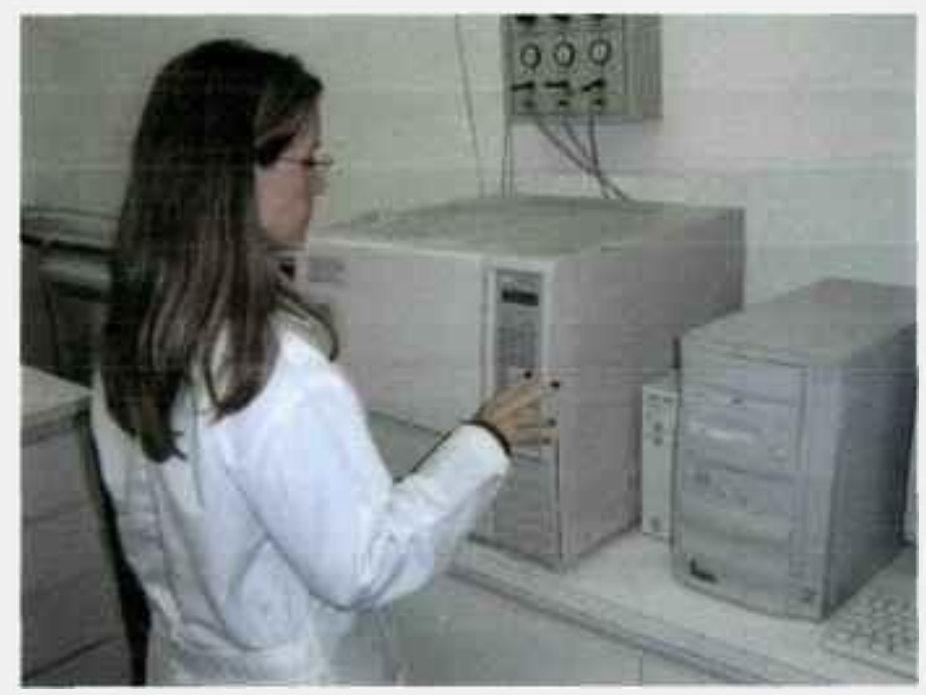

FIGURA 6 - Cromatógrafo a gás HP (modelo 5890).

Os padrões usados foram todos de grau analítico, sendo eles: água purificada pelo sistema Milli-Q (filtro Milipak 40); metanol (Mallinckrodt Chrom HPLC), n-propanol (Carlos Erba), isobutanol (Carlos Erba), butanol (Carlos Erba), isoamílico (Carlos Erba) e acetato de etila (Carlos Erba). 
Os ésteres (acetato de etila) e os alcoóis superiores (metanol, n-propanol, isobutanol, butanol e álcool isoamílico) foram determinados sem prévia concentração da amostra. Alíquotas de $1,00 \mu \mathrm{L}$ de cada amostra foram injetadas diretamente no cromatógrafo para análise.

As soluções padrões dos ésteres (acetato de etila) e dos alcoóis superiores foram obtidas por diluição de suas soluções estoque padrão em meio etanol-água $(40: 60 \mathrm{v} / \mathrm{v})$ nas seguintes faixas de concentração: metanol $(0-400 \mathrm{mg} / \mathrm{L})$, n-propanol $(0-100 \mathrm{mg} / \mathrm{L})$, isobutanol $(0-100 \mathrm{mg} / \mathrm{L})$, butanol $(0-10 \mathrm{mg} / \mathrm{L})$, isoamílico $(0-200 \mathrm{mg} / \mathrm{L})$ e acetato de etila $(0-450 \mathrm{mg} / \mathrm{L})$.

Os estudos da reprodutibilidade e repetibilidade para os alcoóis e acetato de etila foram realizados da seguinte maneira: a reprodutibilidade foi calculada com base nos resultados obtidos realizando-se de 7 injeções de uma mesma amostra durante dois dias, sendo que cada solução foi injetada duas vezes. A repetibilidade foi investigada realizando-se 8 injeções independentes de uma mesma amostra.

As curvas de calibração foram otimizadas por regressão linear, por meio do gráfico da relação entre a razão da área do pico do padrão/área do padrão interno versus concentração. Os coeficientes de correlação aproximaram da unidade. Os padrões foram preparados em solução etanol-água $(40: 60 \mathrm{v} / \mathrm{v})$, procurando-se reproduzir as mesmas condições das amostras. Todas as análises foram feitas em duplicata (PEREZ et al, 2001).

\subsubsection{Determinação de Aldeídos por Cromatografia Líquida de Alta Eficiência}

Para análise de aldeídos foi usado um cromatógrafo líquido de alta eficiência Shimadzu LC (modelo 10-AD) equipado com injetor Shimadzu (20 $\mu \mathrm{L}$ loop) e um detector Shimadzu Ultravioleta-visivel Photodiode Array (modelo SPDM-6A). Este estudo foi realizado no Departamento de Química e Física Molecular do Instituto de Química de São Carlos/USP.

Os padrões usados foram todos de grau analítico, sendo eles: água purificada pelo sistema Milli-Q (filtro Milipak 40); etanol (Mallinckrodt Chrom HPLC); 2,4dinitrofenilhidrazina (Aldrich) purificado por três sucessivas recristalizações com metanol (Mallinckrodt Chrom HPLC), formaldeido (Aldrich), acetaldeído (Aldrich), 5-hidroximetil- 
furfural (Aldrich), acroleína (Aldrich), furfural (Merck), propionaldeído (Merck), butiraldeído (Aldrich), benzaldeído (Aldrich), isovaleraldeido (Aldrich) e n-valeraldeído (Merck).

Os derivados carbonílicos da 2,4-dinitrofenilhidrazina (2,4-DNPH) foram preparados de acordo com NASCIMENTO, et al. (1997): 0,40g de 2,4-DNPH foram dissolvidos em 2,0mL de ácido sulfúrico concentrado e $3,0 \mathrm{~mL}$ de água destilada. Para preparação dos derivados de 2,4-DNPH adicionou-se nesta solução, 0,10g de cada aldeído padrão, dissolvidos em $15,0 \mathrm{~mL}$ de etanol. Os compostos derivatizados foram isolados via filtração e purificados por recristalização (2 vezes) com etanol absoluto. A pureza das hidrazonas foi maior que $99 \%$, sendo confirmada pela determinação do ponto de fusão e análise elementar $(\mathrm{C}, \mathrm{H}, \mathrm{N})$.

Para derivatização das amostras realizou-se o seguinte procedimento: uma solução 0,25\% de 2,4-dinitrofenilhidrazina (2,4-DNPH) foi preparada diluindo uma solução $0,40 \%$ de 2,4-DNPH. Num balão volumétrico, foram colocados $1,00 \mathrm{~mL}$ da solução de 2,4-DNPH $(0,25 \%), 2,0 \mathrm{~mL}$ da amostra e $25,0 \mu \mathrm{L}$ de $\mathrm{HClO}_{4}\left(1 \mathrm{~mol} . \mathrm{L}^{-1}\right)$. Esta solução foi agitada por cerca de 1 minuto, logo depois deixada em repouso por um tempo de 50 minutos, à temperatura ambiente. As injeções foram efetuadas usando-se um volume de $25,0 \mu \mathrm{L}$ no sistema HPLC.

A transformação quantitativa dos aldeídos na bebida em seus correspondentes derivados de 2,4-DNPH é garantida usando excesso da solução de 2,4-DNPH. Foram analisados 10 aldeídos-DNPH nas amostras, utilizando o método do padrão externo para quantificação e detecção com o detector UV-VIS a $365 \mathrm{~nm}$. A análise quantitativa foi realizada pela diluição da solução estoque de $1000 \mathrm{mg} / \mathrm{L}$ de cada aldeído-2,4-DNPH em acetonitrila em meio etanol-água $(40: 60 \mathrm{v} / \mathrm{v})$ nas seguintes faixas de concentração: formaldeído-DNPH (0 $10 \mathrm{mg} / \mathrm{L})$, acetaldeído-DNPH $(0-100 \mathrm{mg} / \mathrm{L})$, acroleína-DNPH $(0-16 \mathrm{mg} / \mathrm{L})$, furfural-DNPH $(0-10 \mathrm{mg} / \mathrm{L})$, propionaldeído-DNPH $(0-20 \mathrm{mg} / \mathrm{L})$, butiraldeído-DNPH $(0-50 \mathrm{mg} / \mathrm{L})$, benzaldeído $(0-20 \mathrm{mg} / \mathrm{L})$, isovaleraldeido-DNPH $(0-8 \mathrm{mg} / \mathrm{L})$ e n-valeraldeído-DNPH $(0-$ $6 \mathrm{mg} / \mathrm{L})$.

As curvas de calibrações para cada aldeído-DNPH foram obtidas por regressão linear, plotando-se área do pico versus concentração do padrão. Os coeficientes de correlação ficaram próximos de 1. As soluções padrões foram preparadas em etanol-água (40:60 v/v). 
Foi usada a coluna cromatográfica de fase estacionária octadecilsilano Shimpack CLC-ODS ( $25 \mathrm{~cm} \times 4,6 \mathrm{~mm}$, diâmetro interno das partículas de $5 \mu \mathrm{m})$. Todas as análises foram feitas em duplicata.

Os compostos presentes nas amostras foram identificados comparando-se seus tempos de retenção com os tempos de retenção dos padrões. A confirmação foi realizada pela adição sucessiva de padrões de cada composto numa amostra, com subseqüente observação do aumento da área do pico, sem alteração da simetria do pico e vizinhança.

A reprodutibilidade para este método foi calculada a partir dos resultados obtidos de 8 injeções de uma mesma amostra em dois dias, sendo que cada solução foi injetada duas vezes. A repetibilidade foi também verificada realizando-se 8 injeções independentes de uma mesma amostra.

O limite de detecção foi determinado utilizando-se uma solução estoque de cada padrão, que foi diluída sucessivamente até que a relação sinal-ruído fosse igual a 3:1.

\subsubsection{Determinação de Ácidos por Cromatografia Gasosa de Alta Resolução}

Este estudo foi feito no Departamento de Química e Física Molecular do Instituto de Química de São Carlos/USP. Para a determinação dos ácidos nas bebidas foi necessário realizar o processo de extração sólido-líquido (SPE), visando concentrar a amostra, conforme descrito por NASCIMENTO, et al. (1998): as amostras foram concentradas utilizando os cartuchos com fase estacionária de octadecilsilano (Spe-de $\left.{ }^{T M}, \mathrm{C} 18 / 18\right)$. Estes cartuchos foram previamente condicionados com $4,0 \mathrm{~mL}$ de metanol, depois com $2,0 \mathrm{~mL}$ de solução etanol-água $(40: 60 \mathrm{v} / \mathrm{v})$ e com $\mathrm{pH}$ ajustado para 5,4 , tentando reproduzir as mesmas condições de acidez da amostra. Transferiu-se para o cartucho $50,0 \mathrm{~mL}$ da amostra contendo $1,00 \mu \mathrm{L}$ de padrão interno (ácido nonanóico) onde foram eluídos através do cartucho, a uma velocidade de $5,0 \mathrm{~mL} / \mathrm{min}$. Após a extração, efetuou-se a eluição com $1,00 \mathrm{~mL}$ de diclorometano.

Os padrões usados foram todos de grau analítico, sendo eles: água purificada pelo sistema Milli-Q (filtro Milipak 40); ácido acético (Merck), ácido propiônico (Merck), ácido isobutírico (Merck), ácido butírico (Merck), ácido isovalérico (Merck), ácido valérico (Merck), ácido isocapróico (Merck), ácido capróico (Merck), ácido heptanóico (Carlos Erba), ácido n-caprilico (Carlos Erba), ácido n-cáprico (Merck), ácido benzóico (Carlos Erba), ácido 
láurico (Carlos Erba), ácido acético (Carlos Erba), ácido mirístico (Carlos Elba) e ácido palmítico (Carlos Elba).

Os ácidos foram identificados e quantificados nas amostras de bebida por cromatografia gasosa de alta resolução, utilizando detector de ionização de chama. Os compostos presentes na amostra foram identificados comparando-se seus tempos de retenção com os tempos de retenção dos padrões. A confirmação foi realizada pela adição sucessiva de padrões de cada composto na amostra, com subseqüente observação do aumento da área do pico, sem alteração da simetria do pico e vizinhança. Para a análise quantitativa, foi utilizado o método do padrão interno. $\mathrm{O}$ ácido nonanóico foi o padrão interno para os ácidos carboxílicos. A concentração utilizada de padrão interno, tanto na solução padrão como na amostra foi de $1000 \mathrm{mg} / \mathrm{L}$.

Foi usada uma coluna moderadamente polar, com fase estacionária: polietilenoglicol modificado com ácido nitrotereftálico HP-FFAP (50m x 0,20mm; espessura de filme $0,33 \mu \mathrm{m})$. O sistema de injeção usado foi "split" de razão de $1: 15$, sendo injetado no sistema $1,00 \mu \mathrm{L}$ da amostra previamente concentrada. $\mathrm{O}$ fluxo de $\mathrm{H}_{2}$ na coluna foi de $1,3 \mathrm{~mL} / \mathrm{min}$. A vazão dos gases no detector foi de $30,0 \mathrm{~mL} / \mathrm{min}$ de $\mathrm{H}_{2}$ e $300 \mathrm{~mL} / \mathrm{min}$ de ar. O programa de temperatura utilizado foi: $50^{\circ} \mathrm{C}$ (por $2 \mathrm{~min}$ ), taxa de aquecimento de $10^{\circ} \mathrm{C} / \mathrm{min}$ até $190^{\circ} \mathrm{C}$ (por $5 \mathrm{~min}$ ) outra taxa de aquecimento de $5^{\circ} \mathrm{C} / \mathrm{min}$ até $230^{\circ} \mathrm{C}$. A temperatura do injetor e do detector usada foi de $250^{\circ} \mathrm{C}$. Todas as análises foram feitas em duplicata.

As soluções padrões dos ácidos foram obtidas por diluição de suas soluções estoque padrão em meio etanol-água $(40: 60 \mathrm{v} / \mathrm{v})$ nas seguintes faixas de concentração: ácido acético $(0-600 \mathrm{mg} / \mathrm{L})$, ácido propiônico $(0-25 \mathrm{mg} / \mathrm{L})$, ácido isobutírico $(0-25 \mathrm{mg} / \mathrm{L})$, ácido butírico $(0-25 \mathrm{mg} / \mathrm{L})$, ácido isovalérico $(0-50 \mathrm{mg} / \mathrm{L})$, ácido capróico $(0-25 \mathrm{mg} / \mathrm{L})$, ácido heptanóico $(0-20 \mathrm{mg} / \mathrm{L})$, ácido n-caprílico $(0-150 \mathrm{mg} / \mathrm{L})$, ácido n-cáprico $(0-150 \mathrm{mg} / \mathrm{L})$, ácido palmítico $(0-50 \mathrm{mg} / \mathrm{L})$, ácido láurico $(0-100 \mathrm{mg} / \mathrm{L})$ e ácido mirístico $(0-100 \mathrm{mg} / \mathrm{L})$.

A reprodutibilidade para análise dos ácidos foi verificada com base nos resultados obtidos realizando-se de 6 injeções de uma mesma amostra durante dois dias, sendo que cada solução foi injetada duas vezes e a repetibilidade foi calculada realizando-se 10 injeções independentes de uma mesma amostra.

O limite de deteç̧ão foi determinado utilizando-se uma solução estoque de cada padrão, que foi diluída sucessivamente até que a relação sinal-ruido fosse igual a 3:1. 


\subsubsection{Análise Sensorial}

\subsubsection{Teste Triangular}

$O$ teste triangular foi utilizado para determinar as diferenças no aroma entre cachaças de alambique não envelhecidas, envelhecidas e rum comercial não irradiados e irradiados com 300Gy.

A equipe de provadores foi composta por 18 pessoas, funcionários e alunos de pós-graduação do Departamento de Food Science and Technology da Cornell University Geneva/NY, EUA. Os provadores tinham entre 23 e 65 anos. Todos já tinham participado de várias análises sensoriais aplicadas em bebidas e alimentos, porém treinamento prévio foi dado aos provadores para este estudo.

O teste foi feito entre 11:30 e 12:30h. As amostras, estocadas à temperatura ambiente, foram diluídas com água deionizada a $11 \%$ de álcool para homogeneizar o conteúdo alcoólico em cada amostra e também por ser dificil detectar o aroma em altas concentrações de álcool.

As três amostras foram apresentadas simultaneamente aos provadores; onde duas amostras eram iguais e uma diferente, sendo perguntado qual era a diferente. Cada amostra foi codificada, usando três dígitos (LA WLESS \& HELMANN, 1998).

O modelo da ficha utilizado no teste descrito está apresentado na FIGURA 7.

Nome:

\section{TESTE TRIANGULAR}

Data:

\section{Grupo 1}

Neste grupo de amostras apresentadas, duas são iguais e uma é diferente. Sinta o aroma de cada uma das amostras da esquerda para direita e circule a amostra diferente.

FIGURA 7 - Modelo de ficha utilizado para o teste triangular. 
As amostras, $30 \mathrm{~mL}$ por taça, foram servidas à temperatura ambiente $\left(20^{\circ} \mathrm{C}\right)$, em taças de vinho transparentes cobertas com vidros de relógio em cabines individuais. Luz vermelha foi usada para reduzir o efeito da variação da cor das amostras (LAWLESS \& HELMANN, 1998).

\subsubsection{Análise Descritiva Quantitativa}

A análise descritiva quantitativa foi usada com o intuito de se avaliar as diferenças entre cachaça de alambique não envelhecida não irradiada e irradiada com $300 \mathrm{~Gy}$, rum comercial não irradiado e irradiado com 300Gy e finalmente cachaça não envelhecida não irradiada e rum não irradiado em relação ao aroma, pois somente nestas amostras foram encontradas diferenças no teste triangular.

As sessões de análise descritiva quantitativa realizadas por uma equipe de provadores, que já tinha participado de várias análises sensoriais aplicadas em bebidas e alimentos, duraram 1 mês, onde foram realizadas 3 sessões por semana, cada uma perdurando no mínimo $1 \mathrm{~h}$, realizadas entre $11: 30$ e 12:30h.

\subsection{Pré-Seleção dos Provadores}

Para compor a equipe de provadores para a análise descritiva quantitativa foi realizada uma pré-seleção de 18 candidatos, funcionários e alunos de pós-graduação do Departamento de Food Science and Technology da Cornell University - Geneva/NY, com idade entre 23 e 65 anos com base em seu poder discriminativo, determinado através de testes triangulares com amostras de cachaça e rum (STONE et al., 1974).

\subsection{Desenvolvimento da Terminologia}

O levantamento dos termos descritivos do aroma foi realizado por uma equipe de 16 pessoas pré-selecionadas, por meio do Método Tradicional, onde foram oferecidas as amostras de cachaça não envelhecida irradiada e não irradiada e de rum não irradiado e irradiado para cada provador, solicitando-se que ele fizesse uma lista completa dos seus atributos sensoriais (DUTCOSKY, 1996). 
O modelo da ficha utilizado no teste descrito está apresentado na FIGURA 8.

Nome:

Data:

\section{Grupo 1}

Por favor, sinta o aroma de cada amostra e descreva todos os atributos que possam ser encontrados nestas bebidas.

Amostra 1:

Amostra 2:

FIGURA 8 - Modelo de ficha utilizado para a descrição dos atributos.

As amostras, $30 \mathrm{~mL}$ por taça, foram apresentadas aos provadores à temperatura ambiente $\left(20^{\circ} \mathrm{C}\right)$, em taças de vinho transparentes cobertas com vidros de relógio que eram retirados no momento do teste. Estas amostras foram estocadas à temperatura ambiente, diluídas com água deionizada a $11 \%$ de álcool para homogeneizar o conteúdo alcoólico em cada amostra e também por ser dificil detectar o aroma em altas concentrações de álcool.

Para auxiliar a construção de tal vocabulário, foram apresentados 24 padrões preparados a partir de uma lista de termos obtida na CG/O para que a equipe de provadores pudesse adicionar novas palavras ou eliminar outras da lista de termos que eles tinham gerado nas sessões anteriores (TABELA 1). 
TABELA 1 - Termos descritores obtidos por CG/O usados como base para análise descritiva e a composição dos padrões de referência correspondentes.

\begin{tabular}{|c|c|c|}
\hline Termo & Padrão de Referência & Fontes \\
\hline Álcool & $\begin{array}{l}\text { Mistura equimolar de isobutanol, } \\
\text { propanol e álcool isoamilico }\end{array}$ & $\begin{array}{l}\text { Sigma, } 99 \% ; \\
\text { Sigma, } 99,5 \% \\
\text { Sigma, } 98,5 \% \text { pureza }\end{array}$ \\
\hline Pungente & Ácido fórmico & Sigma, $95 \%$ pureza \\
\hline Solvente & 2-Metilpropan- I-ol & Sigma, 99,5\% grau HPLC \\
\hline Condimento & Eugenol & Sigma \\
\hline Malte & Extrato de malte & \\
\hline Mofo & 2,4,6-tricloroanisol & Aldrich, $99 \%$ pureza \\
\hline Fruta (éster) & Acetato de isoamila & Aldrich, $95 \%$ pureza \\
\hline Fruta (outro) & Octanoato de etila & Sigma, $99 \%$ pureza \\
\hline Maçã & Hexanoato de etila & Mil-Spec \\
\hline Melão & Dimetil heptanal & Bedoukian \\
\hline Citros & Óleo de citros & Fritz Brothers \\
\hline Floral & 2-fenil etanol & Sigma \\
\hline Baunilha & Etil vanilina & Aldrich \\
\hline Manteiga & Diacetil & Mil-Spec \\
\hline Grama & Cis-3 hexen-1-ol & Aldrich, $98 \%$ pureza \\
\hline Óleo & Heptanal & Eastman \\
\hline Madeira & Extrato de carvalho em etanol & \\
\hline Vegetal & Sulfeto de dimetila & Aldrich, $98 \%$ pureza \\
\hline Remédio & Timol & Aldrich. $98 \%$ pureza \\
\hline Caramelo & Maltol & K \& K Laboratories \\
\hline Detergente & Laurato de etila & Sigma, $99 \%$ pureza \\
\hline Vinagre & Ácido acético & Aldrich, $99,8 \%$ pureza \\
\hline Fumaça & Guaiacol & Sigma \\
\hline Amêndoa & Extrato de amêndoa em etanol & McCornick \\
\hline
\end{tabular}

Fonte - LEE et al (2000); PIGGOTT (1991).

O modelo de ficha utilizado para o levantamento dos atributos é mostrado na FIGURA 9. 
Nome:

Data:

\section{Amostra 240}

Por favor, sinta o aroma da amostra e marque na lista os termos que descrevem melhor a amostra em questão. Para maior acuidade, por favor, descreva como melhor puder cada termo selecionado. Você pode adicionar ou retirar os termos da lista que achar necessário.

\begin{tabular}{|c|l|l|}
\hline Termo & & \\
\hline Álcool & & \\
\hline Pungente & & \\
\hline Solvente & & \\
\hline Condimento & & \\
\hline Malte & & \\
\hline Mofo & & \\
\hline Fruta (éster) & & \\
\hline Fruta (outro) & & \\
\hline Maçã & & \\
\hline Melão & & \\
\hline Citros & & \\
\hline Floral & & \\
\hline Baunilha & & \\
\hline Manteiga & & \\
\hline Grama & & \\
\hline Óleo & & \\
\hline Madeira & & \\
\hline Vegetal & & \\
\hline Remédio & & \\
\hline Caramelo & & \\
\hline Detergente & & \\
\hline Vinagre & & \\
\hline Fumaça & & \\
\hline Amêndoa & & \\
\hline
\end{tabular}

Outros termos:

FIGURA 9 - Ficha utilizada para o levantamento dos atributos sensoriais. 
Por meio de um debate foi gerada uma lista final de termos descritores contendo 10 palavras relativas ao aroma das amostras apresentadas que foram obtidas do consenso grupal (FIGURA 10).

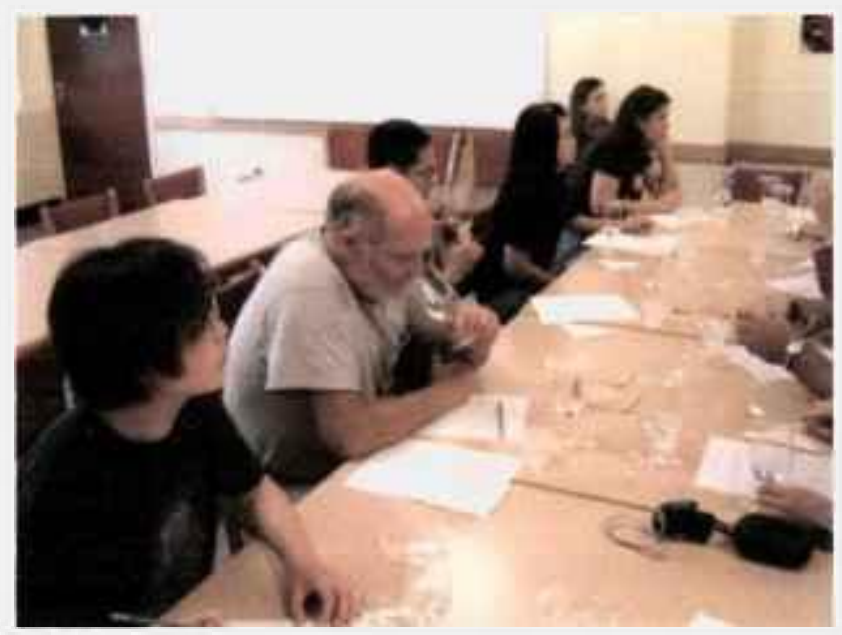

FIGURA 10 - Sessões realizadas para o desenvolvimento da terminologia.

\subsection{Treinamento e Seleção Final dos Provadores}

Por meio da lista final dos descritores escolhida pela equipe de provadores, várias sessões de treinamento foram realizadas para que os provadores pudessem memorizar os termos sensoriais encontrados nas amostras de bebidas (FIGURA 11) e para que as suas notas estivessem na mesma região da escala, através da apresentação das amostras referências com extremos máximos e mínimos de suas intensidades.

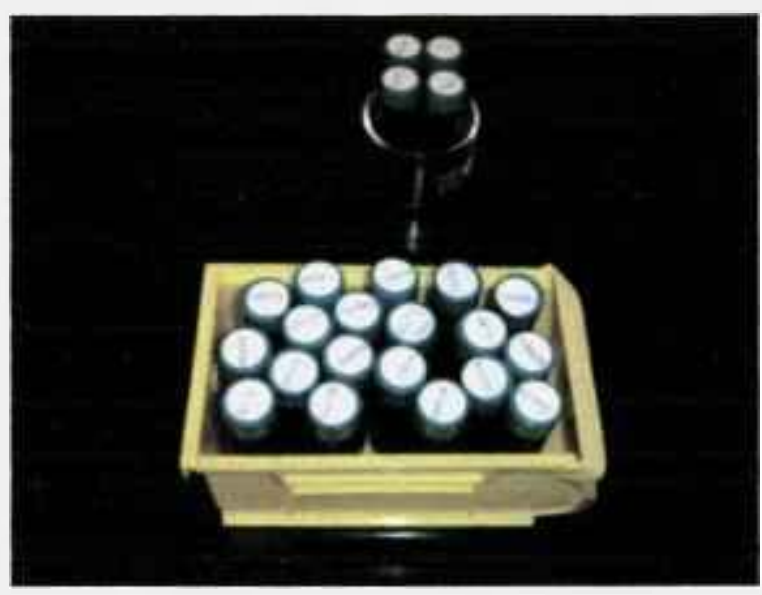

FIGURA 11 - Amostras referências apresentadas durante o treinamento. 
A FIGURA 12 mostra uma ficha utilizada para a memorização dos atributos sensoriais encontrados nas amostras de bebidas.

Nome:

Data:

Por favor, sinta o aroma de cada referência e marque na lista seu número correspondente. Entre cada amostra, cheire sua pele (mão / braço). Descanse por 1-2 minutos e continue com a próxima amostra.

\begin{tabular}{|c|c|}
\hline Referência & No. \\
\hline Álcool & \\
\hline Condimento & \\
\hline Maçã & \\
\hline Melão & \\
\hline Citros & \\
\hline Baunilha & \\
\hline Grama & \\
\hline Vegetal & \\
\hline Caramelo & \\
\hline Vinagre & \\
\hline
\end{tabular}

FIGURA 12 - Ficha utilizada para a memorização dos termos sensoriais encontrados nas amostras de bebidas.

O teste para seleção final da equipe de provadores foi então realizado com as escalas de intensidade para os termos definidos, por meio do programa computacional File Marker Pro 5, Santa Clara, CA que será descrito na sessão 4.2.5.2.4. 


\subsection{Teste de Intensidade dos Atributos}

$\mathrm{O}$ teste de intensidade dos atributos foi realizado em cabines individuais. As amostras, $30 \mathrm{~mL}$ por copo, foram servidas de forma randômica, à temperatura ambiente $\left(20^{\circ} \mathrm{C}\right)$, em taças de vinho transparentes cobertas com vidros de relógio (FIGURA 13 e FIGURA 14). Cada amostra foi codificada, usando três dígitos (as amostras foram avaliadas duas vezes/provador) (LAWLESS \& HELMANN, 1998).

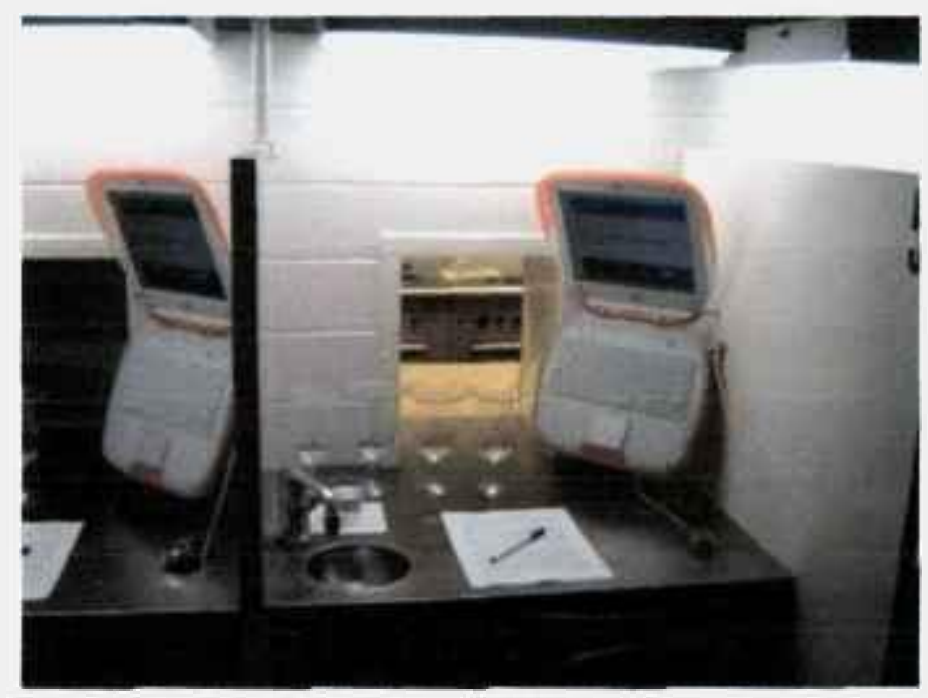

FIGURA 13 - Apresentação das amostras para o Teste de Intensidade dos Atributos.

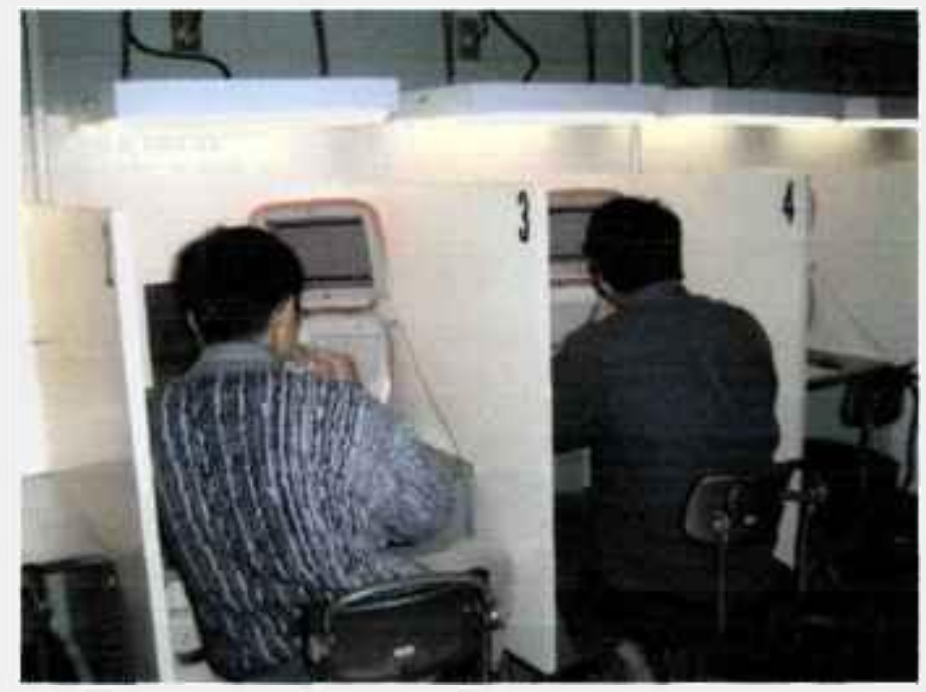

FIGURA 14 - Provadores realizando o Teste de Intensidade dos Atributos. 
A ficha de avaliação da intensidade de cada atributo de aroma foi feita por meio do programa computacional File Marker Pro 5 software, Santa Clara, CA. Esta ficha continha os termos descritores gerados pelo consenso da equipe de provadores, contendo uma escala estruturada de 15 pontos, com as extremidades ancoradas nos termos fraco e forte para cada atributo escolhido, conforme apresentado na FIGURA 15. 


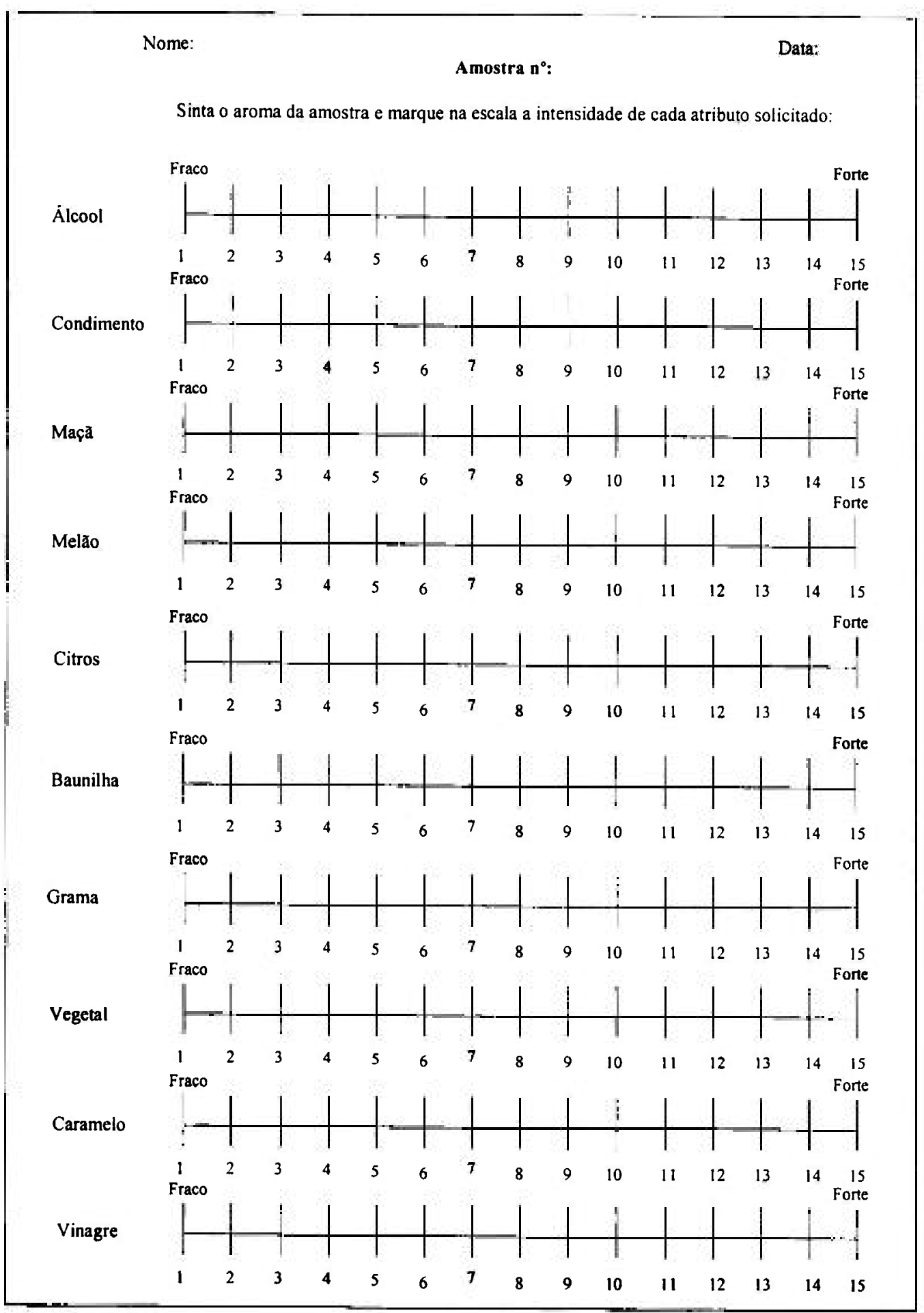

FIGURA 15 - Modelo de ficha utilizado para o Teste de Intensidade dos Atributos. 


\subsubsection{Determinação dos Odores Ativos por Cromatografia Gasosa/Olfatometria}

$\mathrm{O}$ isolamento e a caracterização dos compostos ativos de odor presentes nas amostras de cachaça de alambique não envelhecida e rum comercial não irradiadas e irradiadas com 300Gy foram realizados em um cromatógrafo a gás/olfatômetro do Departamento de Food Science and Technology da Cornell University - Geneva/NY, EUA.

As amostras de bebida foram extraídas para a determinação dos odores ativos, usando as seguintes metodologias:

(1) Solvente Freon-113: as amostras de bebida $(50 \mathrm{~mL})$ foram colocadas em um frasco de extração de $100 \mathrm{~mL}$ junto com $15 \mathrm{~mL}$ de Freon- 113 e agitadas à $20^{\circ} \mathrm{C}$ por $10 \mathrm{~min}$. As fases líquidas foram separadas em um funil de separação de $250 \mathrm{~mL}$. A fase inferior (Freon) foi coletada, e na fase superior foram adicionados mais $5 \mathrm{~mL}$ do solvente que foi novamente agitada como descrito anteriormente. $\mathrm{O}$ procedimento de extração foi repetido por mais uma terceira vez com um total de $15 \mathrm{~mL}$ de Freon. Os extratos foram desidratados com sulfato de magnésio anidro. Estes foram então concentrados até ser obtido $1 \mathrm{~mL}$ sob pressão reduzida $(50,6 \mathrm{kPa})$ usando um evaporador rotatório com banho $\left(30^{\circ} \mathrm{C}\right)$ (FIGURA 16) (ROBERTS et al. 2004).

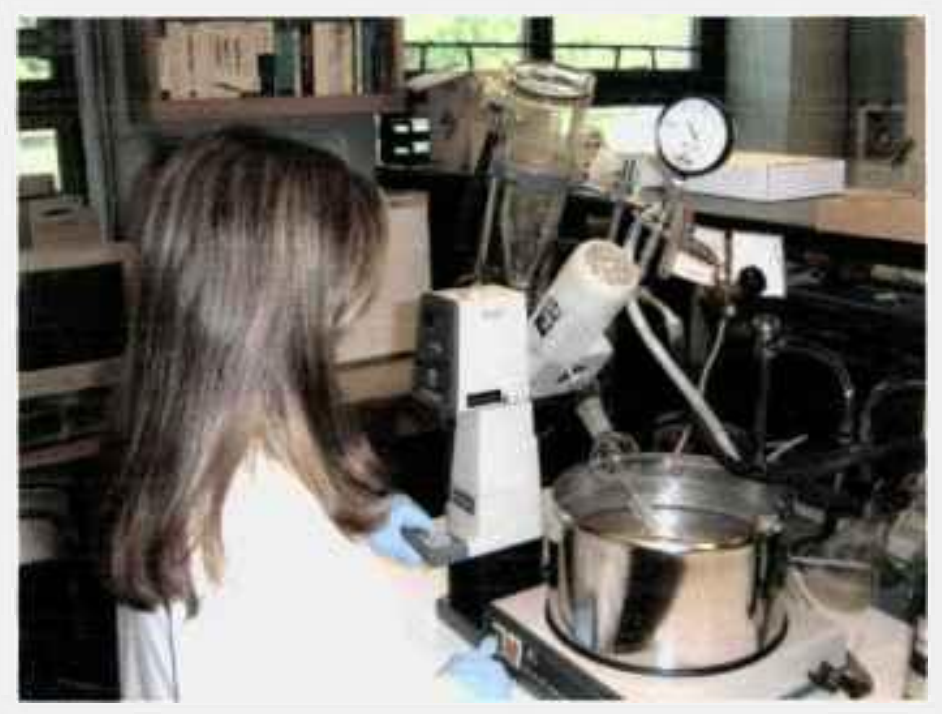

FIGURA 16 - Evaporador rotatório com banho $\left(30^{\circ} \mathrm{C}\right)$. 
(2) SPME (micro-extração em fase sólida): a fibra usada para extrair as amostras foi a divinilbenzeno/carboxeno/ polidimetilsiloxano. Esta foi injetada $1 \mathrm{~cm}$ acima da superfície da solução ( $10 \mathrm{ml}$ da bebida). As amostras foram agitadas com o uso de agitador magnético por Ih (DEIBLER et al., 1999 e EBELER et al., 2000). Na FIGURA 17, encontra-se um esquema da micro-extração em fase sólida (SPME).

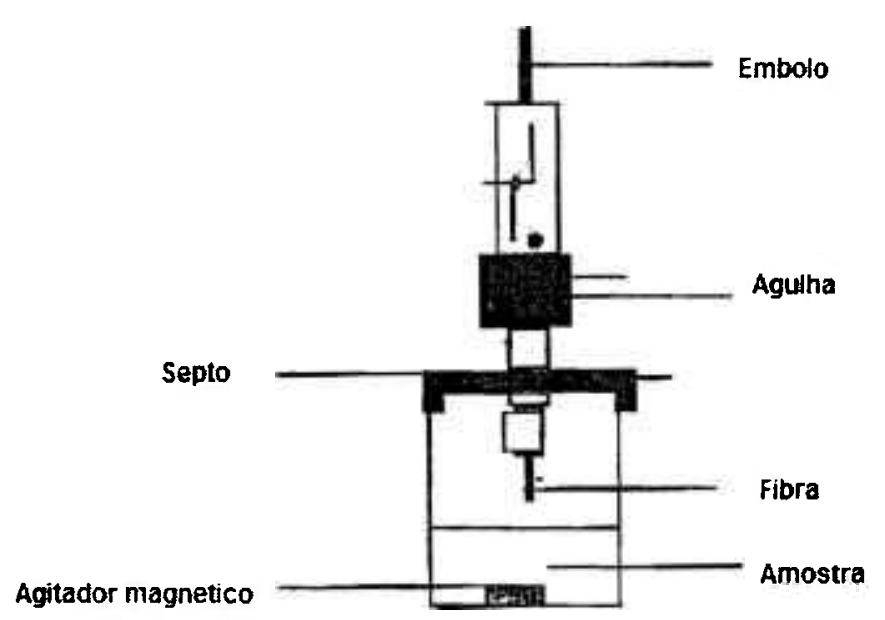

FIGURA 17 - Esquema da micro-extração em fase sólida (SPME).

Após a extração das amostras, estas foram diluídas sucessivamente, usando um fator de 3 até que nenhum odor pudesse ser detectado, geralmente de 1 até 729 . Posteriormente, 01 (um) $\mu \mathrm{L}$ de cada concentração foi injetado dentro de um $\mathrm{CG} / \mathrm{O}$, um cromatógrafo a gás modificado, Hewlett Packard 5890 equipado com uma coluna capilar de sílica fundida ( $0,32 \mathrm{~mm}$ de diâmetro interno e $13,5 \mathrm{~m}$ de comprimento) (DB-5) (5\% fenil $95 \%$ polidimetilsiloxano) e um sistema de olfatometria de alta resolução, que mistura o efluente do cromatógrafo gasoso (CG) com o vapor de ar umedecido (20L/min), para a separação dos compostos. $\mathrm{O}$ injetor foi aquecido à $200^{\circ} \mathrm{C}$ e o $\mathrm{CG}$ foi aquecido à $35^{\circ} \mathrm{C}$ por $3 \mathrm{~min}$, seguido da injeção da amostra e programado à $6^{\circ} \mathrm{C} / \mathrm{min}$ até $225^{\circ} \mathrm{C}$. O vapor de ar que atravessa um tubo de aço com $10 \mathrm{~mm}$ de diâmetro, foi inalado pelo analista, depois que os solventes foram eluídos (FIGURA 18). 


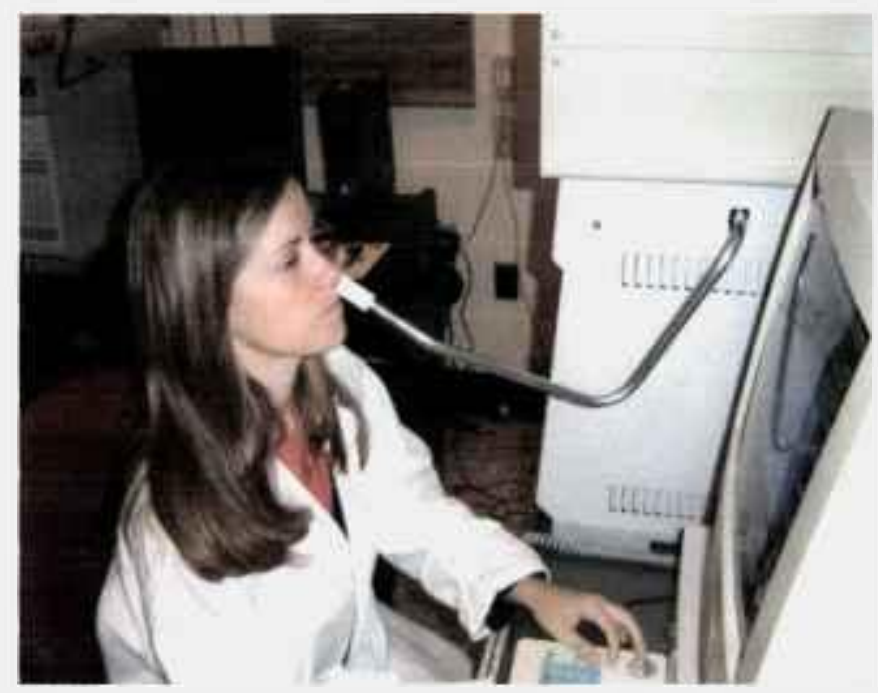

FIGURA 18 - Cromatógrafo a gás/olfatômetro.

Todas as extrações foram analisadas duas vezes (medidas repetidas) até que nenhum odor fosse detectado e o tempo de retenção de cada odor foi convertido em índices de retenção pelo ajuste da corrida de uma série de 7-18 carbonos (n-parafinas) sob as mesmas condições, porém detectado em um detector de ionização de chamas.

Estes dados foram então usados para calcular os "charm values" (áreas dos picos obtidos nos cromatogramas "charm") dos compostos com odores ativos encontrados nas amostras analisadas, para depois obter o espectro de odor (OSV), utilizando o programa “CharmAnalysis ${ }^{T M "}$ de acordo com os procedimentos descritos por ACREE et al. (1984).

A caracterização espectométrica dos aromas dos extratos foi feita utilizando-se um cromatógrafo a gás Hewlett-Packard 5890 (CG) acoplado a um detector seletivo de massa 5970 (MSD). Um $\mu \mathrm{L}$ de cada extrato concentrado (todas as diluições) foi injetado ao cromatógrafo a gás equipado com uma coluna capilar HP5-MS $(0,20 \mathrm{~mm}$ de diâmetro interno e $30 \mathrm{~m}$ de comprimento). $\mathrm{O}$ injetor foi aquecido à $200^{\circ} \mathrm{C}$ e o cromatógrafo gasoso foi aquecido à $35^{\circ} \mathrm{C}$ por $3 \mathrm{~min}$, seguido da injeção da amostra e programado à $4^{\circ} \mathrm{C} / \mathrm{min}$ até $225^{\circ} \mathrm{C}$. A identificação foi somente reportada quando os espectros, tempo de retenção e característica do odor combinavam com um padrão autêntico. 
4.2.7. Análise Estatística - Determinação de Ésteres, Alcoóis Superiores, Aldeídos e Ácidos

Para encontrar o grau de correlação entre os parâmetros estudados, os resultados foram analisados por regressão linear, usando o programa MATLAB. Para determinar a presença de diferença significativa entre a concentração dos compostos voláteis em função da dose de radiação aplicada para uma mesma amostra de bebida, os resultados foram analisados por meio do Teste-F para variância e Teste- t para média, utilizando grau de confiança de $95 \%$ ou $p=0,05$ (SPIEGEL, 1994).

\subsubsection{Análise Estatística - Análise Sensorial}

\subsubsection{Teste Triangular}

A análise dos resultados foi feita em função do número de respostas corretas necessárias para estabelecer diferenças significativas baseando-se no Teste do Qui-quadrado para um grau de significância $p=0,05$ (DUTCOSKY, 1996).

\subsubsection{Análise Descritiva Quantitativa}

\subsection{Pré-seleção dos Provadores}

A pré-seleção dos candidatos foi realizada com base em seu poder discriminativo, determinado através de testes triangulares com amostras de cachaça e rum. A análise dos resultados foi feita em função do número de respostas corretas necessárias para estabelecer diferenças significativas baseando-se no Teste do Qui-quadrado. Foram selecionados os candidatos com mais de $70 \%$ de acertos (STONE et al., 1974).

\subsection{Seleção Final dos Provadores}

Para avaliar o poder de discriminação e a repetibilidade de cada provador foi aplicada uma análise de variância (ANOVA) de dois fatores (amostras e repetições) para cada atributo avaliado com valor de significância $-p<0,30$ para o poder de discriminação e valor $p>0,05$ para repetibilidade (STONE et al., 1974). 


\subsection{Teste de Intensidade dos Atributos}

Análise de fator duplo com repetição foi usada para estudar a variância (ANOVA) para cada bebida para cada atributo com o programa EXCEL para valor - $p<0,001$ (LAURENT et al., 1994). Os resultados foram apresentados em um gráfico denominado "gráfico-aranha" ("spider-web"), onde grafica-se a intensidade de cada atributo, tomando-se o ponto central como zero.

\subsubsection{Análise Estatística - Determinação dos Odores Ativos por Cromatografia/Olfatometria}

As diferenças significativas encontradas nas amostras de bebidas analisadas, quando foram comparados seus aromas, foram determinadas por ANOVA e Teste T-Student $(p<0,05)$ (SPIEGEL, 1994). 


\section{RESULTADOS E DISCUSSÃO}

\subsection{Determinação de Ésteres, Alcoóis Superiores, Aldeídos e Ácidos}

A identificação e quantificação de alguns compostos voláteis importantes para determinação do "flavor" das bebidas destiladas, como, ésteres, expressos em acetato de etila, alcoóis superiores, ácidos e aldeídos são reportadas nesta sessão. As TABELA 2 a TABELA 22 mostram as médias dos diversos parâmetros analisados em função das doses de radiação aplicadas.

As FIGURA 19 a FIGURA 48 ilustram as variações dos parâmetros analisados em função da dose de radiação aplicada. As amostras que se encontravam na presença de raspas de madeira estão representadas como "pm" e as que estavam na ausência de raspas de madeira "am".

O acetato de etila confere às bebidas alcoólicas um aroma agradável e o seu teor é geralmente aumentado durante o envelhecimento. MORAES (2004) observou um aumento da concentração deste composto nas amostras de cachaça envelhecida, quando comparadas com a não envelhecida. As concentrações de acetato de etila foram maiores nas amostras de cachaça envelhecida de acordo com a FIGURA 19. Todos os valores encontrados neste estudo para os ésteres expressos em acetato de etila nas cachaças estão dentro do limite máximo de $200 \mathrm{mg} / 100 \mathrm{~mL}$ álcool anidro recomendado pela legislação brasileira (BRASIL, 2005). 


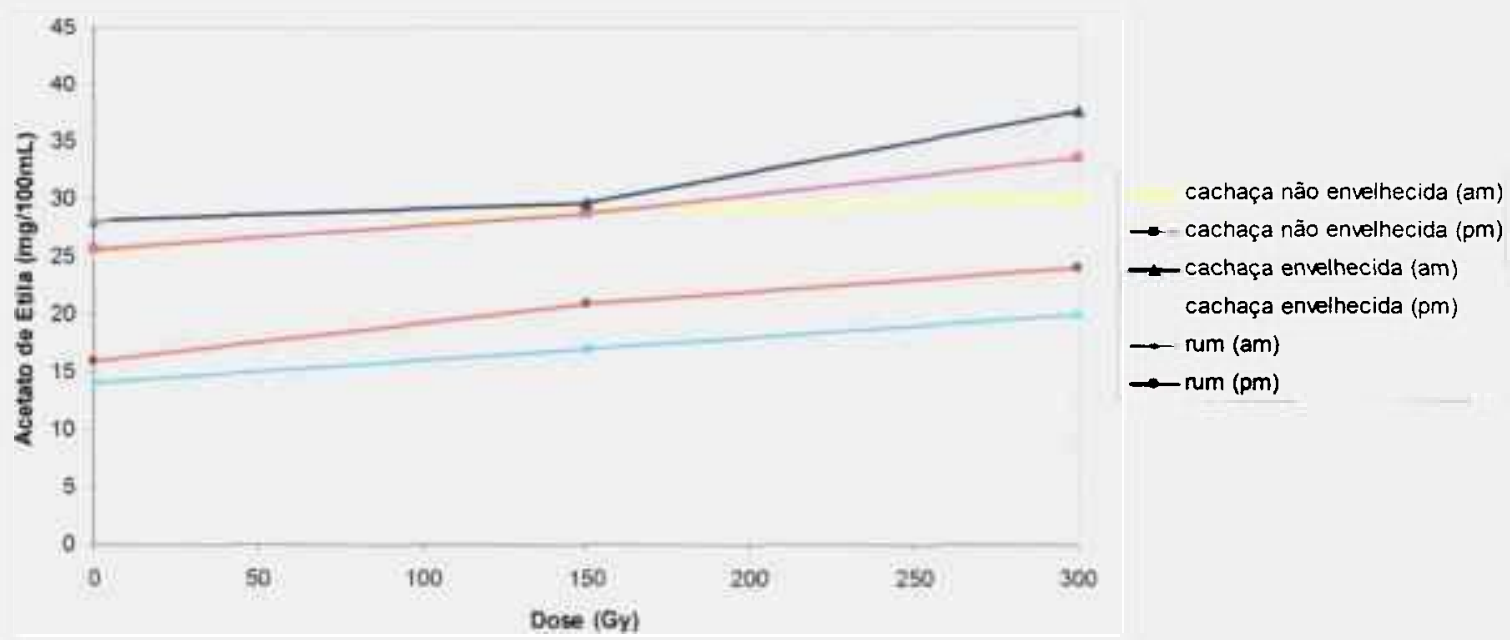

FIGURA 19 - Variação da concentração de acetato de etila em função da dose aplicada em bebidas destiladas.

Como consta na TABELA 2, a concentração máxima de acetato de etila foi obtida com 150Gy para a amostra de cachaça envelhecida (am) e rum (pm) e 300Gy para a cachaça não envelhecida (am), cachaça não envelhecida (pm), cachaça envelhecida (pm) e rum (am).

TABELA 2 - Médias* das concentrações de acetato de etila em $\mathrm{mg} / 100 \mathrm{~mL}$ álcool anidro encontradas nas amostras de bebidas analisadas.

\begin{tabular}{|c|c|c|c|c|c|c|}
\hline \multirow[b]{2}{*}{$\begin{array}{c}\text { Doses } \\
\text { (Gy) }\end{array}$} & \multirow[b]{2}{*}{$\begin{array}{c}\text { Cachaça não } \\
\text { envelhecida } \\
\text { (am) }\end{array}$} & \multirow[b]{2}{*}{$\begin{array}{l}\text { Cachaça não } \\
\text { envelhecida } \\
\text { (pm) }\end{array}$} & \multicolumn{2}{|c|}{ Amostras } & \multirow[b]{2}{*}{$\begin{array}{l}\text { Rum } \\
\text { (am) }\end{array}$} & \multirow[b]{2}{*}{$\begin{array}{l}\text { Rum } \\
\text { (pm) }\end{array}$} \\
\hline & & & $\begin{array}{c}\text { Cachaça } \\
\text { envelhecida } \\
\text { (am) }\end{array}$ & $\begin{array}{c}\text { Cachaça } \\
\text { envelhecida } \\
(\mathrm{pm})\end{array}$ & & \\
\hline 0 & $25,30^{\mathrm{a}}$ & $25,62^{\mathrm{a}}$ & $28,14^{\mathrm{a}}$ & $28,19^{\mathrm{a}}$ & $14,00^{\mathrm{a}}$ & $16,00^{a}$ \\
\hline 150 & $29,17^{\text {a.b }}$ & $28,77^{\mathrm{a}}$ & $37,14^{b}$ & $29,68^{a, b}$ & $17,00^{\mathrm{a}, \mathrm{b}}$ & $21,00^{b}$ \\
\hline 300 & $30,05^{b}$ & $33,52^{b}$ & $39,11^{b}$ & $37,58^{\mathrm{b}}$ & $20,00^{\mathrm{b}}$ & $24,00^{\mathrm{b}}$ \\
\hline
\end{tabular}

* Médias com letras iguais na mesma coluna, não diferem entre si estatisticamente $(p \leq 0,05)$. 
Os alcoóis superiores identificados e quatificados neste trabalho foram: metanol, propanol, isobutanol, butanol e álcool isoamílico.

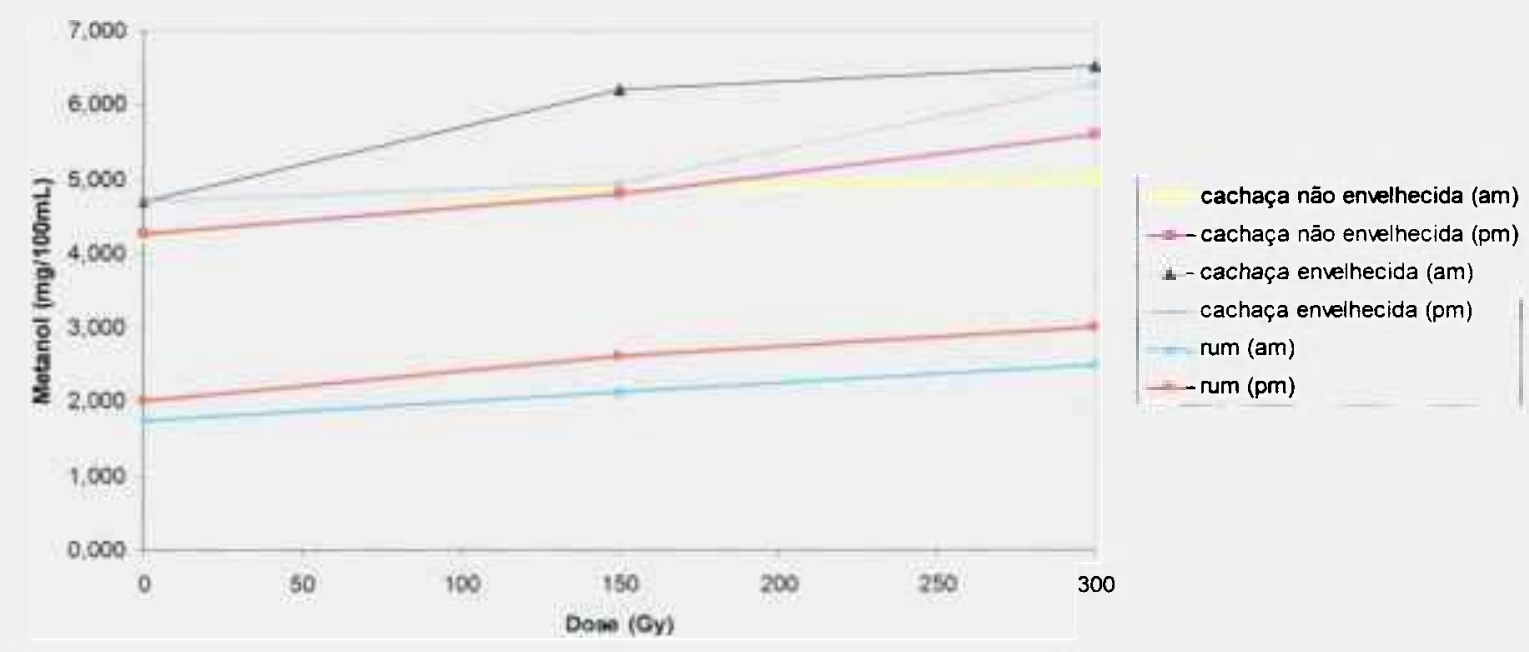

FIGURA 20 - Variação da concentração de metanol em função da dose aplicada em bebidas destiladas.

De acordo com a FIGURA 20, todas as amostras de cachaça encontram-se dentro do limite máximo de $20 \mathrm{mg}$ de metanol $/ 100 \mathrm{~mL}$ álcool anidro exigido por lei (BRASIL, 2005).

Segundo dados descritos na TABELA 3, a concentração máxima de metanol foi obtida com 150Gy para a amostra de cachaça não envelhecida (am), cachaça envelhecida (am) e rum (pm) e; 300Gy para a cachaça envelhecida (pm) e rum (am). A concentração de metanol não variou para a cachaça não envelhecida $(\mathrm{pm})$.

TABELA 3 - Médias* das concentrações de metanol em $\mathrm{mg} / 100 \mathrm{~mL}$ álcool anidro encontradas nas amostras de bebidas analisadas.

\begin{tabular}{|c|c|c|c|c|c|c|}
\hline \multirow[b]{2}{*}{$\begin{array}{c}\text { Doses } \\
(\mathrm{Gy})\end{array}$} & \multicolumn{6}{|c|}{ Amostras } \\
\hline & $\begin{array}{c}\text { Cachaça não } \\
\text { envelhecida } \\
\text { (am) }\end{array}$ & $\begin{array}{c}\text { Cachaça não } \\
\text { envelhecida } \\
(p m)\end{array}$ & $\begin{array}{c}\text { Cachaça } \\
\text { envelhecida } \\
(\mathrm{am})\end{array}$ & $\begin{array}{c}\text { Cachaça } \\
\text { envelhecida } \\
(\mathrm{pm})\end{array}$ & $\begin{array}{l}\text { Rum } \\
\text { (am) }\end{array}$ & $\begin{array}{l}\text { Rum } \\
\text { (pm) }\end{array}$ \\
\hline 0 & $4,28^{\mathrm{a}}$ & $4,27^{\mathrm{a}}$ & $4,69^{\mathrm{a}}$ & $4,69^{\mathrm{a}}$ & $1,75^{\mathrm{a}}$ & $\overline{2,00^{\mathrm{a}}}$ \\
\hline 150 & $4,86^{\mathrm{b}}$ & $4,79^{\mathrm{a}}$ & $6,19^{b}$ & $4,95^{\mathrm{a}}$ & $2,12^{\mathrm{a}, \mathrm{b}}$ & $2,62^{b}$ \\
\hline 300 & $5,01^{b}$ & $5,59^{\mathrm{a}}$ & $6,52^{b}$ & $6,26^{b}$ & $2,50^{\mathrm{b}}$ & $3,00^{\mathrm{b}}$ \\
\hline
\end{tabular}

* Médias com letras iguais na mesma coluna, não diferem entre si estatisticamente $(p \leq 0,05)$. 


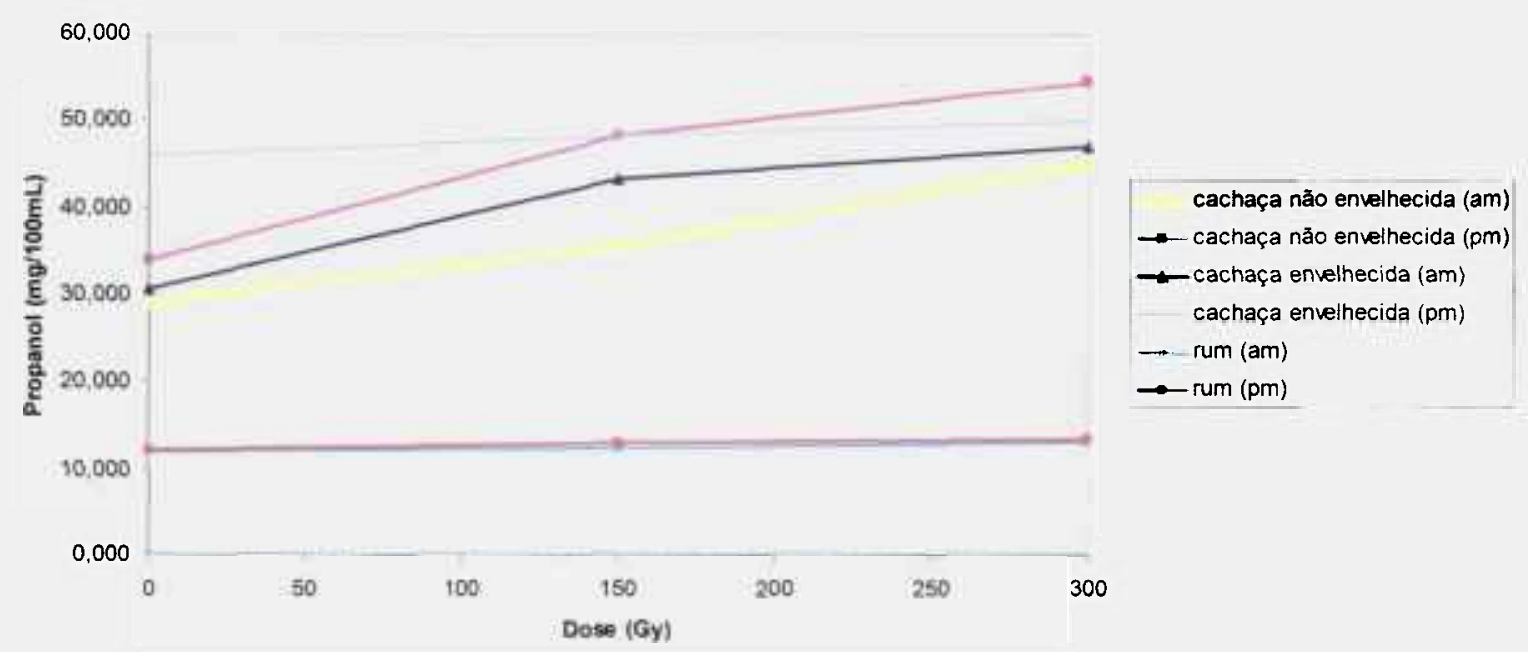

FIGURA 21 - Variação da concentração de propanol em função da dose aplicada em bebidas destiladas.

Segundo os dados obtidos relacionados na TABELA 4, a concentração máxima de propanol foi obtida com 150Gy para a amostra de cachaça não envelhecida (pm), cachaça envelhecida (am) e; 300Gy para a cachaça não envelhecida (am). A concentração de propanol não variou para a cachaça envelhecida (pm), rum (am) e rum (pm).

TABELA 4 - Médias* das concentrações de propanol em $\mathrm{mg} / 100 \mathrm{~mL}$ álcool anidro encontradas nas amostras de bebidas analisadas.

\begin{tabular}{|c|c|c|c|c|c|c|}
\hline $\begin{array}{c}\text { Doses } \\
\text { (Gy) }\end{array}$ & $\begin{array}{c}\text { Cachaça não } \\
\text { envelhecida } \\
\text { (am) }\end{array}$ & $\begin{array}{c}\text { Cachaça não } \\
\text { envelhecida } \\
\text { (pm) }\end{array}$ & $\begin{array}{l}\text { Amostra } \\
\text { Cachaça } \\
\text { envelhecida } \\
(\mathrm{am})\end{array}$ & $\begin{array}{c}\text { Cachaça } \\
\text { envelhecida } \\
(\mathrm{pm})\end{array}$ & $\begin{array}{l}\text { Rum } \\
\text { (am) }\end{array}$ & $\begin{array}{l}\text { Rum } \\
(\mathrm{pm})\end{array}$ \\
\hline 0 & $28,87^{\mathrm{a}}$ & $34,01^{\mathrm{a}}$ & $30,57^{\mathrm{a}}$ & $46,00^{\mathrm{a}}$ & $12,00^{\mathrm{a}}$ & $12,20^{\mathrm{a}}$ \\
\hline 150 & $35,67^{b}$ & $48,23^{b}$ & $43,26^{b}$ & $48,12^{\mathrm{a}}$ & $12,50^{\mathrm{a}}$ & $13,00^{\mathrm{a}}$ \\
\hline 300 & $44,90^{c}$ & $54,40^{\mathrm{b}}$ & $46,98^{b}$ & $49,95^{\mathrm{a}}$ & $13,10^{\mathrm{a}}$ & $13,50^{\mathrm{a}}$ \\
\hline
\end{tabular}

* Médias com letras iguais na mesma coluna, não diferem entre si estatisticamente $(p \leq 0,05)$. 


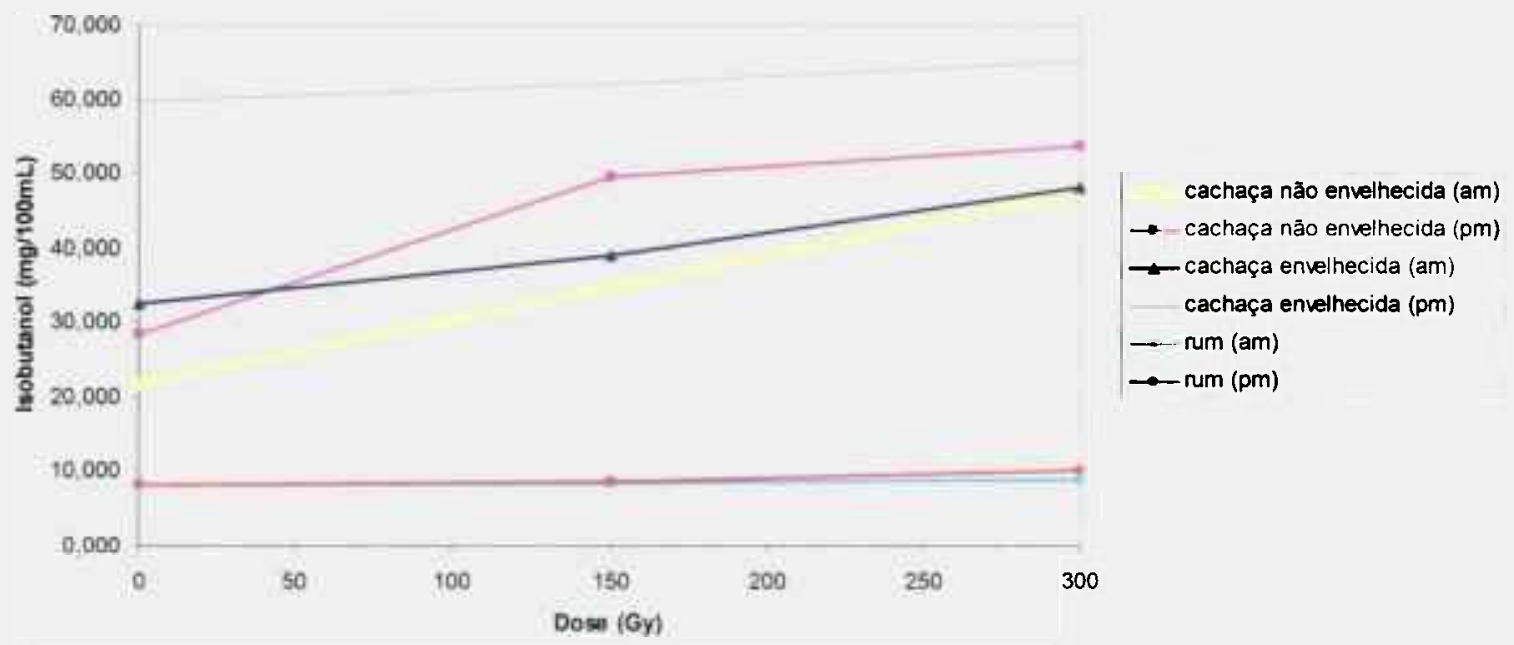

FIGURA 22 - Variação da concentração de isobutanol em função da dose aplicada em bebidas destiladas.

Segundo dados contidos na TABELA 5, a concentração máxima de isobutanol foi obtida com 150Gy para a amostra de cachaça envelhecida (am) e; 300Gy para a cachaça não envelhecida (am) e cachaça não envelhecida (pm). A concentração de isobutanol não variou para cachaça envelhecida (pm), rum (am) e rum (pm).

TABELA 5 - Médias* das concentrações de isobutanol em $\mathrm{mg} / 100 \mathrm{~mL}$ álcool anidro encontradas nas amostras de bebidas analisadas.

\begin{tabular}{ccccccc}
\hline $\begin{array}{c}\text { Doses } \\
(G y)\end{array}$ & $\begin{array}{c}\text { Cachaça não } \\
\text { envelhecida } \\
(\mathrm{am})\end{array}$ & $\begin{array}{c}\text { Cachaça não } \\
\text { envelhecida } \\
(\mathrm{pm})\end{array}$ & $\begin{array}{c}\text { Cachaça } \\
\text { envelhecida } \\
(\mathrm{am})\end{array}$ & $\begin{array}{c}\text { Cachaça } \\
\text { envelhecida } \\
(\mathrm{pm})\end{array}$ & $\begin{array}{c}\text { Rum } \\
(\mathrm{am})\end{array}$ & $\begin{array}{c}\text { Rum } \\
(\mathrm{pm})\end{array}$ \\
\hline 0 & $21,61^{\mathrm{a}}$ & $28,33^{\mathrm{a}}$ & $32,58^{\mathrm{a}}$ & $59,65^{\mathrm{a}}$ & $8,10^{\mathrm{a}}$ & $8,16^{\mathrm{a}}$ \\
150 & $34,71^{\mathrm{b}}$ & $49,49^{\mathrm{b}}$ & $39,00^{\mathrm{a}}$ & $62,00^{\mathrm{a}}$ & $8,35^{\mathrm{a}}$ & $8,58^{\mathrm{a}}$ \\
300 & $47,65^{\mathrm{c}}$ & $53,66^{\mathrm{c}}$ & $48,23^{\mathrm{b}}$ & $65,12^{\mathrm{a}}$ & $9,00^{\mathrm{a}}$ & $10,00^{\mathrm{a}}$ \\
\hline \hline
\end{tabular}

* Médias com letras iguais na mesma coluna, não diferem entre si estatisticamente $(p \leq 0,05)$. 


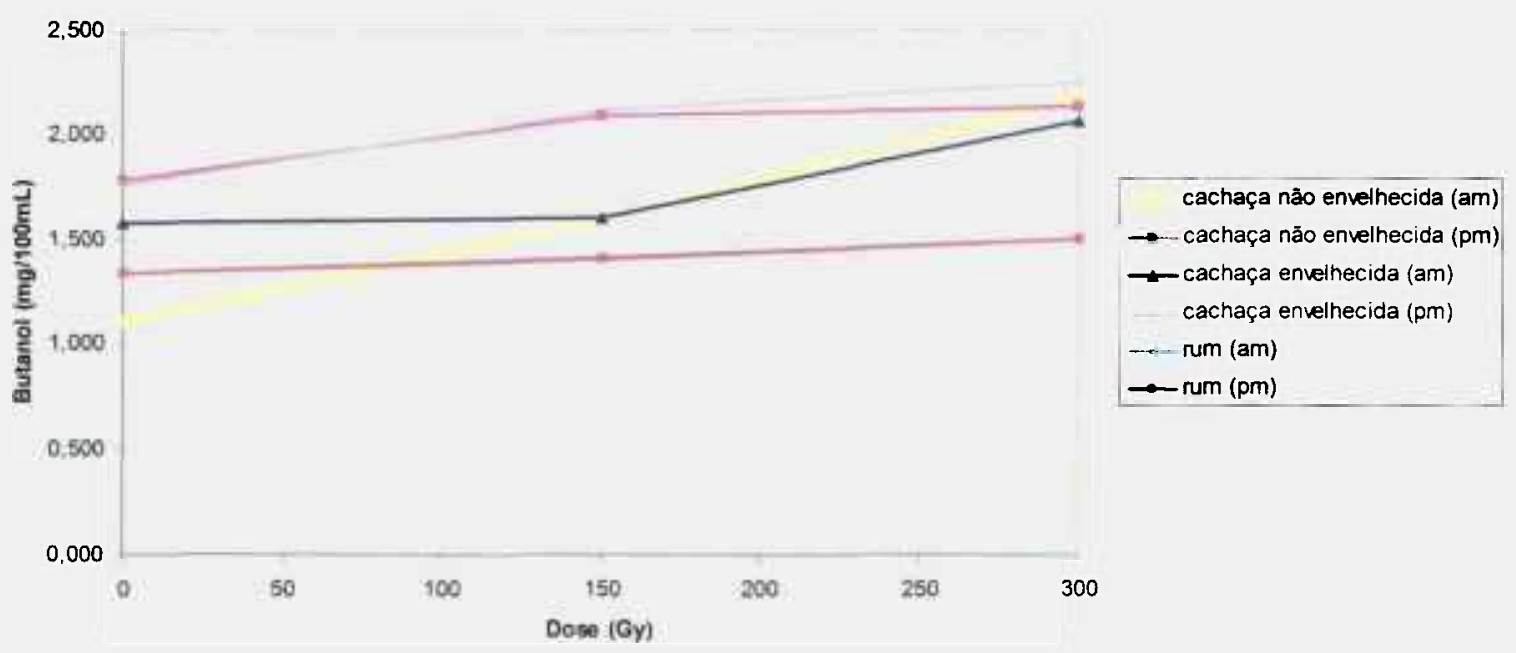

FIGURA 23 - Variação da concentração de butanol em função da dose aplicada em bebidas destiladas.

De acordo com a FIGURA 23, todas as amostras de cachaça encontram-se dentro do limite máximo de $3 \mathrm{mg}$ de butanol/100mL álcool anidro exigido por lei (BRASIL, 2005).

Segundo consta na TABELA 6 , a concentração máxima de butanol foi obtida com 300Gy para a amostra de cachaça não envelhecida (am), cachaça não envelhecida (pm), cachaça envelhecida (am), cachaça envelhecida (pm), rum (am) e rum (pm).

TABELA 6 - Médias* das concentrações de butanol em mg/100mL álcool anidro encontradas nas amostras de bebidas analisadas.

\begin{tabular}{ccccccc}
\hline $\begin{array}{c}\text { Doses } \\
(\text { Gy) }\end{array}$ & $\begin{array}{c}\text { Cachaça não } \\
\text { envelhecida } \\
(\text { am) }\end{array}$ & $\begin{array}{c}\text { Cachaça não } \\
\text { envelhecida } \\
(\mathrm{pm})\end{array}$ & $\begin{array}{c}\text { Cachaça } \\
\text { envelhecida } \\
(\mathrm{am})\end{array}$ & $\begin{array}{c}\text { Cachaça } \\
\text { envelhecida } \\
(\mathrm{pm})\end{array}$ & $\begin{array}{c}\text { Rum } \\
(\mathrm{am})\end{array}$ & $\begin{array}{c}\text { Rum } \\
(\mathrm{pm})\end{array}$ \\
\hline 0 & $1,11^{\mathrm{a}}$ & $1,78^{\mathrm{a}}$ & $1,58^{\mathrm{a}}$ & $1,76^{\mathrm{a}}$ & $1,34^{\mathrm{a}}$ & $1,34^{\mathrm{a}}$ \\
150 & $1,60^{\mathrm{a}}$ & $2,09^{\mathrm{b}}$ & $1,60^{\mathrm{a}}$ & $2,12^{\mathrm{b}}$ & $1,41^{\mathrm{b}}$ & $1,40^{\mathrm{b}}$ \\
300 & $2,17^{\mathrm{b}}$ & $2,13^{\mathrm{c}}$ & $2,06^{\mathrm{b}}$ & $2,25^{\mathrm{c}}$ & $1,50^{\mathrm{c}}$ & $1,50^{\mathrm{c}}$ \\
\hline \hline
\end{tabular}

* Médias com letras iguais na mesma coluna, não diferem entre si estatisticamente $(p \leq 0,05)$. 


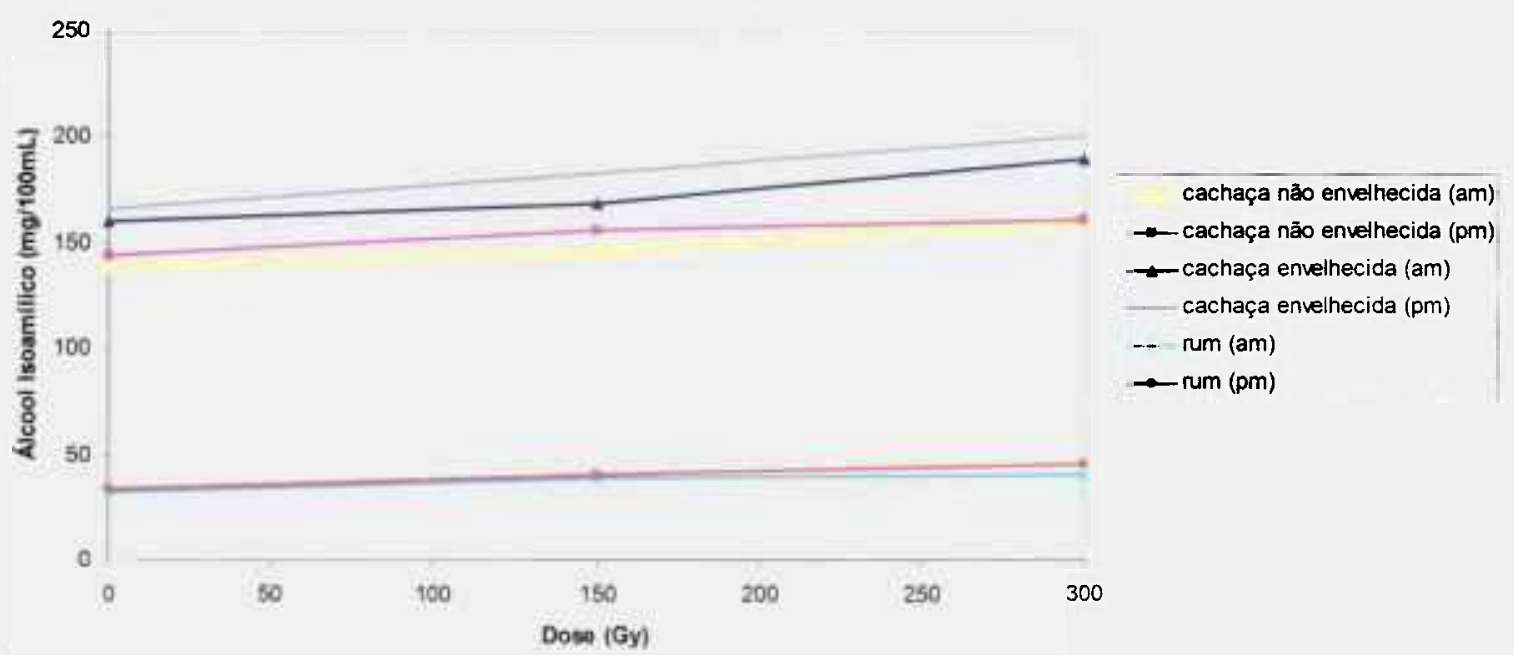

FIGURA 24 - Variação da concentração de álcool isoamílico em função da dose aplicada em bebidas destiladas.

Segundo a TABELA 7, a concentração máxima de álcool isoamílico foi obtida com 300Gy para rum (am) e rum (pm). A concentração de álcool isoamílico não variou para a cachaça não envelhecida (am), cachaça não envelhecida (pm), cachaça envelhecida (am) e cachaça envelhecida (pm).

TABELA 7 - Médias* das concentrações de álcool isoamílico em $\mathrm{mg} / 100 \mathrm{~mL}$ álcool anidro encontradas nas amostras de bebidas analisadas.

\begin{tabular}{ccccccc}
\hline $\begin{array}{c}\text { Doses } \\
(\mathrm{Gy})\end{array}$ & $\begin{array}{c}\text { Cachaça não } \\
\text { envelhecida } \\
(\mathrm{am})\end{array}$ & $\begin{array}{c}\text { Cachaça não } \\
\text { envelhecida } \\
(\mathrm{pm})\end{array}$ & $\begin{array}{c}\text { Cachoça } \\
\text { envelhecida } \\
(\mathrm{am})\end{array}$ & $\begin{array}{c}\text { Cachaça } \\
\text { envelhecida } \\
(\mathrm{pm})\end{array}$ & $\begin{array}{c}\text { Rum } \\
(\mathrm{am})\end{array}$ & $\begin{array}{c}\text { Rum } \\
(\mathrm{pm})\end{array}$ \\
\hline 0 & $138,00^{\mathrm{a}}$ & $143,80^{\mathrm{a}}$ & $159,60^{\mathrm{a}}$ & $165,90^{\mathrm{a}}$ & $32,00^{\mathrm{a}}$ & $33,90^{\mathrm{a}}$ \\
150 & $145,23^{\mathrm{a}}$ & $155,78^{\mathrm{a}}$ & $168,00^{\mathrm{a}}$ & $182,70^{\mathrm{a}}$ & $38,90^{\mathrm{a}}$ & $40,56^{\mathrm{a} b}$ \\
300 & $158,90^{\mathrm{a}}$ & $161,00^{\mathrm{a}}$ & $189,46^{\mathrm{a}}$ & $200,00^{\mathrm{a}}$ & $40,00^{\mathrm{b}}$ & $45,08^{\mathrm{b}}$ \\
\hline
\end{tabular}

* Médias com letras iguais na mesma coluna, não diferem entre si estatisticamente $(p \leqq 0,05)$. 
Segundo a legislação brasileira (BRASIL, 2005), a soma das concentrações dos alcoóis isoamílico, isobutílico e n-propílico na cachaça não deve ultrapassar $360 \mathrm{mg} / 100 \mathrm{~mL}$ álcool anidro. De acordo com a TABELA 8 todas as amostras tiveram seus valores abaixo do limite permissível.

TABELA 8 - Soma das concentrações dos alcoóis isoamílico, isobutílico e n-propilico em $\mathrm{mg} / 100 \mathrm{~mL}$ álcool anidro nas amostras analisadas.

\begin{tabular}{cccc}
\hline \multirow{2}{*}{ Amostras } & \multicolumn{3}{c}{$\begin{array}{c}\text { Soma das concentrações dos alcoóis isoamílico, } \\
\text { isobutílico e n-propílico }\end{array}$} \\
\cline { 2 - 4 } & $0 \mathrm{~Gy}$ & $150 \mathrm{~Gy}$ & $300 \mathrm{~Gy}$ \\
\hline Cachaça não envelhecida (am) & 188,48 & 215,62 & 25,43 \\
Cachaça não envelhecida (pm) & 206,14 & 253,50 & 269,06 \\
Cachaça envelhecida (am) & 222,75 & 250,26 & 284,67 \\
Cachaça envelhecida (pm) & 271,55 & 292,82 & 315,07 \\
Rum (am) & 52,10 & 59,75 & 62,10 \\
Rum (pm) & 54,26 & 62,14 & 68,58 \\
\hline
\end{tabular}

Segundo CARDOSO et al. (2004), no que diz respeito aos alcoóis, o propanol e o isobutanol apresentaram concentrações maiores nas amostras de cachaça do que nas de rum, podendo, assim, ser considerados um dos discriminadores entre estas bebidas. Essa ocorrência foi também observada neste esstudo. 
Os ácidos determinados neste estudo foram: ácido acético, ácido propiônico, ácido isobutírico, ácido butírico, ácido isovalérico, ácido isocapróico, ácido capróico, ácido heptanóico, ácido caprílico, ácido cáprico, ácido mirístico, ácido láurico e ácido palmítico.

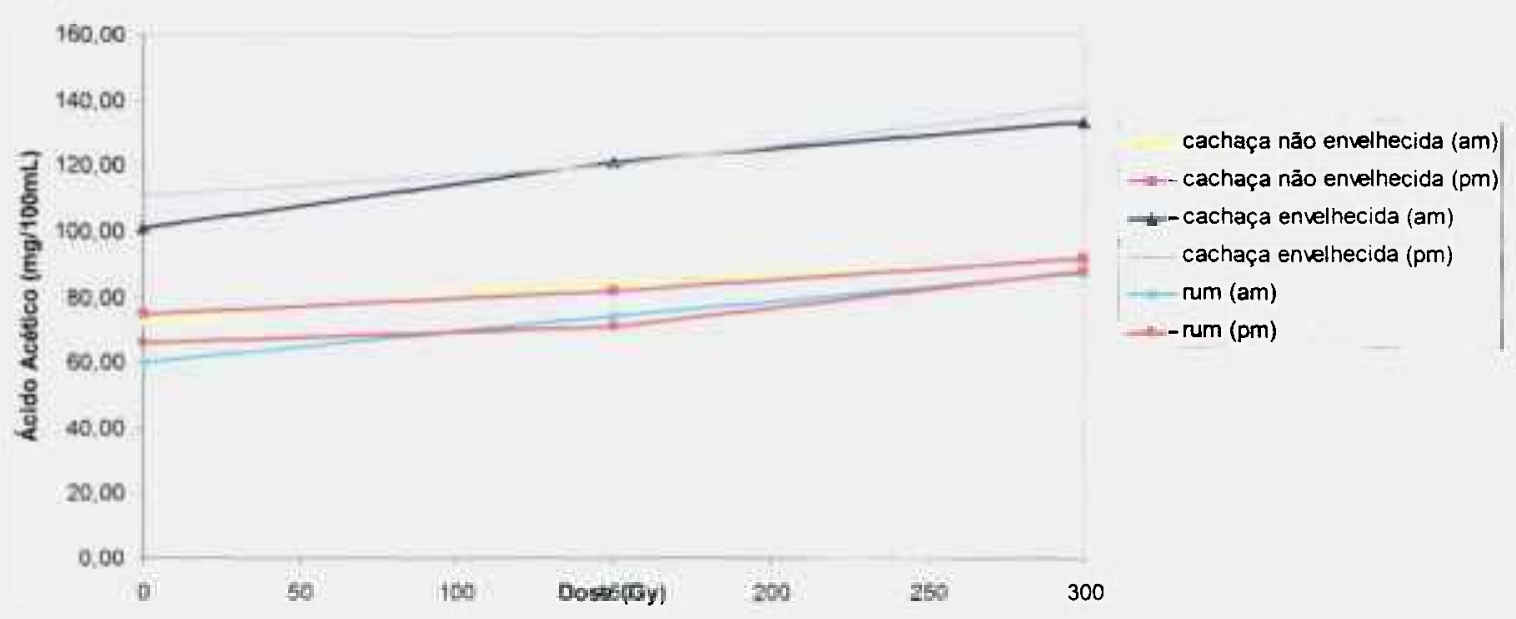

FIGURA 25 - Variação da concentração de ácido acético em função da dose aplicada em bebidas destiladas.

De acordo com a TABELA 9, a concentração máxima de ácido acético foi obtida com 150Gy para a amostra de cachaça não envelhecida (am) e cachaça envelhecida (am) e; 300Gy para a cachaça envelhecida (pm), rum (am) e rum (pm). A concentração de ácido acético não variou para a cachaça não envelhecida (pm).

TABELA 9 - Médias* das concentrações de ácido acético em $\mathrm{mg} / 100 \mathrm{~mL}$ álcool anidro encontradas nas amostras de bebidas analisadas.

\begin{tabular}{ccccccc}
\hline $\begin{array}{c}\text { Doses } \\
(\mathrm{Gy})\end{array}$ & $\begin{array}{c}\text { Cachaça não } \\
\text { envelhecida } \\
(\text { am) }\end{array}$ & $\begin{array}{c}\text { Cachaça não } \\
\text { envelhecida } \\
(\mathrm{pm})\end{array}$ & $\begin{array}{c}\text { Amostras } \\
\text { Cachaça } \\
\text { envelhecida } \\
(\mathrm{am})\end{array}$ & $\begin{array}{c}\text { Cachaça } \\
\text { envelhecida } \\
(\mathrm{pm})\end{array}$ & $\begin{array}{c}\text { Rum } \\
(\mathrm{am})\end{array}$ & $\begin{array}{c}\text { Rum } \\
(\mathrm{pm})\end{array}$ \\
\hline 0 & $73,00^{\mathrm{a}}$ & $75,00^{\mathrm{a}}$ & $101,00^{\mathrm{a}}$ & $111,00^{\mathrm{a}}$ & $60,00^{\mathrm{a}}$ & $66,00^{\mathrm{a}}$ \\
150 & $84,00^{\mathrm{b}}$ & $82,00^{\mathrm{a}}$ & $121,00^{\mathrm{b}}$ & $120,00^{\mathrm{a} b}$ & $74,00^{\mathrm{b}}$ & $70,90^{\mathrm{a}}$ \\
300 & $91,00^{\mathrm{b}}$ & $91,90^{\mathrm{a}}$ & $133,00^{\mathrm{b}}$ & $138,00^{\mathrm{b}}$ & $87,30^{\mathrm{c}}$ & $87,90^{\mathrm{b}}$ \\
\hline
\end{tabular}

* Médias com letras iguais na mesma coluna, não diferem entre si estatisticamente $(p \leq 0,05)$. 


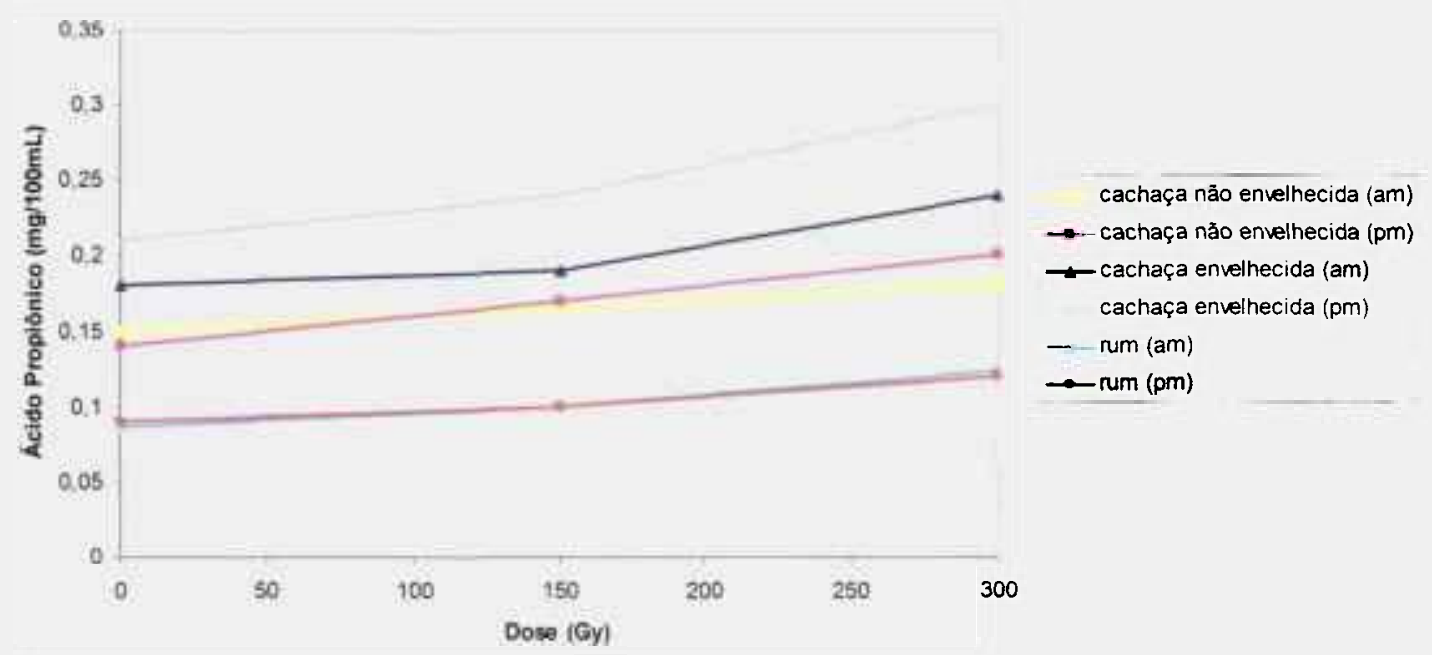

FIGURA 26 - Variação da concentração de ácido propiônico em função da dose aplicada em bebidas destiladas.

Segundo a TABELA 10, a concentração máxima de ácido propiônico foi obtida com 300Gy para a amostra de cachaça não envelhecida (pm), cachaça envelhecida (am), cachaça envelhecida $(\mathrm{pm})$, rum (am) e rum $(\mathrm{pm})$. A concentração de ácido propiônico não variou para a cachaça não envelhecida (am).

TABELA 10 - Médias* das concentrações de ácido propiônico em $\mathrm{mg} / 100 \mathrm{~mL}$ álcool anidro encontradas nas amostras de bebidas analisadas.

\begin{tabular}{ccccccc}
\hline $\begin{array}{c}\text { Doses } \\
(\text { Gy) }\end{array}$ & $\begin{array}{c}\text { Cachaça não } \\
\text { envelhecida } \\
(\text { am) }\end{array}$ & $\begin{array}{c}\text { Cachaça não } \\
\text { envelhecida } \\
(\mathrm{pm})\end{array}$ & $\begin{array}{c}\text { Amostras } \\
\text { Cachaça } \\
\text { envelhecida } \\
(\mathrm{am})\end{array}$ & $\begin{array}{c}\text { Cachaça } \\
\text { envelhecida } \\
(\mathrm{pm})\end{array}$ & $\begin{array}{c}\text { Rum } \\
(\mathrm{am})\end{array}$ & $\begin{array}{c}\text { Rum } \\
(\mathrm{pm})\end{array}$ \\
\hline \hline 0 & $0,15^{\mathrm{a}}$ & $0,14^{\mathrm{a}}$ & $0,18^{\mathrm{a}}$ & $0,21^{\mathrm{a}}$ & $0,09^{\mathrm{a}}$ & $0,09^{\mathrm{a}}$ \\
150 & $0,16^{\mathrm{a}}$ & $0,17^{\mathrm{a}, \mathrm{b}}$ & $0,19^{\mathrm{a}}$ & $0,24^{\mathrm{a}}$ & $0,10^{\mathrm{a}}$ & $0,10^{\mathrm{a}, \mathrm{b}}$ \\
300 & $0,18^{\mathrm{a}}$ & $0,20^{\mathrm{b}}$ & $0,24^{\mathrm{b}}$ & $0,30^{\mathrm{b}}$ & $0,12^{\mathrm{b}}$ & $0,12^{\mathrm{b}}$ \\
\hline
\end{tabular}

\footnotetext{
${ }^{4}$ Médias com letras iguais na mesma coluna, não diferem entre si estatisticamente $(p \leq 0,05)$.
} 


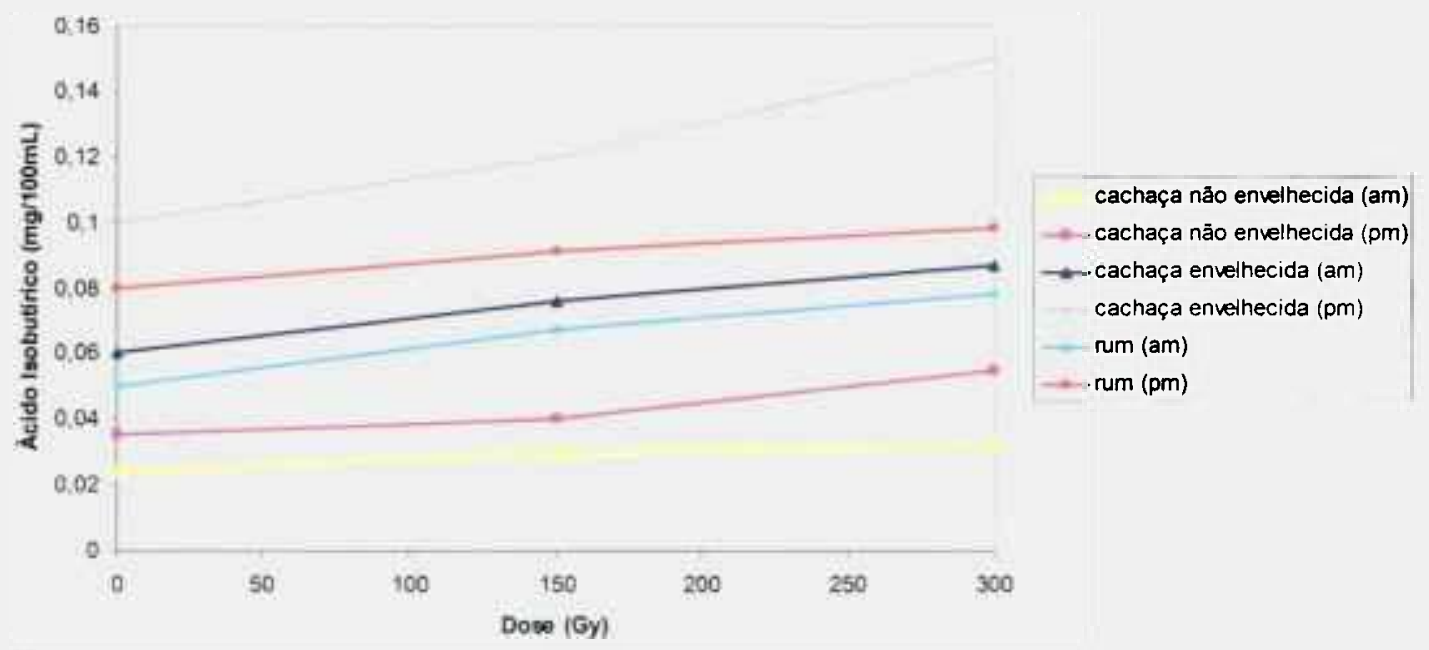

FIGURA 27 - Variação da concentração de ácido isobutírico em função da dose aplicada em bebidas destiladas.

De acordo com a TABELA 11, a concentração máxima de ácido isobutírico foi obtida com 300Gy para a amostra de cachaça não envelhecida $(\mathrm{pm})$, cachaça envelhecida (am), cachaça envelhecida (pm), rum (am) e rum (pm). A concentração de ácido isobutírico não variou para a cachaça não envelhecida (am).

TABELA 11 - Médias* das concentrações de ácido isobutírico em $\mathrm{mg} / 100 \mathrm{~mL}$ álcool anidro encontradas nas amostras de bebidas analisadas.

\begin{tabular}{ccccccc}
\hline $\begin{array}{c}\text { Doses } \\
(\mathrm{Gy})\end{array}$ & $\begin{array}{c}\text { Cachaça não } \\
\text { envelhecida } \\
(\mathrm{am})\end{array}$ & $\begin{array}{c}\text { Cachaça não } \\
\text { envelhecida } \\
(\mathrm{pm})\end{array}$ & $\begin{array}{c}\text { Cachaça } \\
\text { envelhecida } \\
(\mathrm{am})\end{array}$ & $\begin{array}{c}\text { Cachaça } \\
\text { envelhecida } \\
(\mathrm{pm})\end{array}$ & $\begin{array}{c}\text { Rum } \\
(\mathrm{am})\end{array}$ & $\begin{array}{c}\text { Rum } \\
(\mathrm{pm})\end{array}$ \\
\hline 0 & $0,02^{\mathrm{a}}$ & $0,03^{\mathrm{a}}$ & $0,06^{\mathrm{a}}$ & $0,10^{\mathrm{a}}$ & $0,05^{\mathrm{a}}$ & $0,08^{\mathrm{a}}$ \\
150 & $0,03^{\mathrm{a}}$ & $0,04^{\mathrm{a}}$ & $0,08^{\mathrm{a}, \mathrm{b}}$ & $0,12^{\mathrm{a}, \mathrm{b}}$ & $0,07^{\mathrm{a}, \mathrm{b}}$ & $0,09^{\mathrm{a}}$ \\
300 & $0,03^{\mathrm{a}}$ & $0,05^{\mathrm{b}}$ & $0,09^{\mathrm{b}}$ & $0,15^{\mathrm{b}}$ & $0,08^{\mathrm{b}}$ & $0,10^{\mathrm{b}}$ \\
\hline \hline
\end{tabular}

"Médias com letras iguais na mesma coluna, não diferem entre si estatisticamente $(p \leq 0,05)$. 


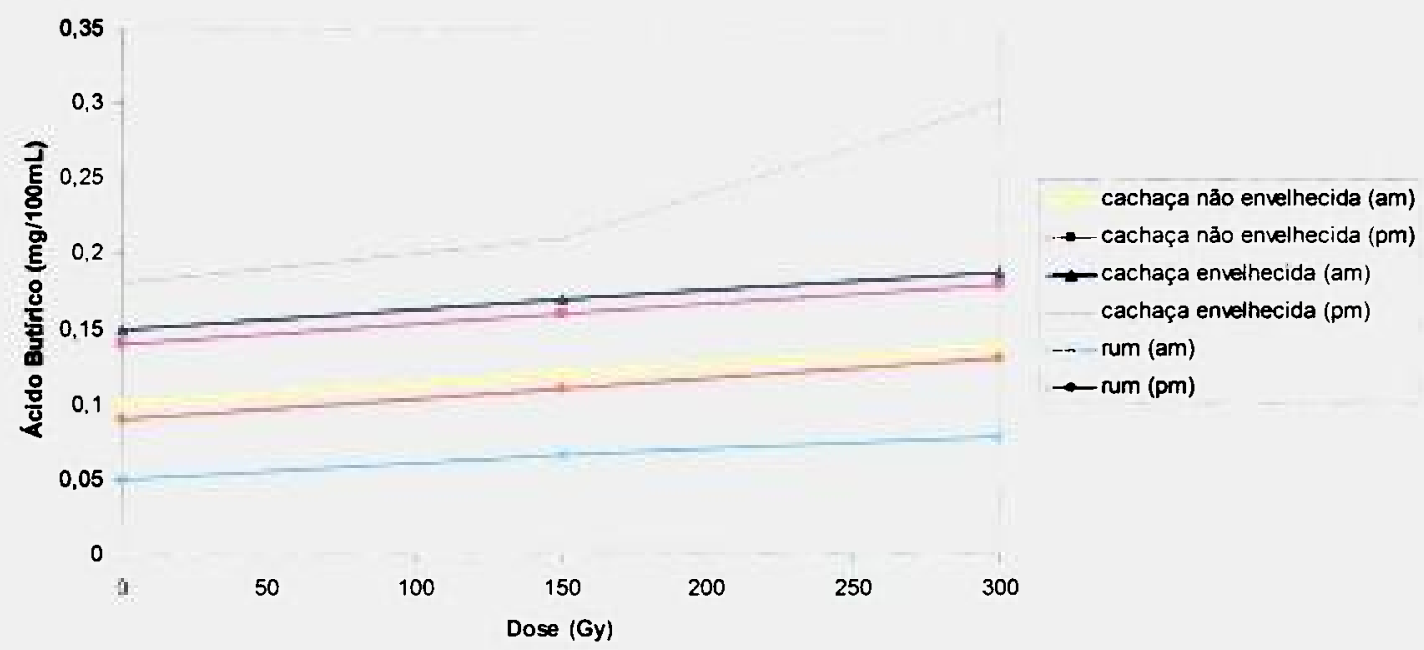

FIGURA 28 - Variação da concentração de ácido butírico em função da dose aplicada em bebidas destiladas.

Da análise dos dados contidos na TABELA 12 é possível perceber que a concentração máxima de ácido butírico foi obtida com 150Gy para a amostra de rum (pm) e; 300Gy para a cachaça não envelhecida (am), cachaça envelhecida (am), cachaça envelhecida (pm) e rum (am). A concentração de ácido butírico não variou para a cachaça não envelhecida (pm).

TABELA 12 - Médias* das concentrações de ácido butírico em $\mathrm{mg} / 100 \mathrm{~mL}$ álcool anidro encontradas nas amostras de bebidas analisadas.

\begin{tabular}{ccccccc}
\hline $\begin{array}{c}\text { Doses } \\
(\mathrm{Gy})\end{array}$ & $\begin{array}{c}\text { Cachaça não } \\
\text { envelhecida } \\
(\mathrm{am})\end{array}$ & $\begin{array}{c}\text { Cachaça não } \\
\text { envelhecida } \\
(\mathrm{pm})\end{array}$ & $\begin{array}{c}\text { Amostras } \\
\text { Cachaça } \\
\text { envelhecida } \\
(\mathrm{am})\end{array}$ & $\begin{array}{c}\text { Cachaça } \\
\text { envelhecida } \\
(\mathrm{pm})\end{array}$ & $\begin{array}{c}\text { Rum } \\
(\mathrm{am})\end{array}$ & $\begin{array}{c}\text { Rum } \\
(\mathrm{pm})\end{array}$ \\
\hline 0 & $0,10^{\mathrm{a}}$ & $0,14^{\mathrm{a}}$ & $0,15^{\mathrm{a}}$ & $0,18^{\mathrm{a}}$ & $0,05^{\mathrm{a}}$ & $0,09^{\mathrm{a}}$ \\
150 & $0,12^{\mathrm{a}, \mathrm{b}}$ & $0,16^{\mathrm{a}}$ & $0,17^{\mathrm{a}, \mathrm{b}}$ & $0,21^{\mathrm{b}}$ & $0,07^{\mathrm{b}}$ & $0,11^{\mathrm{b}}$ \\
300 & $0,14^{\mathrm{b}}$ & $0,18^{\mathrm{a}}$ & $0,19^{\mathrm{a}}$ & $0,30^{\mathrm{c}}$ & $0,08^{\mathrm{c}}$ & $0,13^{\mathrm{b}}$ \\
\hline
\end{tabular}

* Médias com letras iguais na mesma coluna, não diferem entre si estatisticamente $(p \leq 0,05)$. 


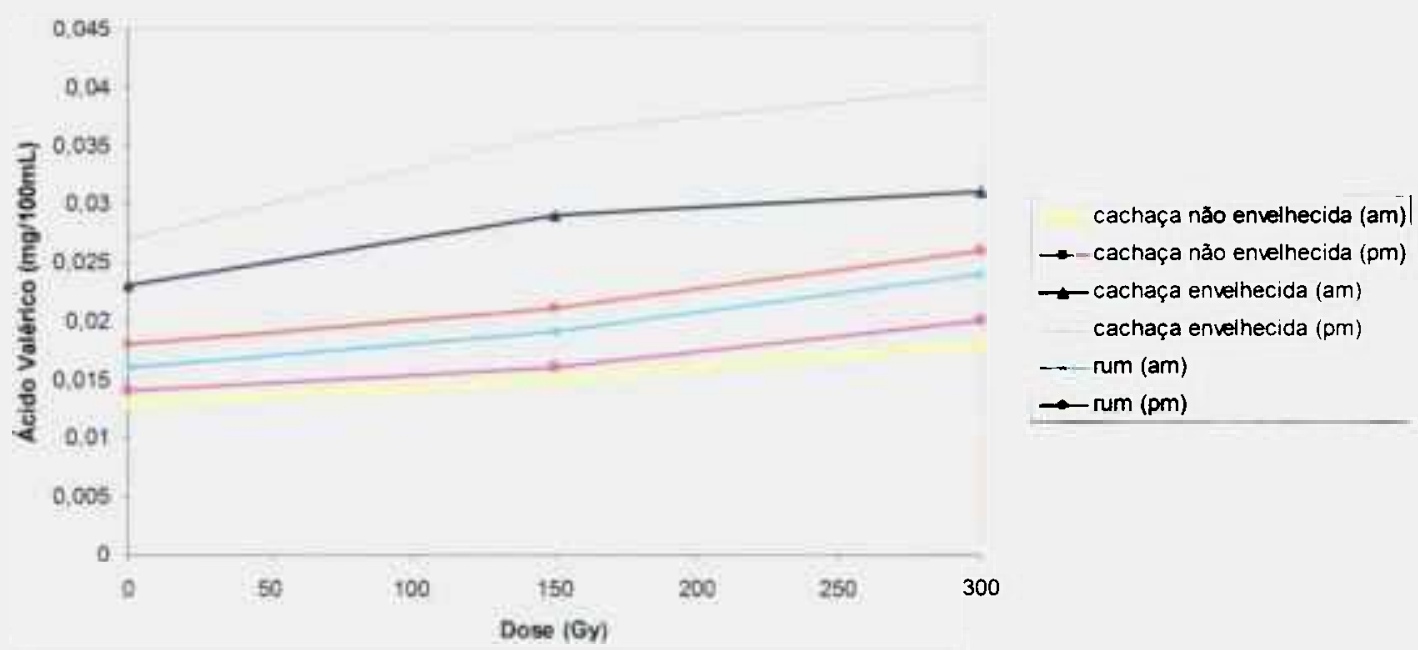

FIGURA 29 - Variação da concentração de ácido valérico em função da dose aplicada em bebidas destiladas.

Segundo a TABELA 13, a concentração máxima de ácido valérico foi obtida com 150Gy para a amostra de cachaça envelhecida (am) e cachaça envelhecida (pm) e; 300Gy para a cachaça não envelhecida (am), cachaça não envelhecida (pm), rum (am) e rum (pm).

TABELA 13 - Médias* das concentrações de ácido valérico em $\mathrm{mg} / 100 \mathrm{~mL}$ álcool anidro encontradas nas amostras de bebidas analisadas.

\begin{tabular}{|c|c|c|c|c|c|c|}
\hline \multirow[b]{2}{*}{$\begin{array}{c}\text { Doses } \\
\text { (Gy) }\end{array}$} & \multicolumn{6}{|c|}{ Amostras } \\
\hline & $\begin{array}{c}\text { Cachaça não } \\
\text { envelhecida } \\
\text { (am) }\end{array}$ & $\begin{array}{l}\text { Cachaça não } \\
\text { envelhecida } \\
\text { (pm) }\end{array}$ & $\begin{array}{c}\text { Cachaça } \\
\text { envelhecida } \\
\text { (am) }\end{array}$ & $\begin{array}{l}\text { Cachaça } \\
\text { envelhecida } \\
(\mathrm{pm})\end{array}$ & $\begin{array}{l}\text { Rum } \\
\text { (am) }\end{array}$ & $\begin{array}{l}\text { Rum } \\
\text { (pm) }\end{array}$ \\
\hline 0 & $0,01^{3}$ & $0,01^{\mathrm{a}}$ & $0,02^{\mathrm{a}}$ & $0,03^{\mathrm{a}}$ & $0,02^{\mathrm{a}}$ & $0,02^{\mathrm{a}}$ \\
\hline 150 & $0,015^{\mathrm{ab}}$ & $0,01^{\mathrm{a}}$ & $0,03^{\mathrm{b}}$ & $0,04^{\mathrm{b}}$ & $0,02^{\mathrm{a}}$ & $0,02^{\mathrm{a}}$ \\
\hline 300 & $0,02^{\mathrm{b}}$ & $0,02^{\mathrm{b}}$ & $0,03^{\mathrm{b}}$ & $0,040^{b}$ & $0,025^{\mathrm{b}}$ & $0,03^{b}$ \\
\hline
\end{tabular}

* Médias com letras iguais na mesma coluna, não diferem entre si estatisticamente $(p \leq 0,05)$. 


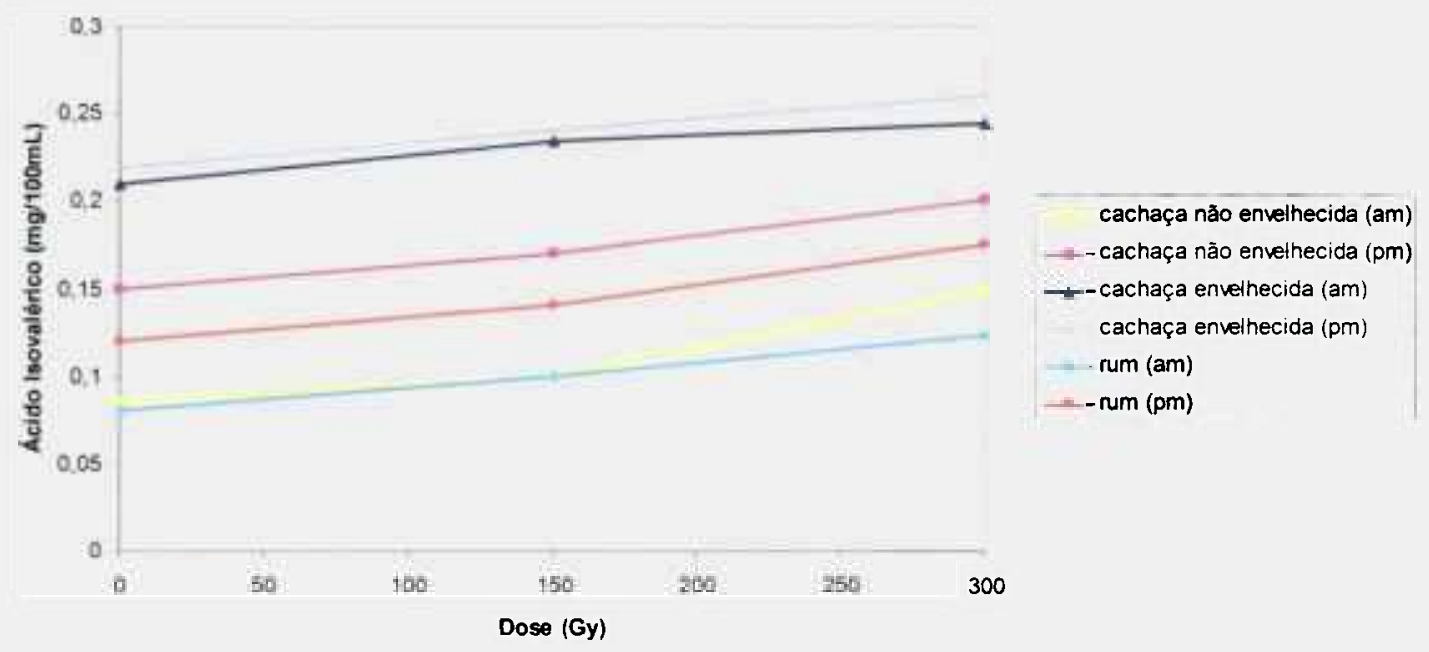

FIGURA 30 - Variação da concentração de ácido isovalérico em função da dose aplicada em bebidas destiladas.

De acordo com a TABELA 14, a concentração máxima de ácido isovalérico foi obtida com 150Gy para a amostra de cachaça envelhecida (pm) e; 300Gy para a cachaça não envelhecida (am), cachaça não envelhecida (pm), cachaça envelhecida (am), rum (am) e rum $(\mathrm{pm})$.

TABELA 14 - Médias* das concentrações de ácido isovalérico em $\mathrm{mg} / 100 \mathrm{~mL}$ álcool anidro encontradas nas amostras de bebidas analisadas.

\begin{tabular}{ccccccc}
\hline $\begin{array}{c}\text { Doses } \\
(\mathrm{Gy})\end{array}$ & $\begin{array}{c}\text { Cachaça não } \\
\text { envelhecida } \\
(\mathrm{am})\end{array}$ & $\begin{array}{c}\text { Cachaça não } \\
\text { envelhecida } \\
(\mathrm{pm})\end{array}$ & $\begin{array}{c}\text { Amostras } \\
\text { Cachaça } \\
\text { envelhecida } \\
(\mathrm{am})\end{array}$ & $\begin{array}{c}\text { Cachaça } \\
\text { envelhecida } \\
(\mathrm{pm})\end{array}$ & $\begin{array}{c}\text { Rum } \\
(\mathrm{am})\end{array}$ & $\begin{array}{c}\text { Rum } \\
(\mathrm{pm})\end{array}$ \\
\hline $\mathbf{0}$ & $0,09^{\mathrm{a}}$ & $0,15^{\mathrm{a}}$ & $0,21^{\mathrm{a}}$ & $0,22^{\mathrm{a}}$ & $0,08^{\mathrm{a}}$ & $0,12^{\mathrm{a}}$ \\
150 & $0,10^{\mathrm{a}}$ & $0,17^{\mathrm{a}, \mathrm{b}}$ & $0,23^{\mathrm{a}}$ & $0,24^{\mathrm{b}}$ & $0,10^{\mathrm{b}}$ & $0,14^{\mathrm{a}}$ \\
300 & $0,15^{\mathrm{b}}$ & $0,20^{\mathrm{b}}$ & $0,24^{\mathrm{b}}$ & $0,26^{\mathrm{b}}$ & $0,12^{\mathrm{c}}$ & $0,17^{\mathrm{b}}$ \\
\hline
\end{tabular}

* Médias com letras iguais na mesma coluna, não diferem entre si estatisticamente $(p \leqq 0,05)$. 


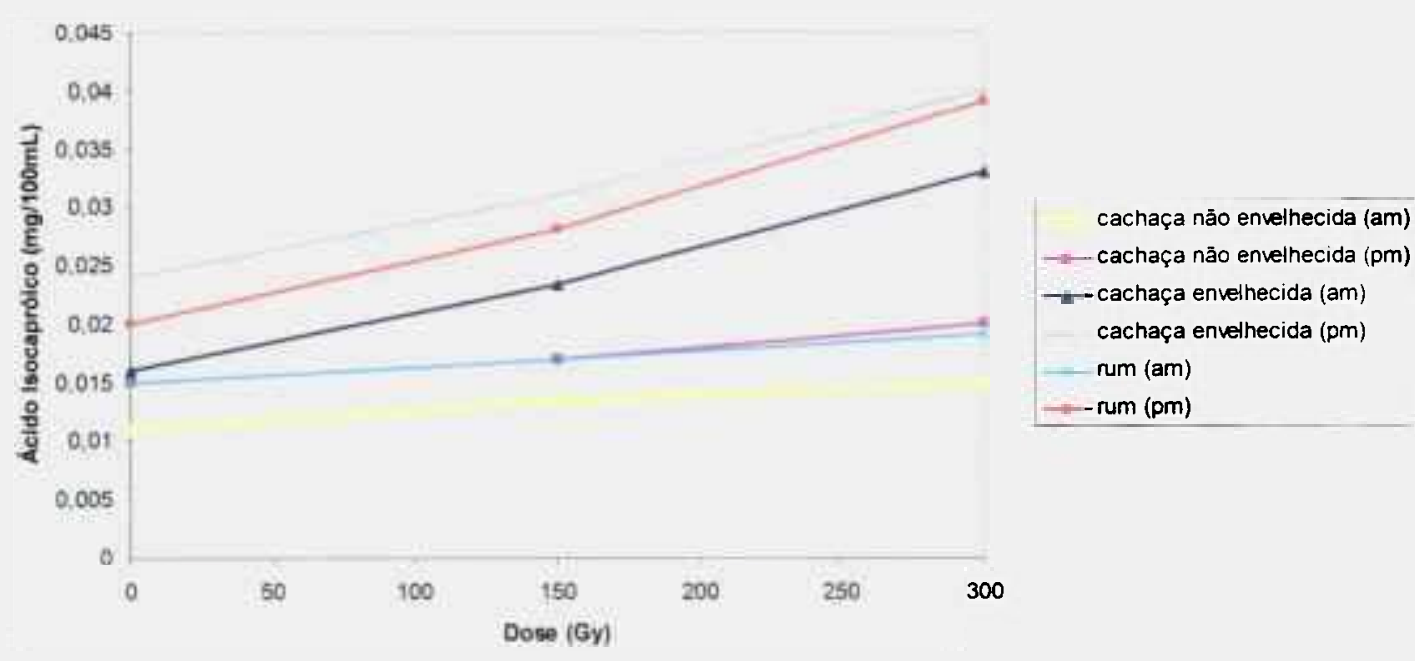

FIGURA 31 - Variação da concentração de ácido isocapróico em função da dose aplicada em bebidas destiladas.

Segundo os dados da TABELA 15, a concentração máxima de ácido isocapróico foi obtida com 150Gy para a amostra de cachaça não envelhecida (am) e rum (pm) e; 300Gy para a cachaça não envelhecida (pm), cachaça envelhecida (am), cachaça envelhecida (pm) e rum (am).

TABELA 15 - Médias* das concentrações de ácido isocapróico em $\mathrm{mg} / 100 \mathrm{~mL}$ álcool anidro encontradas nas amostras de bebidas analisadas.

\begin{tabular}{ccccccc}
\hline $\begin{array}{c}\text { Doses } \\
(\text { Gy })\end{array}$ & $\begin{array}{c}\text { Cachaça não } \\
\text { envelhecida } \\
(\mathrm{am})\end{array}$ & $\begin{array}{c}\text { Cachaça não } \\
\text { envelhecida } \\
(\mathrm{pm})\end{array}$ & $\begin{array}{c}\text { Amostras } \\
\text { Cachaça } \\
\text { envelhecida } \\
(\mathrm{am})\end{array}$ & $\begin{array}{c}\text { Cachaça } \\
\text { envelhecida } \\
(\mathrm{pm})\end{array}$ & $\begin{array}{c}\text { Rum } \\
(\mathrm{am})\end{array}$ & $\begin{array}{c}\text { Rum } \\
(\mathrm{pm})\end{array}$ \\
\hline 0 & $0,01^{\mathrm{a}}$ & $0,01^{\mathrm{a}}$ & $0,01^{\mathrm{a}}$ & $0,02^{\mathrm{a}}$ & $0,015^{\mathrm{a}}$ & $0,02^{\mathrm{a}}$ \\
150 & $0,013^{\mathrm{b}}$ & $0,01^{\mathrm{a}}$ & $0,02^{\mathrm{b}}$ & $0,03^{\mathrm{a}}$ & $0,02^{\mathrm{a} b}$ & $0,03^{\mathrm{b}}$ \\
300 & $0,015^{\mathrm{b}}$ & $0,02^{\mathrm{b}}$ & $0,03^{\mathrm{c}}$ & $0,04^{\mathrm{b}}$ & $0,02^{\mathrm{b}}$ & $0,04^{\mathrm{b}}$ \\
\hline
\end{tabular}

* Médias com letras iguais na mesma coluna, não diferem entre si estatisticamente $(p \leq 0,05)$. 


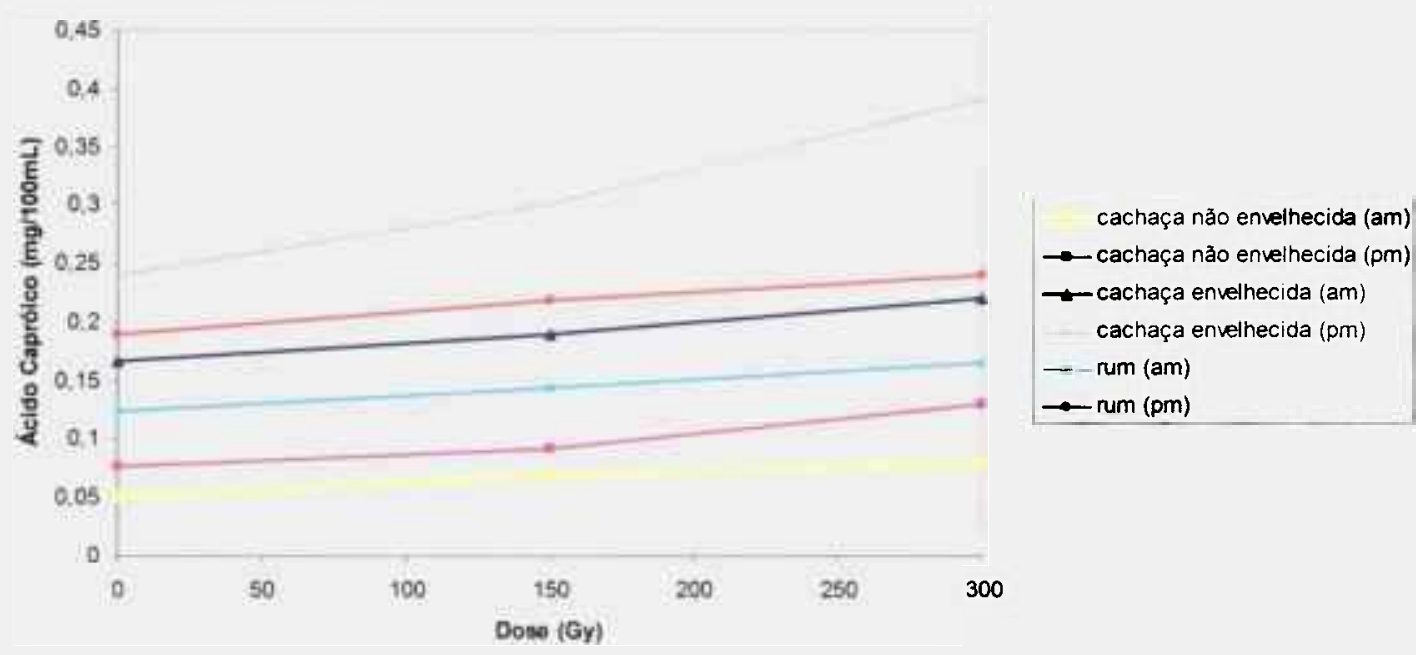

FIGURA 32 - Variação da concentração de ácido capróico em função da dose aplicada em bebidas destiladas.

De acordo com a TABELA 16, a concentração máxima de ácido capróico foi obtida com 150Gy para a amostra de cachaça não envelhecida (am) e; 300Gy para a cachaça não envelhecida (pm), cachaça envelhecida (am), cachaça envelhecida (pm), rum (am) e rum (pm).

TABELA 16 - Médias* das concentrações de ácido capróico em $\mathrm{mg} / 100 \mathrm{~mL}$ álcool anidro encontradas nas amostras de bebidas analisadas.

\begin{tabular}{ccccccc}
\hline $\begin{array}{c}\text { Doses } \\
\text { (Gy) }\end{array}$ & $\begin{array}{c}\text { Cachaça não } \\
\text { envelhecida } \\
(\text { am) }\end{array}$ & $\begin{array}{c}\text { Cachaça não } \\
\text { envelhecida } \\
(\mathrm{pm})\end{array}$ & $\begin{array}{c}\text { Amostras } \\
\text { Cachaça } \\
\text { envelhecida } \\
(\mathrm{am})\end{array}$ & $\begin{array}{c}\text { Cachaça } \\
\text { envelhecida } \\
(\mathrm{pm})\end{array}$ & $\begin{array}{c}\text { Rum } \\
(\mathrm{am})\end{array}$ & $\begin{array}{c}\text { Rum } \\
(\mathrm{pm})\end{array}$ \\
\hline $\mathbf{0}$ & $0,05^{\mathrm{a}}$ & $0,08^{\mathrm{a}}$ & $0,17^{\mathrm{a}}$ & $0,24^{\mathrm{a}}$ & $0,12^{\mathrm{a}}$ & $0,20^{\mathrm{a}}$ \\
150 & $0,07^{\mathrm{b}}$ & $0,09^{\mathrm{a}}$ & $0,19^{\mathrm{a}}$ & $0,30^{\mathrm{b}}$ & $0,14^{\mathrm{a}, \mathrm{b}}$ & $0,22^{\mathrm{a}, \mathrm{b}}$ \\
300 & $0,08^{\mathrm{b}}$ & $0,13^{\mathrm{b}}$ & $0,22^{\mathrm{b}}$ & $0,39^{\mathrm{c}}$ & $0,16^{\mathrm{b}}$ & $0,24^{\mathrm{b}}$ \\
\hline
\end{tabular}

${ }^{*}$ Médias com letras iguais na mesma coluna, não diferem entre si estatisticamente $(p \leq 0,05)$. 


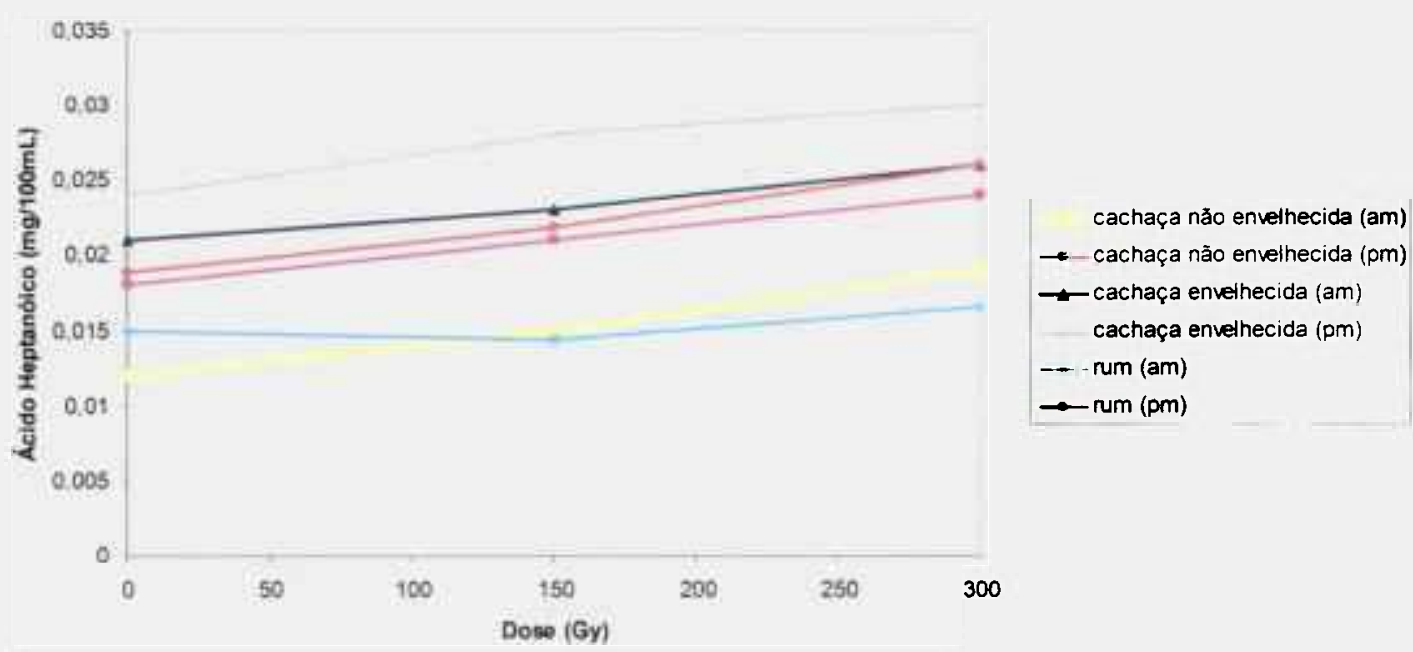

FIGURA 33 - Variação da concentração de ácido heptanóico em função da dose aplicada em bebidas destiladas.

Segundo a TABELA 17, a concentração máxima de ácido heptanóico foi obtida com 150Gy para a amostra de cachaça envelhecida (pm) e; 300Gy para a cachaça não envelhecida (am), cachaça não envelhecida ( $\mathrm{pm})$, cachaça envelhecida (am) e rum (pm). A concentração de ácido heptanóico não variou para a amostra de rum (am).

TABELA 17 - Médias* das concentrações de ácido heptanóico em $\mathrm{mg} / 100 \mathrm{~mL}$ álcool anidro encontradas nas amostras de bebidas analisadas.

\begin{tabular}{ccccccc}
\hline $\begin{array}{c}\text { Doses } \\
(\mathrm{Gy})\end{array}$ & $\begin{array}{c}\text { Cachaça não } \\
\text { envelhecida } \\
(\mathrm{am})\end{array}$ & $\begin{array}{c}\text { Cachaça não } \\
\text { envelhecida } \\
(\mathrm{pm})\end{array}$ & $\begin{array}{c}\text { Amostras } \\
\text { Cachaça } \\
\text { envelhecida } \\
(\mathrm{am})\end{array}$ & $\begin{array}{c}\text { Cachaça } \\
\text { envelhecida } \\
(\mathrm{pm})\end{array}$ & $\begin{array}{c}\text { Rum } \\
(\mathrm{am})\end{array}$ & $\begin{array}{c}\text { Rum } \\
(\mathrm{pm})\end{array}$ \\
\hline $\mathbf{0}$ & $0,01^{\mathrm{a}}$ & $0,02^{\mathrm{a}}$ & $0,02^{\mathrm{a}}$ & $0,02^{\mathrm{a}}$ & $0,015^{\mathrm{a}}$ & $0,02^{\mathrm{a}}$ \\
150 & $0,015^{\mathrm{b}}$ & $0,02^{\mathrm{a}, \mathrm{b}}$ & $0,02^{\mathrm{a}, \mathrm{b}}$ & $0,03^{\mathrm{b}}$ & $0,01^{\mathrm{a}}$ & $0,02^{\mathrm{a}, \mathrm{b}}$ \\
300 & $0,02^{\mathrm{c}}$ & $0,025^{\mathrm{b}}$ & $0,025^{\mathrm{b}}$ & $0,03^{\mathrm{b}}$ & $0,02^{\mathrm{a}}$ & $0,03^{\mathrm{b}}$ \\
\hline
\end{tabular}

"Médias com letras iguais na mesma coluna, não diferem entre si estatisticamente $(p \leqq 0,05)$. 


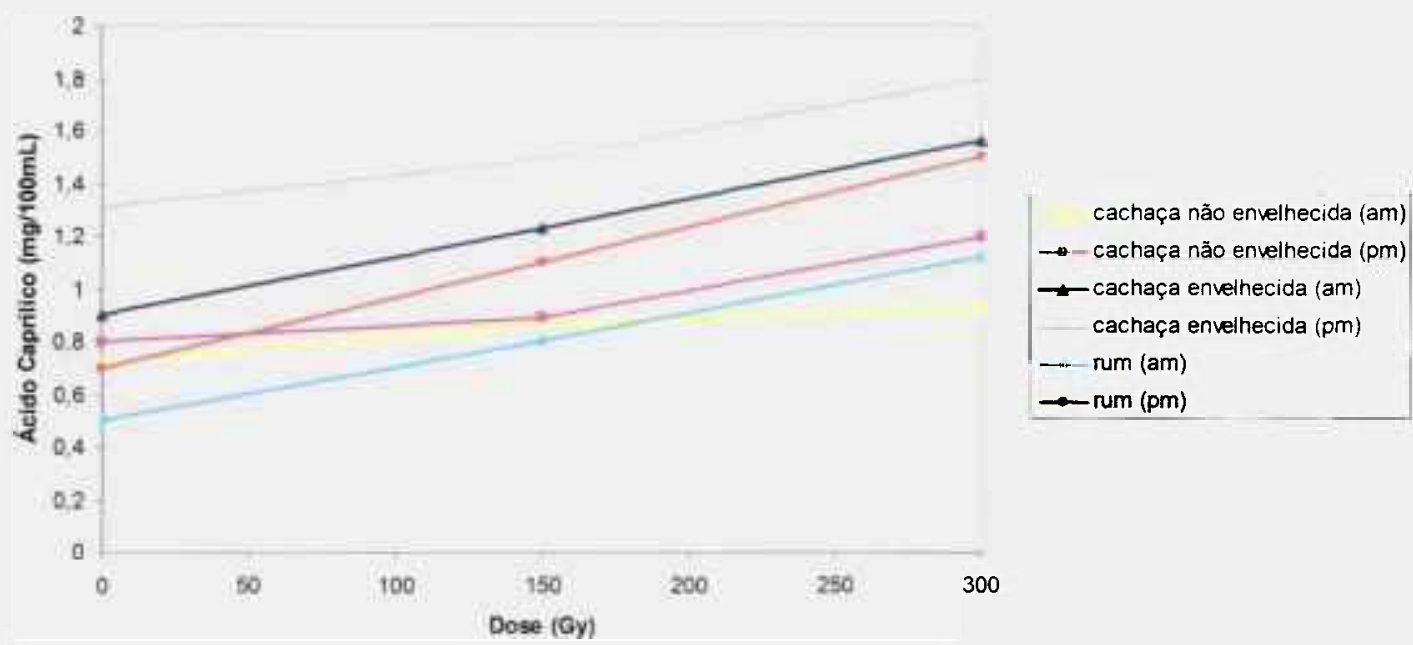

FIGURA 34 - Variação da concentração de ácido caprílico em função da dose aplicada em bebidas destiladas.

De acordo com a TABELA 18, a concentração máxima de ácido caprílico foi obtida com 300Gy para a cachaça não envelhecida (am), cachaça não envelhecida (pm), cachaça envelhecida (am), cachaça envelhecida (pm), rum (am) e rum (pm).

TABELA 18 - Médias* das concentrações de ácido caprílico em $\mathrm{mg} / 100 \mathrm{~mL}$ álcool anidro encontradas nas amostras de bebidas analisadas.

\begin{tabular}{ccccccc}
\hline $\begin{array}{c}\text { Doses } \\
(\text { Gy) }\end{array}$ & $\begin{array}{c}\text { Cachaça não } \\
\text { envelhecida } \\
(\mathrm{am})\end{array}$ & $\begin{array}{c}\text { Cachaça não } \\
\text { envelhecida } \\
(\mathrm{pm})\end{array}$ & $\begin{array}{c}\text { Amostras } \\
\text { Cacha } \\
\text { envelhecida } \\
(\text { am) }\end{array}$ & $\begin{array}{c}\text { Cachaça } \\
\text { envelhecida } \\
(\mathrm{pm})\end{array}$ & $\begin{array}{c}\text { Rum } \\
(\mathrm{am})\end{array}$ & $\begin{array}{c}\text { Rum } \\
(\mathrm{pm})\end{array}$ \\
\hline \hline 0 & $0,72^{\mathrm{a}}$ & $0,80^{\mathrm{a}}$ & $0,90^{\mathrm{a}}$ & $1,31^{\mathrm{a}}$ & $0,50^{\mathrm{a}}$ & $0,70^{\mathrm{a}}$ \\
150 & $0,87^{\mathrm{a}, \mathrm{b}}$ & $0,89^{\mathrm{a}}$ & $1,23^{\mathrm{b}}$ & $1,49^{\mathrm{a}, \mathrm{b}}$ & $0,80^{\mathrm{b}}$ & $1,10^{\mathrm{b}}$ \\
300 & $0,92^{\mathrm{b}}$ & $1,19^{\mathrm{b}}$ & $1,56^{\mathrm{c}}$ & $1,80^{\mathrm{b}}$ & $1,12^{\mathrm{c}}$ & $1,50^{\mathrm{c}}$ \\
\hline \hline
\end{tabular}

* Médias com letras iguais na mesma coluna, não diferem entre si estatisticamente $(p \leq 0,05)$. 


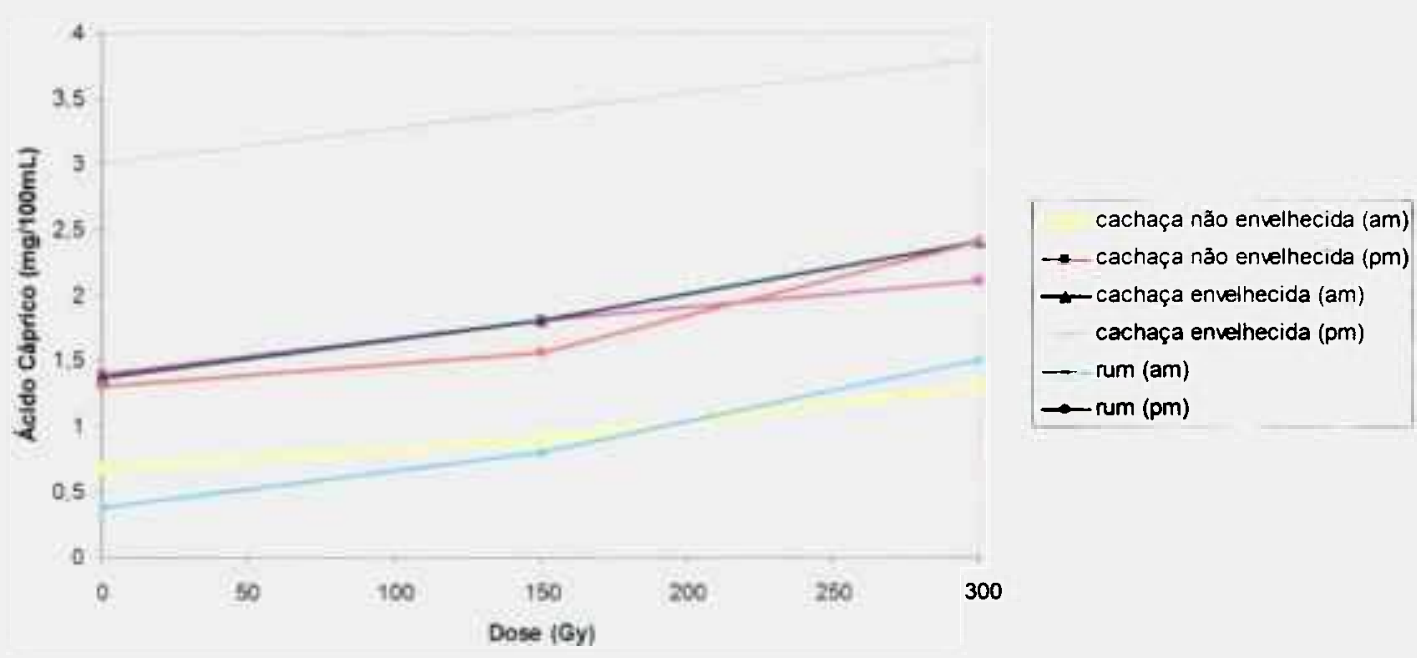

FIGURA 35 - Variação da concentração de ácido cáprico em função da dose aplicada em bebidas destiladas.

Segundo a TABELA 19, a concentração máxima de ácido cáprico foi obtida com 150Gy para a amostra de cachaça não envelhecida $(\mathrm{pm})$ e; 300Gy para a cachaça não envelhecida (am), cachaça envelhecida (am), cachaça envelhecida (pm), rum (am) e rum (pm).

TABELA 19 - Médias* das concentrações de ácido cáprico em $\mathrm{mg} / 100 \mathrm{~mL}$ álcool anidro encontradas nas amostras de bebidas analisadas.

\begin{tabular}{ccccccc}
\hline $\begin{array}{c}\text { Doses } \\
(\mathrm{Gy})\end{array}$ & $\begin{array}{c}\text { Cachaça não } \\
\text { envelhecida } \\
(\mathrm{am})\end{array}$ & $\begin{array}{c}\text { Cachaça não } \\
\text { envelhecida } \\
(\mathrm{pm})\end{array}$ & $\begin{array}{c}\text { Amostras } \\
\text { Cachaça } \\
\text { envelhecida } \\
(\mathrm{am})\end{array}$ & $\begin{array}{c}\text { Cachaça } \\
\text { envelhecida } \\
(\mathrm{pm})\end{array}$ & $\begin{array}{c}\text { Rum } \\
(\mathrm{am})\end{array}$ & $\begin{array}{c}\text { Rum } \\
(\mathrm{pm})\end{array}$ \\
\hline 0 & $0,68^{\mathrm{a}}$ & $1,40^{\mathrm{a}}$ & $1,37^{\mathrm{a}}$ & $3,00^{\mathrm{a}}$ & $0,38^{\mathrm{a}}$ & $1,30^{\mathrm{a}}$ \\
150 & $0,90^{\mathrm{b}}$ & $1,80^{\mathrm{b}}$ & $1,80^{\mathrm{b}}$ & $3,40^{\mathrm{a}, \mathrm{b}}$ & $0,80^{\mathrm{b}}$ & $1,56^{\mathrm{a}}$ \\
300 & $1,30^{\mathrm{c}}$ & $2,10^{\mathrm{b}}$ & $2,40^{\mathrm{c}}$ & $3,80^{\mathrm{b}}$ & $1,50^{\mathrm{c}}$ & $2,40^{\mathrm{b}}$ \\
\hline \hline
\end{tabular}

* Médias com letras iguais na mesma coluna, não diferem entre si estatisticamente $(p \leq 0,05)$. 


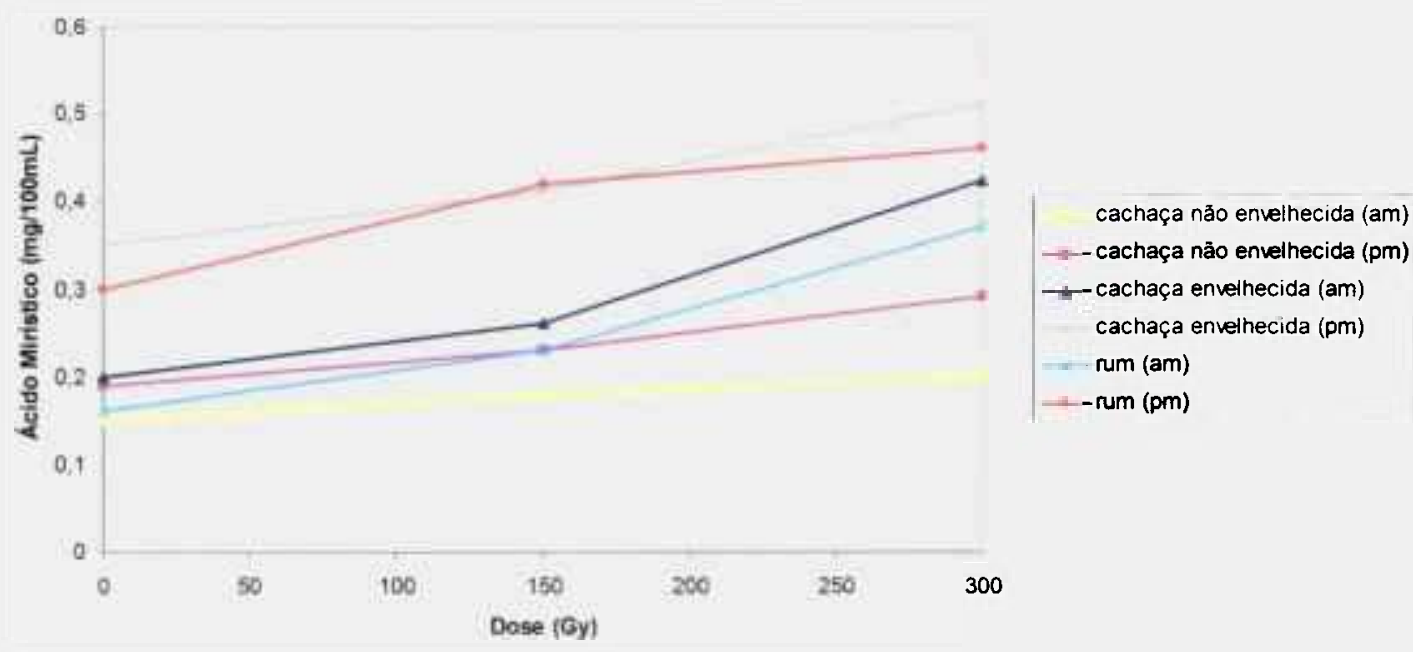

FIGURA 36 - Variação da concentração de ácido mirístico em função da dose aplicada em bebidas destiladas.

De acordo com a TABELA 20, a concentração máxima de ácido mirístico foi obtida com 150Gy para a amostra de rum (pm) e; 300Gy para a cachaça não envelhecida (am), cachaça não envelhecida ( $\mathrm{pm})$, cachaça envelhecida (am), cachaça envelhecida (pm) e rum (am).

TABELA 20 - Médias* das concentrações de ácido mirístico em $\mathrm{mg} / 100 \mathrm{~mL}$ álcool anidro encontradas nas amostras de bebidas analisadas.

\begin{tabular}{ccccccc}
\hline $\begin{array}{c}\text { Doses } \\
(\mathrm{Gy})\end{array}$ & $\begin{array}{c}\text { Cachaça não } \\
\text { envelhecida } \\
(\mathrm{am})\end{array}$ & $\begin{array}{c}\text { Cachaça não } \\
\text { envelhecida } \\
(\mathrm{pm})\end{array}$ & $\begin{array}{c}\text { Amostras } \\
\text { Cachaça } \\
\text { envelhecida } \\
(\mathrm{am})\end{array}$ & $\begin{array}{c}\text { Cachaça } \\
\text { envelhecida } \\
(\mathrm{pm})\end{array}$ & $\begin{array}{c}\text { Rum } \\
(\mathrm{am})\end{array}$ & $\begin{array}{c}\text { Rum } \\
(\mathrm{pm})\end{array}$ \\
\hline 0 & $0,15^{\mathrm{a}}$ & $0,19^{\mathrm{a}}$ & $0,20^{\mathrm{a}}$ & $0,35^{\mathrm{a}}$ & $0,16^{\mathrm{a}}$ & $0,30^{\mathrm{a}}$ \\
150 & $0,18^{\mathrm{a}} \mathrm{b}$ & $0,23^{\mathrm{b}}$ & $0,26^{\mathrm{b}}$ & $0,41^{\mathrm{a}}$ & $0,23^{\mathrm{b}}$ & $0,42^{\mathrm{b}}$ \\
300 & $0,20^{\mathrm{b}}$ & $0,29^{\mathrm{c}}$ & $0,42^{\mathrm{c}}$ & $0,51^{\mathrm{b}}$ & $0,37^{\mathrm{c}}$ & $0,46^{\mathrm{b}}$ \\
\hline \hline
\end{tabular}

* Médias com letras iguais na mesma coluna, não diferem entre si estatisticamente $(p \leq 0,05)$. 


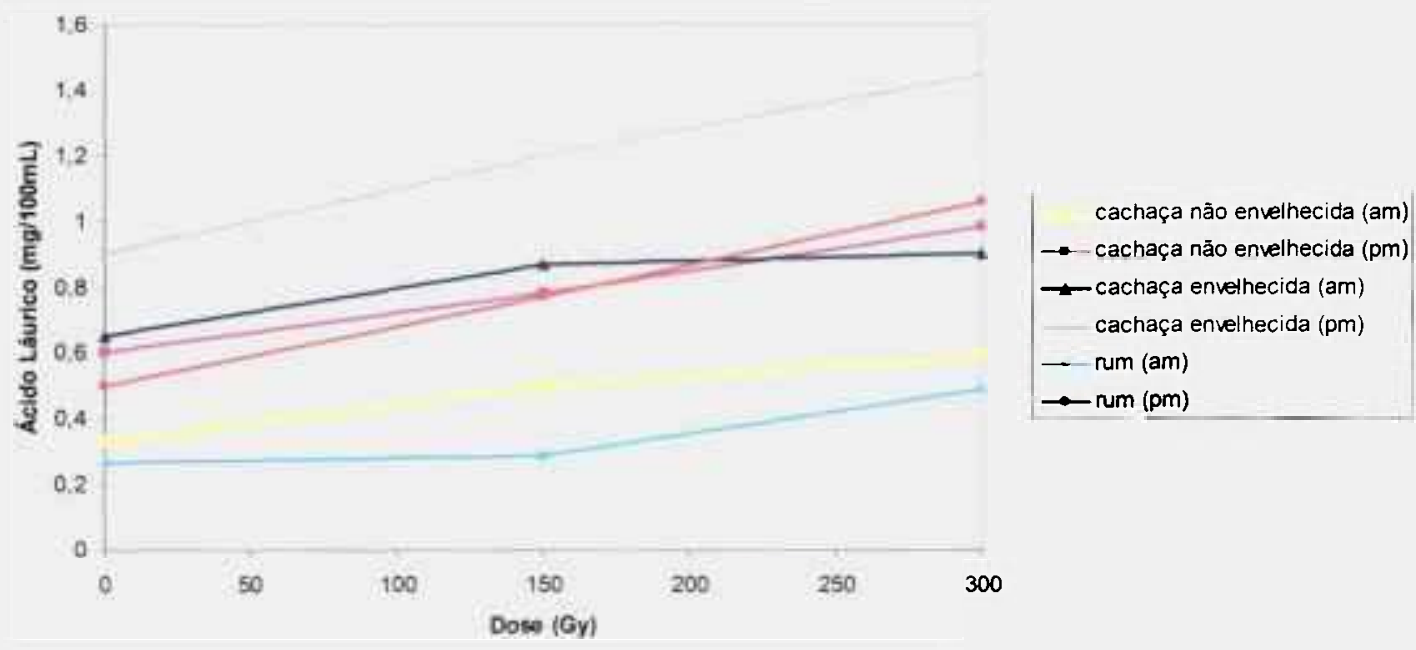

FIGURA 37 - Variação da concentração de ácido láurico em função da dose aplicada em bebidas destiladas.

Segundo a TABELA 21, a concentração máxima de ácido láurico foi obtida com 150Gy para a amostra de cachaça não envelhecida (am) e cachaça envelhecida (pm) e; 300Gy para a cachaça não envelhecida (pm), cachaça envelhecida (am), rum (am) e rum (pm).

TABELA 21 - Médias* das concentrações de ácido láurico em $\mathrm{mg} / 100 \mathrm{~mL}$ álcool anidro encontradas nas amostras de bebidas analisadas.

\begin{tabular}{ccccccc}
\hline $\begin{array}{c}\text { Doses } \\
(\mathrm{Gy})\end{array}$ & $\begin{array}{c}\text { Cachaça não } \\
\text { envelhecida } \\
(\mathrm{am})\end{array}$ & $\begin{array}{c}\text { Cachaça não } \\
\text { envelhecida } \\
(\mathrm{pm})\end{array}$ & $\begin{array}{c}\text { Amostras } \\
\text { Cachaça } \\
\text { envelhecida } \\
(\mathrm{am})\end{array}$ & $\begin{array}{c}\text { Cachaça } \\
\text { envelhecida } \\
(\mathrm{pm})\end{array}$ & $\begin{array}{c}\text { Rum } \\
(\mathrm{am})\end{array}$ & $\begin{array}{c}\text { Rum } \\
(\mathrm{pm})\end{array}$ \\
\cline { 2 - 6 } \cline { 5 - 7 } & $0,33^{\mathrm{a}}$ & $0,60^{\mathrm{a}}$ & $0,65^{\mathrm{a}}$ & $0,90^{\mathrm{a}}$ & $0,26^{\mathrm{a}}$ & $0,50^{\mathrm{a}}$ \\
150 & $0,50^{\mathrm{b}}$ & $0,78^{\mathrm{b}}$ & $0,87^{\mathrm{b}}$ & $1,20^{\mathrm{b}}$ & $0,29^{\mathrm{a}}$ & $0,77^{\mathrm{b}}$ \\
300 & $0,59^{\mathrm{b}}$ & $0,98^{\mathrm{c}}$ & $0,90^{\mathrm{c}}$ & $1,45^{\mathrm{b}}$ & $0,49^{\mathrm{b}}$ & $1,06^{\mathrm{c}}$ \\
\hline
\end{tabular}

* Médias com letras iguais na mesma coluna, não diferem entre si estatisticamente $(p \leq 0,05)$. 


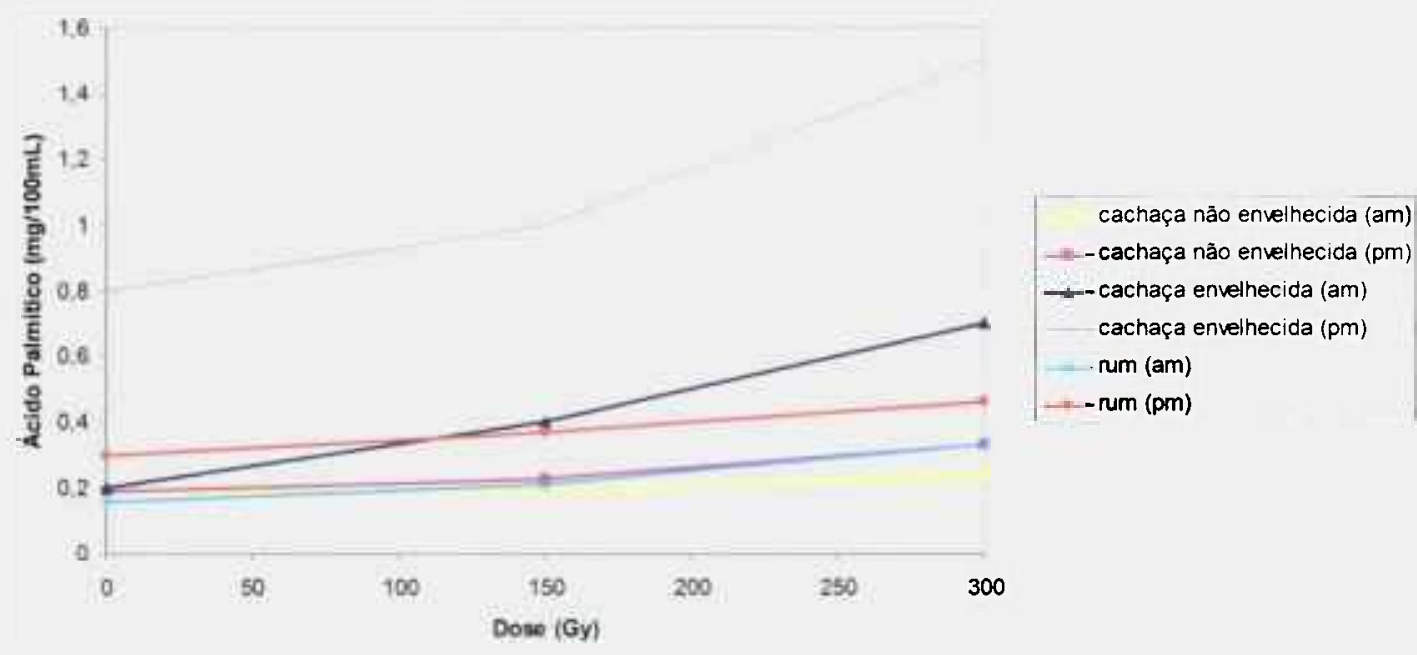

FIGURA 38 - Variação da concentração de ácido palmítico em função da dose aplicada em bebidas destiladas.

De acordo com a TABELA 22, a concentração máxima de ácido palmítico foi obtida com 300Gy para a amostra de cachaça não envelhecida (am), cachaça não envelhecida (pm), cachaça envelhecida (am), cachaça envelhecida (pm), rum (am) e rum (pm).

TABELA 22 - Médias* das concentrações de ácido palmítico em $\mathrm{mg} / 100 \mathrm{~mL}$ álcool anidro encontradas nas amostras de bebidas analisadas.

\begin{tabular}{ccccccc}
\hline $\begin{array}{c}\text { Doses } \\
(\mathrm{Gy})\end{array}$ & $\begin{array}{c}\text { Cachaça não } \\
\text { envelhecida } \\
(\mathrm{am})\end{array}$ & $\begin{array}{c}\text { Cachaça não } \\
\text { envelhecida } \\
(\mathrm{pm})\end{array}$ & $\begin{array}{c}\text { Amostras } \\
\text { Cachaça } \\
\text { envelhecida } \\
(\mathrm{am})\end{array}$ & $\begin{array}{c}\text { Cachaça } \\
\text { envelhecida } \\
(\mathrm{pm})\end{array}$ & $\begin{array}{c}\text { Rum } \\
(\mathrm{am})\end{array}$ & $\begin{array}{c}\text { Rum } \\
(\mathrm{pm})\end{array}$ \\
\hline 0 & $0,19^{\mathrm{a}}$ & $0,19^{\mathrm{a}}$ & $0,20^{\mathrm{a}}$ & $0,80^{\mathrm{a}}$ & $0,16^{\mathrm{a}}$ & $0,30^{\mathrm{a}}$ \\
150 & $0,19^{\mathrm{a}}$ & $0,23^{\mathrm{b}}$ & $0,40^{\mathrm{b}}$ & $1,00^{\mathrm{b}}$ & $0,21^{\mathrm{b}}$ & $0,37^{\mathrm{b}}$ \\
300 & $0,24^{\mathrm{b}}$ & $0,33^{\mathrm{c}}$ & $0,70^{\mathrm{c}}$ & $1,50^{\mathrm{c}}$ & $0,33^{\mathrm{c}}$ & $0,46^{\mathrm{c}}$ \\
\hline
\end{tabular}

* Médias com letras iguais na mesma coluna, não diferem entre si estatisticamente $(p \leq 0,05)$.

Como descrito por NASCIMENTO et al. (1998) e observado neste trabalho, o conteúdo de ácidos totais nas amostras de cachaça foi também maior do que os observados em outras bebidas destiladas, como, uísque e rum. Isto se deve ao alto teor de ácido acético encontrado na cachaça. Os resultados encontrados para os ácidos estavam dentro do intervalo 
de concentrações encontrado por NASCIMENTO et al. (1998). Observou-se na TABELA 23 que todas as amostras de cachaça estavam em conformidade com a legislação brasileira (BRASIL, 2005), onde limite máximo de acidez volátil, expresso em ácido acético é $150 \mathrm{mg} / 100 \mathrm{~mL}$.

MORAES (2004) também encontrou maiores concentrações de ácido acético nas amostras de cachaça, quando estudados cachaças e runs comerciais e de laboratório envelhecidas e não envelhecidas.

TABELA 23 - Soma das concentrações dos ácidos em mg/100mL álcool anidro encontrados nas amostras de bebidas analisadas.

\begin{tabular}{cccc}
\hline \multirow{2}{*}{ Amostras } & \multicolumn{3}{c}{ Soma das concentrações dos Ácidos } \\
\cline { 2 - 4 } & $0 \mathrm{~Gy}$ & $150 \mathrm{~Gy}$ & $300 \mathrm{~Gy}$ \\
\hline Cachaça não envelhecida (am) & 75,51 & $\mathbf{8 7 , 1 6}$ & 94,86 \\
Cachaça não envelhecida (pm) & 78,77 & 86,61 & 97,62 \\
Cachaça envelhecida (am) & 105,14 & 126,49 & 140,05 \\
Cachaça envelhecida (pm) & 118,38 & 128,70 & 148,57 \\
Rum (am) & 61,90 & 76,77 & 92,34 \\
Rum (pm) & 69,72 & 75,85 & 94,63 \\
\hline
\end{tabular}


Os aldeídos identificados e quantificados nas amostras de cachaça e rum irradiados e não irradiados foram: formaldeído, 5 hidroximetilfurfural, acetaldeído, acroleína, furfural, propionaldeído, butiraldeído, benzaldeído, isovaleraldeído e valeraldeído.

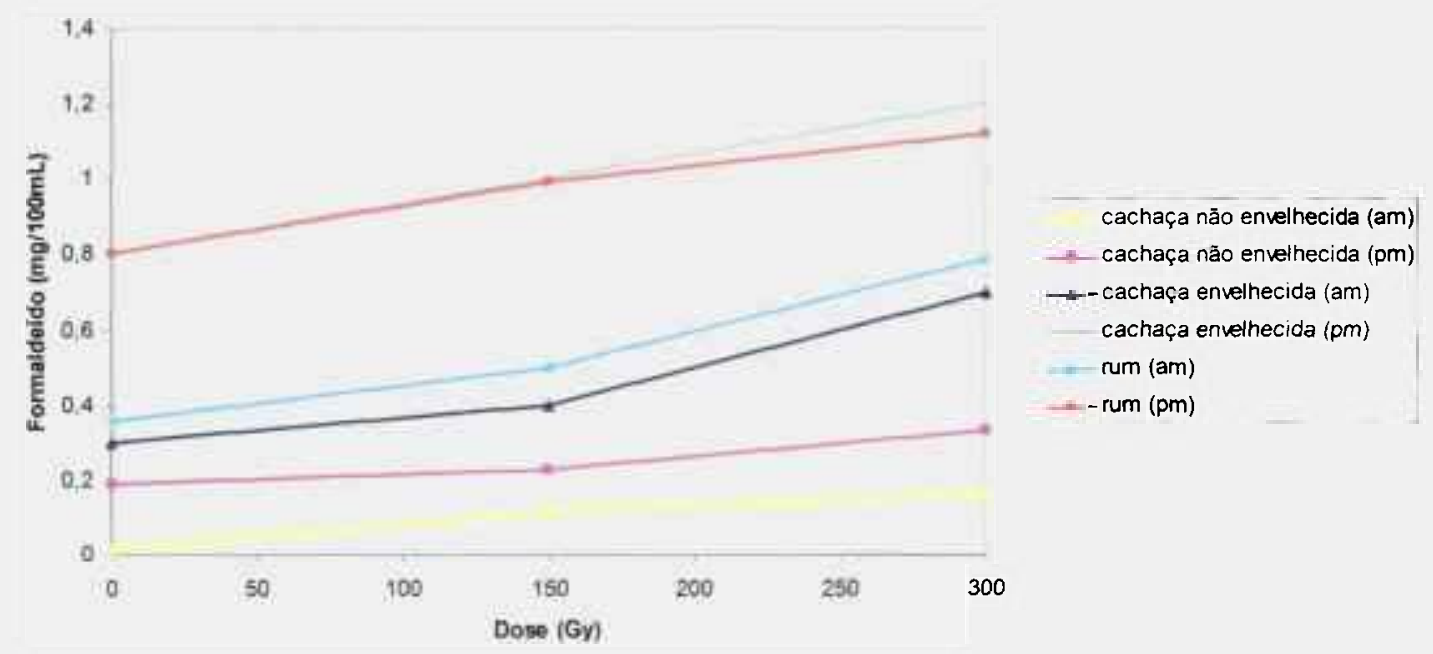

FIGURA 39 - Variação da concentração de formaldeído em função da dose aplicada em bebidas destiladas.

Segundo a TABELA 24, a concentração máxima de formaldeído foi obtida com 150Gy para a amostra de cachaça envelhecida $(\mathrm{pm})$ e rum $(\mathrm{pm})$ e; 300Gy para a cachaça não envelhecida (am), cachaça não envelhecida (pm), cachaça envelhecida (am) e rum (am).

TABELA 24 - Médias* das concentrações de formaldeído em $\mathrm{mg} / 100 \mathrm{~mL}$ álcool anidro encontradas nas amostras de bebidas analisadas.

\begin{tabular}{ccccccc}
$\begin{array}{c}\text { Doses } \\
(\mathrm{Gy})\end{array}$ & $\begin{array}{c}\text { Cachaça não } \\
\text { envelhecida } \\
(\mathrm{am})\end{array}$ & $\begin{array}{c}\text { Cachaça não } \\
\text { envelhecida } \\
(\mathrm{pm})\end{array}$ & $\begin{array}{c}\text { Amostras } \\
\text { Cachaça } \\
\text { envelhecida } \\
(\mathrm{am})\end{array}$ & $\begin{array}{c}\text { Cachaça } \\
\text { envelhecida } \\
(\mathrm{pm})\end{array}$ & $\begin{array}{c}\text { Rum } \\
(\mathrm{am})\end{array}$ & $\begin{array}{c}\text { Rum } \\
(\mathrm{pm})\end{array}$ \\
\hline \hline 0 & $0,01^{\mathrm{a}}$ & $0,19^{\mathrm{a}}$ & $0,30^{\mathrm{a}}$ & $0,80^{\mathrm{a}}$ & $0,35^{\mathrm{a}}$ & $0,80^{\mathrm{a}}$ \\
150 & $0,12^{\mathrm{b}}$ & $0,23^{\mathrm{a}}$ & $0,40^{\mathrm{b}}$ & $1,00^{\mathrm{b}}$ & $0,50^{\mathrm{b}}$ & $0,99^{\mathrm{b}}$ \\
300 & $0,16^{\mathrm{c}}$ & $0,33^{\mathrm{b}}$ & $0,70^{\mathrm{c}}$ & $1,20^{\mathrm{b}}$ & $0,79^{\mathrm{c}}$ & $1,12^{\mathrm{b}}$ \\
\hline
\end{tabular}

* Médias com letras iguais na mesma coluna, não diferem entre si estatisticamente $(p \leq 0,05)$. 


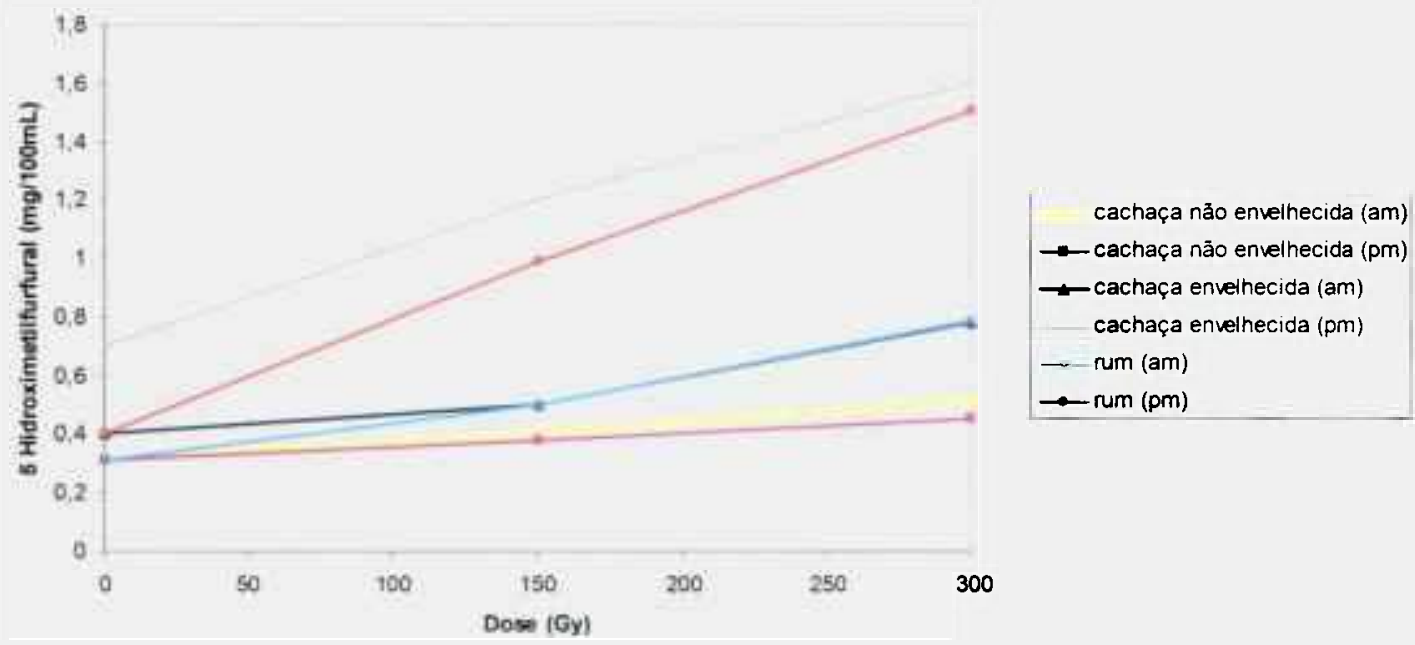

FIGURA 40 - Variação da concentração de 5 hidroximetilfurfural em função da dose aplicada em bebidas destiladas.

De acordo com a TABELA 25, a concentração máxima de 5 hidroximetilfurfural foi obtida com 150Gy para a amostra de cachaça não envelhecida (pm) e; 300Gy para a cachaça não envelhecida (am), cachaça envelhecida (am), cachaça envelhecida (pm), rum (am) e rum $(\mathrm{pm})$.

TABELA 25 - Médias* das concentrações de 5 hidroximetilfurfural em $\mathrm{mg} / 100 \mathrm{~mL}$ álcool anidro encontradas nas amostras de bebidas analisadas.

\begin{tabular}{ccccccc}
\hline \hline $\begin{array}{c}\text { Doses } \\
(\mathrm{Gy})\end{array}$ & $\begin{array}{c}\text { Cachaça não } \\
\text { envelhecida } \\
(\mathrm{am})\end{array}$ & $\begin{array}{c}\text { Cachaça não } \\
\text { envelhecida } \\
(\mathrm{pm})\end{array}$ & $\begin{array}{c}\text { Amostras } \\
\text { Cachaça } \\
\text { envelhecida } \\
(\text { am })\end{array}$ & $\begin{array}{c}\text { Cachaça } \\
\text { envelhecida } \\
(\mathrm{pm})\end{array}$ & $\begin{array}{c}\text { Rum } \\
(\mathrm{am})\end{array}$ & $\begin{array}{c}\text { Rum } \\
(\mathrm{pm})\end{array}$ \\
\hline \hline 0 & $0,32^{\mathrm{a}}$ & $0,31^{\mathrm{a}}$ & $0,40^{\mathrm{a}}$ & $0,70^{\mathrm{a}}$ & $0,31^{\mathrm{a}}$ & $0,40^{\mathrm{a}}$ \\
150 & $0,40^{\mathrm{b}}$ & $0,38^{\mathrm{b}}$ & $0,50^{\mathrm{b}}$ & $1,20^{\mathrm{b}}$ & $0,50^{\mathrm{b}}$ & $0,99^{\mathrm{b}}$ \\
300 & $0,51^{\mathrm{c}}$ & $0,45^{\mathrm{b}}$ & $0,78^{\mathrm{c}}$ & $1,60^{\mathrm{c}}$ & $0,79^{\mathrm{c}}$ & $1,50^{\mathrm{c}}$ \\
\hline
\end{tabular}

${ }^{*}$ Médias com letras iguais na mesma coluna, não diferem entre si estatisticamente $(p \leqq 0,05)$. 


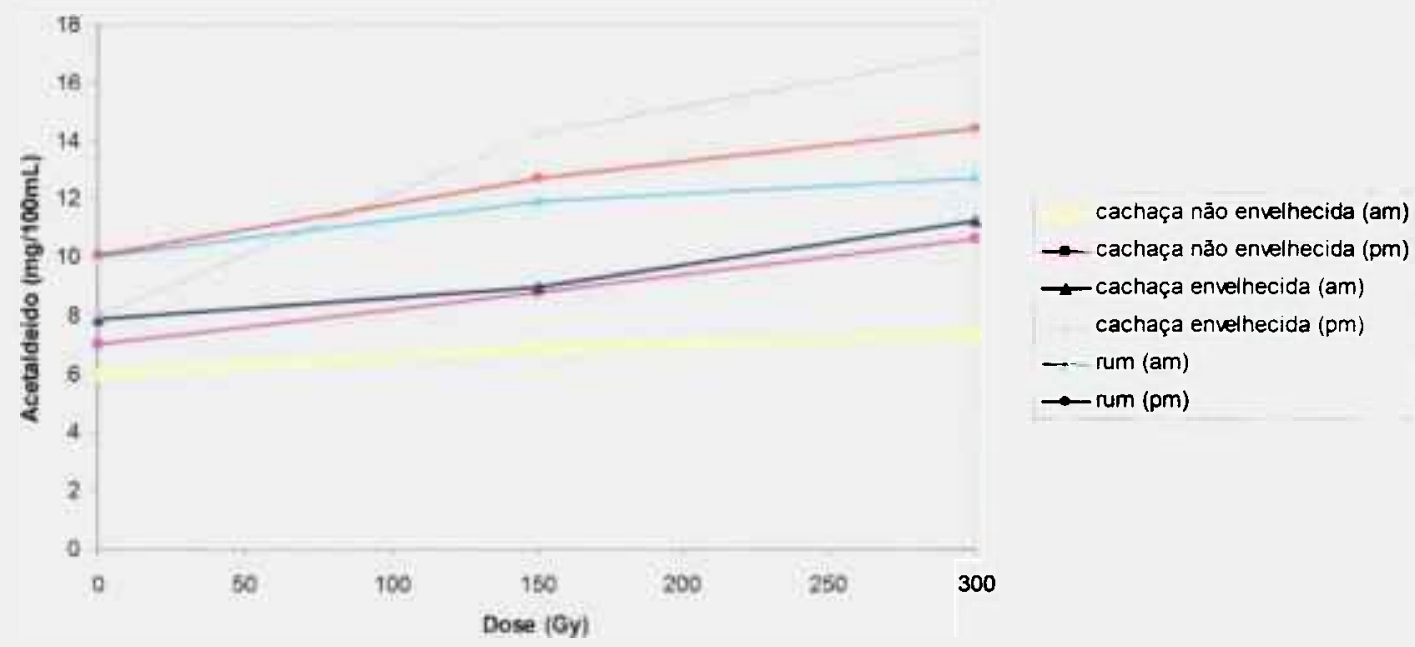

FIGURA 41 - Variação da concentração de acetaldeído em função da dose aplicada em bebidas destiladas.

Segundo a TABELA 26, a concentração máxima de acetaldeído foi obtida com 150Gy para a amostra de cachaça não envelhecida $(\mathrm{pm})$, cachaça envelhecida $(\mathrm{pm})$ e rum $(\mathrm{pm})$ e; 300Gy para a cachaça não envelhecida (am), cachaça envelhecida (am) e rum (am).

TABELA 26 - Médias* das concentrações de acetaldeído em $\mathrm{mg} / 100 \mathrm{~mL}$ álcool anidro encontradas nas amostras de bebidas analisadas.

\begin{tabular}{ccccccc}
\hline \hline $\begin{array}{c}\text { Doses } \\
(\mathrm{Gy})\end{array}$ & $\begin{array}{c}\text { Cachaça não } \\
\text { envelhecida } \\
(\mathrm{am})\end{array}$ & $\begin{array}{c}\text { Cachaça não } \\
\text { envelhecida } \\
(\mathrm{pm})\end{array}$ & $\begin{array}{c}\text { Amostras } \\
\text { Cachaça } \\
\text { envelhecida } \\
(\mathrm{am})\end{array}$ & $\begin{array}{c}\text { Cachaça } \\
\text { envelhecida } \\
(\mathrm{pm})\end{array}$ & $\begin{array}{c}\text { Rum } \\
(\mathrm{am})\end{array}$ & $\begin{array}{c}\text { Rum } \\
(\mathrm{pm})\end{array}$ \\
\hline $\mathbf{0}$ & $6,00^{\mathrm{a}}$ & $7,00^{\mathrm{a}}$ & $7,90^{\mathrm{a}}$ & $8,00^{\mathrm{a}}$ & $10,00^{\mathrm{a}}$ & $10,09^{\mathrm{a}}$ \\
150 & $6,90^{\mathrm{a}, \mathrm{b}}$ & $8,80^{\mathrm{b}}$ & $9,00^{\mathrm{a}}$ & $14,20^{\mathrm{b}}$ & $11,90^{\mathrm{a}} \mathrm{b}$ & $12,70^{\mathrm{b}}$ \\
300 & $7,34^{\mathrm{b}}$ & $10,60^{\mathrm{b}}$ & $11,20^{\mathrm{b}}$ & $17,00^{\mathrm{b}}$ & $12,70^{\mathrm{b}}$ & $14,40^{\mathrm{b}}$ \\
\hline
\end{tabular}

- Médias com letras iguais na mesma coluna, não diferem entre si estatisticamente $(p \leq 0,05)$. 


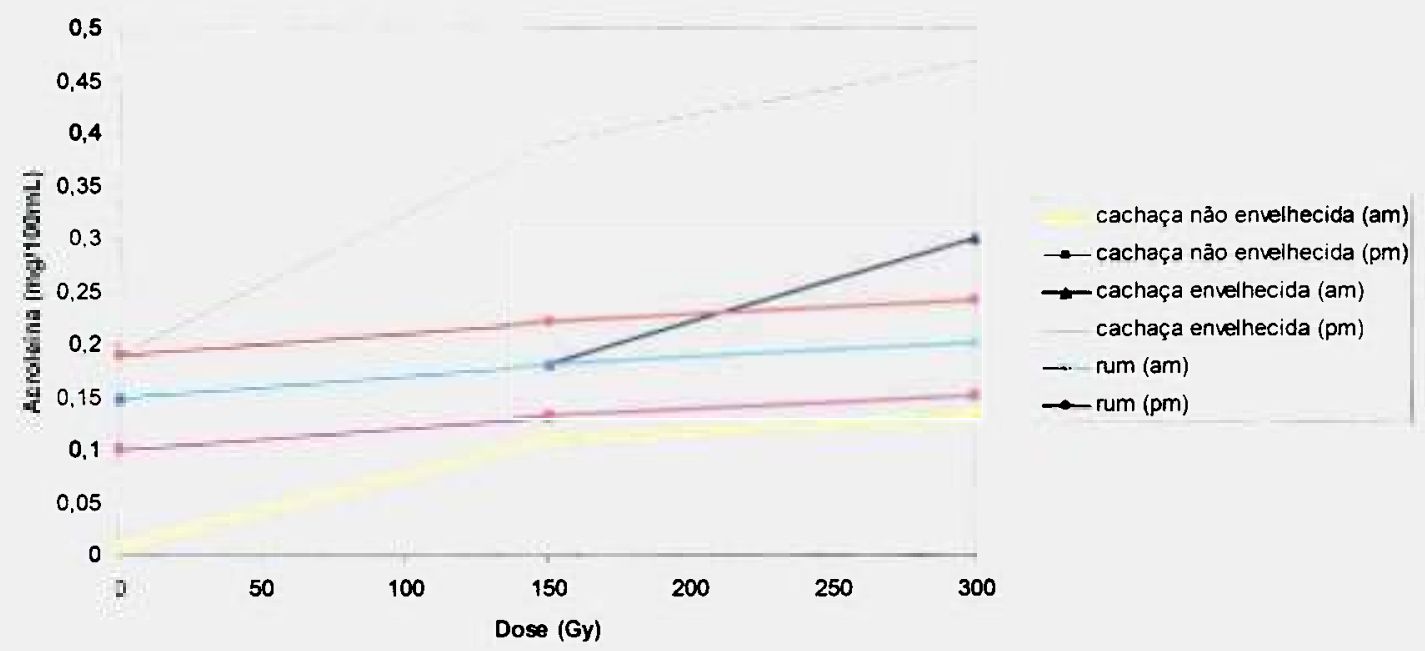

FIGURA 42 - Variação da concentração acroleína em função da dose aplicada em bebidas destiladas.

Segundo a legislação brasileira (BRASIL, 2005), o limite máximo de acroleína na cachaça é de $5 \mathrm{mg} / 100 \mathrm{~mL}$ de álcool anidro. Os resultados apresentados na FIGURA 42 mostram que todas as amostras estavam dentro do limite permitido.

De acordo com a TABELA 27, a concentração máxima de acroleína foi obtida com 150Gy para a amostra de cachaça não envelhecida (am), cachaça não envelhecida (pm), cachaça envelhecida (pm) e; 300Gy para a cachaça envelhecida (am), rum (am) e rum (pm).

TABELA 27 - Médias* das concentrações de acroleína em $\mathrm{mg} / 100 \mathrm{~mL}$ álcool anidro encontradas nas amostras de bebidas analisadas.

\begin{tabular}{ccccccc}
\hline $\begin{array}{c}\text { Doses } \\
(\mathrm{Gy})\end{array}$ & $\begin{array}{c}\text { Cachaça não } \\
\text { envelhecida } \\
(\mathrm{am})\end{array}$ & $\begin{array}{c}\text { Cachaça não } \\
\text { envelhecida } \\
(\mathrm{pm})\end{array}$ & $\begin{array}{c}\text { Amostras } \\
\text { Cachaça } \\
\text { envelhecida } \\
(\mathrm{am})\end{array}$ & $\begin{array}{c}\text { Cachaça } \\
\text { envelhecida } \\
(\mathrm{pm})\end{array}$ & $\begin{array}{c}\text { Rum } \\
(\mathrm{am})\end{array}$ & $\begin{array}{c}\text { Rum } \\
(\mathrm{pm})\end{array}$ \\
\hline \hline 0 & $0,01^{\mathrm{a}}$ & $0,10^{\mathrm{a}}$ & $0,15^{\mathrm{a}}$ & $0,19^{\mathrm{a}}$ & $0,15^{\mathrm{a}}$ & $0,19^{\mathrm{a}}$ \\
150 & $0,11^{\mathrm{b}}$ & $0,13^{\mathrm{b}}$ & $0,18^{\mathrm{a}}$ & $0,39^{\mathrm{b}}$ & $0,18^{\mathrm{a}, \mathrm{b}}$ & $0,22^{\mathrm{a}, \mathrm{b}}$ \\
300 & $0,13^{\mathrm{b}}$ & $0,15^{\mathrm{b}}$ & $0,30^{\mathrm{b}}$ & $0,47^{\mathrm{b}}$ & $0,20^{\mathrm{b}}$ & $0,24^{\mathrm{b}}$ \\
\hline \hline
\end{tabular}

* Médias com letras iguais na mesma coluna, não diferem entre si estatisticamente $(p \leqq 0,05)$. 


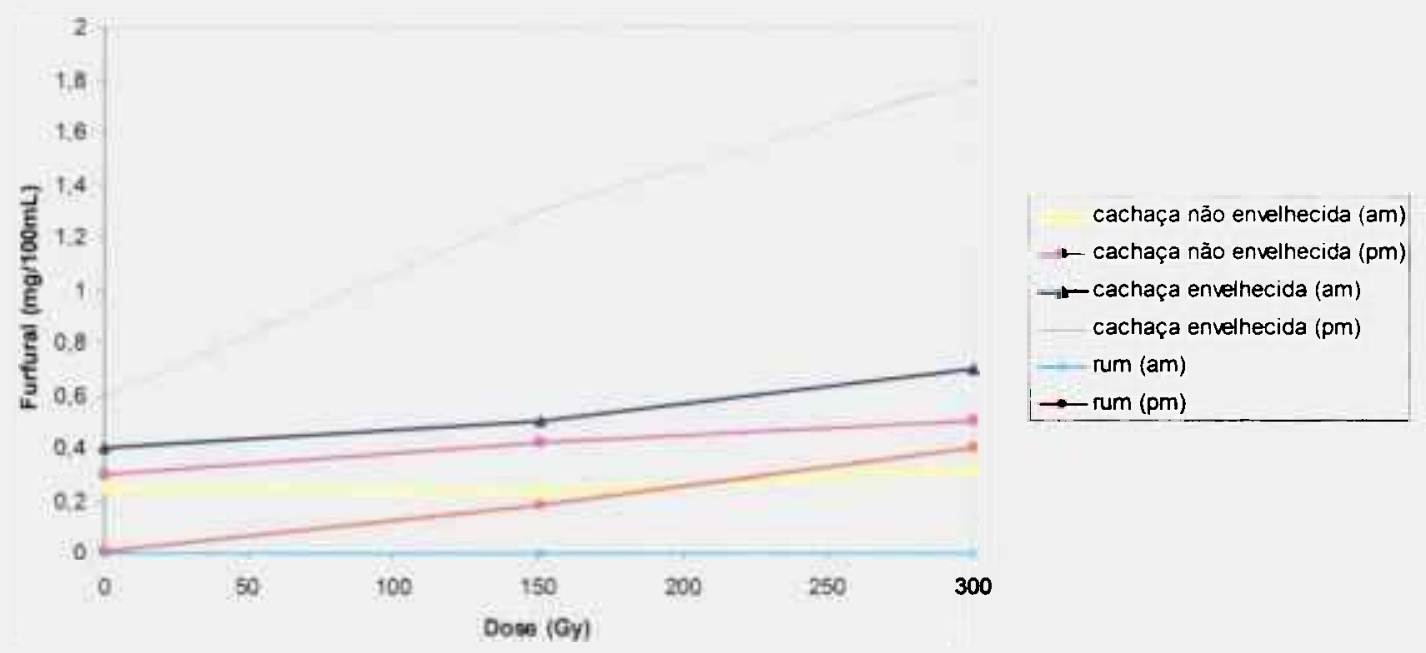

FIGURA 43 - Variação da concentração furfural em função da dose aplicada em bebidas destiladas.

Segundo a TABELA 28, a concentração máxima de furfural foi obtida com 150Gy para a amostra de cachaça não envelhecida (pm) e; 300Gy para a cachaça não envelhecida (am), cachaça envelhecida (am), cachaça envelhecida (pm) e rum (pm).

TABELA 28 - Médias* das concentrações de furfural em $\mathrm{mg} / 100 \mathrm{~mL}$ álcool anidro encontradas nas amostras de bebidas analisadas.

\begin{tabular}{ccccccc}
\hline $\begin{array}{c}\text { Doses } \\
(\mathrm{Gy})\end{array}$ & $\begin{array}{c}\text { Cachaça não } \\
\text { envelhecida } \\
(\mathrm{am})\end{array}$ & $\begin{array}{c}\text { Cachaça não } \\
\text { envelhecida } \\
(\mathrm{pm})\end{array}$ & $\begin{array}{c}\text { Cachaça } \\
\text { envelhecida } \\
(\mathrm{am})\end{array}$ & $\begin{array}{c}\text { Cachaça } \\
\text { envelhecida } \\
(\mathrm{pm})\end{array}$ & $\begin{array}{c}\text { Rum } \\
(\mathrm{am})\end{array}$ & $\begin{array}{c}\text { Rum } \\
(\mathrm{pm})\end{array}$ \\
\hline 0 & $0,25^{\mathrm{a}}$ & $0,30^{\mathrm{a}}$ & $0,40^{\mathrm{a}}$ & $0,60^{\mathrm{a}}$ & $\mathrm{ND}^{* *}$ & $0,01^{\mathrm{a}}$ \\
150 & $0,23^{\mathrm{a}}$ & $0,42^{\mathrm{b}}$ & $0,50^{\mathrm{b}}$ & $1,30^{\mathrm{b}}$ & $\mathrm{ND}^{* *}$ & $0,18^{\mathrm{b}}$ \\
300 & $0,32^{\mathrm{b}}$ & $0,50^{\mathrm{b}}$ & $0,70^{\mathrm{c}}$ & $1,80^{\mathrm{c}}$ & $\mathrm{ND}^{* *}$ & $0,40^{\mathrm{c}}$ \\
\hline \hline
\end{tabular}

* Médias com letras iguais na mesma coluna, não diferem entre si estatisticamente $(p \leq 0,05)$.

** $\mathrm{ND}=$ não detectado. 


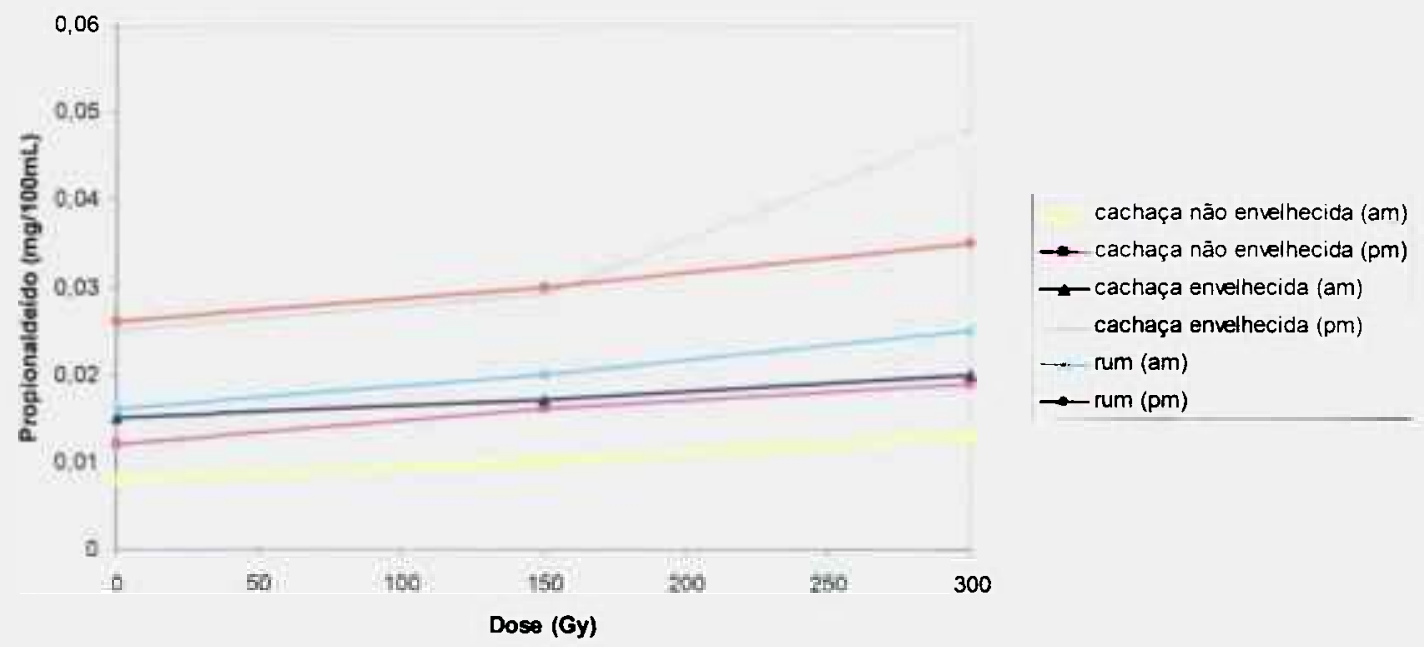

FIGURA 44 - Variação da concentração propionaldeído em função da dose aplicada em bebidas destiladas.

De acordo com a TABELA 29, a concentração máxima de propionaldeído foi obtida com 150Gy para a amostra de cachaça não envelhecida (pm) e; 300Gy para a cachaça não envelhecida (am), cachaça envelhecida (am), cachaça envelhecida (pm) e rum (am) e rum (pm).

TABELA 29 - Médias* das concentrações de propionaldeído em $\mathrm{mg} / 100 \mathrm{~mL}$ álcool anidro encontradas nas amostras de bebidas analisadas.

\begin{tabular}{ccccccc}
\cline { 3 - 7 } $\begin{array}{c}\text { Dose } \\
(\mathrm{Gy})\end{array}$ & $\begin{array}{c}\text { Cachaça não } \\
\text { envelhecida } \\
(\mathrm{am})\end{array}$ & $\begin{array}{c}\text { Cachaça não } \\
\text { envelhecida } \\
(\mathrm{pm})\end{array}$ & $\begin{array}{c}\text { Amostras } \\
\text { Cachaça } \\
\text { envelhecida } \\
(\mathrm{am})\end{array}$ & $\begin{array}{c}\text { Cachaça } \\
\text { envelhecida } \\
(\mathrm{pm})\end{array}$ & $\begin{array}{c}\text { Rum } \\
(\mathrm{am})\end{array}$ & $\begin{array}{c}\text { Rum } \\
(\mathrm{pm})\end{array}$ \\
\hline 0 & $0,005^{\mathrm{a}}$ & $0,01^{\mathrm{a}}$ & $0,015^{\mathrm{a}}$ & $0,025^{\mathrm{a}}$ & $0,015^{\mathrm{a}}$ & $0,025^{\mathrm{a}}$ \\
150 & $0,01^{\mathrm{b}}$ & $0,02^{\mathrm{b}}$ & $0,017^{\mathrm{a}, \mathrm{b}}$ & $0,03^{\mathrm{a}}$ & $0,02^{\mathrm{b}}$ & $0,03^{\mathrm{a}, \mathrm{b}}$ \\
300 & $0,015^{\mathrm{c}}$ & $0,02^{\mathrm{b}}$ & $0,02^{\mathrm{b}}$ & $0,05^{\mathrm{b}}$ & $0,025^{\mathrm{c}}$ & $0,035^{\mathrm{b}}$ \\
\hline
\end{tabular}

- Médias com letras iguais na mesma coluna, não diferem entre si estatisticamente $(p \leqq 0,05)$. 


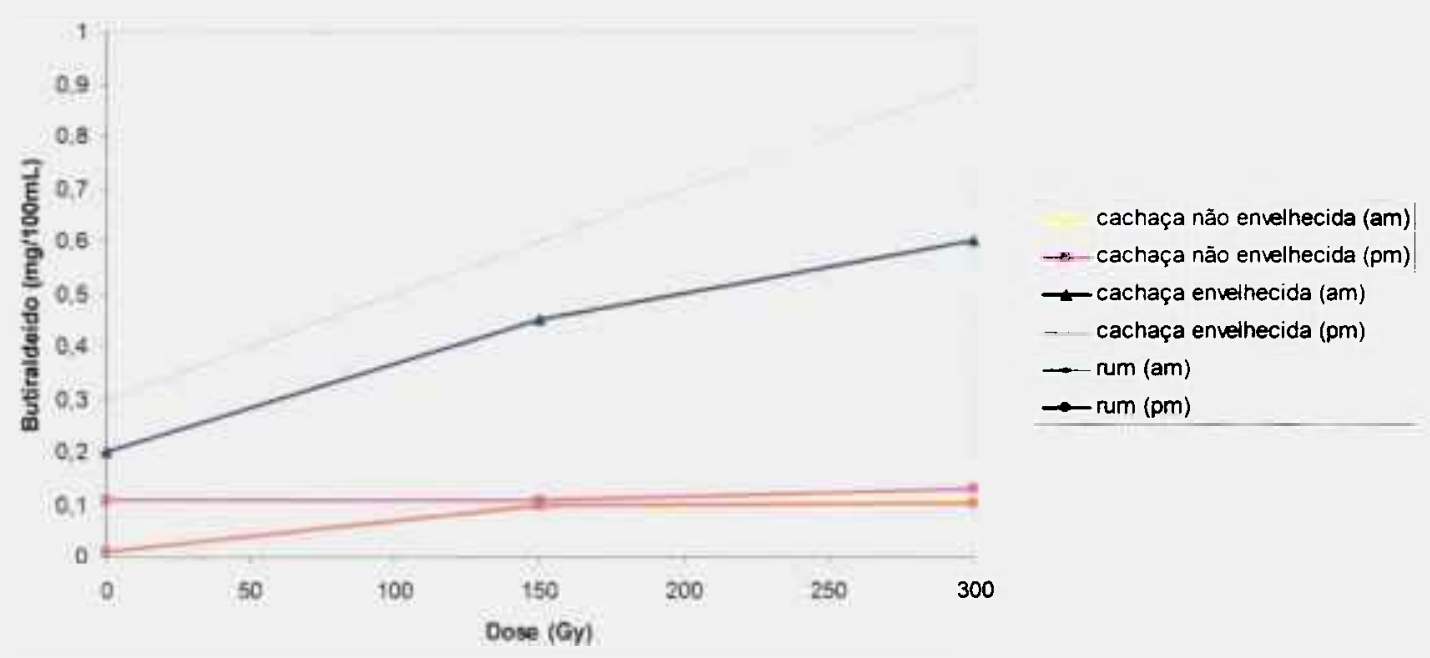

FIGURA 45 - Variação da concentração butiraldeído em função da dose aplicada em bebidas destiladas.

Segundo a TABELA 30 , a concentração máxima de butiraldeído foi obtida com 150Gy para a amostra de cachaça não envelhecida (am), rum (am) e rum (pm) e; 300Gy para a cachaça envelhecida (am) e cachaça envelhecida (pm). A concentração de butiraldeído não variou para a amostra cachaça não envelhecida (pm).

TABELA 30 - Mćdias* das concentrações de butiraldeído em $\mathrm{mg} / 100 \mathrm{~mL}$ álcool anidro encontradas nas amostras de bebidas analisadas.

\begin{tabular}{ccccccc}
\hline $\begin{array}{c}\text { Doses } \\
(\mathrm{Gy})\end{array}$ & $\begin{array}{c}\text { Cachaça não } \\
\text { envelhecida } \\
(\mathrm{am})\end{array}$ & $\begin{array}{c}\text { Cachaça não } \\
\text { envelhecida } \\
(\mathrm{pm})\end{array}$ & $\begin{array}{c}\text { Amostras } \\
\text { Cachaça } \\
\text { envelhecida } \\
(\mathrm{am})\end{array}$ & $\begin{array}{c}\text { Cachaça } \\
\text { envelhecida } \\
(\mathrm{pm})\end{array}$ & $\begin{array}{c}\text { Rum } \\
(\mathrm{am})\end{array}$ & $\begin{array}{c}\text { Rum } \\
(\mathrm{pm})\end{array}$ \\
\hline 0 & $0,01^{\mathrm{a}}$ & $0,11^{\mathrm{a}}$ & $0,20^{\mathrm{a}}$ & $0,30^{\mathrm{a}}$ & $0,01^{\mathrm{a}}$ & $0,01^{\mathrm{a}}$ \\
150 & $0,10^{\mathrm{b}}$ & $0,11^{\mathrm{a}}$ & $0,45^{\mathrm{b}}$ & $0,60^{\mathrm{b}}$ & $0,10^{\mathrm{b}}$ & $0,10^{\mathrm{b}}$ \\
300 & $0,10^{\mathrm{b}}$ & $0,13^{\mathrm{a}}$ & $0,60^{\mathrm{c}}$ & $0,90^{\mathrm{c}}$ & $0,10^{\mathrm{b}}$ & $0,10^{\mathrm{b}}$ \\
\hline
\end{tabular}

* Médias com letras iguais na mesma coluna, não diferem entre si estatisticamente $(p \leq 0,05)$. 


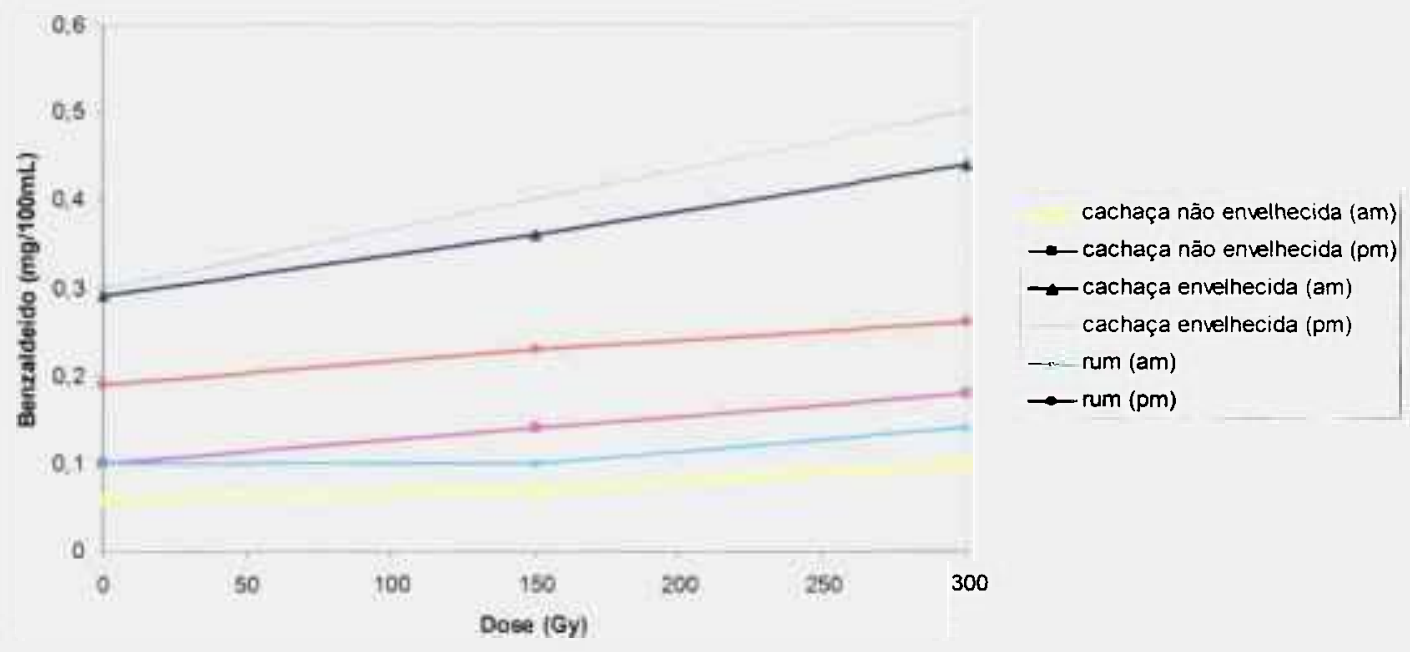

FIGURA 46 - Variação da concentração benzaldeído em função da dose aplicada em bebidas destiladas.

De acordo com a TABELA 31, a concentração máxima de benzaldeído foi obtida com 300Gy para a cachaça não envelhecida (am), cachaça não envelhecida (pm), cachaça envelhecida (am), cachaça envelhecida (pm), rum (am) e rum (am).

TABELA 31 - Médias* das concentrações de benzaldeído em $\mathrm{mg} / 100 \mathrm{~mL}$ álcool anidro encontradas nas amostras de bebidas analisadas.

\begin{tabular}{ccccccc}
\hline $\begin{array}{c}\text { Doses } \\
(\mathrm{Gy})\end{array}$ & $\begin{array}{c}\text { Cachaça não } \\
\text { envelhecida } \\
(\mathrm{am})\end{array}$ & $\begin{array}{c}\text { Cachaça não } \\
\text { envelhecida } \\
(\mathrm{pm})\end{array}$ & $\begin{array}{c}\text { Amostras } \\
\text { Cachaça } \\
\text { envelhecida } \\
(\mathrm{am})\end{array}$ & $\begin{array}{c}\text { Cachaça } \\
\text { envelhecida } \\
(\mathrm{pm})\end{array}$ & $\begin{array}{c}\text { Rum } \\
(\mathrm{am})\end{array}$ & $\begin{array}{c}\text { Rum } \\
(\mathrm{pm})\end{array}$ \\
\hline 0 & $0,06^{\mathrm{a}}$ & $0,10^{\mathrm{a}}$ & $0,29^{\mathrm{a}}$ & $0,30^{\mathrm{a}}$ & $0,10^{\mathrm{a}}$ & $0,19^{\mathrm{a}}$ \\
150 & $0,07^{\mathrm{a}}$ & $0,14^{\mathrm{b}}$ & $0,36^{\mathrm{b}}$ & $0,40^{\mathrm{b}}$ & $0,10^{\mathrm{a}}$ & $0,23^{\mathrm{a}, \mathrm{b}}$ \\
300 & $0,10^{\mathrm{b}}$ & $0,18^{\mathrm{c}}$ & $0,44^{\mathrm{c}}$ & $0,50^{\mathrm{c}}$ & $0,14^{\mathrm{b}}$ & $0,26^{\mathrm{b}}$ \\
\hline
\end{tabular}

* Médias com letras iguais na mesma coluna, não diferem entre si estatisticamente $(p \leq 0,05)$. 


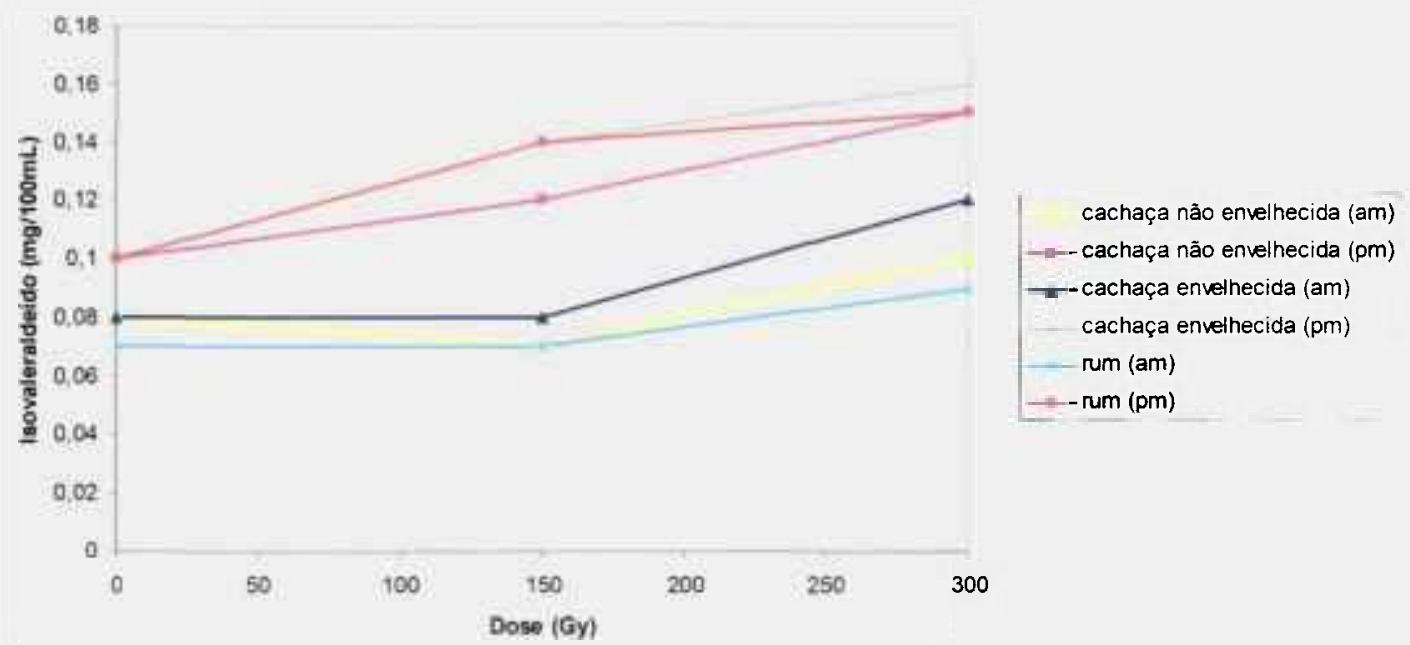

FIGURA 47 - Variação da concentração isovaleraldeído em função da dose aplicada em bebidas destiladas.

Segundo a TABELA 32, a concentração máxima de isovaleraldeído foi obtida com 150Gy para a amostra de cachaça envelhecida (pm) e rum (pm) e; 300Gy para a cachaça não envelhecida (am), cachaça não envelhecida (pm), cachaça envelhecida (am) e rum (am).

TABELA 32 - Médias* das concentrações de isovaleraldeído em $\mathrm{mg} / 100 \mathrm{~mL}$ álcool anidro encontrados nas amostras de bebidas analisadas.

\begin{tabular}{ccccccc}
\hline $\begin{array}{c}\text { Doses } \\
(\text { Gy) }\end{array}$ & $\begin{array}{c}\text { Cachaça não } \\
\text { envelhecida } \\
(\mathrm{am})\end{array}$ & $\begin{array}{c}\text { Cachaça não } \\
\text { envelhecida } \\
(\mathrm{pm})\end{array}$ & $\begin{array}{c}\text { Amostras } \\
\text { Cachaça } \\
\text { envelhecida } \\
(\mathrm{am})\end{array}$ & $\begin{array}{c}\text { Cachaça } \\
\text { envelhecida } \\
(\mathrm{pm})\end{array}$ & $\begin{array}{c}\text { Rum } \\
(\mathrm{am})\end{array}$ & $\begin{array}{c}\text { Rum } \\
(\mathrm{pm})\end{array}$ \\
\hline 0 & $0,08^{\mathrm{a}}$ & $0,10^{\mathrm{a}}$ & $0,08^{\mathrm{a}}$ & $0,10^{\mathrm{a}}$ & $0,07^{\mathrm{a}}$ & $0,10^{\mathrm{a}}$ \\
150 & $0,07^{\mathrm{a}}$ & $0,12^{\mathrm{a}}$ & $0,08^{\mathrm{a}}$ & $0,14^{\mathrm{b}}$ & $0,07^{\mathrm{a}}$ & $0,14^{\mathrm{b}}$ \\
300 & $0,10^{\mathrm{b}}$ & $0,15^{\mathrm{b}}$ & $0,12^{\mathrm{b}}$ & $0,16^{\mathrm{b}}$ & $0,09^{\mathrm{b}}$ & $0,15^{\mathrm{b}}$ \\
\hline
\end{tabular}

* Médias com letras iguais na mesma coluna, não diferem entre si estatisticamente $(p \leq 0,05)$. 


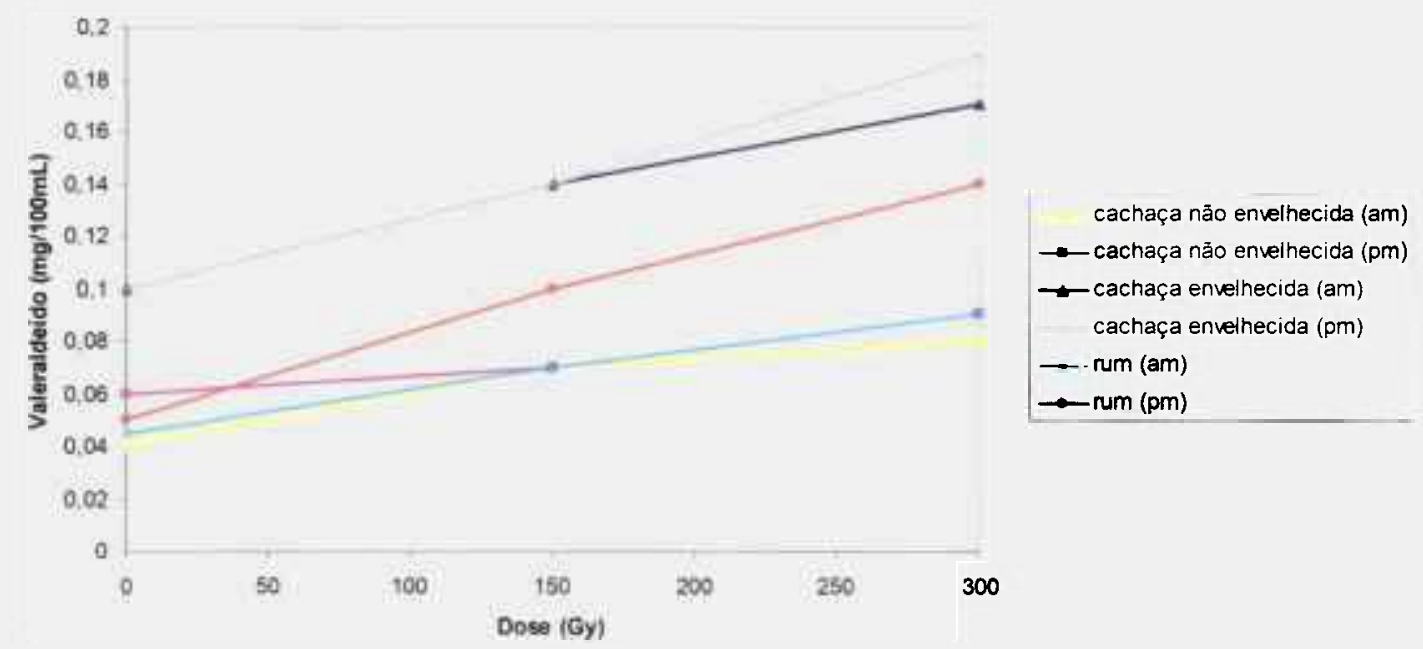

FIGURA 48 - Variação da concentração valeraldeído em função da dose aplicada em bebidas destiladas.

De acordo com a TABELA 33, a concentração máxima de valeraldeído foi obtida com 150Gy para a amostra de cachaça não envelhecida (am), cachaça envelhecida (am) e; 300Gy para a cachaça não envelhecida (pm), cachaça envelhecida (pm), rum (am) e rum (pm).

TABELA 33 - Médias* das concentrações de valeraldeído em $\mathrm{mg} / 100 \mathrm{~mL}$ álcool anidro encontrados nas amostras de bebidas analisadas.

\begin{tabular}{ccccccc}
\hline $\begin{array}{c}\text { Doses } \\
(\text { Gy) }\end{array}$ & $\begin{array}{c}\text { Cachaça não } \\
\text { envelhecida } \\
(\text { am) }\end{array}$ & $\begin{array}{c}\text { Cachaça não } \\
\text { envelhecida } \\
(\mathrm{pm})\end{array}$ & $\begin{array}{c}\text { Amostras } \\
\text { Cachaça } \\
\text { envelhecida } \\
(\text { am) }\end{array}$ & $\begin{array}{c}\text { Cachaça } \\
\text { envelhecida } \\
(\mathrm{pm})\end{array}$ & $\begin{array}{c}\text { Rum } \\
(\mathrm{am})\end{array}$ & $\begin{array}{c}\text { Rum } \\
(\mathrm{pm})\end{array}$ \\
\hline 0 & $0,04^{\mathrm{a}}$ & $0,06^{\mathrm{a}}$ & $0,10^{\mathrm{a}}$ & $0,10^{\mathrm{a}}$ & $0,04^{\mathrm{a}}$ & $0,05^{\mathrm{a}}$ \\
150 & $0,07^{\mathrm{b}}$ & $0,07^{\mathrm{a}}$ & $0,14^{\mathrm{b}}$ & $0,14^{\mathrm{b}}$ & $0,07^{\mathrm{b}}$ & $0,10^{\mathrm{b}}$ \\
300 & $0,08^{\mathrm{b}}$ & $0,09^{\mathrm{b}}$ & $0,17^{\mathrm{b}}$ & $0,19^{\mathrm{c}}$ & $0,09^{\mathrm{c}}$ & $0,14^{\mathrm{c}}$ \\
\hline
\end{tabular}

* Médias com letras iguais na mesma coluna, não diferem entre si estatisticamente $(p \leqq 0,05)$.

De acordo com a legislação brasileira (BRASIL, 2005), a soma máxima das concentrações permitida de aldeídos totais é $30 \mathrm{mg}$ de acetaldeído/100mL de álcool anidro e para furfural e 5 hidroximetilfurfural é $5 \mathrm{mg} / 100 \mathrm{~mL}$ de álcool anidro. Como pode ser observado na TABELA 34, o conteúdo de aldeídos nas cachaças não excedeu o limite permitido. De acordo com a TABELA 35, a soma das concentrações de furfural e 5 
hidroximetilfurfural para todas as amostras de cachaça foi menor que o permitido por lei (BRASIL, 2005). Os resultados encontrados para os aldeídos estavam dentro do intervalo de concentrações encontrado por NASCIMENTO et al. (1997). O principal aldeído encontrado foi o acetaldeído, onde a maior concentração encontrada foi na amostra de cachaça envelhecida irradiada com 300Gy. No entanto, MORAES (2004) encontrou maiores concentrações de acetaldeído na amostra de rum "light", quando estudados cachaças e runs comerciais e de laboratório envelhecidos e não envelhecidos.

Sabe-se que o conteúdo de aldeídos nas bebidas destiladas aumenta com os processos oxidativos (MORAES, 2004). Os processos de envelhecimento e irradiação são conhecidos com sendo processos oxidativos, onde, a exposição de amostras aquosas à radiação gama sob condições aeróbicas aumenta o potencial de óxido-redução do sistema, formando radicais livres, compostos altamente reativos como o superóxido (O2-) e radical hidroxila (.OH) (BABIOR, 1997). Nesse sentido, conclui-se que os radicais livres formados pela interação da radiação com os compostos contidos nas bebidas analisadas induziram um fenômeno químico semelhante àquele que acontece através da lenta ação do tempo, ou seja, um aumento da concentração de aldeídos, uma das classes de substâncias responsáveis pelo "flavor" específico da bebida envelhecida.

TABELA 34 - Soma das concentrações dos aldeídos em mg/100mL álcool anidro encontrados nas amostras de bebidas analisadas.

\begin{tabular}{cccc}
\hline \multirow{2}{*}{ Amostras } & \multicolumn{3}{c}{ Soma das concentrações dos aldeídos } \\
\cline { 2 - 3 } & $0 \mathrm{~Gy}$ & $150 \mathrm{~Gy}$ & $300 \mathrm{~Gy}$ \\
\hline Cachaça não envelhecida (am) & 6,78 & 8,07 & 8,86 \\
Cachaça não envelhecida (pm) & 8,18 & 10,42 & 12,60 \\
Cachaça envelhecida (am) & 9,83 & 11,63 & 15,03 \\
Cachaça envelhecida (pm) & 11,11 & 19,40 & 23,87 \\
Rum (am) & 11,05 & 13,44 & 14,91 \\
Rum (pm) & 11,86 & 15,68 & 18,09 \\
\hline
\end{tabular}


TABELA 35 - Soma das concentrações de furfural e 5 hidroximetilfurfural em $\mathrm{mg} / 100 \mathrm{~mL}$ álcool anidro nas amostras analisadas.

\begin{tabular}{cccc}
\hline & \multicolumn{3}{c}{ Soma das concentrações de furfural e } \\
& \multicolumn{3}{c}{5 hidroximetilfurfural } \\
\cline { 2 - 4 } & $0 \mathrm{~Gy}$ & $150 \mathrm{~Gy}$ & $300 \mathrm{~Gy}$ \\
\hline Cachaça não envelhecida (am) & 0,57 & 0,63 & 0,83 \\
Cachaça não envelhecida (pm) & 0,61 & 0,8 & 0,95 \\
Cachaça envelhecida (am) & 0,8 & 1,0 & 1,48 \\
Cachaça envelhecida (pm) & 1,3 & 2,5 & 3,4 \\
Rum (am) & 0,31 & 0,5 & 0,79 \\
Rum (pm) & 0,41 & 1,17 & 1,9 \\
\hline
\end{tabular}

Segundo SPIEGEL (1994), uma forte correlação entre os parâmetros analisados possui $R^{2}>0,7$; uma média correlação possui $R^{2}=0,7$ e uma fraca correlação entre os dados possui $\mathrm{R}^{2}<0,7$.

Nas TABELA 36 a TABELA 40 são mostrados os valores do fator de correlação $\left(R^{2}\right)$ entre os parâmetros analisados e as doses de radiação aplicadas nas amostras.

TABELA 36 - Valores do fator de correlação $\left(R^{2}\right)$ entre os ésteres e alcoóis superiores analisados e as doses de radiação aplicadas nas amostras.

\begin{tabular}{ccccccc}
\hline \multirow{2}{*}{ Amostras } & \multicolumn{7}{c}{ Parâmetros } \\
& Ac. Etila & Metanol & Propanol & Isobutanol & Butanol & Alc. Isoamílico \\
\hline Cachaça não envelhecida (am) & 0,95 & 0,96 & 0,99 & 0,99 & 0,99 & 0,99 \\
Cachaça não envelhecida (pm) & 0,99 & 0,99 & 0,98 & 0,96 & 0,95 & 0,98 \\
Cachaça envelhecida (am) & 0,93 & 0,96 & 0,97 & 0,99 & 0,91 & 0,98 \\
Cachaça envelhecida (pm) & 0,91 & 0,95 & 0,99 & 0,99 & 0,98 & 0,99 \\
Rum (am) & 0,99 & 0,99 & 0,99 & 0,98 & 0,99 & 0,95 \\
Rum (pm) & 0,99 & 0,99 & 0,99 & 0,97 & 0,99 & 0,99 \\
\hline
\end{tabular}


TABELA 37 - Valores do fator de correlação $\left(R^{2}\right)$ entre os ácidos analisados e as doses de radiação aplicadas nas amostras.

\begin{tabular}{cccccccc}
\hline & \multicolumn{5}{c}{ Parâmetros } \\
& $\begin{array}{c}\text { Ac. } \\
\text { Acético }\end{array}$ & $\begin{array}{c}\text { Ac. } \\
\text { Propiônico }\end{array}$ & $\begin{array}{c}\text { Ac. } \\
\text { Isobutírico }\end{array}$ & $\begin{array}{c}\text { Ac. } \\
\text { Butírico }\end{array}$ & $\begin{array}{c}\text { Ac. } \\
\text { Valérico }\end{array}$ & $\begin{array}{c}\text { Ac. } \\
\text { Isovalérico }\end{array}$ & $\begin{array}{c}\text { Ac. } \\
\text { Isocapróico }\end{array}$ \\
\hline Cachaça não envelhecida (am) & 0,99 & 0,99 & 0,97 & 0,99 & 0,99 & 0,97 & 0,99 \\
Cachaça não envelhecida (pm) & 0,99 & 0,99 & 0,97 & 0,99 & 0,98 & 0,99 & 0,99 \\
Cachaça envelhecida (am) & 0,99 & 0,95 & 0,99 & 0,99 & 0,97 & 0,98 & 0,99 \\
Cachaça envelhecida (pm) & 0,98 & 0,98 & 0,99 & 0,97 & 0,98 & 0,99 & 0,99 \\
Rum (am) & 0,99 & 0,99 & 0,99 & 0,99 & 0,99 & 0,99 & 0,99 \\
Rum (pm) & 0,97 & 0,98 & 0,99 & 0,99 & 0,99 & 0,99 & 0,99 \\
\hline
\end{tabular}

TABELA 38 - Valores do fator de correlação $\left(R^{2}\right)$ entre os ácidos analisados e as doses de radiação aplicadas nas amostras.

\begin{tabular}{|c|c|c|c|c|c|c|c|}
\hline \multirow[b]{2}{*}{ Amostras } & \multicolumn{7}{|c|}{ Parãmetros } \\
\hline & $\begin{array}{c}\text { Ac. } \\
\text { Capróico }\end{array}$ & $\begin{array}{c}\text { Ac. } \\
\text { Heptanóico }\end{array}$ & $\begin{array}{c}\text { Ac. } \\
\text { Caprílico }\end{array}$ & $\begin{array}{c}\text { Ac. } \\
\text { Cáprico }\end{array}$ & $\begin{array}{c}\text { Ac. } \\
\text { Mirístico }\end{array}$ & $\begin{array}{c}\text { Ac. } \\
\text { Láurico }\end{array}$ & $\begin{array}{c}\text { Ac. } \\
\text { Palmítico }\end{array}$ \\
\hline Cachaça não envelhecida (am) & 0,99 & 0,99 & 0,97 & 0,99 & 0,99 & 0,99 & 0,90 \\
\hline Cachaça não envelhecida (pm) & 0,98 & 0,99 & 0,97 & 0,99 & 0,99 & 0,99 & 0,98 \\
\hline Cachaça envelhecida (am) & 0,99 & 0,99 & 0,99 & 0,99 & 0,97 & 0,95 & 0,99 \\
\hline Cachaça envelhecida (pm) & 0,99 & 0,99 & 0,99 & 0,99 & 0,99 & 0,99 & 0,98 \\
\hline Rum (am) & 0,99 & 0,72 & 0,99 & 0,99 & 0,98 & 0,94 & 0,98 \\
\hline Rum (pm) & 0,99 & 0,99 & 0,99 & 0,97 & 0,97 & 0,99 & 0,99 \\
\hline
\end{tabular}

TABELA 39 - Valores do fator de correlação $\left(R^{2}\right)$ entre os aldeídos analisados e as doses de radiação aplicadas nas amostras.

\begin{tabular}{cccccc}
\hline Amostras & Formaldeido & HMF & $\begin{array}{c}\text { Parâmetros } \\
\text { Acetaldeido }\end{array}$ & Acroleina & Furfural \\
\hline Cachaça não envelhecida (am) & 0,98 & 0,99 & 0,98 & 0,96 & 0,78 \\
Cachaça não envelhecida (pm) & 0,98 & 0,99 & 0,99 & 0,99 & 0,99 \\
Cachaça envelhecida (am) & 0,97 & 0,97 & 0,98 & 0,96 & 0,98 \\
Cachaça envelhecida (pm) & 0,99 & 0,99 & 0,98 & 0,98 & 0,99 \\
Rum (am) & 0,98 & 0,98 & 0,98 & 0,99 & ND \\
Rum (pm) & 0,99 & 0,99 & 0,99 & 0,99 & 0,99 \\
\hline
\end{tabular}

$\mathrm{ND}=$ não detectado.

$\mathrm{HMF}=5$ Hidroximetilfurfural. 
TABELA 40 - Valores do fator de correlação $\left(R^{2}\right)$ entre os aldeídos analisados e as doses de radiação aplicadas nas amostras.

\begin{tabular}{cccccc}
\hline \multirow{2}{*}{ Amostras } & \multicolumn{5}{c}{ Parâmetros } \\
& Propionaldeído & Butiraldeido & Benzaldeido & Isovaleraldeido & Valeraldeido \\
\hline Cachaça não envelhecida (am) & 0,99 & 0,94 & 0,97 & 0,67 & 0,97 \\
Cachaça não envelhecida (pm) & 0,99 & 0,90 & 0,99 & 0,99 & 0,98 \\
Cachaça envelhecida (am) & 0,99 & 0,99 & 0,99 & 0,90 & 0,99 \\
Cachaça envelhecida (pm) & 0,95 & 0,99 & 0,99 & 0,99 & 0,99 \\
Rum (am) & 0,99 & 0,92 & 0,90 & 0,90 & 0,99 \\
Rum (pm) & 0,99 & 0,92 & 0,99 & 0,96 & 0,99 \\
\hline
\end{tabular}

De acordo com as TABELA 36 a TABELA 40, pode-se afirmar que houve forte correlação entre a concentração dos compostos voláteis analisados com a dose de radiação aplicada em todas as amostras.

\subsection{Análise Sensorial}

\subsubsection{Teste Triangular}

Em relação às amostras não irradiadas, todos os juízes puderam distinguir a cachaça envelhecida do rum e a cachaça não envelhecida do rum, porém eles não puderam achar diferença entre a cachaça não envelhecida e a envelhecida para a concentração alcoólica de $11 \%$. Em relação às amostras irradiadas, foi encontrada diferença significativa entre a cachaça envelhecida e o rum e entre a cachaça não envelhecida e o rum, porém não foi achada diferença entre a cachaça não envelhecida e a envelhecida, quando foi realizado o teste triangular para um grau de significância $p=0,05$. Por esta razão, a análise descritiva quantitativa foi conduzida para determinar somente as diferenças entre cachaça não envelhecida e rum não irradiados e irradiados.

\subsubsection{Análise Descritiva Quantitativa}

Para compor a equipe de provadores para a análise descritiva quantitativa foi realizada uma pré-seleção de 18 candidatos, com base em seu poder discriminativo, por meio de testes triangulares com amostras de cachaça e rum. Foram pré-selecionados 16 candidatos, pois estes obtiveram mais de $70 \%$ de acertos. Destes 16 candidatos foram selecionados finalmente 12, por meio de uma análise de variância (ANOVA) de fator duplo (amostras e 
repetições) para cada atributo avaliado com valor $-p<0,30$ para o poder de discriminação $\mathrm{e}$ valor $-p>0,05$ para repetibilidade.

Os atributos de aroma selecionados pela equipe de provadores que melhor representavam as amostras de cachaça não envelhecida e rum não irradiados e irradiados foram: álcool, condimento, maçãa, melão, citros, baunilha, grama, vegetal, caramelo e vinagre.

A TABELA 41 apresenta a lista final dos atributos relacionados ao aroma das amostras estudadas com suas respectivas definições.

TABELA 41 - Lista final dos atributos selecionados com suas respectivas definições.

\begin{tabular}{cc}
\hline Termo & Definição \\
\hline Álcool & Etanol, antisséptico, bebida alcoólica \\
Condimento & Canela, mostarda, pimenta, ervas \\
Maçã & Cidra, suco de maçã, maçã madura, maçã verde \\
Melão & Melão, pepino, melância \\
Citros & Lima, limão, laranja \\
Baunilha & Malte, açúcar, bolo, sorvete de creme, cookies \\
Grama & Grama fresca cortada, folhas maceradas \\
Vegetal & Couve flor cozida, repolho, aspargo, alho, cebola, ovo podre \\
Caramelo & Açúcar queimado, açúcar caramelizado, algodão doce, \\
Vinagre & margarina, melado, barril de madeira, madeira tostada \\
\hline
\end{tabular}

Segundo MORAES (2004), a lista de atributos de aroma selecionada para descrever as amostras de cachaça e rum não envelhecidos, envelhecidos, comerciais e de laboratório continha os seguintes termos: álcool, madeira, floral e caramelo.

MARCELLINI (2000) realizou a análise descritiva de amostras de cachaça comerciais e destiladas em alambiques de cobre e aço-inoxidável, encontrando os seguintes termos descritivos para o aroma: alcoólico, adocicado e sulfurado. FURTADO (1995) obteve os seguintes termos descritores para o aroma de aguardentes recém-destiladas: álcool, melaço 
de cana, melaço de cana fermentado, madeira, erva, frutas, compostos orgânicos e perfume. CARDELLO \& FARIA (1998) levantaram os seguintes atributos para aroma de cachaças não envelhecidas e envelhecidas: alcoólico, madeira e baunilha.

Oceano, fruta, mel, caramelo, madeira, canela, baunilha, manteiga, fumaça, banana e vinagre foram os atributos de aroma encontrados, quando diversas amostras de rum foram estudadas (GOMEZ, 2002). LAURENT et al. (1994) usaram os termos: vegetal, fruta, floral, manteiga, condimento e suor para descrever o aroma de vinhos "Chardonnay".

A FIGURA 49, a FIGURA 50 e a FIGURA 51 mostram as intensidades médias dos atributos para aroma encontrados na cachaça e no rum não irradiados; nas cachaças não envelhecidas não irradiadas e irradiadas e nos runs não irradiados e irradiados que foram plotadas em gráficos aranhas usando 10 termos. Nestes diagramas, o centro de cada figura representava baixa intensidade, sendo a intensidade 15 a máxima encontrada para cada atributo no final do eixo.

Análises de Variância (ANOVA) destes resultados mostraram que a cachaça não envelhecida e o rum não irradiados diferiram entre si em seus atributos de aroma classificados, como, álcool, vinagre, baunilha, citros, melão, condimento, vegetal e grama. Já, em relação aos aromas; caramelo e maçã não foram encontradas diferenças significativas entre estas bebidas (FIGURA 49).

MORAES (2004) encontrou diferenças nas amostras de cachaça não envelhecida e rum comercial "light" para os atributos de aroma floral e alcoólico. 


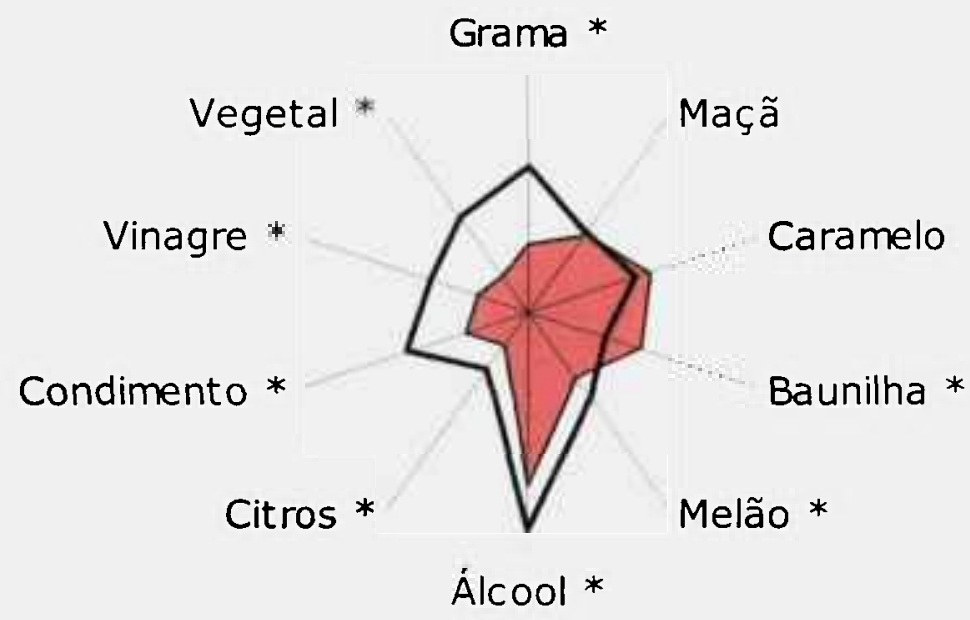

Rum não irradiado Q Cachaça não irradiada

FIGURA 49 - Gráfico aranha de cachaça não envelhecida e rum não irradiados. A distância a partir da origem é proporcional à média. Todos os valores de $p$ foram $<0,001$ exceto para caramelo $(p=0,14)$ e maçã $(p=0,90)$.

As análises de variância (ANOVA) mostraram que as cachaças não envelhecidas não irradiadas e irradiadas e os runs não irradiados e irradiados diferiram entre si em seus atributos de aroma classificados, como, maçã, caramelo, vinagre, baunilha, citros, melão, condimento, vegetal e grama. Porém, em relação ao aroma álcool não foi encontrada diferença significativa entre estas bebidas (FIGURA 50 e FIGURA 51). 


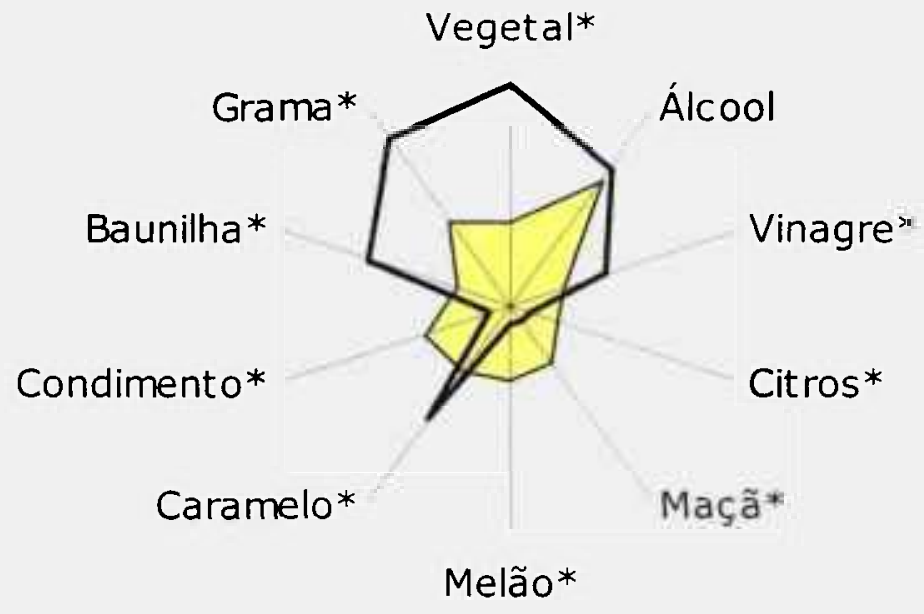

$\square$ Cachaça não irradiada $\square$ Cachaça irradiada

FIGURA 50 - Gráfico aranha de cachaça não envelhecida não irradiada e irradiada. A distância a partir da origem é proporcional à média. Todos os valores de $p$ foram $<0,001$ exceto para álcool $(p=1,36)$.

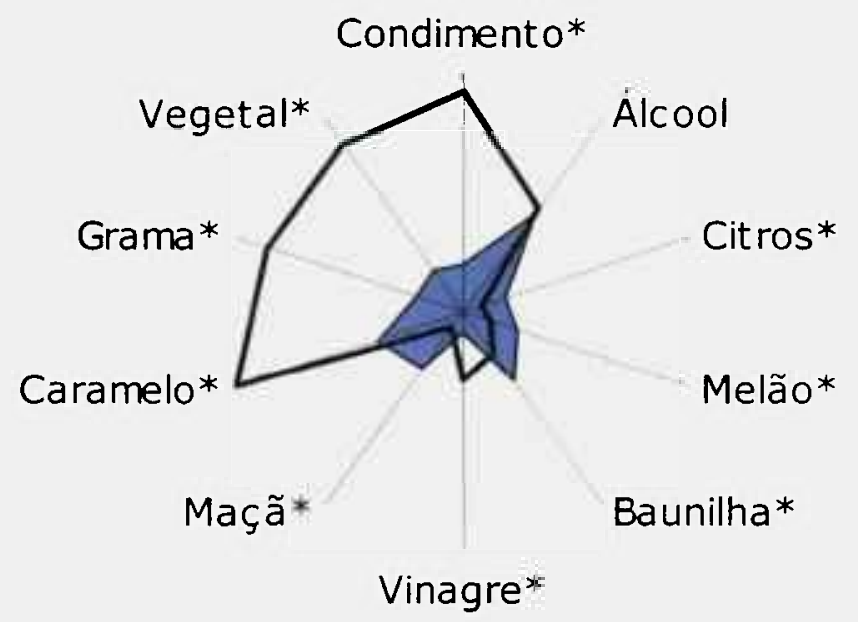

घ Rum não irradiado Q Rum irradiado

FIGURA 51 - Gráfico aranha de rum não irradiado e irradiado. A distância a partir da origem é proporcional à média. Todos os valores de $p$ foram $<0,001$ exceto para álcool $(p=1,03)$. 


\subsection{Determinação dos Odores Ativos por Cromatografia/Olfatometria}

Devido ao fato de não ter sido encontrada diferença significativa no teste triangular entre cachaça envelhecida e não envelhecida (tanto irradiada como não irradiada), somente as amostras de cachaça e rum não envelhecidas irradiadas e não irradiadas foram extraidas, usando duas metodologias diferentes. A SPME foi utilizada como uma ferramenta complementar para extração com Freon. No entanto, os dados da SPME não detectaram compostos extras que poderiam ter sido co-eluídos com o solvente. Desta maneira, neste estudo, foram somente considerados os resultados obtidos com a extração com Freon.

As tabelas a seguir mostram os odores, os valores "Charm" e os valores do espectro de odor (OSV) que foram detectados nas amostras estudadas pela técnica de CG/O. A análise com $\mathrm{CG} / \mathrm{O}$ detectou 24 compostos voláteis com odores ativos nos extratos de cachaça não envelhecida não irradiada, como mostra a TABELA 42.

TABELA 42 - Odores encontrados na cachaça não envelhecida não irradiada.

\begin{tabular}{|c|c|c|c|c|c|c|c|c|}
\hline \multirow{2}{*}{$\begin{array}{c}\text { Pico } \\
\text { no. }\end{array}$} & \multirow{2}{*}{ Composto detectado } & \multirow{2}{*}{$\begin{array}{c}\text { CAS } \\
\text { Registro no. }\end{array}$} & \multirow{2}{*}{$\begin{array}{l}\text { Indice de } \\
\text { retencão }\end{array}$} & \multirow{2}{*}{ Termo } & \multirow{2}{*}{$\begin{array}{c}\text { Valor } \\
\text { Charm }\end{array}$} & \multirow{2}{*}{ OSV } & \multicolumn{2}{|c|}{ Detectado por } \\
\hline & & & & & & & & \\
\hline 24 & $\beta$-damascenona & $23726-93-4$ & 1383 & Floral/fruta & 60974 & 100 & + & + \\
\hline 23 & Eugenol & $95-53-0$ & 1368 & Condimento & 6625 & 32,96 & + & + \\
\hline 3 & Dietil acetal & $105-57-57$ & 730 & Fruta & 5009 & 28,66 & + & + \\
\hline 14 & Etil fenol & $60-12-8$ & 1111 & Floral & 3705 & 24,65 & + & + \\
\hline 4 & Isobutirato de etila & $97-62-1$ & 758 & Melão & 1806 & 17,21 & + & + \\
\hline 16 & Desconhecido I & & 1174 & Cereal & 1327 & 14,75 & + & \\
\hline 6 & Butirato de metil-2-etila & $7452-79-1$ & 850 & Maçã & 1120 & 13,55 & + & + \\
\hline 20 & Acetato de etil-2-fenila & $103-45-7$ & 1255 & Floral & 768 & 11,22 & + & + \\
\hline 19 & Acetato de fenil etila & $101-97-3$ & 1243 & Fruta & 702 & 10,73 & + & + \\
\hline 18 & 2,4 nonadienal & $5910-87-2$ & 1214 & Floral & 675 & 10,52 & + & + \\
\hline 21 & 4-etil guaiacol & $2785-89-9$ & 1279 & Condimento & 581 & 9,76 & + & + \\
\hline 12 & Desconhecido 2 & & 1066 & Outro & 376 & 7,85 & + & \\
\hline 7 & Desconhecido 3 & & 866 & Cereal & 340 & 7,47 & + & \\
\hline 1 & Diacetil & $431-03-8$ & 645 & Manteiga & 254 & 6,45 & + & + \\
\hline 13 & Guaiacol & $90-05-1$ & 1088 & Remédio & 252 & 6,43 & + & + \\
\hline 17 & Desconhecido 4 & & 1204 & Outro & 232 & 6,17 & + & + \\
\hline 2 & Acrilato de etila & $140-88-5$ & 702 & Plástico & 231 & 6,16 & + & + \\
\hline 22 & 4-vinil-2-metoxifenol & $7786-61-0$ & 1316 & Condimento & 220 & 6,01 & + & + \\
\hline 9 & Heptanal & $111-71-7$ & 901 & Solvente & 178 & 5,4 & + & + \\
\hline 11 & Desconhecido 5 & & 1045 & Floral & 143 & 4,84 & + & \\
\hline 8 & Acetato de isoamila & $123-92-2$ & 877 & Fruta & 117 & 4,38 & + & + \\
\hline 5 & Butirato de etila & $105-54-4$ & 803 & Maçà & 113 & 4,3 & + & + \\
\hline 10. & 1-octen-3-ona & $4312-99-6$ & 978 & Cogumelo & 91 & 3,86 & + & + \\
\hline 15 & E-2-nonenal & $18829-56-6$ & 1159 & Grama & 75 & 3.51 & + & + \\
\hline
\end{tabular}

Entre os compostos voláteis detectados pela técnica $\mathrm{CG} / \mathrm{O}, \beta$-damascenona, eugenol, dietil acetal, etil fenol, isobutirato de etila, desconhecido (cereal), butirato de metil-2etila, acetato de etil-2-fenila, acetato de etil fenila, 2,4 nonadienal, 4-etil guaiacol foram 
identificados como sendo os odores mais potentes na cachaça não envelhecida não irradiada. LEE \& NOBLE, (2003) e CULLERE et al. (2004), observaram em diversos vinhos, a presença de $\beta$-damascenona, isobutirato de etila, acetato de isoamila, acetato de fenil etila, etil fenol, 4 etil guaiacol, eugenol, 4-vinil-2-metoxifenol, butirato de metil-2-etila, 1-octen-3-ona e E-2nonenal, compostos com odores ativos, que também foram encontrados na cachaça. $\beta$ damascenona, com aroma caracteristico floral/fruta teve a maior atividade de odor na cachaça não envelhecida não irradiada. Este é um potente composto de "flavor" em muitos produtos naturais, como, óleo de rosa Bulgária (DEMOLE et al, 1970), maçãs (CUNNIGHAM et al, 1986), citros (ARAKI \& SAKAKIBARA, 1991), várias variedades de uvas (ACREE et al., 1981), rum (DUBOIS \& RIDAUD, 1975), vinhos (LEE \& NOBLE, 2003) e bebidas alcoólicas (MATSUDA \& NISHIMURA, 1980). Outros termos fornecidos pela análise descritiva foram encontrados como, o aroma condimento, detectados como eugenol e 4-etil guaiacol; melão detectado como isobutirato de etila e o aroma maçã detectado como butirato de metil-2-etila no cromatógrafo gasoso/olfatômetro.

No extrato de cachaça não envelhecida irradiada, a técnica de CG/O permitiu detectar 23 voláteis com odores ativos, como apresentado na TABELA 43. Entre os compostos detectados, os 10 odores ativos mais potentes foram: dietil acetal (fruta), etil fenol (floral), guaiacol (remédio), desconhecido (cereal), eugenol (condimento), $\beta$-damascenona (floral/fruta), acetato de fenil etila (fruta), heptanal (solvente), E-2-nonenal (grama) e diacetil (manteiga). Alguns dos termos encontrados na análise descritiva foram encontrados no cromatógrafo gasoso/olfatômetro como: o aroma condimento, detectado como eugenol e o aroma grama como o composto E-2-nonenal. 
TABELA 43 - Odores encontrados na cachaça não envelhecida irradiada.

\begin{tabular}{ccccccccc}
\hline $\begin{array}{c}\text { Pico } \\
\text { no. }\end{array}$ & Composto detectado & CAS & Indice de & Termo & \multicolumn{2}{c}{ Valor } & OSV & \multicolumn{2}{c}{ Detectado por } \\
CGarm & Registro no. & retenção & CG/MS \\
\hline 4 & Dietil acetal & $105-57-57$ & 730 & Fruta & 2995 & 100 & + & + \\
15 & Etil fenol & $60-12-8$ & 1111 & Floral & 1551 & 71,96 & + & + \\
14 & Guaiacol & $90-05-1$ & 1088 & Remédio & 1519 & 71,22 & + & + \\
17 & Desconhecido 6 & & 1174 & Cereal & 1494 & 70,63 & + & \\
22 & Eugenol & $95-53-0$ & 1368 & Condimento & 1333 & 66,71 & + & + \\
23 & B-damascenona & $23726-93-4$ & 1383 & Floral/fruta & 963 & 56,70 & + & + \\
20 & Acetato de fenil etila & $101-97-3$ & 1243 & Fruta & 851 & 53,30 & + & + \\
10 & Heptanal & $111-71-7$ & 901 & Solvente & 812 & 52,07 & + & + \\
16 & E-2-nonenal & $18829-56-6$ & 1159 & Grama & 731 & 49,40 & + & + \\
1 & Diacetil & $431-03-8$ & 645 & Manteiga & 674 & 47,44 & + & + \\
13 & Desconhecido 7 & & 1078 & Remédio & 662 & 47,01 & + & \\
12 & Desconhecido 8 & & 1065 & Cogumelo & 655 & 46,77 & + & \\
8 & Desconhecido 9 & & 863 & Amêndoa & 468 & 39,53 & + & \\
3 & Acrilato de etila & $140-88-5$ & 702 & Plástico & 450 & 38,76 & + & + \\
18 & Desconhecido 10 & & 1191 & Floral & 420 & 37,45 & + & \\
19 & Desconhecido 11 & & 1204 & Floral & 393 & 36,22 & + & \\
6 & Butirato de metil-2-etila & $7452-79-1$ & 850 & Maçã & 344 & 33,89 & + & + \\
11 & 1-octen-3-ona & $4312-99-6$ & 978 & Cogumelo & 276 & 30,36 & + & + \\
21 & 4-vinil-2-metoxifenol & $7786-61-0$ & 1316 & Condimento & 197 & 25.65 & + & + \\
5 & Isobutirato de etila & $97-62-1$ & 758 & Melão & 162 & 23,26 & + & + \\
9 & Mercaptopentona & $67633-97-0$ & 898 & Vegetal & 156 & 22,82 & + & + \\
2 & Desconhecido 12 & & 672 & Borracha & 144 & 21,93 & + & \\
7 & Desconhecido 13 & & 853 & Condimento & 136 & 21,31 & + & + \\
\hline
\end{tabular}

No rum não irradiado foram encontrados 16 odores. Entre os compostos voláteis detectados, $\beta$-damascenona; dietil acetal; desconhecido (solvente); butirato de metil-2-fenila; isobutirato de etila; butirato de etila; desconhecido (mofo); $\beta$-metil- $\gamma$-octalactona e vanilina foram identificados como sendo os odores mais potentes (TABELA 44).

Como na cachaça não envelhecida não irradiada, o composto $\beta$-damascenona foi o odor mais potente encontrado nesta amostra, mas sua potência foi quatro vezes menor.

Os atributos de aroma obtidos na análise descritiva, como, maçã, melão e baunilha foram também detectados pela técnica de CG/O, como, butirato metil-2-etila e butirato de etila (maçã); isobutirato de etila (melão); $\beta$-metil- $\gamma$-octalactona e vanilina (baunilha). 
TABELA 44 - Odores encontrados no rum não irradiado.

\begin{tabular}{ccccccccc}
\hline $\begin{array}{c}\text { Pico } \\
\text { no. }\end{array}$ & Composto detectado & $\begin{array}{c}\text { CAS } \\
\text { Registro no. }\end{array}$ & $\begin{array}{c}\text { Indice de } \\
\text { retenção }\end{array}$ & Termo & \multicolumn{2}{c}{$\begin{array}{c}\text { Valor } \\
\text { Charm }\end{array}$} & OSV & \multicolumn{2}{c}{$\begin{array}{c}\text { Detectado por } \\
\text { CG/O }\end{array}$} \\
\hline 15 & B-damascenona & $23726-93-4$ & 1386 & Floral/fruta & 15467 & 100 & + & + \\
1 & Dietil acetal & $105-57-57$ & 730 & Fruta & 1035 & 25,87 & + & + \\
4 & Desconhecido 14 & & 825 & Solvente & 791 & 22,61 & + & \\
5 & Butirato de metil-2-etila & $7452-79-1$ & 850 & Maçã & 633 & 20,23 & + & + \\
2 & Isobutirato de etila & $97-62-1$ & 758 & Melâo & 313 & 14,23 & + & + \\
3 & Butirato de etila & $105-54-4$ & 803 & Maça & 192 & 11,14 & + & + \\
12 & Desconhecido 15 & & 1204 & Mofo & 145 & 9,68 & + & \\
14 & $\beta$-metil- - -octalactona & $39212-23-2$ & 1326 & Baunilha & 140 & 9,51 & + & + \\
16 & Vanilina & $121-33-5$ & 1401 & Baunilha & 134 & 9,31 & + & + \\
9 & 2,5-dimetil-3-etilpirazina & $13360-65-1$ & 1084 & Batata & 84 & 7,37 & + & + \\
11 & Etil fenol & $60-12-8$ & 1114 & Floral & 83 & 7,33 & + & + \\
13 & Acetato de etil-2-fenila & $103-45-7$ & 1257 & Citros & 75 & 6,96 & + & + \\
10 & Guaiacol & $90-05-1$ & 1089 & Remédio & 54 & 5,91 & + & + \\
6 & Acetato de isoamila & $123-92-2$ & 877 & Fruta & 47 & 5,51 & + & + \\
8 & 1-octen-3-ona & $4312-99-6$ & 974 & Cogumelo & 47 & 5,51 & + & + \\
7 & 2-heptanol & $543-49-7$ & 903 & Cogumelo & 37 & 4,89 & + & + \\
\hline
\end{tabular}

Os dados da TABELA 45 indicam que os odores ativos mais potentes encontrados no extrato de rum irradiado foram: dietil acetal (fruta), guaiacol (remédio), desconhecido (fruta), desconhecido (condimento), etil fenol (floral), butirato de etila (maçã), desconhecido (amêndoa), $\beta$-damascenona (floral/fruta), 1-octen-3-ona (cogumelo) e isobutirato de etila (melão). Alguns dos termos encontrados na análise descritiva foram encontrados no cromatógrafo gasoso/olfatômetro como o aroma maçã detectado como butirato de etila e o aroma melão detectado como isobutirato de etila.

De acordo com NYKANEN \& SUOMALAINEN (1983), alguns dos ésteres encontrados no rum são: acetato de metila, acetato de etila, acetato de butila, isobutirato de etila, butirato de etila, butirato de propila, butirato 2-metil etila, laurato de etila, também apresentados na TABELA 44 e na TABELA 45.

Segundo LEHTONEN \& SUOMALAINEN (1977), o mais abundante acetal encontrado no rum é o dietil acetal, como observado na TABELA 44 e na TABELA 45. De acordo com DUBOIS \& RIGAUD (1975), são vários os fenóis que compõem o rum, como: guaiacol, 4-metil guaiacol, 4-vinil guaiacol, 4-etil guaiacol, 4-propil guaiacol, eugenol, isoeugenol, 4-vinil-2-metoxifenol e vanilina. LEHTONEN \& SUOMALAINEN (1977), também relatou a presença de vários fenóis encontrados no rum, como: guaiacol, p-etil guaiacol, p-metil guaiacol, eugenol, vanilina, o-cresol, m-cresol e p-cresol. Nas amostras de rum não irradiado e irradiado foram encontrados os fenóis guaiacol e vanilina. 
TABELA 45 - Odores encontrados no rum irradiado.

\begin{tabular}{|c|c|c|c|c|c|c|c|c|}
\hline \multirow{2}{*}{$\begin{array}{l}\text { Pico } \\
\text { no. }\end{array}$} & \multirow{2}{*}{ Composto detectado } & \multirow{2}{*}{$\begin{array}{c}\text { CAS } \\
\text { Registro no. }\end{array}$} & \multirow{2}{*}{$\begin{array}{l}\text { Índice de } \\
\text { retenção }\end{array}$} & \multirow{2}{*}{ Termo } & \multirow{2}{*}{$\begin{array}{l}\text { Valor } \\
\text { Charm }\end{array}$} & \multirow{2}{*}{ OSV } & \multicolumn{2}{|c|}{ Detectado por } \\
\hline & & & & & & & $\mathrm{CG} / \mathrm{O}$ & $\mathrm{CG} / \mathrm{MS}$ \\
\hline 2 & Dictil acetal & $105-57-57$ & 730 & Fruta & 2872 & 100 & + & + \\
\hline 12 & Guaiacol & $90-05-1$ & 1089 & Remédio & 1253 & 66,05 & + & + \\
\hline 5 & Desconhecido 16 & & 843 & Fruta & 310 & 32,85 & + & \\
\hline 7 & Desconhecido 17 & & 853 & Condimento & 307 & 32,69 & + & \\
\hline 13 & Etil fenol & $60-12-8$ & 1114 & Floral & 304 & 32,53 & + & + \\
\hline 4 & Butirato de etila & $105-54-4$ & 803 & Maçã & 299 & 32,27 & + & + \\
\hline 8 & Desconhecido 18 & & 864 & Amêndoa & 227 & 28,11 & + & \\
\hline 14 & $\beta$-damascenona & $23726-93-4$ & 1386 & Floral/fruta & 217 & 27,49 & + & + \\
\hline 11 & 1-octen-3-ona & $4312-99-6$ & 974 & Cogumelo & 173 & 24,54 & + & + \\
\hline 3 & Isobutirato de etila & $97-62-1$ & 758 & Melão & 154 & 23,16 & + & + \\
\hline 6 & Butirato de metil-2-etila & $7452-79-1$ & 850 & Maçã & 108 & 19,39 & + & + \\
\hline 1 & Desconhecido 19 & & 672 & Borracha & 78 & 16,48 & + & \\
\hline 10 & Desconhecido 20 & & 966 & Cogumelo & 76 & 16,27 & + & \\
\hline 9 & Desconhecido 21 & & 921 & Grama & 59 & 14,33 & + & \\
\hline
\end{tabular}

Na FIGURA 52, FIGURA 53 e FIGURA 54 são apresentadas as diferenças significativas encontradas entre cachaça e rum não irradiados, cachaça não irradiada e irradiada e; rum não irradiado e irradiado quando seus aromas foram comparados por ANOVA e Teste t-Student $(p<0,05)$.

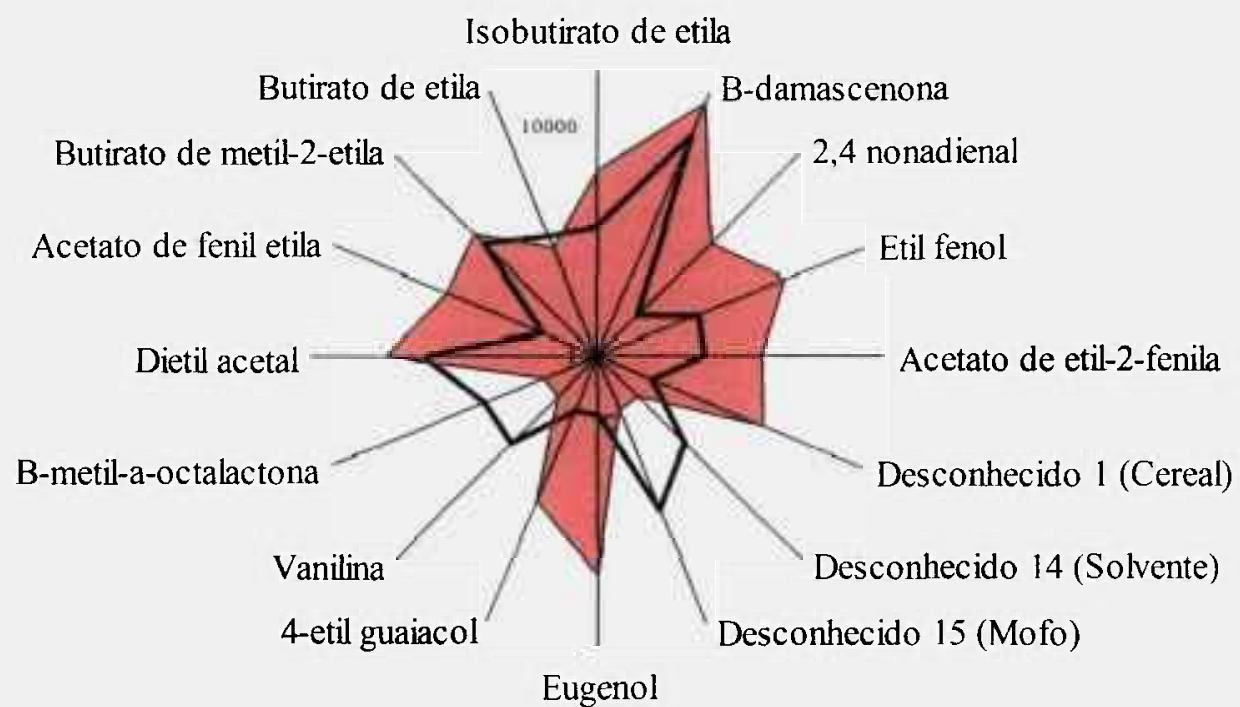

■l Cachaça não irradiada $\mathbf{D}$ Rum não irradiado

FIGURA 52 - Os odores mais potentes na cachaça não envelhecida e rum não irradiados. 


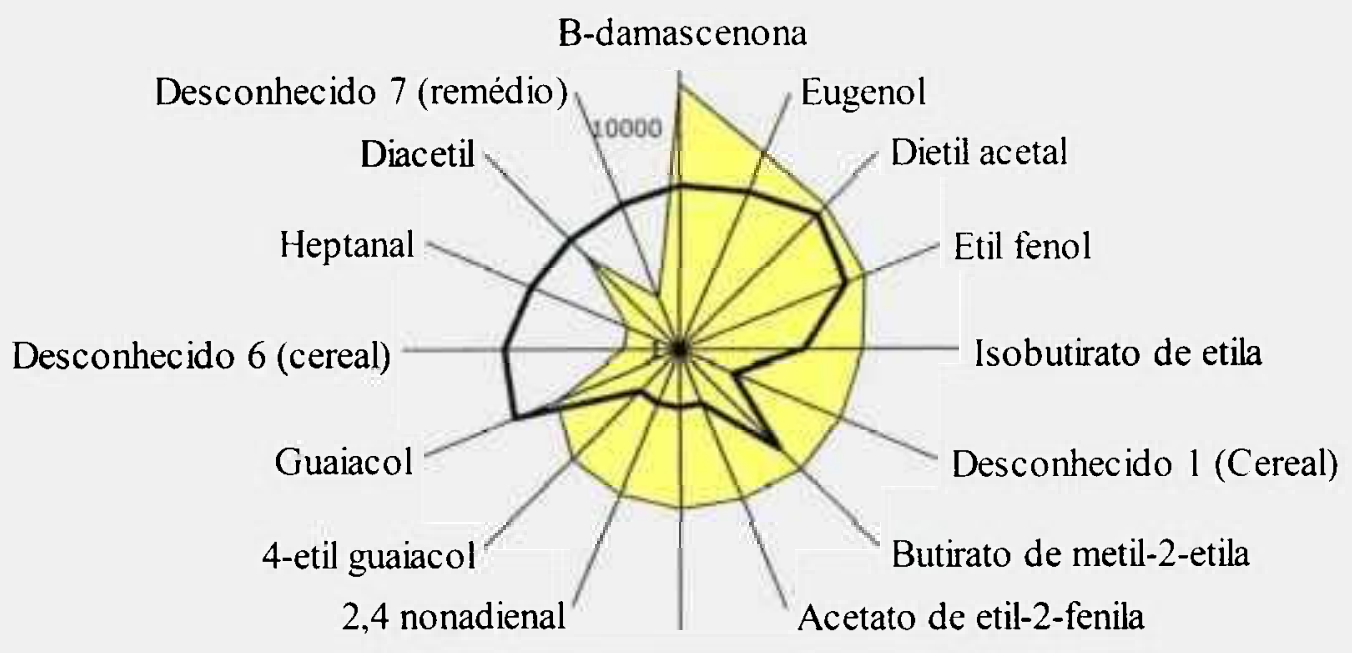

Acetato de fenil etila

\section{Cachaça não irradiada $\mathbf{D}$ Cachaça irradiada}

FIGURA 53 - Os odores mais potentes nas cachaças não envelhecidas não irradiadas e irradiadas.

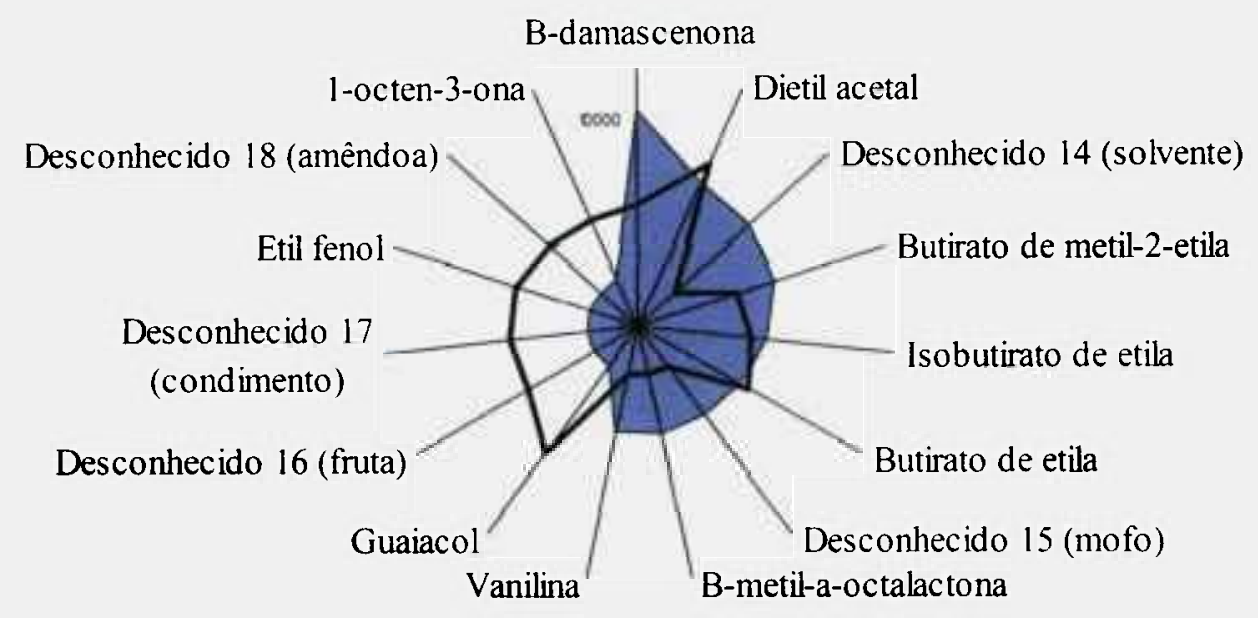

Rum não irradiado $\boldsymbol{D}$ Rum irradiado

FIGURA 54 - Os odores mais potentes nos runs não irradiados e irradiados. 


\section{CONCLUSÕES}

- A concentração dos compostos voláteis analisados apresentou forte correlação com a dose de radiação aplicada em todas as amostras.

- Observou-se um aumento na concentração de aldeídos em todas as amostras de bebida com o aumento da dose de radiação aplicada.

- Os valores de ésteres, metanol, butanol, ácidos totais, aldeídos, acroleína, a soma das concentrações dos alcoóis isoamílico, isobutílico e n-propílico e a soma das concentrações de furfural e 5 hidroximetilfurfural nas cachaças irradiadas ficaram dentro dos limites máximos recomendados pela legislação brasileira.

- No que diz respeito aos alcoóis, o propanol e o isobutanol apresentaram concentrações maiores nas amostras de cachaça do que nas de rum, podendo, assim, ser considerados um dos discriminadores entre estas bebidas.

- Os conteúdos de ácidos totais nas amostras irradiadas de cachaça foram maiores do que os observados nas amostras de rum, fato que se deve ao alto teor de ácido acético encontrado nas cachaças.

- De acordo com os testes triangulares, somente para aroma, todos os provadores puderam distinguir nas amostras não irradiadas, a cachaça envelhecida do rum e a cachaça não envelhecida do rum, porém, não foi observada diferença entre a cachaça não envelhecida e a envelhecida. Em relação às amostras irradiadas com $300 \mathrm{~Gy}$ foi encontrada diferença significativa entre a cachaça envelhecida e o rum e entre a cachaça não envelhecida e o rum, no entanto, diferença não foi observada entre a cachaça não envelhecida e a envelhecida.

- No que diz respeito à análise descritiva quantitativa, as amostras não irradiadas de cachaça não envelhecida e o rum diferiram entre si, em seus atributos de aroma classificados, como, álcool, vinagre, baunilha, citros, melão, condimento, enxofre e grama. Já, em relação aos aromas: caramelo $e$ maçã não foram encontradas diferenças significativas entre estas bebidas. Quando comparadas às amostras de cachaças não envelhecidas não 
irradiadas e irradiadas com 300Gy e; quando confrontados os runs não irradiados e irradiados com 300Gy, tais diferiram entre si, em seus atributos de aroma classificados, como, maçã, caramelo, vinagre, baunilha, citros, melão, condimento, enxofre e grama. Porém, em relação ao aroma álcool não foi encontrada diferença significativa entre estas bebidas.

- O isolamento e a caracterização dos compostos ativos de odor presentes nas amostras de cachaça não envelhecida e rum irradiadas com 300Gy e não irradiadas foram realizados em um cromatógrafo gasoso/olfatômetro (CG/O), mostrando haver diferenças significativas no aroma de cachaça e rum não irradiados; cachaça não irradiada e cachaça irradiada; e rum não irradiado e irradiado.

- A técnica de $\mathrm{GC} / \mathrm{O}$ mostrou ser eficaz no fornecimento de um elo entre as análises químicas e os dados sensoriais. Seria recomendável uma aplicação mais extensa desta metodologia em outras amostras de bebidas, considerando que este estudo foi realizado em somente um determinado grupo de amostras.

- De acordo com os resultados obtidos, conclui-se que o tratamento por radiação pode ser aplicado para a melhoria dos atributos de qualidade destas bebidas destiladas. 


\section{REFERÊNCIAS}

ACREE, T. E.; BARNARD, J. Gas chromatography-olfactometry and CharmAnalysis ${ }^{\mathrm{TM}}$ Trends in Flavour Research. v. 35, p. 211-220, 1994.

ACREE, T. E.; BARNARD, J; CUNNINGHAM, D. G. A procedure for the sensory analysis of gas chromatographic effluents. Food Chem. v. 14, p. 273-286, 1984.

ACREE, T. E.; BRAELL, P. A.; BUTTS, R. M. The presence of damascenone in cultivar of Vitis vinifera (Linneaus), rotundifolia (Michaux), and labruscana (Baily). J. Agric. Food Chem. v. 29, p. 688-690, 1981.

ACREE, T. E. CG/Olfactometry. Anal. Chem. News \& Features. March 1, p. 170A -175A 1997.

ALASALVAR, C. SHAHIDI, F.; CADAWALLADER, K. R. Comparison of natural and roasted turkish tombul hazelnut (Corylus avellana L.) volatiles and flavor by DHA/GC/MS and descriptive sensory analysis. J. Agric. Food Chem. v. 51, p. 5067-5072, 2003.

AMERINE, M. A. Principles of sensory evaluation of food. New York: Academic, 1965. p. 349-397.

AMERINE, M. A.; BERG, H. W.; CRUESS, W. V. The technology of wine making. West port. The AVI Publ.: 1972 apud BOZA, Y. E. A. G. Influência da condução da destilação sobre a composição e a qualidade sensorial da aguardente de cana. 1996. Dissertação (Mestrado) Escola Superior de Agricultura "Luiz de Queiroz". Universidade de São Paulo, Piracicaba.

AMPAQ. Disponivel em <http://www.ampaq.com.br $>$ Acesso em: 20/08/2005.

ANDRADE-SOBRINHO, L. G.; BOSCOLO, M.; LIMA-NETO, B. S.; FRANCO, D. W. Carbamato de etila em bebidas alcoólicas (cachaça, tiquira, uísque e grapa). Quim. Nova, v. 25, n. 6B, p. 1074-1077, 2002. 
ARAKI, C.; SAKAKIBARA, H. Changes in the volatile flavor compounds by heating Satsuma mandarin (Citros unshiu Marcov.) juice. Agric. Biol. Chem. v. 55, p. 1421-1423, 1991.

ASKEW, B.; LISLE, D.B. Variation in the concentrations of higher alcohols, methanol and etyl acetate in brandies. J. Sci. Food Agric., v.22, n. 2, p.102-104,

BABIOR, B. M. Superoxide: a two-edged sword. Brazilian Journal of Medical and Biological Research, v. 30, p. 141-155, 1997.

BERRY, D. R.; WATSON, D. C. Production of organoleptic compounds. Yeast Biotechnology (Berry, D.R., Russell, I., and Stewart, G.G., eds.) London: Allen and Unwin, 1987. p. 345-368.

BONATO, P. S. Cromatografia gasosa. In: COLLINS, C. H.; BRAGA, G. L.; BONATO, P. S. Introdução a métodos cromatográficos. Campinas, S.P.: Unicamp, 1995. p. 141-238.

BRANDT, M. A.; SKINNER, E.; COLEMAN, J. Texture profile method. J. Food Sci. v. 28, p. $404-409,1963$.

BRASIL. Decreto $n^{\circ} 72.718$, de 29 de agosto de 1973. Dispõe sobre normas gerais para a irradiação de alimentos. Diário Oficial [da] República Federativa do Brasil, Brasília. D.F. 30 de agosto de 1973.

BRASIL. Divisão Nacional de Vigilância Sanitária de Alimentos, da Secretaria Nacional de Vigilância Sanitária do Ministério da Saúde. Portaria $\mathrm{n}^{0} 09$ de 08 de março de 1985. Diário Oficial [da] República Federativa do Brasil, Brasília. D.F. 13 de março de 1985. Seção 1.

BRASIL. Divisão Nacional de Vigilância Sanitária de Alimentos, da Secretaria Nacional de Vigilância Sanitária do Ministério da Saúde. Portaria $n^{0} 30$ de 25 de setembro de 1989. Diário Oficial [da] República Federativa do Brasil, Brasilia. D.F. 28 de setembro de 1989. Seção 1.

BRASIL. Agência Nacional de Vigilância Sanitária de Alimentos, da Secretaria Nacional de Vigilância Sanitária do Ministério da Saúde. Resolução $n^{0} 21$ de 26 de janeiro de 2001. Diário Oficial [da] República Federativa do Brasil, Brasília. D.F. 27 de janeiro de 2001.

BRASIL. Decreto $\mathrm{n}^{\circ} 4.851$, de 2 de outubro de 2003. Diário Oficial [da] República Federativa do Brasil, Brasília. D.F. 3 de outubro de 2003. 
BRASIL. Ministério da Agricultura, Pecuária e Abastecimento. Instrução Normativa $n^{0} 13$ de 29 de junho de 2005. Diário Oficial [da] República Federativa do Brasil, Brasília. D.F. 30 de junho de 2005. Seção 1.

BREGVADZE, U. D.; SHIKHASHVILI, T. G. IR absorption spectra of brandy spirits. Trudy, - Gruzinskii - Nauchno - Issledovatel'skii - Institut - Pshchevoi - Promyshlennosti, v.5, p.3-6, 1971 apud SILVA JÚNIOR, L. S. Avaliação fisico-quimica e sensorial da cachaça durante o envelhecimento em ancorote de carvalho (Quercus sp) irradiado. 1999. Dissertação (Mestrado) - Faculdade de Ciências Farmacêuticas, Universidade Estadual Paulista "Julio de Mesquita Filho", Araraquara.

CAIRNCROSS, S. E.; SJOSTROM, L. B. Flavour profiles: a new approach to flavour problems. Food Technol.v. 4, p. 308-311, 1950.

CARDELLO, H. M. A. B.; FARIA, J.B. Análise descritiva quantitativa da aguardente de cana durante o envelhecimento em tonel de carvalho (Quercus alba L.) Cienc. Tecnol. Aliment. v.18, n.2, p.169-175, 1998.

CARDOSO, D. R.; ANDRADE SOBRINHO, L. G.; LEITE NETO, A. F.; RECHE, R. V.; ISIQUE, W. D.; FERREIRA, M. M. C.; LIMA NETO, B. S.; FRANCO, D. W. Comparison between cachaça e rum using pattern recognition methods. J. Agric. Food Chem. v. 52, p. 3429-3433, 2004.

CARPINO, S.; ACREE, T. E.; BARBANO, D. M.; LICITRA, G.; SIEBERT, K. J. Chemometric analysis of ragusano cheese flavor. J. Agric. Food Chem. v. 50, p. 1143-1149, 2002.

CHISHOLM, M. G.; GUIHER, L. A.; VONAH, T. M.; BEAUMONT, J. L. Comparison of some french american hybrid wines with white riesling using gas chromatographyolfactometry. Am. J. Enol. Vitic. v. 45, n. 2, p. 201-211, 1994.

CIOLA, R. Fundamentos da cromatografia a gás. São Paulo, S.P.: Edgard Blucher, 1985.

CLUTTON, D. W. Rum. The flavor Ind. Nov/Dec, p. 286-288, 1974.

CULLERE, L.; ESCUDERO, A.; CACHO, J.; FERREIRA, V. Gas chromatographyolfactometry and chemical quantitative study of the aroma of six premium quality spanish aged red wines. J. Agric. Food Chem. v. 52, p. 1653-1660, 2004. 
CUNNINGHAM, D. G.; ACREE, T. E.; BARNARD, J.; BUTTS, R. M.; BRAELL, P. A. Charm analysis of apple volatiles. Food Chem., v. 19, p. 137-14, 1986.

DEIBLER, K. D.; LAVIN, E. H. ACREE, T. E.; Solid phase microextration application in gas chromatography/olfactometry dilution analysis. J. Agric. Food Chem. v. 47, p. 1616-1618, 1999.

DEMOLE, E.; ENGGIST, P.; SAUBERLI, U.; STOLL, M. Structure and synthesis of damascenone [2,6,6-trimethyl-1-trans-crotonyl-1,3-cyclohexadiene], odorous constituent of Bulgarian rose oil (Rosa damascena). Helv. Chim. Acta, v. 53, p. 541-551, 1970.

DEL MASTRO, N. L. Alimentos esterilizados para uso em hospitais e rações militares. Rev. Bras. Pesqui. Desenvol., v.2, n.1, p.1-4, 1999.

DIAS, S.; MAIA, A.; NELSON, D. Efeito de diferentes madeiras sobre a composição da aguardente envelhecida. Cienc. Tecnol. Aliment., v.18, n.3, p.331-334, 1998.

DIEHL, J. F. Safety of Irradiated Foods. 1 ed. New York: Marcel Dekker, 1990. p. 272-310.

DIEHL, J. F. Will irradiation enhance or reduce food safety? Food Policy.,v.18 p.143-151, 1993.

DRAVNIEK, A. O'DONNELL J. Agric. Food Chem., v. 19, p. 1049-1056, 1971 apud FENG, Y. W.; ACREE, T. E. Gas chromatography olfactometry in aroma analysis. Food \& Food ingredientes Journal of Japan, n. 179, 1999.

DUBOIS, P.; RIDAUD, J. Etude qualitative et quantitative des constituents volatils du rhum. Ann. Technol. Agric., v. 24, n. 3-4, p. 307-315, 1975.

DUTCOSKY, S. D. Análise sensorial de alimentos. Curitiba: Champagnat, 1996.

DZHANPOLADYAN, L. M.; PETROSYAN, T. S. L. Ageing of oak wood under the influence of uv-rays. Izdatel'stvo-Nauka, Moscow, p.47-55, 1972 apud SILVA JÚNIOR, L. S. Avaliação fisico-quimica e sensorial da cachaça durante o envelhecimento em ancorote de carvalho (Quercus sp) irradiado. 1999. Dissertação (Mestrado) - Faculdade de Ciências Farmacêuticas, Universidade Estadual Paulista "Julio de Mesquita Filho", Araraquara. 
DZHANPOLADYAN, L. M.; PETROSYAN, T. S. L. et al. Method for producing agent for acceleration of brandy maturation. USSR - Patent, 1971 apud SILVA JÚNIOR, L. S. Avaliação físico-química e sensorial da cachaça durante o envelhecimento em ancorote de carvalho (Quercus sp) irradiado. 1999. Dissertação (Mestrado) - Faculdade de Ciências Farmacêuticas, Universidade Estadual Paulista "Julio de Mesquita Filho", Araraquara.

EBELER, S. E.; TERRIEN, M. B.; BUTZKE, C. E. Analysis of brandy aroma by solid-phase microextraction and liquid-liquid extraction. J. Sci. Food Agric., v. 80, p. 625-630, 2000.

FENG, Y. W.; ACREE, T. E. Gas chromatography olfactometry in aroma analysis. Food \& Food ingredientes Journal of Japan, n. 179, 1999.

FIFIELD, F. W.; KEALEY, D. Principles and practice of analytical chemistry. Oxford: Blackwell Science. 2000.

FRIEDRICH, J. E.; ACREE, T. E. Standardization of human subjects for gas chromatography (GC/O). In: XVIII CONGRESS OF EUROPEAN CHEMORECEPTION RESEARCH ORGANISATION, Siena, Italy apud FENG, Y. W.; ACREE, T. E. Gas chromatography olfactometry in aroma analysis. Food \& Food ingredientes Journal of Japan, n. 179, 1999.

FULLER, G. H; STELTENKAMP, R; TISSERAND, G. A. Annals. $\boldsymbol{N}$. $\boldsymbol{Y}$. Acad. Sci., v. 116, p. 711-724, 1964 apud FENG, Y. W.; ACREE, T. E. Gas chromatography olfactometry in aroma analysis. Food \& Food ingredientes Journal of Japan, n. 179, 1999.

FURTADO, S. M. B. Avaliação sensorial descritiva de aguardente de cana (Saccharum officinarum $L$.): influência da composição em suas características sensoriais e correlação entre as medidas sensoriais e fisico-quimicas. 1995. Tese (Doutorado) - Faculdade de Engenharia de Alimentos, Universidade Estadual de Campinas.

GÓMEZ, M. S. Rum aroma descriptive analysis. 2002. Dissertação (Mestrado) - Louisiana State University, Food Science Department, Louisiana, EUA.

GUADAGNI, D. C.; OKANO, S.; BUTTERY, R. G.; BURR, H. K. Food Technol. v. 20, p. 166-169, 1966 apud FENG, Y. W.; ACREE, T. E. Gas chromatography olfactometry in aroma analysis. Food \& Food ingredientes Journal of Japan, n. 179, 1999.

GUOZHU, L.; XIAOLING, H. A Study on the wine-date preservation using Co-60, $\gamma$, gamma. In: INTERNATIONAL MEETING IN RADIATION PROCESSING, 8, Sept. 13-18, 1992, Beijin. Proceedings...Radiat. Phys. Chem., v.42, p.101, 1992. 
GUTIERREZ, L. E. Produção de alcoóis superiores por linhages de Saccharomyces durante a fermentação alcoólica. Scientia Agricola, v.50, n.3, p.464-472, 1993.

GUYMON, J. F. Chemical aspects of distilling wines into brandy. In: WEBB, A. D. (Ed.) Chemistry of Winemaking. Washington, D.C.: American Chemical Society, 1974. p.232-253.

HALL, E.J. Radiobiology for the Radiologist. Philadelphia: J. B. Lippincott, 1994.

HASHIZUME, T. Considerações sobre ésteres nas bebidas alcoólicas. Instruções Técnicas, n.9, p.109-121, 1976.

HOUSE, A. K.; ACREE, T. E. Sensory impact of free fatty acids on the aroma of a model cheddar cheese. Food Quality and Preference. v. 13, p. 481-488, 2002.

INTERNATIONAL CONSULTIVE GROUP ON FOOD IRRADIATION. Training manual on operation of food irradiation facilities, Vienna, 1992. (Documento n.14)

KILLIAN, E.; OUGH, C. S. Fermentation esters-formation and retention as affected by fermentation temperature. Am. J. Enol. Vitic., v.30, n.4, p.301-305, 1979.

KITTEL, K. M. Gas chromatography olfactometry analysis of Carabao Mango (Mangifera indica L. cultivar carabao) fruit, nectar and puree. 2003. Dissertação (Mestrado) - Cornell University, Food Science Department, Ithaca, EUA.

KITSON, F. G.; LARSEN, B. S.; Mc EWEN, C. M. Gas chromatography and mass spectrometry: A practical guide. San Diego: Academic, 1996.

KOZUB, G. I.; MAKSIMOVA, A. S.; SKORBANOVA, E. A.; MAMAKOVA, Z. A. Composition of volatile substances in sherry-type wines treated by UV and Ir rays. Sadovodstvo - Vinogradarstvo-I-Vinodelie-Moldavii; n.1, p.33-35, 1985 apud SILVA JÚNIOR, L. S. Avaliação fisico-química e sensorial da cachaça durante o envelhecimento em ancorote de carvalho (Quercus sp) irradiado. 1999. Dissertação (Mestrado) - Faculdade de Ciências Farmacêuticas, Universidade Estadual Paulista "Julio de Mesquita Filho", Araraquara.

L'ANSON. Rum manufacture. Process Biochem. v. 6, p. 35-39, 1971. 
LAURENT, M. H.; HENICK-KLING, T.; ACREE, T. E. Changes in the aroma and odor of Chardonnay wine due to malolactic fermentation. Vitic. Enol. Sci., v. 49, p. 3-10, 1994.

LAWLESS, H. T.; HELMANN, H. Sensory evaluation of food. Principles and practices. New York: Champman Hall, 1998.

LEE, S. J.; NOBLE, A. C. Characterization of odor-active compounds in californian chardonnay wines using GC-olfactometry and GC-mass spectrometry. J. Agric. Food Chem., v. 51, p. 8036-8044, 2003.

LEE, K. Y. M.; PATERSON, A.; PIGGOTT, J. R. Perception of whisky flavor reference compounds by Scottish distillers. Inst. Brewing., v. 106, p. 203-208, 2000.

LEHTONEN, M. Volatile and non-volatile compounds in the flavour of alcoholic beverages. Flavor of Distilled Beverages: Origin and development (Piggot, J.R., ed.) Chichester: Ellis Horwood Ltd., 1983. p. 65-78.

LEHTONEN, M.; SUOMALAINEN, H. Rum. Alcoholic beverages (Rose, A. H. ed.), London: Academic, 1977. p. 595-633.

LIMA, U. A. Estudos dos principais fatores que afetam os componentes do coeficiente não álcool das aguardentes de cana. 1964. (Provimento de Cátedra) - Escola Superior de Agricultura "Luiz de Queiroz", Universidade de São Paulo, Piracicaba.

LIMA, U. A. Fabricação em pequenas destilarias. Piracicaba: Fundação Estudos Agrários "Luiz de Queiroz", 1999.

LLISTÓ, A. M. S. M.; SOUZA, L. G.; MISCHAN, M. M. Alguns componentes do coeficiente não-álcool das aguardentes de cana: Ésteres. Brasil Açúcareiro, v.92, n.5, p.34 1-346, 1979.

LOAHARANU, P. Status of food irradiation worldwide. Preharambeno-technol. Biotehnol. v.30, n.4, p.131-134, 1992.

LOAHARANU, P. Cost/benefit aspects of food irradiation: A summary of the report and recommendations of working group of the Food and Agriculture Organization, International Atomic Energy Agency, World Health Organization, Food Technol., v.1, p.104-108, 1994. 
LOPES, D. C.; FRANGA, S. R.; RESENDE, C. M. Principais compostos responsáveis pelo aroma de mangas brasileiras comerciais identificadas por HRGC/Olfatometry/MS. Química Nova. v. 22, n. 1, p. 31-36, 1999.

LUXNER, L. Puerto Rico, Virgin islands oppose mexican duty-free rum petition. $J$. Commerce and Commercial. v. 30, 5 A, 1991.

MAGA, J. A. The contribution of wood to flavor of alcoholic beverages. Food Rev. Int., v. 5, p. 39-99, 1989.

MAIA, A. B. Componentes secundários da aguardente. STAB, v.12, n.6, p.29-34, 1994.

MARCELLINI, P. S. Análise descritiva quantitativa de aguardentes de cana (Saccharum spp) comerciais e destiladas em alambiques de cobre e aço-inoxidável. 2000. Dissertação (Mestrado). Faculdade de Ciências Farmacêuticas. Universidade Estadual Paulista "Júlio de Mesquita Filho", Araraquara.

MATSUDA, M.; NISHIMURA, K. Occurrence and formation of damascenone, trans-2,6,6trimethyl-1-trans-crotonyl-cyclohexa-1,3-diene, in alcoholic beverages. J. Food Sci., v. 45, p. 396-397, 1980.

MECREDY, J.M., SONNEMANN, J.C., LEHMANN, S.J. Sensory profiling of beer by a modified QDA methodology. Food Technology. Nov. p. 36-41, 1974.

MEILGAARD, M. C.; CIVILLE, G. V.; CARR, B. T. Sensory evaluation techniques. 2 ed. Florida: CRC, 1991.

MORAES, J. S. Estudo comparativo das caracteristicas químicas e sensoriais do rum e da cachaça. 2004. Dissertação (Mestrado) - Faculdade de Ciências Farmacêuticas, Universidade Estadual Paulista "Julio de Mesquita Filho", Araraquara.

MOSKOWITZ, H. Descriptive analysis of perceptions. Product Testing and Sensory Evaluation of Foods. Connecticut: Food and Nutrition, 1983. p. 20-78.

MUÑOZ, A.M.; CIVILLE, G.V. Universal, product, and attribute specific scaling and the development of common lexicons in descriptive analysis. J. Sensory Studies. v. 13, p. 57-75, 1998. 
MURTA, A. L. M.; KUGLER, W.; LINSIGEN, U. I. B.; BERG, R. G. Determinação da composição de aguardentes de cana de açúcar por cromatografia gasosa. Arq. Biol. Tecnol., v.25, n.2, p.221-226, 1982.

NASCIMENTO, R. F.; MARQUES, J. C.; LIMA NETO, B. S.; DE KEUKELEIRE, D.; FRANCO, D. W. Qualitative and quantitative high-performance liquid chromatographic analysis of aldehydes in Brazilian sugar cane spirits and other distilled alcoholic beverages. $J$. Chromatogr. A, v. 782, p. 13-23, 1997.

NASCIMENTO, R. F.; CARDOSO, D. R.; LIMA NETO, B. S.; FRANCO, D. W. Determination of acids in Brazilian sugar cane spirits and other distilled alcoholic beverages by HRGC-SPE. Chromatographia, v. 48, n. 11/12, p. 751-757, 1998.

NICOL, D. A. Chapter Rum. In: Fermented beverage production, edition 2; Lea, A. G. H.; Piggott, J. R.; Eds. New York: Kluwer Academic/Plenum, 2003, p. 263-287.

NISHIMURA, K.; MATSUYAMA, R. Identification of some flavor characteristic compounds in alcoholic beverages. In: Nykanen, L.; Lehtonen, P.(Eds.). Flavour Research of Alcoholic Beverages. Finland: Foundation of Biotechnol. Ind. Ferm. Res. Helsink, 1985.

NOBLE, A.C. Analysis of wine sensory properties. Modern Methods of Plant Analysis. v. 6. (Linskin, A.F., and Jackson, J.F., eds.) Berlin: Springer-Vela, 1998.

NYKANEN, L.; NYKANEN, I.; SUOMALAINEN, H. Distribution of esters produced during sugar fermentation between the yeast cell and medium. J. Inst. Brew., v.83, p.32-34, 1977.

NYKÄNEN, L.; NYKÄNEN, I. Rum flavor. In: Piggott, J.R. (ed.) Flavor of Alcoholic Beverages; Origin and Development. Chichester, West Sussex: E. Horwood Ltd., 1983. p. 49-63.

NYKÄNEN, L.; NYKÄNEN, I. Distilled beverages. Volatile compounds in food and beverages (Maarse, H, ed.). New York: Mercel Dekker, 1991.

NYKÄNEN, L.; SUOMALAINEN, H. Aroma of beer, wine, and distilled alcoholic beverages. Berlin: D. Reidel, 1983.

PEREZ, E. R.; CARDOSO, D. R.; FRANCO, D. W. Análise dos alcoóis, ésteres e compostos carbonílicos em amostras de óleo fúsel. Quim. Nova, v. 24, n. 1, p. 10-12, 2001. 
PETER, K. C.; ONG, P. K. C.; ACREE, T. E. Gas chromatography/olfactory analysis of lychee (Litchi chinesis Sonn.) J. Agric. Food Chem., v. 46, p. 2282-2286, 1998.

PETROSYAN, P. L.; DZHANPOLADYAN, L. M.; KHACHOYAN, A. V.; DAVTYAN, I. A. Treatment of oak wood and oak barrels with UV rays. Vinodelie-I-Vinogradarstvo-SSSR; p.48-49, 1986 apud SILVA JÚNIOR, L. S. Avaliação físico-química e sensorial da cachaça durante o envelhecimento em ancorote de carvalho (Quercus sp) irradiado. 1999. Dissertação (Mestrado) - Faculdade de Ciências Farmacêuticas, Universidade Estadual Paulista "Julio de Mesquita Filho", Araraquara.

PIGGOT, J.R., HOSE, L.; SHARP, R. Expressing flavor: a system for Scotch, Brew. Distill. Int. v. 10, p. 48-49, 1980.

PIGGOT, J.R.; HOLM, A.M. Descriptive sensory analysis of gin flavour. In Flavour of Distilled Beverages: Origin and Development (Piggot, J.R., ed.), Chichester: Ellis Horwood, 1983. p. 145-153.

PIGGOTT, J. R. Chapter Descriptive analysis: terms. In: Sensory science theory and applications in food, Lawless, H. T.; Lein, B. P.; Ed. Chicago: IFT Basic Symposium Series, 1991. p. 339-349.

RIBEREAU-GAYON, J. Contribution à l'étude des oxydations et réductions dans les vins. 2. ed. Bordeaux: Delmas, 1933.

ROBERTS, J. S.; GENTRY, T. S.; BATES, A. W. Utilization of dried apple pomace as a press aid to improve the quality of straberry, raspberry, and blueberry juices. J. Food Sci. v. 69, n. 4 , p. $181-190,2004$.

ROSE, A. H. Alcoholic beverages. London: Academic, 1977.

SALGADO, A. A.; MARQUES, T. A.; ALMEIDA, C. L. F. Madeiras nacionais para o envelhecimento natural de aguardente. Álcool \& Açúcar, n. 83, p. 22-27, 1996.

SANCHES, N. B.; LEDERER, C. L.; NIKERSON, G. B.; LIBBEY, L. M.; MCDANIEL, M. $R$. Sensory and analytical evaluation of beers brewed with three varieties of hops and unhopped beer. In: 6th INTERNATIONAL FLAVOR CONFERENCE In. Proceedings... 6th International Flavor Conference, 1992 apud FENG, Y. W.; ACREE, T. E. Gas chromatography olfactometry in aroma analysis. Food \& Food ingredientes Journal of Japan, n. 179, 1999. 
SANTIN, M. Food irradiation: A guidebook. Lancaster: Technomic, 1993.

SANWA SHURUI COMPANY; EIM ELECTRIC COMPANY; T. Igisu; T. Omori; M. Shimoda. Process for manufacturing alcoholic liquors well-aged quality within a short period of time utilizing ultrasonic vibration. European Pat., 1989 apud SILVA JÚNIOR, L. S. Avaliação físico-química e sensorial da cachaça durante o envelhecimento em ancorote de carvalho (Quercus sp) irradiado. 1999. Dissertação (Mestrado) - Faculdade de Ciências Farmacêuticas, Universidade Estadual Paulista "Julio de Mesquita Filho", Araraquara.

SILVA JÚNIOR, L. S. Avaliação físico-química e sensorial da cachaça durante o envelhecimento em ancorote de carvalho (Quercus sp) irradiado. 1999. Dissertação (Mestrado) - Faculdade de Ciências Farmacêuticas, Universidade Estadual Paulista "Julio de Mesquita Filho", Araraquara.

SINGLETON, V. L.. Changes in quality and composition produced in wine by cobalt- 60 gamma irradiations. Food Technol., v.17, p.112-115, 1963.

SINGLETON, V. L. Some aspects of the wood container as a factor wine maturation. In: WEBB, A. D. (Ed.) Chemistry of Winemaking. Washington, D.C.: American Chemical Society, 1974. p.254-277.

SOUZA, M. D. C. A. Efeito da radiação gama sobre a aguardente de cana-de-açúcar. 2000. Dissertação (Mestrado). Instituto de Pesquisas Energéticas e Nucleares. Universidade de São Paulo, São Paulo.

SPIEGEL, M. R. Estatistica. 3 ed. São Paulo: Makron, 1994.

STEVENS, S. S. Measurement and man. Science, v. 127, p. 383-389, 1958.

STONE, H., SIDEL, J., OLIVER, S., WOOLSEY, A., SINGLETON, R.C. Sensory evaluation by quantitative descriptive analysis. Food Technology. v. 28, p. 24-34, 1974.

STONE, H., SIDEL, J. Sensory evaluation practices. London: Academic. 1985.

SUOMALAINEN, H.; LEHTONEN, M. The production of aroma compounds by yeast. $J$. Ins. Brew., v.85, n.3, p.149-156,1979. 
TAKUO, H. Maturação e envelhecimento de vinhos. Bol. Inst. Tecnol. Alim., n.51, p.1-13, 1977.

ULLRICH, F.; GROSCH, W. Identification of the most intense volatile flavor compounds formed during autoxidation of linoleic acid. Zeitschrift fuer Lebensmittel-Untersuchung undForschung. v. 184, n. 4, p. 277-282, 1987 apud FENG, Y. W.; ACREE, T. E. Gas chromatography olfactometry in aroma analysis. Food \& Food ingredientes Journal of Japan, n. 179, 1999.

URBAIN, W. M. Food Irradiation. New York: Academic, 1986.

URBAIN, W. M. Economics aspects of food irradiation. In: Cost-benefit aspects of food irradiation processing. Vienna: IAEA SM 328/60, 1993. p.1-16.

WALDER, J. M. M; SPOTO, M.H.F.; NOVAES, F.V.; ALCARDE, A. R. Uso da radiação gama no envelhecimento da aguardente de cana de açúcar. In: Proceedings do $6^{\circ}$ Encontro Nacional de Aplicações Nucleares, 2002, Rio de Janeiro. 4p. Cd Rom.

WILDENRADT, H.L.; SINGLETON, V. L. The production of aldehydes as a result of oxidation of polyphenolic compounds and its relation to wine aging. Am. J. Vitic. n.25, p.119126, 1974.

WORLD HEALTH ORGANIZATION. La comestibilidade de los alimentos irradiados: Report of a joint Food and Agriculture Organization; International Atomic Energy Agency; World Organization Expert Committee, Geneva: 1977. (Technical report series, 604).

WORLD HEALTH ORGANIZATION. Wholesomeness of irradiated food: Report of a joint Food and Agriculture Organization; International Atomic Energy Agency; World Organization Expert Committee. Geneva: 1981. (Technical report series, 659).

WORLD HEALTH ORGANIZATION. High-dose irradiation: Wholesomeness of food irradiated with doses above 10kGy: Report of a joint Food and Agriculture Organization; International Atomic Energy Agency; World Organization Study Group. Geneva: 1999. (Technical report series, 890). 